\title{
KRAFT BLACK LIQUOR DELIVERY SYSTEMS
}

Report No. 1 for the Period October 1988-October 1989

By

Terry N. Adams

H. L. Empie

N. Obuskovic

T. M. Spielbauer

February 1990

Work Performed Under Contract No. FC02-88CE40839

For

U.S. Department of Energy

Office of Industrial Programs

Washington, D.C.

By

Institute of Paper Science and Technology

Atlanta, Georgia 


\section{DISCLAIMER}

This report was prepared as an account of work sponsored by an agency of the United States Governmemt. Neither the United States Covernment nor any' agency thereof, nor any of their employees, makes any warranty, express or implied, or assumes any legal liability or responsibility for the accuracy, completeness, or usefi!ness of any information, apparanus, pexluct, or process disclosed. or represems that its use would not infringe privately owned rights. Reference herein to any specific commercial product, process, or service by trade nante, irademark, manufacturer, or otherwise dexes not necessarily constitute or imply its endorsement, recommendation, or favoring he the linited States (joverument of any agency thereof. The views and opiniots of authors ex pessed herein do not necessarily state or reflect those of the United States Government or ans atences therest

This report has been reponduced directly from the best available copy.

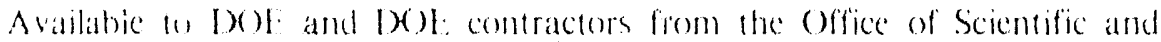
Iechnical Information, P.(). Box 62. Oak Ridge. TN 37831: prices avallable from $(6,151576,84017$, Fis $6.26,840) 1$.

Avalable we the public from the Natmal Technical Information Service, U. S. Department of (ommeree. 52855 Port Reryal Rd., Springételd, VA 22161

Price: Primed cons Alit

Micrefiche All 
KRAFT BLACK LIQUOR DELIVERY SYSTEMS

( OCTOBER 1988 - OCTOBER 1989 )

REPORT No. 1

By:

Terry N. Adams

H. L. Empie

N. Obuskovic

T. M. Spielbauer

FEBRUARY 1990

Work Performed Under Contract No. DE-FC02-88CE40839

INSTITUTE OF PAPER SCIENCE AND TECHNOLOGY (IPST)

CHEMICAL RECOVERY GROUP

CHEMICAL SCIENCES DIVISION

57514 th St. N.W.

Atlanta, Georgia 30318

Prepared For:

Stanley F. Sobczynski

Program Manager, CE-142

OFFICE OF INDUSTRIAL PROGRAMS

CONUERVATION AND RENEWABLE ENERGY

U. S, DEPARTMENT OF ENERGY

WASHINGTON, D.C. 20585 


\section{NOTICE AND DISCLAIMER}

The Institute of Paper Chemistry (IPC) has provided a high standard of protessional service and has exerted lis best elforts within the time and tunds available for this project. The information and conclusions are advisory and are intended only for the internal use by any company who may recoive this report. Each company must decide tor itself the best approach to solving any problems it may have and how, or whether, this reported intormation should be considered in its approach.

IPC does not recommend particular products, precodures, materials, or services. These are included only in the interest of completeness within a laboratory context and budgetary constraint. Actual products, procedures, materials, and services used may differ and are peculiar to the operations of each company.

In no event shall IPC or its employees and agents have any obligation or liability for damages, including, but not limited to. consequential darnages, arising out of or in connection with any company's use of, or inability to use, the reported information. IPC provides no warranty or guaranty of results. 
Abstract

PAGE

Acknowl edgments

List of Tables

List of Figures

Executive Summary

1.0 Introduction

1.1 Objectives

1.2 Deliverables

12

1.3 Benefits

13

1.4 Organization

1.4

1.5 Schedule

1.6 Summary of Current Nozzle Technology

2.0 Droplet Formation with Pressure Nozzles

2.1 Droplet Formation from Ligaments

2.2 Black Liquor Nozzle Data

2.3 Effects of Drying

3.0 Black Liquor Nozzle Flow and Pres sure Drop Characteristics 21

3.1 Introduction

3.2 IPC Spray Facility Description

3.3 Black Liquor Nozzle Description

3.4 B\&W Splash Plate Nozzle Data

3.5 CE U-type and V-type Nozzle Data

3.6 Discussion

35

3.7 Conclusions

4.0 Fluid Sheet Thickness and Velocity for a B\&W Splash Plate Nozzle 38

4.1 Introduction

4.2 Experimental Apparatus

4.3 Range of Test Conditions

4.4 Sheet Thickness and Velocity Data

4.5 Development of a Correlation Technique

4.6 Discussion

4.7 Conclusions 
TABLE OF CONTENTS (CONTINUED)

5.0 Droplet Size Distribution of Black Liquor Sprays

PAGE

5.1 Introduction

5.2. Facility Description and Test Conditions

62

5.3 Correlation of Size Distribution Data

67

5.4 Discussion

69

5.5 Conclusions

71

6.0 Droplet Size Distribution Functions

72

6.1 Introduction

6.2 Normal Distribution

6.3 Size Distribution of Black l.iquor Sprays

6.4 Distribution Function for Black Liquor Sprays

6.5 Estimation of Mean Diameter

72

.72

73

74

75

7.0 Flash X-Ray Technique for Black Liquor Sprays

7.1 Introduction

89

7.2 Image Blur or Penumbra

89

7.3 Black Liquor Spray Thickness

90

7.4 Limitation of the Source-to-Film Distance

91

7.5 Image Contrast

92

7.6 Conclusions

8.0 High Speed Video Technique for Black Liquor Sprays

105

8.1 Velocity Measurements

105

8.2 High Speed Video Imaging

105

8.3 Discussion

8.4 Conclusions

105

107

9.0 Nozzle Stability and the Impact of High Solids 108

9.1 Black Liquor Flashing Inside a Nozzle 108

9.2 Performance at Typical Conditions 110

9.3 Performance at High Solids

References

Appendix

1. Reference (3)

2. Imaging Equipment Specifications 


\section{ACKNOWLEDGMENTS}

The authors thank Stanley F. Sobczynski, Program Manager, Office of Industrial Programs, U. S. Department of Energy for providing guidance and critical support. The authors would like to acknowledge those who have provided invaluable input; included are the support staff and students at IPST, Dr. Ted Farrington (project originator) of Kimberly Clark Corp., Dr. Dave Clay of James River Corp., and Dr. Tom Grace of T. M. Grace Co. Industrial support was gratefully received from personnel at The Babcock \& Wilcox Research Center at Alliance, $\mathrm{OH}$; Weyerhaeuser Paper Co. at Tacoma, WA; and James River Corp., Camas, WA. 


\section{LIST OF TABLES}

1.1 Benefits from Proposed Research

2.1 Sensitivity of the Predicted Droplet Diameter to Fluid and Operating Paraineters

3.1 Fluid Properties and Operating Conditions for the IPST Nozzle Flow / $\Delta$ P Tests

3.2 Typical Dimensions and Flows for B\&W Splashplate Nozzles

3.3 Typical Dimensions and Flows for CE Swirl Cone, V-type, and U-type Nozzles

4.1 Fluid Properties and Operating Parameters for IPST Sheet Thickness and Velocity Tests

4.2 Values for the LMS Fit Coristants for Equations (12)-(14)

5.1 Malvern ST2600 Analyzer Calibration

5.2 Data from B\&W Alliance Research Center

5.3 Data from Institute of Paper Science and Technology 


\section{LIST OF FIGURES}

2.1 Droplet Formation by Liquid Sheet Disintegration based on Dombrowski and Co-workers

3.1 Schematic Diagram of a B\&W Splashplate Black Liquor Nozzle

3.2 Schematic Diagram of a CE V-type and a CE U-type Black Liquor Nozzle

3.3 Schematic Diagram of a CE Swirl Cone Black Liquor Nozzle

3.4 Flow Coefficient Data and correlation for two B\&W Splashplate Nozzles using two Working Fluids - Black Liquor and Corn Syrup

3.5 Comp.rison of Actual and Predicted Pressure Drop for Two B\&W Splashplate Nozzles using two Working Fluids - Black Liquor and Corn Syrup

3.6 Flow Coefficient Data and Correlation for a CE U-type and a V-type Nozzle using Corn Syrup as a Working Fluid

3.7 Comparison of Actual and Predicted Pressure Drop for a CE U-type and V-type Nozzle using Corn Syrup as a Working Fluid

4.1 Schematic Diagram of the Sheet Thickness and Top Surface Velocity

Measurement Positions for the B\&W Splashplate Nozzle

4.2 Photograph of the Sheet Thickness and Top Surface Velocity Measurement Apparatus

4.3 Photograph of a Low Velocity Corn Syrup Spray Showing Center and Edge non-Uniformities

4.4 Sheet Thickness Data for the B\&W 15-52 Nozzle Using Corn Syrup as a Working Fluid at a Nozzle Velocity of $7.1 \mathrm{~m} / \mathrm{s}$

4.5 Sheet Top Surface Velocity Data for the B\&W 15-52 Nozzle Using Corn Syrup as a Working Fluid at a Nozzle Flow of $0.791 / \mathrm{s}$

4.6 Reduced Sheet Thickness as a Function of Angular Position for A11 Test Series

4.7 Reduced Sheet Top Surface Velocity as a Function of Anguiar Position for All Test Series

4.8 Correlation Between Reduced Sheet Velocity and Reduced Sheet Thickness Based on the Continuity Equation for the B\&W 15-52 Nozzle

4.9 Correlation Between Reduced Sheet Velocity and Reduced Sheet Thickness Based on the Continuity Equation for the B\&W 12-49 Nozzle 


\section{LIST OF FIGURES (Cont'd.)}

4.10 Momentum Equation Parameter as a Function of Reduced Viscosity for the B\&W 15-52 Nozzle

4.11 Momentum Equation Parameter as a Function of Reduced Viscosity for the B\&W 12-49 Nozzle

4.12 Comparison of Droplet Median Size Data and Calculated Sheet Thickness as a Function of Nozzle Velocity for a B\&W 12-49 Nozzle Firing Liquor at a Viscosity of $150 \mathrm{~m} \mathrm{Pa-s}$

4.13 Comparison of Droplet Velocity Data and Calculated Sheet Top Surface Velocity as a Function of Nozzle Velocity for a B\&W 12-49 Nozzle Firing Liquor at a Viscosity of $150 \mathrm{~m} \mathrm{Pa-s}$

4.14 Calculated Sheet Thickness as a Function of Fluid Viscosity for a B\&W 12-49 Nozzle Operating at $15 \mathrm{~m} / \mathrm{s}$

5.1 Comparison of Black Liquor Droplet Size Distribution Data for Three Test Conditions with Square-Root-Normal Fit of the Data for B\&W Splashplate Nozzles

5.2 Shadowgraph Image for a Black Liquor Spray Using the IPST Flash X-ray Imaging System

5.3 Comparison of Black Liquor Droplet Size Distribution Data for Three Test Conditions with Square-Root-Norma: Fit of the Data for CE Swirl Cone Nozzles

5.4 Mass Median Droplet Diameter of Black Liquor Sprays from B\&W Nozzles as a function of Maximum Nozzle Velocity for Three Spray Locations and Two Splashplate Angles

5.5 Normalized Standard Deviation of Black Liquor Sprays from B\&W Nozzles as a Function of Maximum Nozzle Veloctty for Three Spray Locations and Two Splashplate Angles

6.1 Normal Curve Plotted as a Function of the Number of Standard Deviations Away from the Median

6.2 Sample Plots of Black Liquor Spray Size Distribution for Two B\&W Splashplate Nozzles at Alliance Research Center

6.3 IPST Black Liquor Spray Size Distribution Data for Two Nozzle Types and Various Operating Conditions

6.4 Square-Root-Normal Size Distribution Using Four Assumed Scales

6.5 Plot of Square-Root-Normal Distribution with and without a Lower Cutoff Limit

6.6 Data for One B\&W Black Liquor Spray Size Distribution. Plotted Using Four Assumed Scales 


\section{LIST UF FIGURES (Cont ' $d$.)}

6.7 Square-Root-Normal Plots of Four B\&W Black Liquor Spray Size Distributions

6.8 Square-Root-Normal Plots of Four IPST Black Liquor Spray Size

Distributions for Two B\&W Splashplate Nozzles Operating at 66\% Solids

6.9 Square-Root-Normal Plots of Four IPST Black Liquor Spray Size

Distributions for a CE Swirl Cone Nozzle

6.10 Square-Root-Normal Plots of Two IPST Black Liquor Spray Size Distributions for a CE Swirl Cone Nozzle Operating with $72 \%$ Solids

6.11 Effect of a Lower Cutoff Limit on the Square-Root-Normal Plot Shape and Observed Median Diameter for Four Ratios of Lower Cutoff Limit to Median Diameter

6.12 Error Measurement of the Median Diameter Due to a Lower Cutoff Limit

6.13 Error Measurement of the Median Diameter Due to an Upper Cutoff Limit

7.1 Geometry for X-ray Absorption and Inage Grey Leve1 on the Film

7.2 Droplet Formation by Liquid Sheet Disintegration

7.3 Photon-Energy Spectrum for a Flash $X$-ray Source

7.4 Mass Attenuation Coefficients for Monoenergetic $X$-rays for Various Materials

7.5 Attenuation of $X$-ray Dose with Distance from the Source Through a Vacuum and Through Air

7.6 Absorptivity of X-rays by Air Alone and by Air Plus Black Liquor as a Function of Photon Energy

7.7 Relative Grey Level of Flash X-ray Image of Black Liquor Droplets of Various Sizes

7.8 Flash X-ray Shadowgraph for Black Liquor Spray

7.9 Relative Grey Level of Flash X-ray Image of $0.1 \mathrm{mmll}$ Clay Sphere

7.10 Flash $X$-ray Shadowgraph of Small Spray Showing Good Resolution

9. 1 Viscosity and Elevated Boiling Point as a Function of Liquor Dry Solids Content at $66 \%$ and $110^{\circ} \mathrm{C}$.

9.2 Maximum Liquor Dry Solids Content at the Elevated Boiling Point as a Function of Viscosity at $66 \%$ and $110^{\circ} \mathrm{C}$.

9.3 Minimum llozzle Pressure Drop Required to Suppress Flashing ahead of the Nozzle for Three Liquors. 


\section{- EXECUTIVE SUMMARY}

The research work descrtbed in thits report represents the results of the first year of a four-year project designed specifically to develop th optimum black liquor delivery system for the current kraft recovery boller. Black liquor obtatned from norinal mill operation is being used in this development. Some experiments with model fluids are to be carried out to answer specific questions resulting from the black liquor studies.

The primary objectives of the research program are:

-To develop laboratory equipment and methods for quantitatively studying commerclal black liquor" nozzle designs when spraying kraft liquors at typical operating conditions;

- To quantify droplet size distribution, velocity, and mass distribution for commercial nozzles spraying kraft liquors at typical boller conditions;

-To develop techniques currently envisioned for improving the control of black liquor spray droplet size distribution with commercial nozzles;

-To extend current liquor spraying technology by testing several fundamentally different, but commercially viable, delivery systems.

Success with this program should yield benefits in increased thermal efficiency and process productivity, as well as have potential for improvements in equipment design and process control. Coupled with the fundamental combustion research currently in progress at IPST, the potential value of these programs to the industry is approximately $\$ 110 \mathrm{MM} /$ year for increased thermal efficiency and $\$ 100 \mathrm{Mm} /$ year for increased productivity.

Though research is incomplete, some information is available about the performance of the three basic types of black liquor spray nozzles: the splashplate, the swirl cone, and the U- or V-type. Data are presented on the flow and pressure drop characteristics of two of these nozzle types which allows judgment of the sensitivity of the flow to norinal mill variations in liquor properties. Data are also presented on several aspects of spray formation and droplet size distribution. Considerations of nozzle stability with respect to flashing ahead of the nozzle have shown that the minimum nozzle operating pressure will have to be significantly iricreased to suppress flashing ahead of the nozzle when firing high solids, viscous liquors.

Flow coefficient correlations for hot and cold black liquor and corn syrup (a model comparison fluid) have been developed for two types of black liquor nozzles: the B\&W splashplate and the CE U- and V-type. The correlating parameter is Reynolds Number based upon the ininimum flow diameter. Corn syrup is useful because its viscosity and density are similar to those for black liquor, and it is easier to handle.

The formation of droplets from a black liquor stream requires the prior formation of a fluid sheet by the nozzle. The ultimate droplet size can be directly related to the initial sheet thickness and velocity. Sheet thickness, 
and therefore liquor droplet size, has been found to increase with liquor viscosity (and hence black liquor solids) for tine B\&W splashplate nozzle. This change in nozzle performance at high solids should be mild enough to allow routine mill optimization of existing B\&W nozzles without replacing them with a new design when changing to high solids firing.

Droplet size distribution is important for efficient, stable, and safe operation of recovery boilers. Data on droplet size distributions from a B\&W splashplate nozzle and a CE swirl cone nozzle have been obtaineci. Droplet size does vary with operating conditions; however, it shows a weak dependence on liquor velocity and fluid physical properties. Furthermore, the size distribution is almost the same for all nozzles when the size data are normalized by dividing the actual droplet size by the mass median diameter. Using this approach, there appears to be very little impact of nozzle geometry, fluid properties, or operating conditions. This suggests that any two nozzles and operating conditions which produce the same mass median size also produce the same size distribution. When calculating normalized size distributions, use of a lower cut off limit of one-third the observed median yields the best results. For a $2 \mathrm{~mm}$ mass median size which is typical of black liquor sprays the lower cutoff limit would then be $0.66 \mathrm{~mm}$. This is readily justified because of measurement 1 imitations below diameters of about $0.5 \mathrm{~mm}$.

The Flash $X$-ray (FXR) shadowgraph technique originally proposed for this program vias shown to be inferior to use of a high-speed video approach. This is because black liquor is a weak absorber of radiation resulting in poor image contrast for diameters under $0.5 \mathrm{~mm}$, and it gives an image blur of about $0.5 \mathrm{~mm}$, the end result being poor sensitivity for droplet diameters under one millimeter. The resolution of the high speed video varies with the selected field-of-view, but appears to be approximately $0.1 \mathrm{~mm}$. In addition, the number of FXR images per run was limited so that droplet history could not be recorded; such is not the case with the video approach.

Major activities for the present year involve reinstallation of the spraying equipment in an environmentally acceptable configuration at our new Atlanta location followed by spraying studies for conventional splash plate nozzles using simple fluids and non-flashing black liquors. A companion spraying study at one or more mill sites to examine spraying characteristics of black liquor in an operating recovery boiler will also be conducted. Comparison of results from the laboratory and inill activities should produce some interesting insights into black liquor spraying phenomena. 
1.0 INTRODUCTION

1.1 OBJECTIVES

The research work detailed in this report represents a very applied effort designed specifically to identify the optimum black liquor delivery system for the current kraft recovery boiler and to present it to the industry in a timely fashion. Only commercially viable (large capacity) delivery systems are being considered. Since the primary focus of this program is a system to deliver black liquor, a large number of experiments are to be conducted with actual (well characterized) liquors. Experiments with model systems will be carried out to answer specific questions arising from the liquor studies. The total program will answer the following very specific questions:

a. Exactly how good or bad are the nozzles currently used for black liquor spraying?

b. Do other commercially available (off the shelf) spraying systems exist which perform better than liquor nozzles now in use?

c. Can vibratory assist or concepts from fluidics such as controlled vortex shedding be employed to develop significantly improved spraying systems?

d. Are there more radically different delivery systems not involving the spraying of droplets which offer the opportunity for quantum improvements in recovery boiler operations?

In order to answer these questions the research program has the following main objectives:

a. To put in place a unique laboratory facility for the quantitative study of commercially viable black liquor nozzles which are tested with black liquors at typical operating conditions.

b. To quantify the performance (droplet size distribution, velocity, and mass distribution) of commercially available nozzles when spraying kraft black liquors at typical boiler conditions.

c. To test several potential techniques currently envisioned for improving the control of black liquor spray droplet size distribution with commercially viable nozzles.

d. To proceed beyond current spray technology to test several fundamentally different but commercially viable delivery systems.

\subsection{DELIVERABLES}

This research effort will deliver the following:

a. A test facility capable of quantitatively assessing the performance of commercially viable spray systems while spraying kraft black liquors at typical boiler feed conditions.

b. The best commercial spray delivery system available with current technology.

c. An appraisal of the commercial viability of several fundamentally different black liquor delivery systems. 


\subsection{BENEFITS}

To a large degree, the objective of this program can be viewed as delivering the tools required to realize the benefits of several other research activities in the black liquor area. Primary among these is the fundamental combustion research currently under way at IPST. This fundamental work will determine the optimum black liquor droplet size and velocity distribution to maximize effective use of the furnace volume. Development of a system to achieve this desired liquor distribution is the objective of the present program. As such, potential benefits from this very applied study are essentially the same as projected for the fundamentals of the combustion program. These are reproduced verbatim from a previous report by Clay et al. (7) in Table 1.1 .

The increased thermal efficiency value for the industry is approximately $\$ 110 \mathrm{million} /$ year. The minimum process productivity value for the industry is estimated at $\$ 100 \mathrm{milli}$ ion/year. Table 1.1 provides supporting detail. These costs reflect savings increments above the best state-of-the-art recovery boiler technology available. Increments from industry average conditions to improved levels could approach 1.5 to 2.5 times the above values.

Table 1.1. Benefits from Proposed Research.

Goals: 1. Increased thermal efficiency

2. increased process productivity

3. Improved equipment design potential

4. Improved process control potential

Targets :

1. Increased thermal efficiency

Element

Increased fired percent solids

Reduced flue gas temperature

Reduced carbon in smelt

Reduced sootblowing steam
Imp rovement

70 to $75 \%$

350 to $325^{\circ} \mathrm{F}$

1.5 to $1.0 \%$

3.0 to $2.5 \%$

(Total)

\begin{tabular}{cc}
\multicolumn{2}{c}{ Value } \\
\hline 105 Btu/adtp & $\$$ /adtp \\
2.3 & 1.5 \\
1.2 & 0.74 \\
0.86 & 0.54 \\
0.72 & 0.45 \\
5.1 & 3.2
\end{tabular}

2. Increased process productivity

Incremental production $\quad 1 \%$ inc. $\quad 2.25 \$ /$ adtp

INDUSTRY VALUE:

1. Increased thermal efficienty

$5.1 \times 10^{5}$ Btu/adtp $\times 44 \times 10^{6}$ adtp/yr $=2.2 \times 10^{13}$ Btu/yr

$2.2 \times 10^{13}$ Btu/yr $\times \$ 5.0 \times 10^{-6} / \mathrm{Btu}=\$ 110,000,000 / \mathrm{yr}$

2. Increased process productivity $(1 \%)$

$0.01 \times \$ 225 / \mathrm{adtp} \times 44 \times 10^{6} \mathrm{adtp} / \mathrm{yr}=\$ 100,000,000 / \mathrm{yr}$ 
Thermal efficiency and process productivity goals are not independent. The recovery boiler is often found to be the bottleneck in the entire pulping process. Thermal efficiency is often sacrificed for high productivity. Thermal efficiency and productivity increases may not be realized simultaneously. On the other hand, the recovery boller is the only pulp mill operation which can often claim that improved unit productivity will result in increased mill-wide productivity.

The in-place capital investment in recovery boiler technology is so large $(\$ 10,000,000,000)$ that radical changes, expansions, and replacements will be rare for the foreseeable future. Barring a significant departure from the kraft process in the near term, the industry will be firing black liquor in "Tomlinson-like" bollers through the year 2000.

\subsection{ORGANIZATION}

Organization of the project initially came from Dr. T. E. Farrington, Assistant Professor in the Engineering Division of IPST, and Dr. D. T. Clay, Associate Professor, and Dr. T. M. Grace, Profassor, in the Chemical Sciences Division. With the move of IPST from Appleton to Atlanta, these individuals elected not to relocate. To maintain project continuity, IPST engaged consultant Dr. T. N. Adams on a part time basis to assume primary technical responsibility. Subsequent to this, Dr. H. L. Empie was hired as Group Leader for Recovery and accepted organizational responsibility for the project. Mr. T. M. Spielbauer, a PhD candidate at IPST, elected to do his thesis research in the area of liquor droplet formation mechanisms, and is expected to contribute significantly to the success of the project.

\subsection{SCHEDULE}

The work reported here represents Tasks 1 and 2 of a 5 -task project covering a total of 4 years. Successful completion should lead to a second phase involving implementation at some mill location.

\subsection{SUMMARY OF CURRENT NOZZLE TECHNOLOGY}

The performance of spray nozzles for kraft black. liquor has been the subject of recent investigations $(2,3,19)$. Though research is incomplete, some information is available about the performance of the three basic types of black liquor spray nozzles: the splashplate, the swirl cone, and the U- or V-type. Data are presented on the flow and pressure drop characteristics of two of these nozzle types which allows judgment of the sensitivity of the flow to normal mill variations in liquor properties. Data are also presented on several aspects of spray formation and droplet size distribution. Nozzle stability is discussed with respect to flashing ahead of the nozzle. It is found that the minimum nozzle operating pressure will have to be significantly increased to suppress flashing ahead of the nozzle when firing high solids, viscous liquors. Ref. (3) is attached as Appendix 1 . 


\subsection{DROPLET FORMATION WITH PRESSURE NOZZLES}

\subsection{DROPLET FORMATION FROM LIGAMENTS}

All of the conventional commercial black liquor nozzles bulong to the category known as pressure atomizing nozzles. Pressure atomizing nozzles form droplets by first forming sheets of liquid at che edge of a stationary or rotating surface. The sheets break up into droplets due to surface tension and viscous forces within the liquid, and the action of shear forces between the liquid sheet and the surrounding gas. This mechanism is referred to as wave disintegration. It is illustrated in Figure 2.1.

The oscillatory motion in wave disintegration is caused by aerodynamic forces. This type of motion is called Helmholtz instability and is the same phenomenon observed with a flag blowing in the wind. The sheet begins to oscillate soon after it is formed. Surface waves in the liquid sheet are reinforced by aerodynamic drag forces. The oscillations grow until the sheet ruptures between the wave nodes and ribbons of fluid detach from the sheet at the leading edge. The ribbons which detach are half a wavelength in width. They collapse into cylindrical ligaments, due to surface tension forces, and the ligaments collapse into droplets.

The initiation of waves in liquid sheets is not entirely understood, but seems to result from disturbances upstream of the nozzle, from pumps, piping, or the nozzie itself. The key feature of these disturbances is that they are random and disorganized. This will contribute to the breadth of the ultimate droplet size distribution. Whatever the nature of the disturbarices, it is the action of the surrounding gas on the sheet which accentuates the resulting waves and eventually causes the sheet to break up. Dombrowski and coworkers $(8,9,10,14)$ have studied droplet formation by the wave disintegration mechanism. Their model of this process provides a quantitative relationship between liquid properties, droplet size, and operating parameters.

The mathematical model of Dombrowski and coworkers is for a circular, sheet forming nozzle. They treat the natural oscillation frequency of the sheet which depends on the liquid velocity and the gas and liquid properties to calculate a single characteristic droplet size. Their expression for this droplet size is:

$$
D_{\text {drop }}=D_{\text {ligament }}\left[\frac{3 \pi}{\sqrt{2}}\right]^{1 / 3}\left[1+\frac{3 \mu}{\sqrt{\rho f \sigma D_{\text {ligamen }}}}\right]^{1 / 6}
$$

where

$$
D_{\text {ligamen1 }}=0.96\left[\frac{\rho_{1}}{\rho_{g}}\right]^{1 / 6}\left[\frac{B_{n} \sigma}{\rho_{1} v^{2}}\right]^{1 / 3}\left[1+2.6 \mu\left\{\frac{B_{n} \rho_{g}^{4} v ? !}{72 \rho_{1}^{2} \sigma^{5}}\right\}^{1 / 3}\right]^{1 / 5}
$$

The term $B_{n}$ in Equation (2-2) is a constant for a particular nozzle given by:

$$
B_{n}=4.87 \times 10^{-7}+0.553 A_{n}
$$




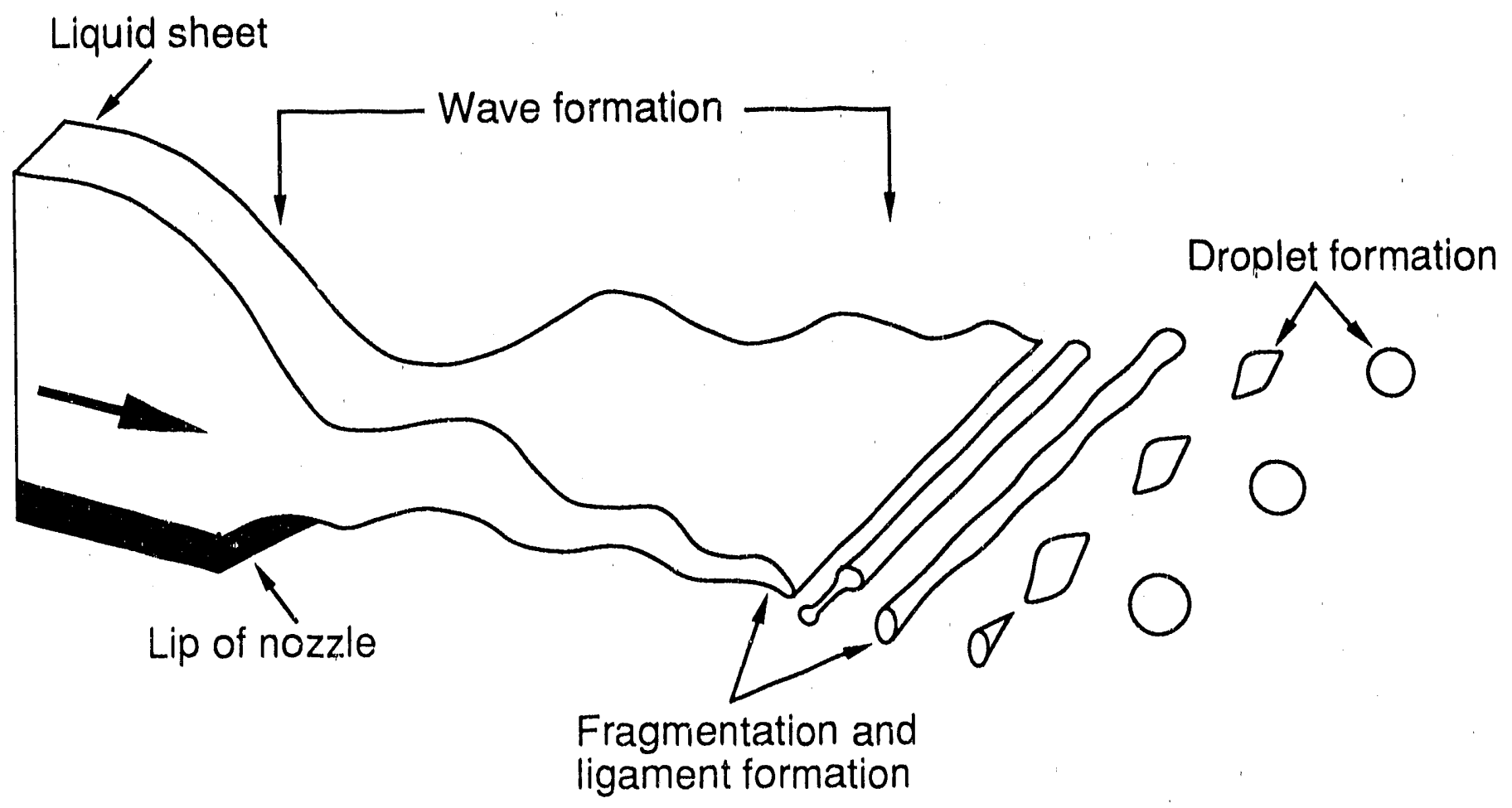

Figure 2.1. Droplet formation by liquid sheet disintegration based on Dombrowski and co-workers $(8,9,10,14)$. 
where:

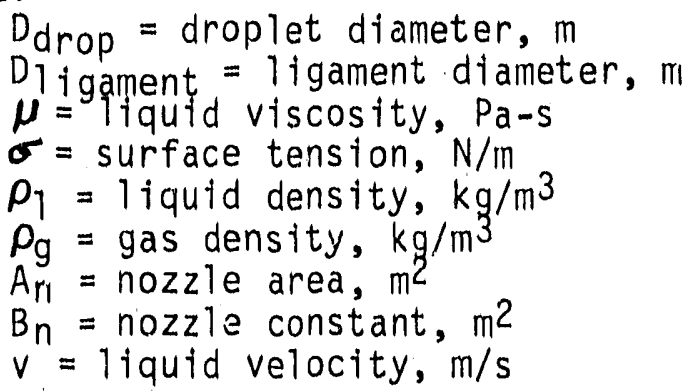

A considerable simplification of the above equations is possible for typical black liquor nozzles. The last term in the expression for Dligament in Equation (2-2) which involves $2.6 \mu$ is always much smaller than one for all conditions of firing black liquor, so it can be ignored.

Table 2.1

Sensitivity of Predicted Drop Diameter to Fluid and Operating Parameters

\begin{tabular}{|c|c|c|c|c|c|}
\hline & Low & $\frac{\text { eter }}{\text { High }}$ & $\frac{\text { Prec }}{\text { Droplet }}$ & $\begin{array}{l}\text { ted } \\
\text { meter,mm } \\
\text { High }\end{array}$ & $\begin{array}{c}\text { Change } \\
\text { with Increase }\end{array}$ \\
\hline Nozzle diameter, $D_{n}, m m$ & 12.5 & 50 & 2.5 & 6.1 & $+47 \%$ \\
\hline Fluid velocity, $v, \mathrm{~m} / \mathrm{s}$ & 7 & 23 & 4.69 & 2.60 & $-45 \%$ \\
\hline Fluid viscosity, $\mu, \mathrm{Pa}-\mathrm{s}$ & 0.03 & 0.3 & 2.71 & 3.88 & $+43 \%$ \\
\hline Fluid density, $\rho_{1}, \mathrm{~kg} / \mathrm{m}^{3}$ & 1250 & 1450 & 3.16 & 3.05 & $-4 \%$ \\
\hline Fluid surface tension, $\sigma, \mathrm{N} / \mathrm{m}$ & 0.025 & 0.06 & 2.93 & 3.34 & $+14 \%$ \\
\hline Gas density, $\rho_{\mathrm{g}}, \mathrm{kg} / \mathrm{m}^{3}$ & 0.25 & 1.0 & 3.10 & 3.08 & $-1 \%$ \\
\hline
\end{tabular}

Table 2.1 indicates that the expected sensitivity of droplet diameter to changes in fluid properties is not very strong. The two onerating parameters, nozzle diameter and fluid velocity, are far more influential in droplet formation by the mechanisin of sheet break up. Below, these predicted results will be compared to the limited data available on black liquor nozzles. 


\section{2.? BLACK LIQUOR NOZZLE DATA}

Bennington and Kerekes [7] were the first to report on the size and size distribution of droplets from black liquor nozzles. They used small, commercially avaflable grooved-core nozzles similar in operation to the CE-type swirl cone nozzles used currently for firing black liquor. The nozzle orifice size for their nczzles was only $0.7 \mathrm{~mm}$ in diameter, about one thirtieth the size of a commercial nozzle. The droplet sizes from these nozzles are much sinaller (about $0.3 \mathrm{~mm}$ ) than those from connercial black liquor nozzles (about $3 \mathrm{mmII}$ ). The spray chamber used by Bennington and Kerekes was not heated, so surface cooling of the spray may have influenced the droplet formation process.

Bennington and Kerekes obtained data on water and on $65 \%$ glycerol/water solution at room temperature, and on black liquor at elevated temperature. The black liquor had a dry solids content of $55 \%$ and was fired at a temperature of $120^{\circ} \mathrm{C}\left(248^{\circ} \mathrm{F}\right)$. The resulting viscosity was somewhat lower than typical black liquor firing conditions at $0.015 \mathrm{~Pa} \cdot \mathrm{s}(15 \mathrm{cp})$. The viscosity of the glycerol/water was also about $0.015 \mathrm{~Pa} \cdot \mathrm{s}$. The nozzle pressure for each was the same, $1.38 \mathrm{MPa}(200 \mathrm{psi})$. This high pressure along with the small nozzle size and the relatively low viscosity led to the small droplet size obtained in their tests.

Results of their tests showed that black liquor appears to yield a much broader size distribution than water or glycerol/water.

The apparent differences in this data are somewhat misleading. The mass median droplet sizes for the three fluids under apparently similar conditions are quite different. The viscosity of glycerine and black liquor is fifteen times that of water. However, black liquor sprayed at $120^{\circ} \mathrm{C}$ into a $25{ }^{\circ} \mathrm{C}$ environment would lose water by evaporation and cool during droplet formation. Its viscosity would increase, and the resulting droplet size would be larger. Given this, the observed differences in median droplet sike are not too surprising.

The data show two important features of this type of droplet formation. When ploted as a function of the diameter divided by the mass-median diameter, the data from the three fluids are nearly identical. The very brodd size distribution for black liquor is solely a result of its large median diarleter. This grooved-core nozzle produces the same type of size distribution for all three fluids.

It is important to note that, if the operating conditions for the three lluids were manipulated to produce the same mass-median droplet size, then the size distributions for each would be identical. The size distribution about the mean is not a function of the operating paraneters or fluid properties, but of the mechanism for sheot break up. The basic characteristic of this mechanism is that it is random or disordered, and this results in a broad size distribution.

Bennington and Kerekes correlated their data on water and glycerine sprays with a relatively simple equation. For grooved-core nozzles they used

correlations of the form:

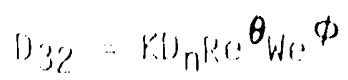


where:

$$
\begin{aligned}
& D_{32}=\text { Sauter mean diameter of the size distribution, in } \\
& K=\text { an enpirical constant } \\
& D_{n}=\text { nozzle diameter, } m \\
& \text { Re }=\text { Reynolds number } \\
& \text { We }=\text { Weber number } \\
& \boldsymbol{\theta , \phi}=\text { correlating exponents }
\end{aligned}
$$

The drop'et diameter $D_{32}$ is the Sauter mean diameter. This is the fictitious spherical droplet which has the same surface-to-volume ratio as the distribution as a whole. The subscripts stand for exponents on the diameter in the integration to evaluate the surface area of the droplets. The Sauter mean diameter is often used when surface transfer processes such as droplet drying or combustion are being considered. The Sauter mean diameter and the mass-median diameter are directly related; $D_{32}$ is typically $80 \%$ of the massmedian $\cdot$ diameter.

Bennington and Kerekes correlated their data for water and glycerol/water sprays based on the Sauter mean diameter. Their correlation is:

$$
D_{32}=1.6 D_{n} W e^{-0.18} R^{-0.18 \quad \pm 44 \%}
$$

The substantial uncertainty indicated by the $+44 \%$ scatter is unfortunately characteristic of droplet spray data. Equation (2-5) under-predicts the droplet size data for black liquor sprays by a factor of two. Although the operating conditions for glycerol/water and black liquor were the same, the black liquor produced substantially larger droplets. The initial black liquor viscosity was the same as the glycerol/water viscosity, but these droplets are small enough, and the liquor hot enough, to cause drying and cooling to occur during droplet formation with black liquor. Bennington and Kerekes speculated that this might be the cause of the differences. Much more data would be required to evaluate this. However, if it were true, changes in the black liquor properties would have to be very substantial to cause the observed differences in the droplet size. This would substantially complicate black liquor nozzle design because droplet size would then be very dependent on the thermal enviromment surrounding the spray of black liquor.

In another study reported by Farrington [11], practical black liquor nozzles and other commercially available nozzles were evaluated. Included are a CE-type swirl cone nozzle, a B\&W splash-plate nozzle, and a commercial hollow cone nozzle. As with the previous data, Farrington's data have been plotted as a function of the diameter divided by the mass-median diameter. These curves, like those of Bennington and Kereke;, overlap substantially, indicating that the size distribution for each nozzle is very similar. Had the three nozzles been operated to produce the same mass-median droplet size, the size distributions would be very difficult to tell apart. All three nozzles were operated with the same fluid, so the differences in the droplet size would be due to nozzle diameter and fluid velocity. Neither was reported.

The size distributions from the two studies are very similar. This similarity is initially surprising considering that three different fluids were 
used, including black liquor, and that four different nozzles were used, one of which was one-thirtieth the size of the others. This similarity allows several important conclusions to be drawn about sheet-forining nozzles, despite the very limited data that are available:

1. The massmedian size of the droplet size distribution will depend specifically on the design and operation of the nozzle.

2. The mean droplet size will not be very sensitive to reasonable variations in the measurable fluid properties.

3. With black. liquor there is an, as yet, unknown interaction with the nozzle or the environment which causes the mean size to be different from that for fluids with apparently similar properties.

4. For a surprisingly wide range of designs and conditions the size distribution from sheet-forining nozzles is very similar.

5. The size distributions from sheet-forming nozzles are always much broader than would be desirable to control both entrainment and wet liquor to the bed in black liquor recovery boilers.

\subsection{EFFECTS OF DRYING}

A few aspects of black liquor drying will be presented here. First, an important physical feature of black liquor is that its basic character changes as it $i j$ evaporated to higher solids. At dry solids contents below approximately $50 \%$, water is the continuous phase with the inorganic and organic dissolved or suspended in the water. However, at dry solids contents above approximately $50 \%$, and certainly at firing conditions above $62 \%$ solids, the water is no longer the continuous phase [23]. The polymeric solids form the continuous phase and the water is distributed within the polymer phase. This leads to several important features of black liquor, one of which is its characteristic of drying.

When strong black liquor droplets are exposed to a high temperature environment, heat transfer and drying begin almost immediately. Surface evaporation occurs as well as vaporization of water within the droplet. When internal vaporization occurs, the observed effect is rapid expansion, bursting, and collapse of the droplet. This is a very dynamic process, but no observation of whole droplet shattering has been made. Rather, the effect is more like a balloon which expands due to internal gas pressure to the limit of strength of the elastic material of the balloon. The balloon splits, gas is expelled, and the balloon matertal collapses back onto itself, without loss of balloon material. This is the routine observation in black liquor droplet drying, and is probably due to the fact that the polymeric dry solids material in black liquor is the continuous phase under normal firing conditions. Flashing of steam within the droplets just after leaving the nozzle would be expected to show the same effects, very violent expansion, bursting, and collapse without substantial loss of solid material. Flashing would then not be expected to cause shattering of the droplets.

The only data available on the effect of superheat on droplet size distribution is that of Bennington and Kerekes [7] as part of the study described above. They first showed the effect of superheat on the sauter mean iroplet size for water sprays. At temperatures below $100^{\circ} \mathrm{C}\left(212^{\circ} \mathrm{F}\right)$ increasing water temperature decreased the droplet size, as would be expected from Equation (2-5). However, when the temperature exceeded the bolling point of water, the droplet size increased by nearly $50 \%$ ! The effect of temperature on 
black 1iquor was different than for water. With black 1:quor, the mean droplet size decreased smoothly as the liquor temperature was increased past its bolling point. Though this is very little data to base a final judgment of the effects of flashing on black 1iquor, it is consistent with the basic mechanisin of black liquor droplet drying. Evaporation of water from black liquor during droplet formation probably does play a key roll, but in its effects on the viscosity and surface tension rather than in flashing.

Once liquor droplets are formed, they are subject to stresses assoctated with derodynamic shear as they move through the surrounding gas. An important issue in dealing with droplet combustion is whether or not the droplets break up into sinaller droplets as a result of these stresses. Droplets disintegrate by this mechantsin depending on a balance between the forces due to lift and drag, and the resistance to breakup due to surfice tension and viscosity.

\subsection{FLOW AND PRESSURE DROP CHARACTERISTICS OF BLACK LIQUOR NOZZLES}

\subsection{INTRODUCTION}

Control of the black liquor droplet size for combustion optimization in practical mill applications is the main thrust of these studies. Proper selection of nozzle size and number is dependent on a knowledge of the flow and pressure drop characteristics of these nozzles.

In the mill situation, black liquor nozzles are connected through rigid gun extensions and flexible hoses to ring headers which encircle the recovery boller. These ring headers are typically $15 \mathrm{~cm}$ ( 6 inches) in diameter while the connections to the individual nozzles are 2.5 to $5 \mathrm{~cm}$ ( 1 to 2 inches) in diameter. Reasonable engineering calculations of flow and pressure drop characteristics in these lines are possible, given a knowledge of the black liquor viscosity. However, the geometry of the various types of nozzles has made calculation of the pressure drop across them less certain.

The purpose of thits section is to present data on the flow and pressure drop characteristics of black liquor nozzles. The discussion is broken into sections which: 1) describe the three most common types of black liquor nozzles and show the range of their usual operation; 2) describe the spray facility where the flow/ $\Delta$ P data for the nozzles were taken; 3 ) present the avallable data for four nozzles; and 4 ) discuss the data in terms of the fluid mechanics of nozzle flow.

\subsection{IPST SPRAY FACILITY DESCRIPTION}

The experimental facility used to obtain the data reported in this section was constructed at The Institute of Paper Chemistry in Appleton, WI (now the Institute of paper Science and Technology in Atlanta, GA) in order to study the spray characteristics of black liquor nozzles (2). The flow loop consists of a $1.9 \mathrm{~m}^{3}$ (500 gallon) storage tank, fluid preparation and pumping systems, and a spray booth. The spray nozzle being tested is located at the top of the spray booth and sprays the working fluid down into a catch tank at the bottom of the booth. The pressure, temperature, and flow of the fluid are measured immediately ahead of the nozzle. The fluid viscosity can be measured either off-line in the laboracory using a benchtop viscometer 
from Brookfleld Engineering Labs., Inc., Stoughton, MA, or continuous ly in a by-pass line located aread of the spray nozzle using a Brookfield on-line viscometer. Viscosity data along with all other data around the flow loop is continuously recorded using a digital data acquisition system.

Three flutds were used in taking the data presented below: two kraft black liquors and a corn syrup. One of the liquors was obtatned from an east coast southern kraft mil1. The other liquor was obtained from an upper midwestern kraft mill. Corn syrup was selected as another working fluid for these nozzle tests because it has a solids content and a viscosity similar to black liquor at typical mill firing conditions, Corn syrup is also known to be a Newtonian fluid over a wide range of shear rates. The Newtonian viscosity measured by the Brookfield instruments was sufficient to characterize black liquor and corn syrup viscosity at the relatively low shear rates in these nozzles. The range of fluid properties and operating conditions used in these tests is presented in Table 3.1.

\section{TABLE 3.1}

Fluid Properties and Operating Conditions for the IPST Nozzle Flow/AP Tests

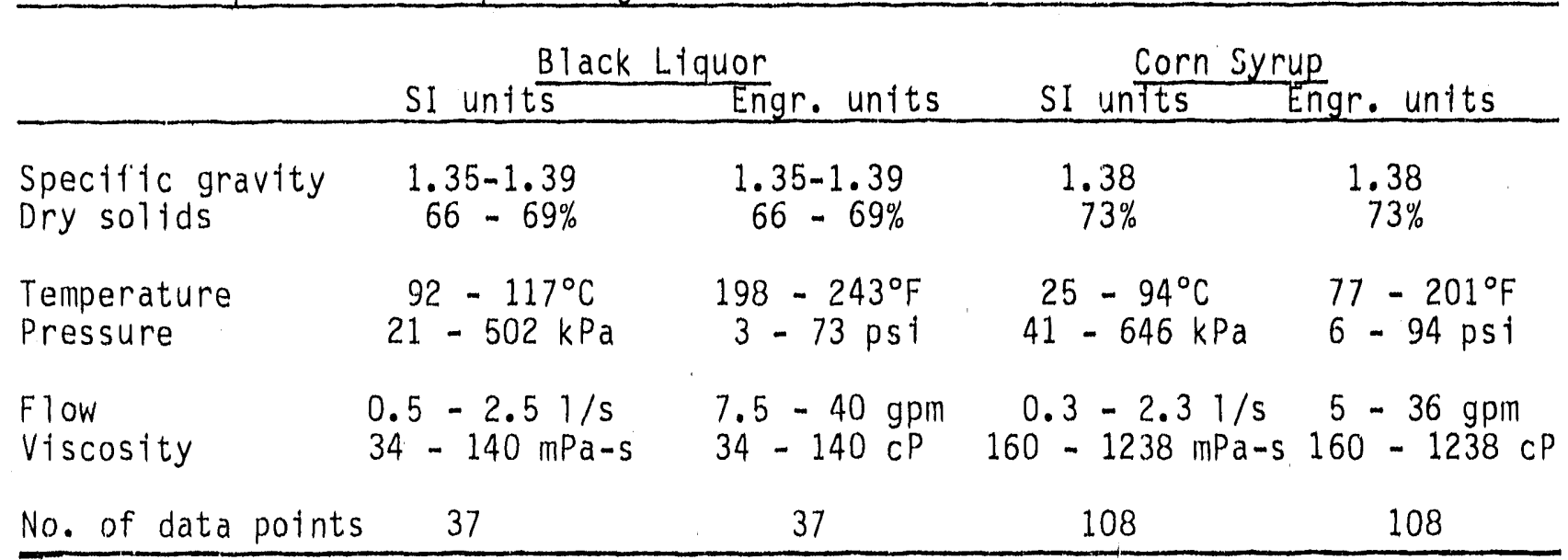

In addition to the above data, three data points were used from work on a B\&W 12-49 splashplate nozzle by the B\&W Alliance Research Center (18). These data were taken with a midwestern kraft black liquor at $53 \%$ solids and $25^{\circ} \mathrm{C}\left(77^{\circ} \mathrm{F}\right)$.

\subsection{BLACK LIQUOR NOZZLE DESCRIPTION}

Babcock \& Wilcox Splashplate Nozzle

Splashplate-type nozzles are widely used for black liquor spraying. The basic arrangement is a straight tapering nozzle section which causes the black liquor flow to finpinge on a flat plate at angles ranging from $35^{\circ}$ to $55^{\circ}$. The flow flattens into a broad fluid sheet which subsequently breaks into ligaments and droplets after leaving the plate. A schematic diagram of a typical black liquor splashplate nozzle from the Babcock and Wilcox Co. (B\&W) is shown in Figure 3.1. Two of these nozzles were used in taking the data presented in the following sections. 
B\&W splashplate nozzle

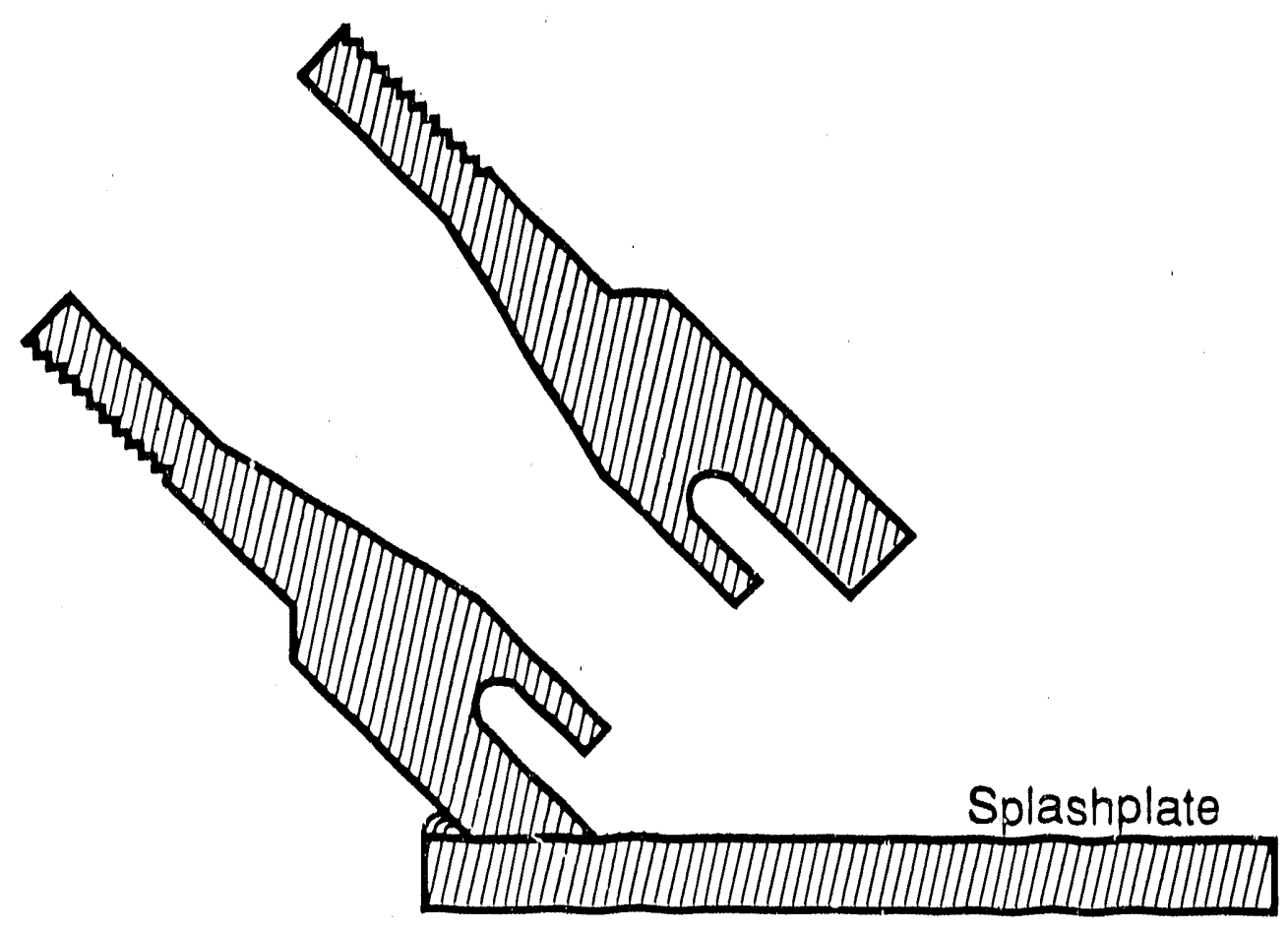

Figure 3.1. Schematic diagram of a B\&W splashplate black liquor nozzle. 
One nozzle will be referred to as a B\&W 12-49 while the other is a B\&W 15-52. The first two digits in this nozzle designation refer to the nozzle exit cliameter measured in thirty-seconds of an inch. The diameter for the first is $12 / 32(0.375$ inches or $0.95 \mathrm{~cm})$ while the second is $15 / 32$ $(0.469$ inches or $1.19 \mathrm{~cm})$. The second two digits in this nozzle designation refer to the angle at which the fluid exiting the nozzle orifice strikes the splashplate. The jet from the first nozzle impinges on the splashplate at a $49^{\circ}$ angle. Due to practical test considerations these nozzles were selected from the small end of the spectrum of nozzle sizes used in commercial service.

For all the nozzle types the flow/ $\Delta \mathrm{P}$ characteristics will be presented in terms of flow coefficients which are used in equations of the form:

$$
\Delta \mathrm{P}=\mathrm{C}_{\mathrm{f}} \frac{1}{2} \rho \mathrm{V}_{\mathrm{n}}^{2}
$$

where:

$$
\begin{aligned}
& \Delta P=\text { pressure drop across the nozzle, } P_{a} \\
& C_{f}=\text { flow coefficient, unitless } \\
& P=\text { fluid density }, \mathrm{kg} / \mathrm{m}^{3} \\
& V_{n}=\text { fluid velocity at the minimum flow area, } \mathrm{m} / \mathrm{s}
\end{aligned}
$$

The characteristic flow velocity for the nozzle is evaluated at the minimum flow area. The minimum flow area is easy to identify for the B\&W splashplate nozzle because it is the exit area, but it is less straightforward for some of the other nozzles.

The flow coefficient is related to the other commonly used parameter for characterizing the flow/ $\mathrm{PP}$ relationship for nozzles-the discharge coefficient, $C_{D}$. The discharge coefficient is used in the equation:

$$
\mathrm{Q}=\mathrm{C}_{\mathrm{D}} \mathrm{A} \sqrt{\frac{2 \Delta \mathrm{P}}{\rho}}
$$

where:

$$
\begin{aligned}
& Q=\text { volume flow rate }, \mathrm{m}^{3} / \mathrm{s} \\
& A:=\text { flow area, } \mathrm{m}^{2} \\
& C_{D}=\text { discharge coefficient, unitless }
\end{aligned}
$$

so that:

$$
C_{f}=\frac{1}{C_{D}^{2}}
$$


A sharp-edged orifice has a $C_{D}$ of approximately 0.6 while a flow nozzle has a $C_{D}$ near 1.0 . This results in a range for $C_{f}$ from 1.0 to 2.8 .

The flow coefficient is the sum of contributions from inertial acceleration and viscous losses. The inertial acceleration term is the difference in velocity head between the entrance and the minimum flow area. The inertial acceleration term will be unaffected by the specific condition at the no.zle entrance if the initial velocity head is much smaller than the velocity head at the minimum flow area. The velocity head is given by:

$$
h_{v}=\frac{1}{2} v^{2}
$$

where:

$$
h_{v}=\text { velocity head, } m^{2} / s^{2}
$$

By continuity:

$$
A_{e} V_{e}=A_{n} V_{n}
$$

where:

$A_{e}=$ flow area at the entrance, $\mathrm{m}^{2}$

$\mathrm{V}_{\mathrm{e}}=$ velocity at the entrance, $\mathrm{m} / \mathrm{s}$

$A_{n}=$ minimum flow area of the nozzle, $m^{2}$

so that for circular cross sectional areas:

$$
\frac{h_{v e}}{h_{v n}}=\left(\frac{D_{n}}{D_{e}}\right)^{4}
$$

where:

$$
\begin{aligned}
& D_{e}=\text { diameter at the entrance, } m \\
& D_{n}=\text { diameter at the minimum flow area, } m
\end{aligned}
$$

For the B\&W splashplate nozzle the entrance diameter is approximately 1.8 times the nozzle diameter so that:

$$
\frac{h_{\mathrm{ve}}}{\mathrm{h}_{\mathrm{vn}}}=\left(\frac{1}{1.8}\right)^{4}=0.095
$$

The entrance velecity head is less than $10 \%$ of the nozzle exit velocity head, so the flow coefficient will be insensitive to specific inlet conditions. 
The viscous term for fully developed pipe flow is expressed in the form:

$\Delta P=\frac{1}{2} \rho V^{2} \stackrel{L}{-}-\frac{C}{R e^{n}}$

with:

$\operatorname{Re}=\frac{\rho V D}{\mu}$

where:

$$
\begin{aligned}
V & =\text { local average velocity, } \mathrm{m} / \mathrm{s} \\
C, n & =\text { constants } \\
\mathrm{Re} & =\text { Reynolds number } \\
\mu & =\text { fluid viscosity } \mathrm{Pa-s} \\
L / D & =\text { pipe length-to-diameter ratio }
\end{aligned}
$$

Characteristic dimensions and flows for the mill application of B\&W splashplate nozzles are presented in Table 3.2 .

TABLE 3.2

Typical dimensions and flows for B\&W splashplate nozzles

\begin{tabular}{lcc} 
& \multicolumn{1}{c}{ SI units } & Engr. units \\
\hline Nozzle exit diameter & 1.9 to $3.2 \mathrm{~cm}$ & 0.75 to $1.25 \mathrm{in}$. \\
Operating pressure & 124 to $330 \mathrm{kPa}$ & 18 to $48 \mathrm{psi}$ \\
Nozzle exit velocity & 13.7 to $24 \mathrm{~m} / \mathrm{s}$ & 45 to $80 \mathrm{ft} / \mathrm{s}$ \\
Black liquor viscosity & 0.05 to $0.25 \mathrm{~Pa}-\mathrm{s}$ & 50 to $250 \mathrm{cP}$ \\
Reynolds number & 1400 to 21,000 & 1400 to 21,000
\end{tabular}

Using an upper limit for Reynolds number of 2000 for laminar flow, it can be seell that the flow regime for the $B \& W$ splashplate nozzle spans the range from laminar flow to turbulent flow.

Equation (3-8) is specisically for fully developed flow. Fully developed flow only occurs when the pipe length-to-diameter ratio, $L / D$, is fairly large. The usual range for fully developed turbulent flow is an $L / D$ greater than 10 , while $L / D$ must be greater than 100 for many laminar flow situations. For the B\&W splashplate nozzle the L/D is only approximately 4.3, and most of this length is tapering. Therefore, the fully developed flow equation for viscous loss is not directly applicable to this nozzle, or to the other black. liquor nozzles. For this reason a prior calculation of flow-pressure drop characteristics of black liquor nozzles would be quite difficult. 


\section{Combustion Engineering V-type and U-type Nozzles}

V-type and U-type nozzles are widely used in spray applications. Combustion Engineering Inc. offers both types for black liquor service. A schematic diagram for each type is shown in Figure 3.2 The nozzle consists of a cylindrical passage capped with a hemisphere. A V-shaped or U-shaped notch is cut diagonally across the cap, producing an approximately elliptical nozzle opening. The opening in the V-type nozzle has a narrower aspect ratio and sharper corners than the U-type. The plan area of the U-type is closely approximated by a true ellipse, while the V-type is somewhat less so. The area and equivalent circular diameter for each are given by:

$$
\begin{aligned}
& A_{u}=\frac{\pi}{4} b c \\
& D_{u}=\sqrt{b c} \\
& A_{v}=0.9 \frac{\pi}{4} b c \\
& D_{v}=0.95 \sqrt{b c}
\end{aligned}
$$

where:

$$
\begin{aligned}
& A_{u}=\text { nozzle exit area for } U \text {-type nozzle, } m^{2} \\
& D_{u}=\text { equivalent circular diameter for the } U \text {-type nozzle, } m \\
& A_{V}=\text { nozzle exit area for the } V \text {-type nozzle, } m^{2} \\
& D_{V}=\text { equivalent nozzle diameter for the } V \text {-type nozzle, } m \\
& b, c=\text { major and minor axis dimensions for the } U \text { - and } V \text {-type nozzles, } m
\end{aligned}
$$

For the data described below, a CE U-type nozzle was used for which the major and minor axis dimensions were $13.5 \mathrm{~mm}$ and $9.1 \mathrm{~mm}$ ( 0.53 inches and 0.36 inches). The equivalent circular nozzle diameter is $11.1 \mathrm{~mm}$ (0.44 inches). As well, a CE V-type nozzle was used for which the major and minor axis dimensions were $18.3 \mathrm{~mm}$ and $8.3 \mathrm{~mm}$ ( 0.72 inches and 0.33 inches). The equivalent circular nozzle diameter is $11.7 \mathrm{~mm}$ ( 0.46 inches). 


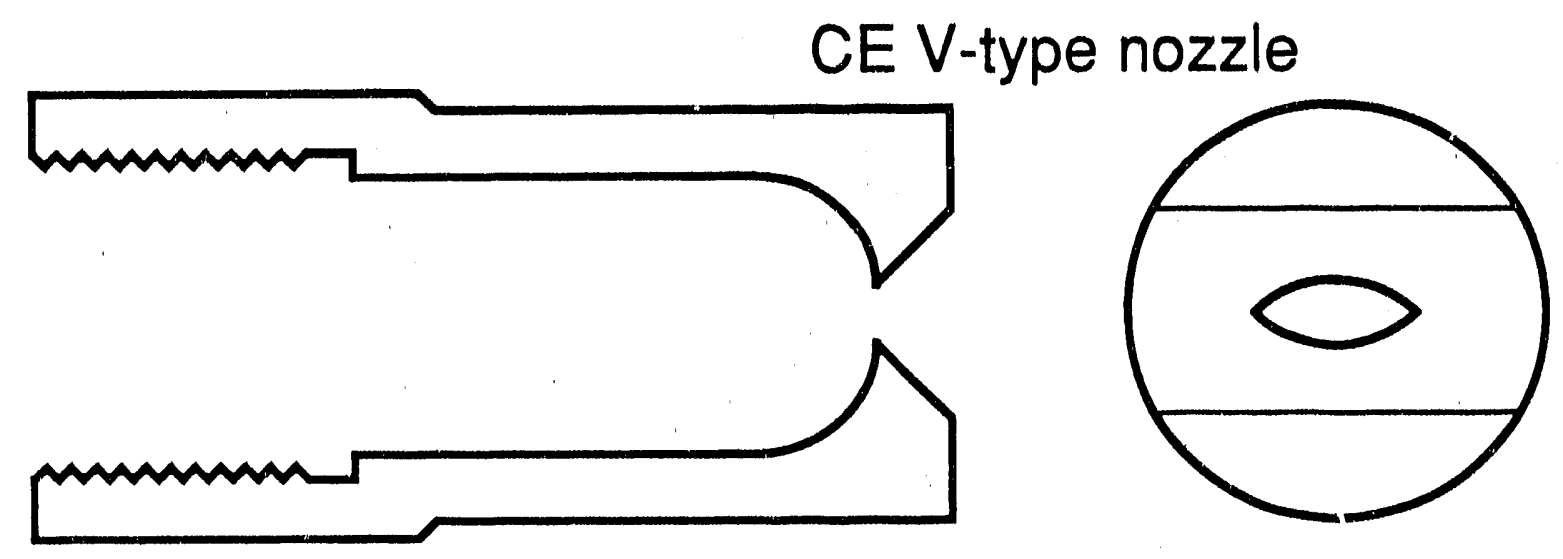

CE U-type nozzle
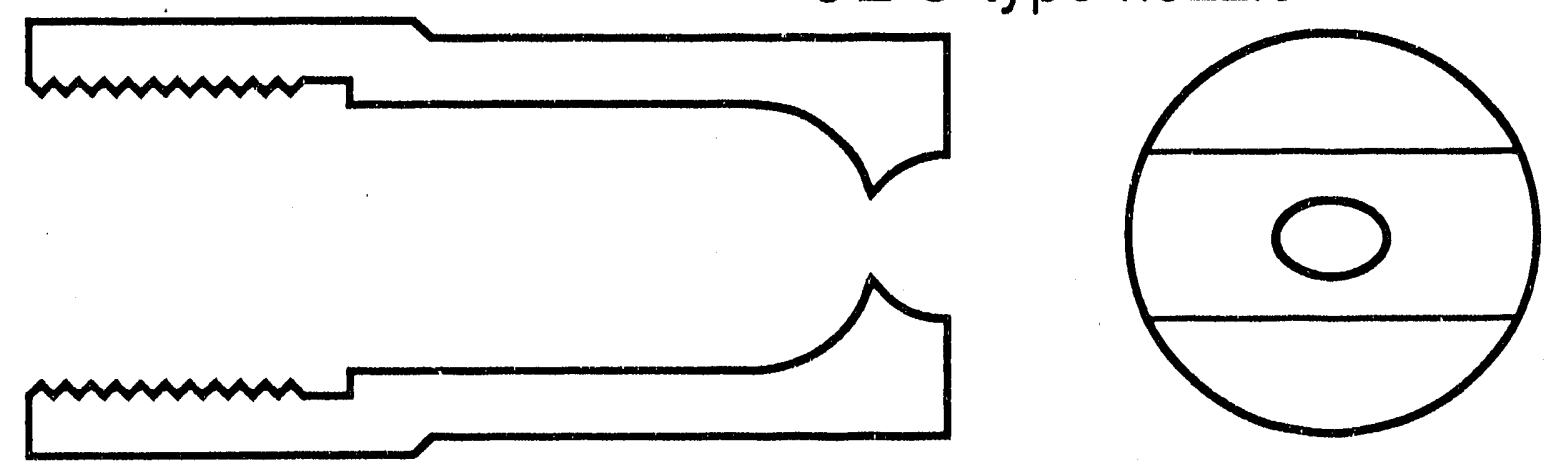

Figure 3.2. Schematic diagram of a CE V-type and a

CE U-type black liquor nozzle. 
For both the U-type and the V-type nozzle the entrance diameter is more than twice the nozzle exit diameter. As with the splashplate nozzle, the flow/ $\Delta \mathrm{P}$ characteristics will be insensitive to the initial flow conditions at the nozzle entrance.

$V$-type and U-type nozzles have not been in black liquor service as long as the splashplate or the other common nozzle, the swirl cone. However, values of dimensions and flows for current practice with $V$-type and U-type nozzles should be similar to those for the swirl cone. Typical values are presented in Table 3.3

TABLE 3.3

Typical dimensions and flows for $C E$ swirl cone. V-type and U-type nozzles

\begin{tabular}{lcc} 
& \multicolumn{1}{c}{ SL units } & Engr. units \\
\hline Minimum nozzle diarneter & 1 to $1.9 \mathrm{~cm}$ & 0.4 to $0.75 \mathrm{in}$. \\
Operating pressure & 82 to $125 \mathrm{kPa}$ & 12 to $18 \mathrm{psi}$ \\
Nozzle velocity & 9 to $11 \mathrm{~m} / \mathrm{s}$ & 30 to $37 \mathrm{ft} / \mathrm{s}$ \\
Black liquor viscosity & 0.03 to $0.15 \mathrm{~Pa}-\mathrm{s}$ & 30 to $150 \mathrm{cP}$ \\
Reynolds number & 810 to 9405 & 810 to 9405
\end{tabular}

\section{Combustion Engineering Swirl Cone Nozzle}

Swirling conical spray nozzles are also widely used in spray applications. Combustion Engineering Inc. has used a swirl cone nozzle for black liquor service extensively. Only in the past several years have the V-type and U-type nozzles been offered as an alternative. Figure 3 shows a schematic diagram of a CE swirl cone nozzle. It consists of a pipe with a conical cap which contains a circular exit orifice. Immediately behind the cap is a plate or block which contains two spiral grooves that impart a swirl component to the flow. This combination results in a swirling conical spray pattern from these nozzles.

The geometry for these nozzles results in a minimum flow area at the grooves in the swirl plate. For a typical black liquor nozzle in mill service, the diameter of the exit orifice is 1 inch $(2.5 \mathrm{~cm})$ while the equivalent circular flow area dimension for the grooves is only 0.75 inches $(1.9 \mathrm{~cm})$. The groove area is the appropriate one to use in order to characterize the flow/ $\Delta \mathrm{P}$ behavior of these nozzles.

As with the other black liquor nozzles, the entrance dimension is more than twice the minimum flow dimension, so the inlet conditions will not affect the flow/ $\triangle \mathrm{P}$ characteristics of $\mathrm{CE}$ swirl cone nozzles. The swirl cone nozzle contains a tapered section and its length-to-diameter ratio is similar to the splashplate nozzle. The general impact of viscous losses would be expected to be similar to that of the splashplate nozzle. The typical dimensions and flow characteristics are the same as for the V-type and U-type nozzles given in Table 3.3. 


\section{CE swirl cone nozzle}

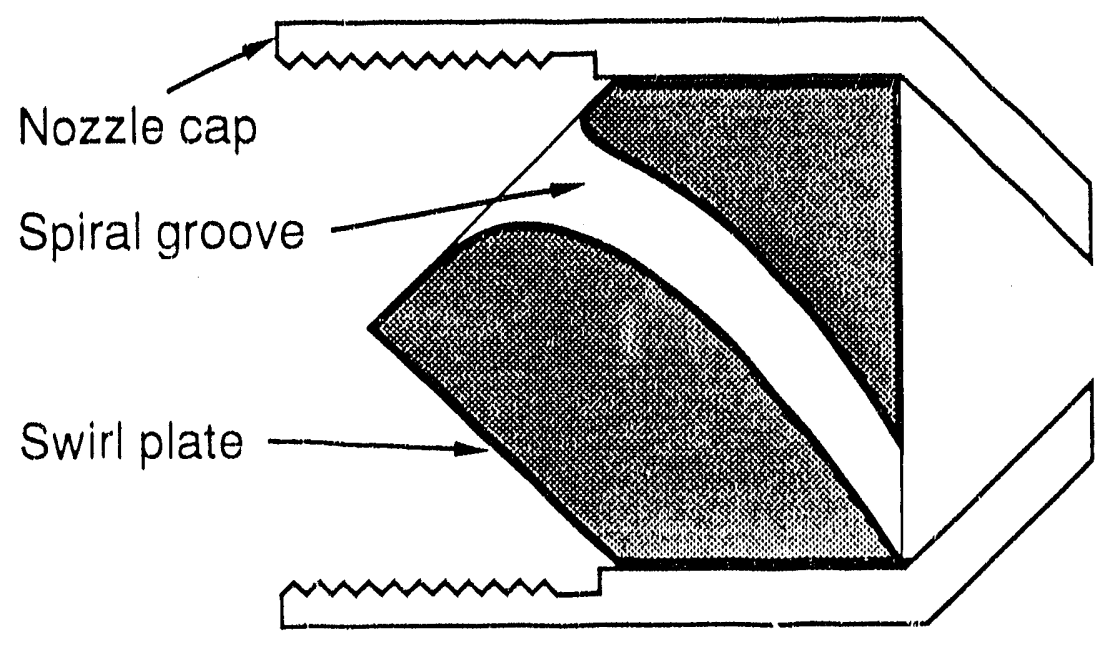

Figure 3.3. Schematic diagram of a CE swirl cone black liquor nozzle. 


\subsection{SPLASHPLATE NOZZLE DATA}

Data for the two B\&W splashplate nozzles on pressure drop, flow rate, viscosity, and nozzle geometry were used to calculate the maximum velocity, the nozzle Reynolds number, and the flow coeffictent. Shown in Figure 3.4 is a plot of flow coeffictent as a function of Reynolds number. The pat tern shown in Figure 3.4 is typical of many flow situations where $C_{f}$ decreases smoothiy with increasing Reynolds number until a constant value is reached. Flow coefficient correlations are usually for a single flow element of uniform dimensions. This is not exactly analogous to the situation of the more complex splashplate nozzle. The curve in Figure 3.4 would apply only to nozzles which are geometrically similar to the $B \& W$ splashplate nozzle. Geometric similarity would count on similarity of nozzle length-to-diameter ratio, and on similarity of the taper from the entrance to the exit. The flow would also have to disengage from the nozzle extt before striking the splashplate itself.

The data in Figure 3.4 have been correlated with a simple two-term equation resulting in an overall flow coefficient which is equal to a constant term plus a terin which is a function of Reynolds number. The correlation is:

$$
C_{f}=1.17+\frac{373}{\operatorname{Re}^{0.92}}
$$

The constant term in this expression, 1.17, represents the contribution due to inertial acceleration. The second term involving the Reynolds number, Re, represents the contribution of viscous loss.

A plot of the predicted $\Delta P$ based on Equations (3-1) and (3-14) versus the actual measured $\Delta P$ for the splashplate nozzle is shown in Figure 3.5. The fit of the data is seen to be quite good. The black liquor data is differentiated from the corn syrup data in this figure. It can be seen that the data fit and the data scatter for the two fluids (actually four flutds because three black liquors were used) are very similar. Not readily apparent in this figure is that the three black liquors (two fired hot and one fired cold) are also very similar to each other.

\subsection{U-TYPE NOZZLE DATA}

The pressure drop data for the CE U-type and V-type nozzles are plotted in Figure 3.6 in a manner sintlar to the splashiplate nozzle data. It can be seen that there is very little difference in the flow coefficient between the CE U-type and V-type nozzles. The same general pattern can be seen for the flow coeffictent as a function of Reynolds number in this figure as was seen for the splashplate nozzle, but with one key difference -- the curve is displaced to lower Reynolds numbers. This is not too surprising considering the geometric differences between the splashplate and the U-type and $V$-type nozzles. The entry section of the U-type and V-type is very large compared to the nozzle orifice so the velocity head is quite low. Viscous losses in these nozzles would be appreciable only at low Reynolds numbers. 


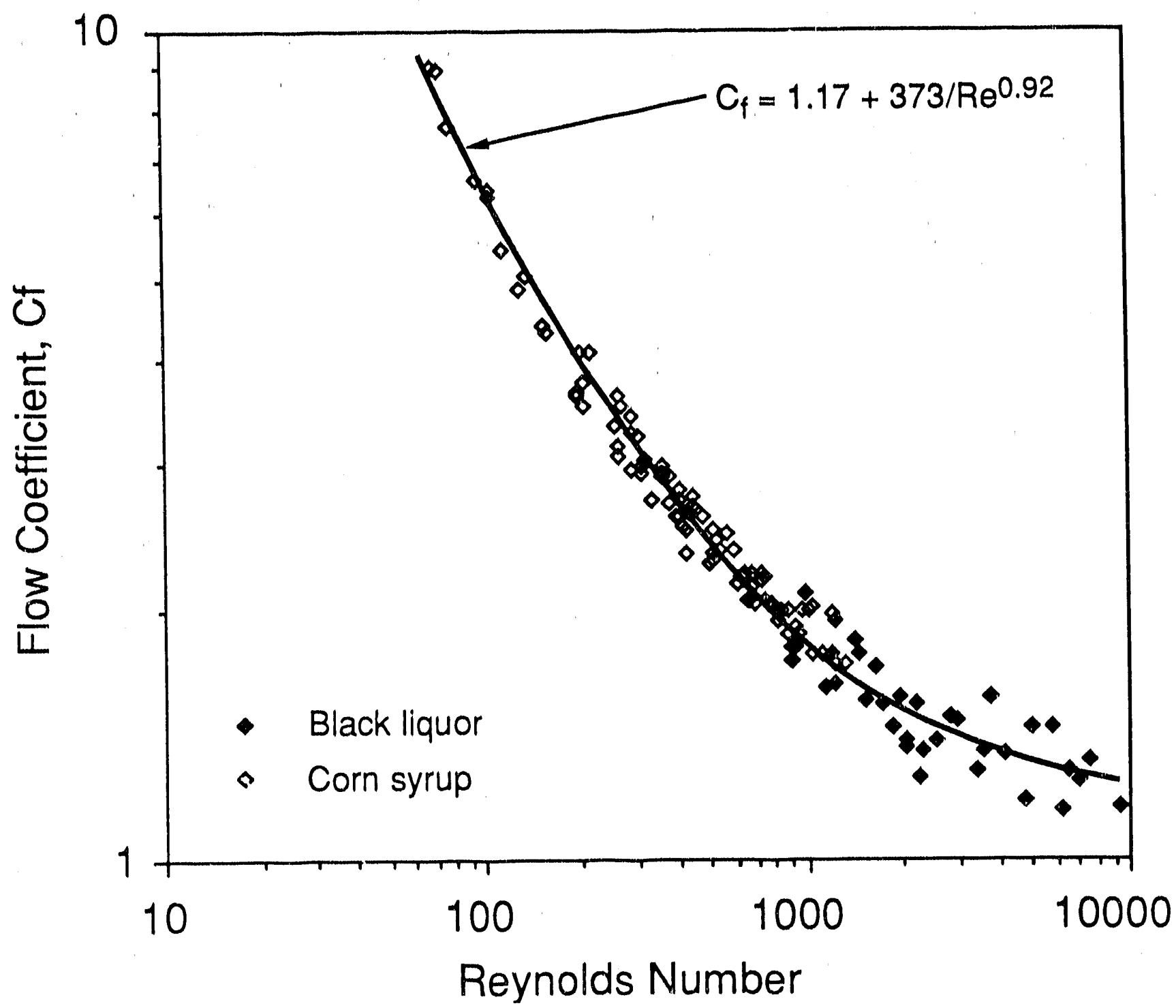

Figure 3.4. Flow coeffictent data and correlation for two B\&W splashplate nozzles using two working fluids -- black liquor and corn syrup. 


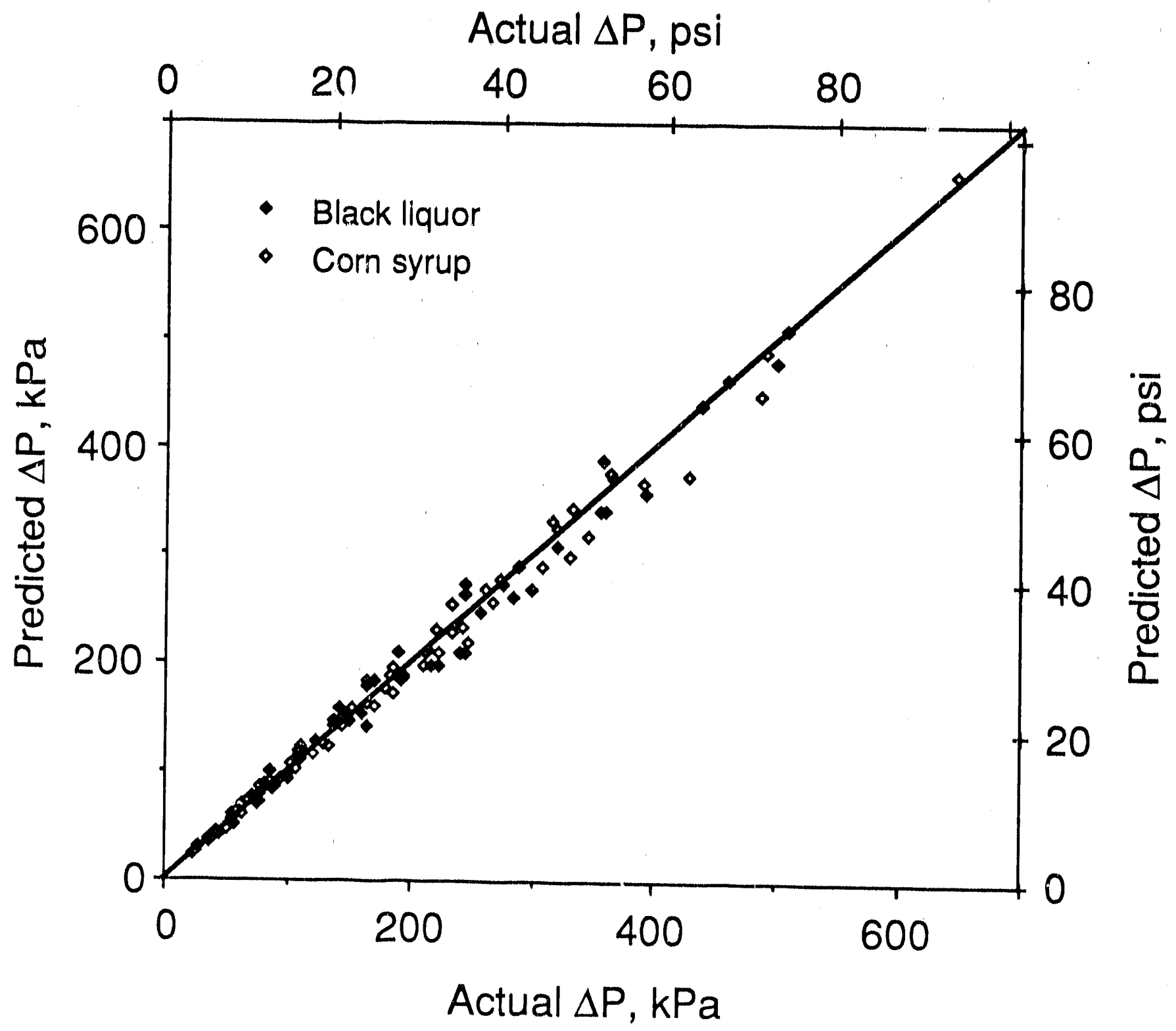

Figure 3.5. Comparison of actual and predicted pressure drop for two B\&W splashplate nozzles using two working fluids -- black liquor and corn syrup. 


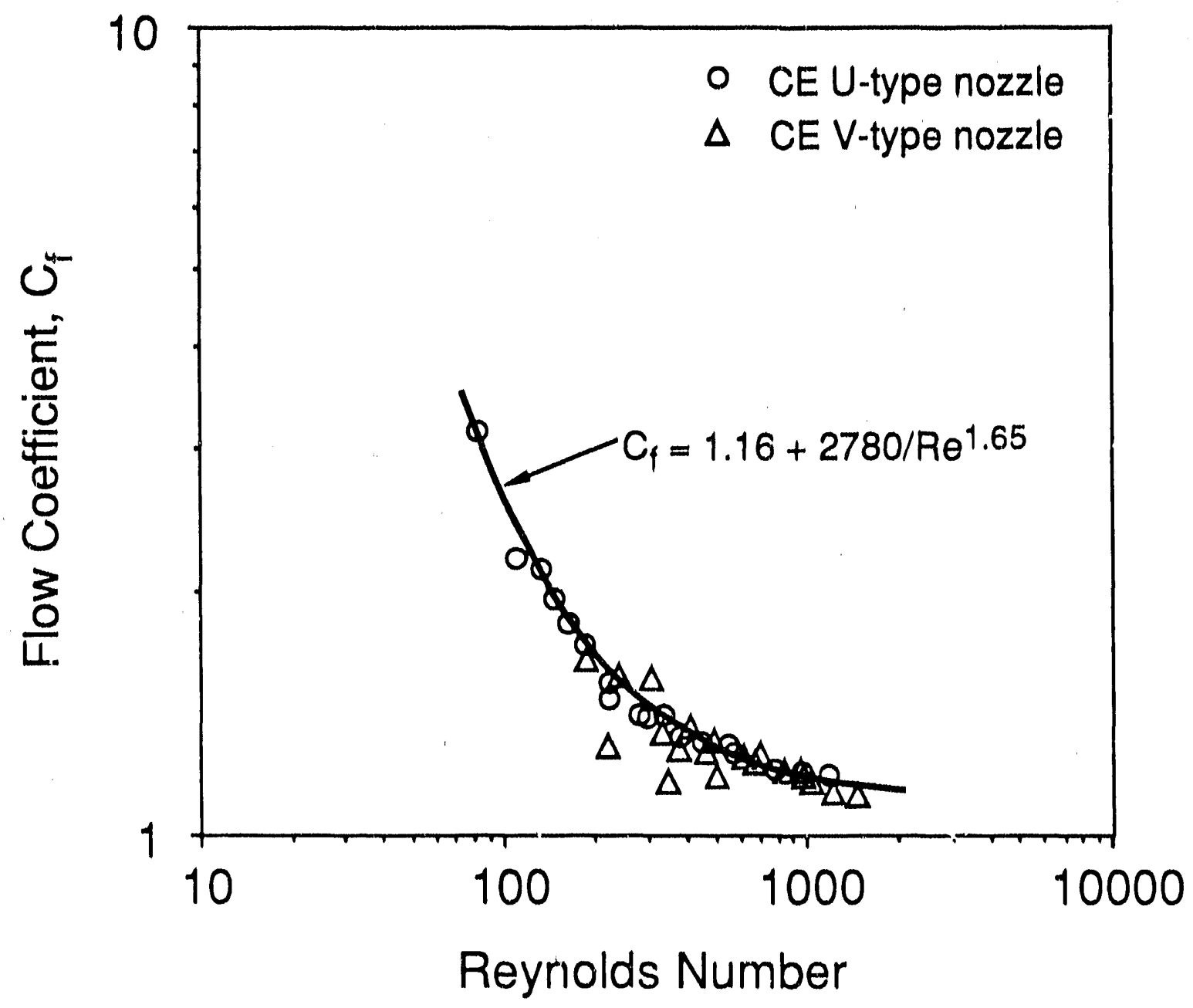

Figure 3.6. Flow coeffictent data and correlation for a $C E$ U-type and a V-type nozzle using corn syrup as a worktng flutd. 
The data in Figure 3.6 have been correlated in a manner similar to that for the splashplate nozzle. The best fit flow coefficlent correlation is:

$$
C_{f}=1.16+\frac{2780}{R_{e} 1.65}
$$

A plot of the predicted $\Delta P$ based on Equations $(3-1)$ and $(3-15)$ versus the actual measured $\Delta P$ for the $U$-type and $V$-type nozzles is shown in Figure 3-7. Data for these nozzles were only taken with corn syrup. The compartson in Figure 3.7 is quite good.

\subsection{DISCUSSION}

The data and correlations presented for the two types of black liquor nozzles reveal some important practical results for both the fleld applicatton of these nozzles and for the laboratory study of black liquor sprays.

Comparing the usual operating conditions for the B\&W splashplate nozzle given in Table 3.2 to the data in Figure 3.4 shows that black liquor viscosity is not an timportant parameter in this nozzle's flow characteristics. The flow coefficient for this type nozzle at the lowest practical Reynolds number of 1400 is only 1.65 and above this Re it quickly decreases to the constant value of 1.17 . The viscous loss term constitutes only $29 \%$ of the overall flow coefficient at the most extreme practical operating point. It would be expected that the flow coefficlent is nearly a constant for the broad range of routine mill operations. The flow characteristics would therefore be nearly independent of black liquor viscosity, temperature, and solids. This would coniribute to the insensitivity of these nozzles to normal fluctuations in mill operating condtions, and would make operating pressure a good indicator of black liquor flow (though ring header pressure would have to be corrected to nozzle pressure drop).

The same comments would be true for the CE U-type and V-type nozzle. Though the operating Reynolds number range for these nozzles is generally lower, the flow coefficlent curve is also shifted lower. At the lowest practical Reynolds number of 810 the viscous term contributes little to the flow coefficient. Again in the broad range of practical mill operations, the flow characteristics of the $U$-type and $V$-type nozzles would be insensitive to black liquor viscosity, solids, and temperature.

Though data are not avallable for the CE swirl cone nozzle, the geometric parameters indicate that the flow characteristics of this nozzle should be similar to those for the B\&W splashplate nozzle shown in Figure 3.4. Viscous losses will be more timportant for this nozzle than for tile other nozzles. The goneral operating conditions for the swirl cone are given in Table 3.3. Comparing the operating condtitons to the likely flow characteristics reveals signiflcantly greater likelihood of sensitivity of this nozzle to routine liquor property fluctuations and settings. Data will be required to confirin this speculation. 
An additional practical result from these tests is black liquor's apparent similarity to other flulds. Though black liquor viscosity can change dramatically with sollds and temperature, as well as from liquor-to-liquor, its flow characteristics at a given viscosity are apparently the same as other flulds at the same viscosity and density. As well, in comparing black llquor under the highest shear rates for norilal flow conditions to a flutd which is known to be Newtonlan, there is no apparent effect of black liquor's known complex rheology at high shear rate (15). This is mainly due to the relatively modest actual shear rates compared to those requitred for black liquor to show non-Newtontan rheology. This supports the use of simple flulds, such as corn syrup, for callbration and other purposes in studies of black liquor sprays. Such use signiflcantly eases experimental procedure and extends the range of experimental conditions with a flutd which is far easler to handle and characterize than black liquor.

\subsection{CONCLUSIONS ON FLOW/AP CHARACTERISTICS OF BLACK LIQUOR NOZZLES}

Tests have been carrled out on four black liquor spray nozzles idsing three black 1lquors and one corn syrup. B\&W splashplate nozzles and UE. U-type and $V$-type nozzles were investigated over a range of operating conditions which spanned the range of routine pulp and paper inill operations. The following conclustons can be drawn from these tests:

1. The flow and pressure drop characteristics of black liquor nozzles follow a regular pattern with respect to a Reynolds number which is based on the mintmum flow area.

2. Flow coefficient datia for these nozzles can be correlated with a simple two-terin fit. The first term represents inertial acceleration and the second represents viscous loss.

3. For both types of nozzles tested, the viscous loss term is only mintmally important at the extreme lower end of the normal mill operating conditions. Thus, for most normal operating conditions, only the constant inertial acceleration term is important to the flow characteristics.

4. As a result of the constant inertial acceleration term, the $B \& W$ splashplate and the CE U-type and $V$-type nozzles should be insensitive to routine fluctuations in black liquor viscosity, solids, and temperature.

5. Due to the particular geometry of the CE swirl cone nozzle, its flow characteristics are likely to be much more sensitive to rout ine black liquor fluctuations, but additional nozzle flow data is needed to confirin this.

6. Comparison between the three black liquors and the corn syrup reveals that the low-shear Newtontan viscosity of black liquor characterizes this flutd well for flow studies. 


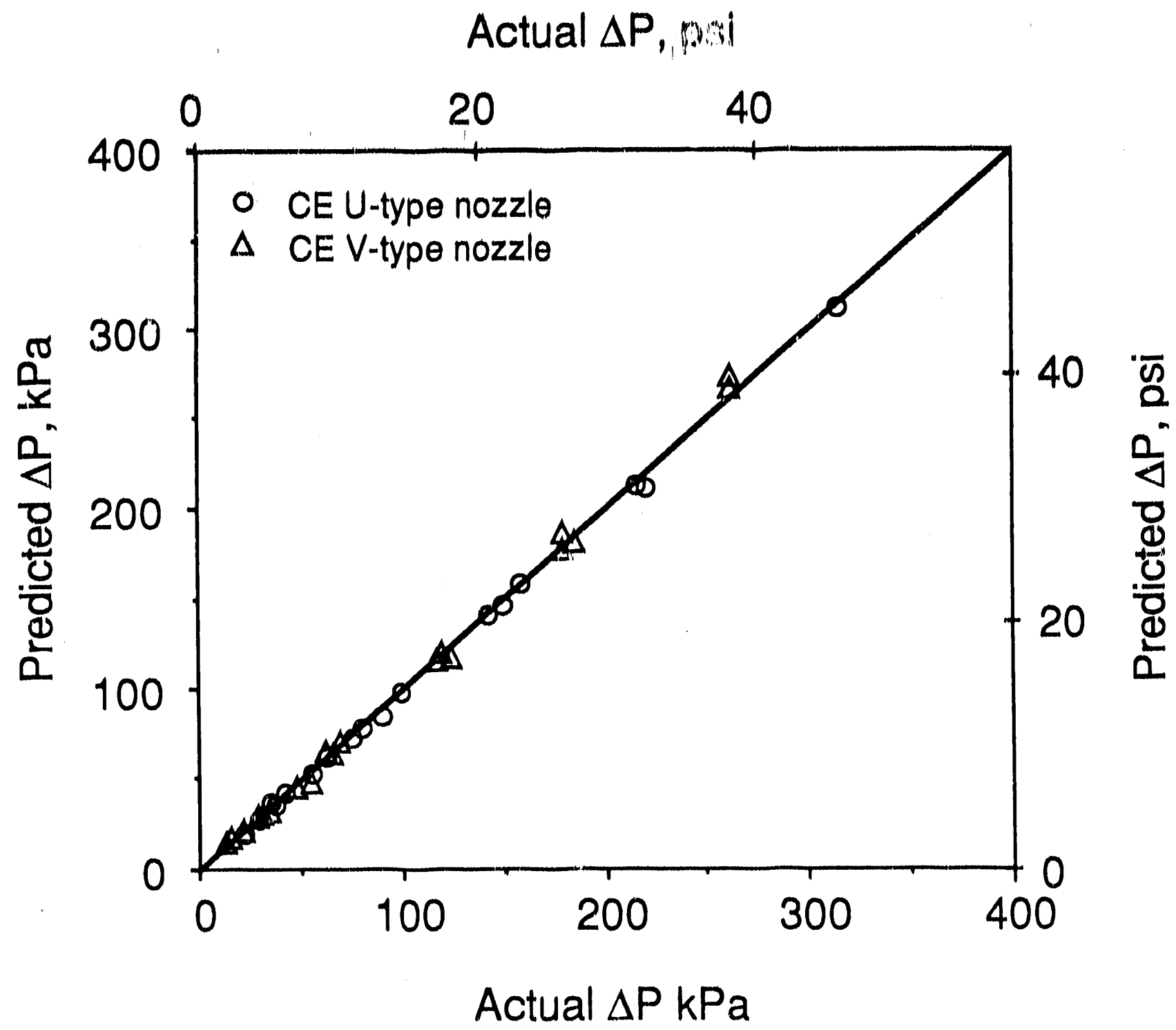

Figure 3.7. Comparison of actual and predicted pressure drop for a CE U-type and V-type nozzle using corn syrup as a working flutd. 
4.0 FLUID SHEET THICKNESS AND VELOCITY AT THE TIP OF A BLACK LIQUOR SPLASHPLAT: NOZZLE

4.1 INTRODUCTION

All current commerclal black ilquor nozzles are designed to produce a flutd sheet which expands as it moves away from the nozzle. Expansion causes thinning, while at the same time aerodynamic forces cause the sheet to become wavy instead of smooth. As we discussed in Section 2.1, the combination of these two effects eventually causes the sheet to break into ilgaments, which subsequently break into droplets.

\subsection{EXPERIMENTAL}

The velocity of the top surface of the fluid sheet was measured with an optical instrument loaned to the ins'stute of Paper Chemistry by the Belott Corp., Beloit, WI. The principle of operation of this device is described in an article by Franzen (13). This instrument consists of two fiber optic probes located a short distance apart in the direction of flow and a small distance above the fluid sheet. The transit time of the fluid between these two probes is deterinined by cross correlating the passage of randoin irregularities in the sheet surface. Top surface velocity is calculated from the ratio of the known probe separation distance divided by the measured transit time. Aligninent of the probe with the direction of flow is important. This was accomplished by rotating the probe slightly at each angular position until the maxtmum veloctty reading was obtatned.

Two problems contribute to the lack of previous study of the relationship between the fluid sheet and the inttial flutd stream. First, the flow geometry between the final nozzle passage and the point of formation of the fluld sheet is complex enough to defy analytical description. Only recently have numerical procedures been developed which could eventually predict the flutd flow pattern of these nozzles. The second reason no literature is available on the formation of fluid sheets in spray nozzles is the expert. mental difficulty due to the small size of most nozzles. Nozzles are typically destgned to produce droplet sizes in the range from 20 to $200 \mu \mathrm{m}$. Sheet thicknesses have similar dimensions and nozzle passages are typically only ten times larger. This results in extreme experimental difficulty.

Black liquor nozzles have a significant advantage over most nozzles. They are always designed for large flows $1.9-9.51 / \mathrm{s}(30-150 \mathrm{gpm})$, and for large drop sizes of approximately 2 to $4 \mathrm{~mm}$. This simpliffes measurement of both sheet thickness and velocity and provides a untque opportunity to investigate the lripact of fluid properties and nozzle flow parameters on them.

This section will present data and a simple analys is of the fluid sheet thickness and veloclty for one type of black liquor nozzle, the Babcock and Wilcox Co. splashplate nozzle. The experimental facility used to obtain the data reported here was the same as reported in the previous section.

Two fluids were used in taking the data presented below: black liquor and corn syrup. The liquor was obtained from an upper midwestern kraft mill. 
The two splashplate nozzles (described previously) were instrumented to measure the sheet thickness at three angular locations along the rim of the splashplate itself. The velocity of the top surface of the fluid sheet was measured at six angular locations just beyond the rim. A schematic diagram of these locations is shown in Figure 4.1. A photograph of a fully instrumented splashplate nozzle is shown in Figure 4.2.

Measurement of sheet thickness was accomplished with simple extension micrometers. The calibrated micrometer handle located away from the spray was connected by a flexible extension to a support, plate located above the splashplate surface. Sheet thickness measurements were taken by moving the micrometer tip inward until it just touched the flowing fluid sheet surface. The point at which the tip just came into contact with the surface was very precisely indicated by a large visible disturbance in the fluid top surfaci flow pattern. The micrometer reading noted at the top surface of the fiuid was subtracted from the reading obtained by extending the micrometer tip to the surface of the splashplate to obtain the fluid sheet thickness. 


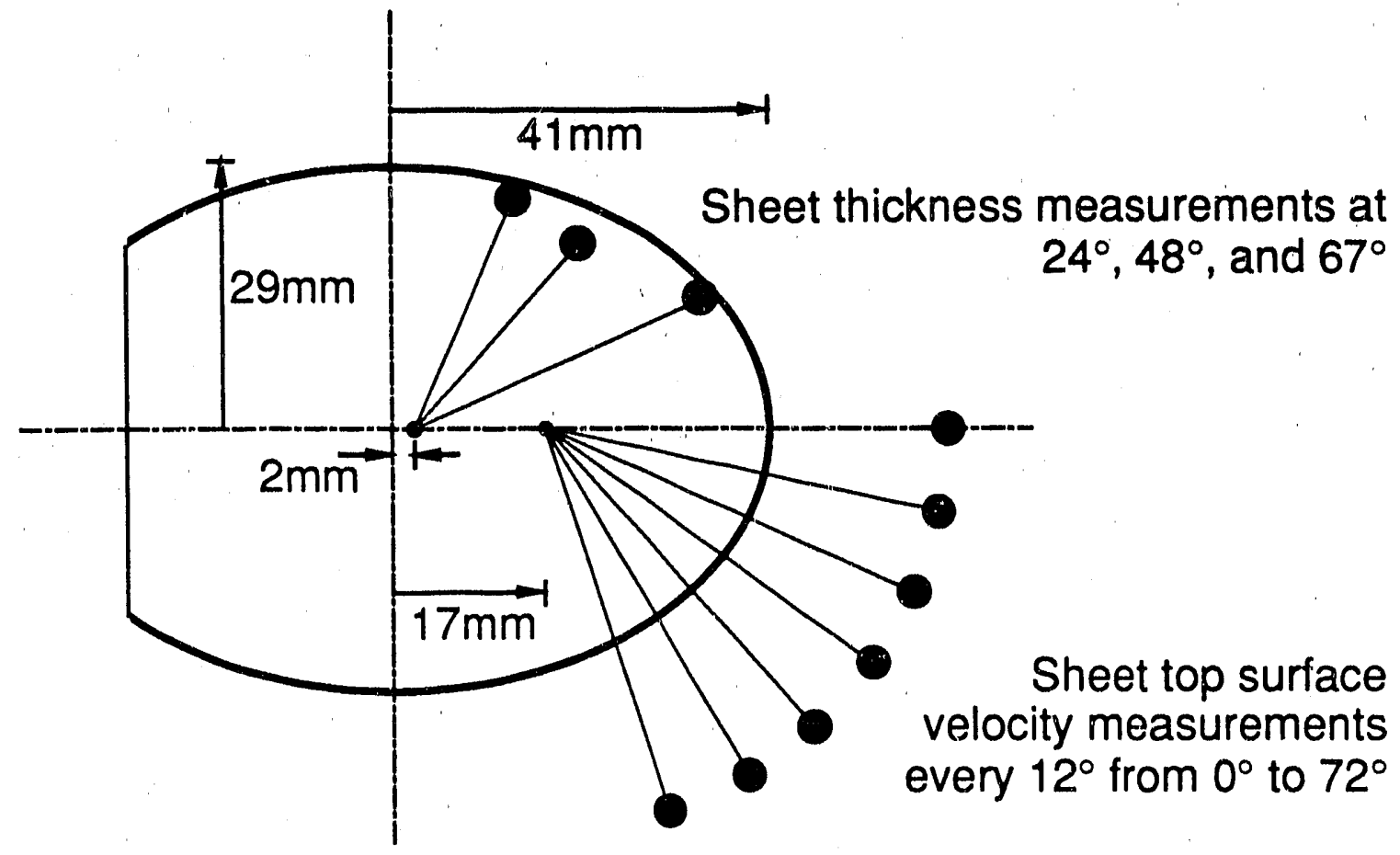

Figure 4.1. Schematic diagram of the sheet thickness and top surface velocity measurement positions for the B\&W splashplate nozzle. 


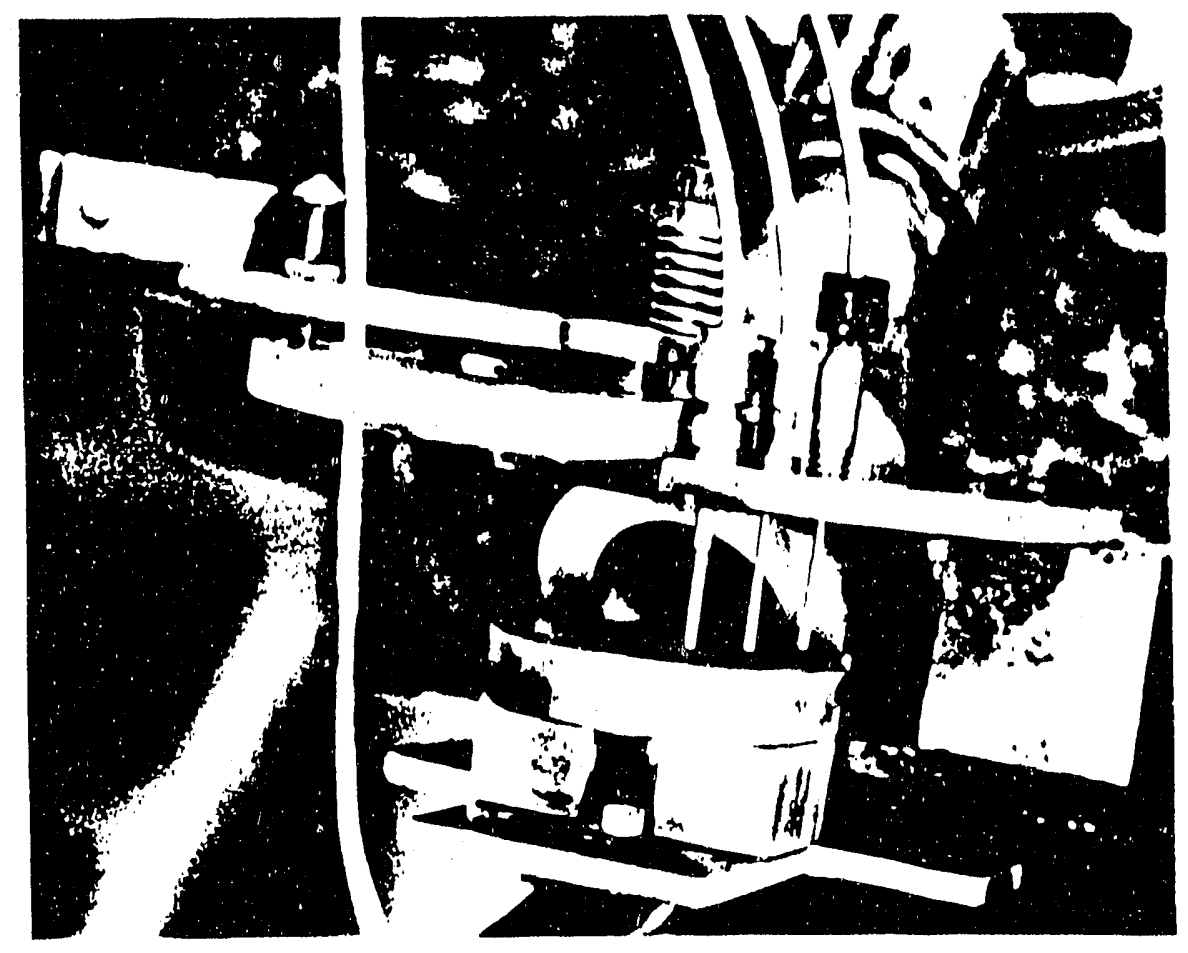

Figure 4.2. Photograph of the sheet thickness and top surface velocity measurement apparatus. 


\subsection{RANGE OF TEST CONDITIONS}

The ranges of fluid property and operating parameters for these tests are given in Table 4.1 .

TABLE 4.1

Fluid Properties and Operating Parameters for the IPST Sheet Thickness and Velocity Tests

\begin{tabular}{lcc|cc} 
& \multicolumn{2}{c}{ Black Liquor } & \multicolumn{2}{c}{ Corn Syrup } \\
& SI units & Engr. units & SI units & Engr. units \\
\hline Nozzle diameter & $9.5-12 \mathrm{~mm}$ & $0.375-0.47 \mathrm{inch}$ & $9.5-12 \mathrm{~mm}$ & $0.375-0.47 \mathrm{inch}$ \\
Dry solids & $66-69 \%$ & $66-69 \%$ & $73 \%$ & $73 \%$ \\
Temperature & $92-104^{\circ} \mathrm{C}$ & $198-219^{\circ} \mathrm{F}$ & $49-68^{\circ} \mathrm{C}$ & $120-154^{\circ} \mathrm{F}$ \\
Pressure & $21-501 \mathrm{kPa}$ & $3-73 \mathrm{psi}$ & $41-488 \mathrm{kPa}$ & $6-71 \mathrm{psi}$ \\
Flow & $0.5-1.61 / \mathrm{s}$ & $7.5-25 \mathrm{gpm}$ & $0.5-1.51 / \mathrm{s}$ & $7.5-23 \mathrm{gpm}$ \\
Nozzle Velocity & $4.2-22 \mathrm{~m} / \mathrm{s}$ & $14-72 \mathrm{ft} / \mathrm{s}$ & $4.2-18 \mathrm{~m} / \mathrm{s}$ & $14-59 \mathrm{ft} / \mathrm{s}$ \\
Viscosity & $73-135 \mathrm{mPa}-\mathrm{s}$ & $73-135 \mathrm{cP}$. & $159-397 \mathrm{mPa}-\mathrm{s}$ & $159-397 \mathrm{cP}$ \\
Number of tests & 24 & 24 & 45 & 45
\end{tabular}

The flow pattern for splashplate nozzles is by no means simple. First, the circular flow from the nozzle exit strikes the splashplate at an angle between $35^{\circ}$ and $55^{\circ}$. Though most of the flow goes forward and spreads out on the splashplate, there is a stagnation point at the center of the splashplate approximately in line with the centerline axis of the nozzle passage. This means that some of the flow will be directed back on the splashplate surface toward the nozzle exit. This backward flow causes two flow irregularities. First, a portion of this flow will enter the groove which surrounds the nozzle exit. It will flow around the groove from both directions, meet at the top, and be forced out along the flow direction on the top free surface of the nozzle exit flow. As well, the backward flow which does not enter the groove will be forced out the sides of the nozzle resulting in a very thick edge or rim on the fluid sheet. This is shown in Figure 4.3 for one very low-pressure corn syrup flow. In this case the rims are extraordinarily thick and the central flow from the groove is completely separated from the main flow. This extreme case shows the effect of the back flow, though under normal circumstances the rims are somewhat less prominent and the groove flow enters the top of the main nozzle flow causing a $V$-shaped disturbance in the fluid sheet.

This description emphasizes that fluid flow is quite complex for even this relatively simple geometry. The data presented below cover the range of lateral angles which is lease affected by these flow non-uniformities. As such they represent only a partial picture of the whole sheet of spray. 


\subsection{SHEET THICKNESS AND VELOCITY DATA}

Shown in Figure 4.4 is a plot of the sheet thickness as a function of angular position for corn syrup at two viscosities and one flow rate for the B\&W 15-52 nozzle. Figure 4.5 shows the sheet top surface velocity data for the same tests. These are typical of the data taken throughout this test series both in terms of apparent scatter and the observed trends.

In order to present all the data on a readily comparable basis, it is convenient to non-dimensionalize the thickness and velocity data. A reduced sheet thickness and reduced sheet velocity were defined as follows:

$$
\begin{aligned}
& Y_{r}=\frac{Y}{D} \\
& V_{r}=\frac{V}{V_{n}}
\end{aligned}
$$

where:

$$
\begin{aligned}
& Y_{r}=\text { reduced sheet thickness, unitless } \\
& Y=\text { sheet thickness, mm } \\
& D=\text { nozzle exit diameter, mm } \\
& V_{r}=\text { reduced top surface velocity, unitless } \\
& V=\text { sheet top surface velocity, } \mathrm{m} / \mathrm{s} \\
& V_{n}=\text { nozzle exit velocity, } \mathrm{m} / \mathrm{s}
\end{aligned}
$$




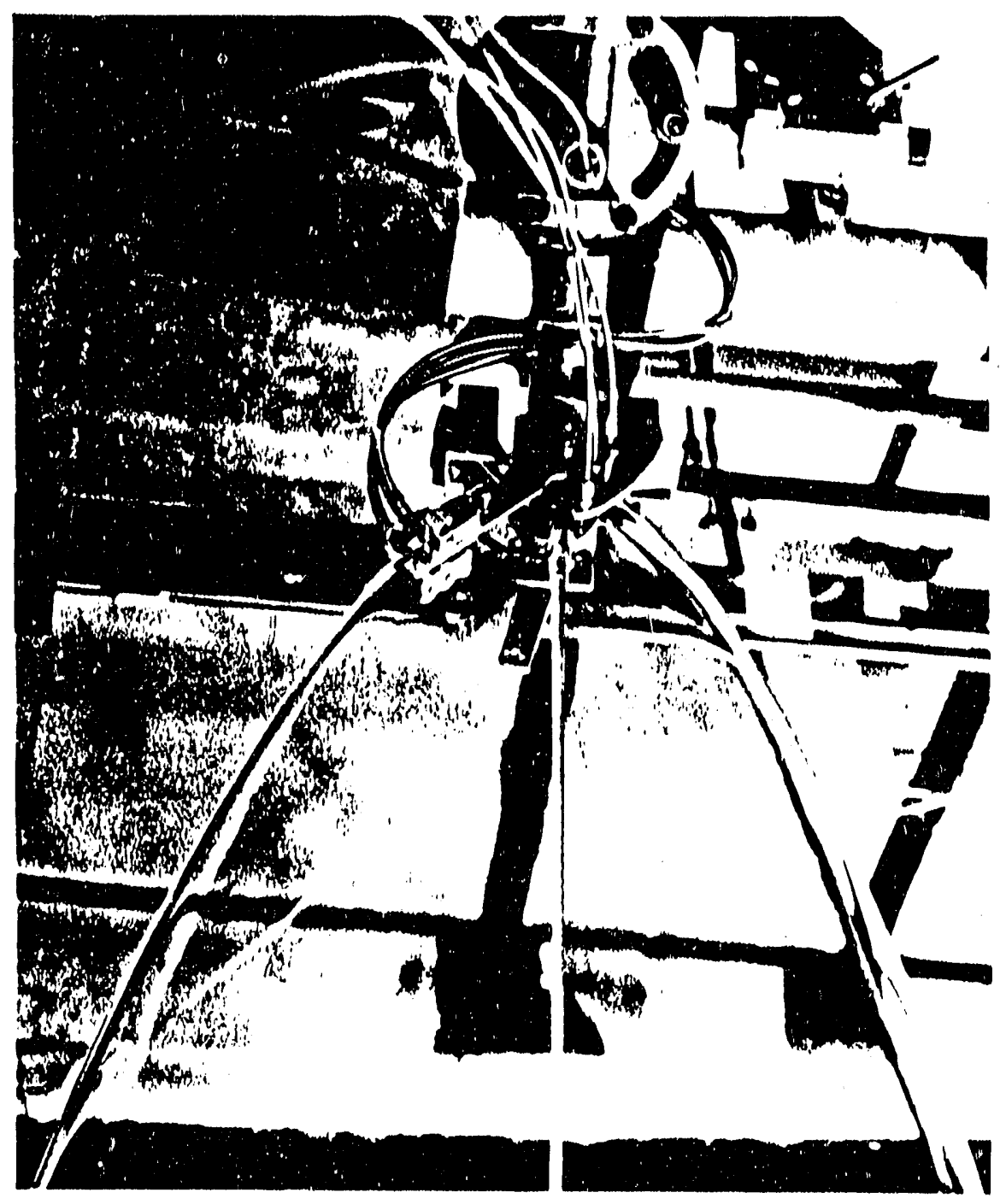

Figure 4.3. Photograph of a low velocity corn syrup spray showing center and edge non-untformities. 


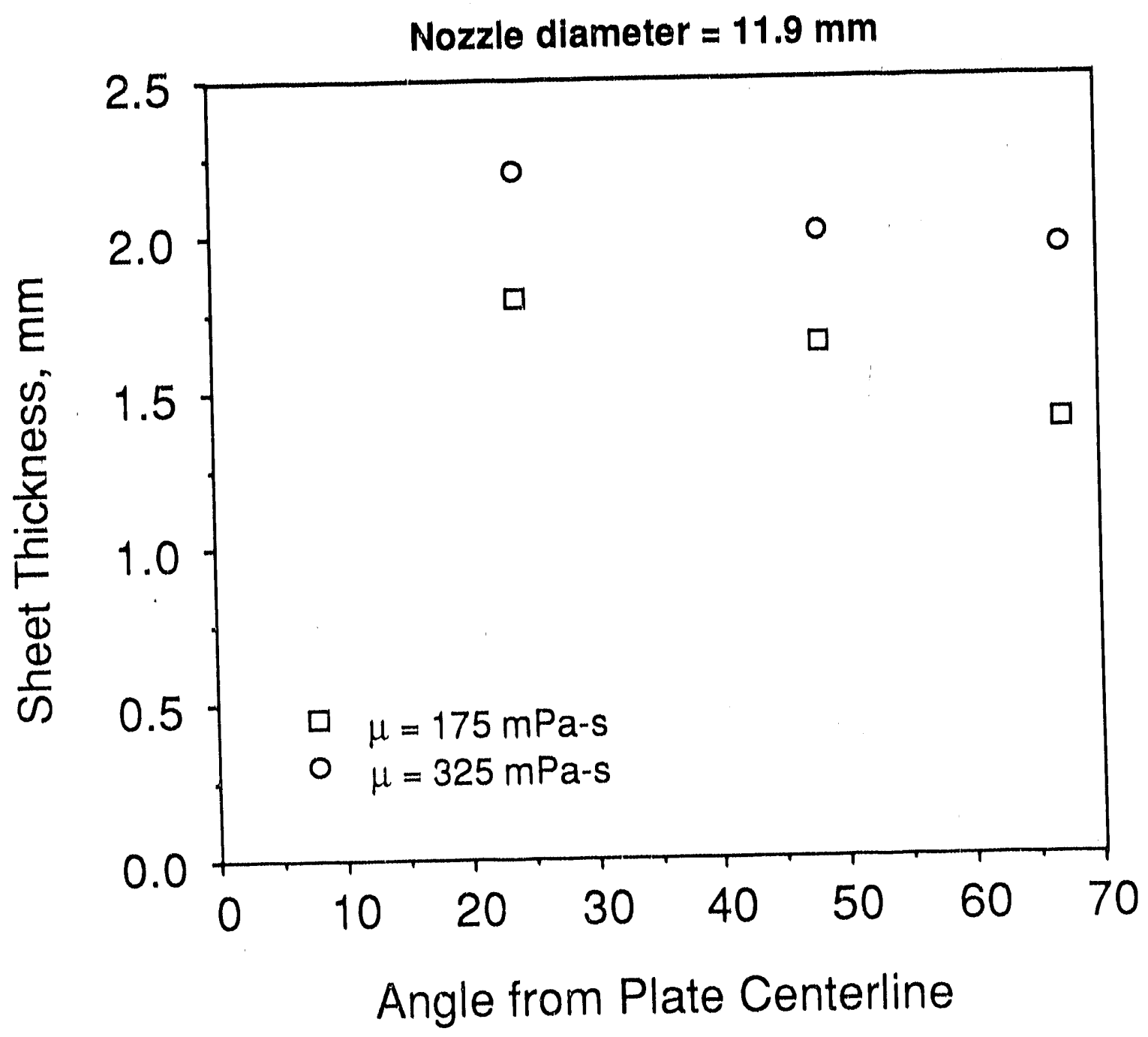

Figure 4.4. Sheet thtckness data for the B\&W 15-52 nozzle using corn syrup as a worktng flutd at a nozzle velocity of $7.1 \mathrm{~m} / \mathrm{s}(12.5 \mathrm{gpm})$. 


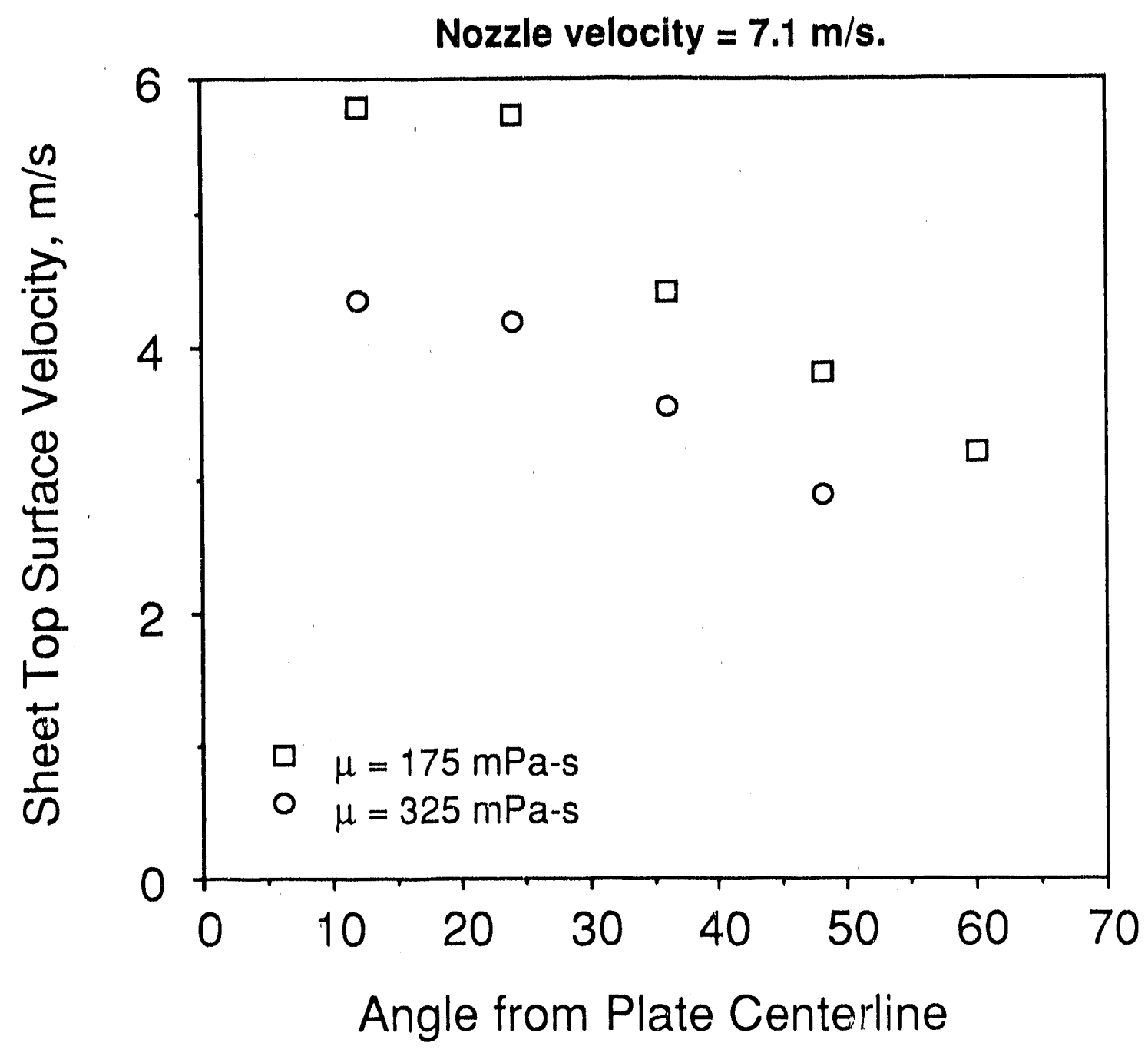

Figure 4.5. Sheet top surface velocity data for the B\&W 15-52 nozzle using corn syrup as a working fluid at a nozzle flow of $0.191 / \mathrm{s}(12.5 \mathrm{gpm})$. 
In addition it will be conventent to define a reduced viscosity as:

$$
\mu r=\frac{\mu}{\rho D V n}
$$

where:

$$
\begin{aligned}
& \mu_{\rho}=\text { reduced viscosity, unitiess } \\
& { }=\text { density of the fluid, } \mathrm{kg} / \mathrm{m}^{3}
\end{aligned}
$$

Thts reduced viscosity can be recognized as the rectprocal of the nozzle Reynolds number.

Using the reduced parameters, data for sheet thickness and top surface velocity have been plotted as a function of angular position in Figures 4.6 and 4.7. In Figure 4.6, reduced sheet thickness generally decreases with increasing angle from the sheet centerline, though at higher viscosittes the data show an increase for the highest angle. This figure also shows that sheet thickness generally increases with fluild viscosity.

Figure 4.7 for reduced top sheet velocity as a function of angle shows that reduced velocity also generally decreases with arigle. Reduced velocity, however, generally decreases with increased viscosity.

Though some trends emerge from these data, 11ttle use can be made of them in their present form. Though complete analysis of the fluid flow is not possible, a simple analysis leads to correlation techniques useful in extracting more information from these data.

\subsection{DEVELOPMENT OF CORRELATION TECINIQUE}

Though portions of the flow on the splashplate surface are affected by back flow, the middle angles investigated in this study are relatively free of these effects. In addition, though the fluid mechanics of oblique impingement of a round liquid jet on a flat plate is beyond current analysis procedures, it is likely that the parameter dependence of this flow is similar to that for normal impingement. A simple analysis of the flow with normal impingement is possible.

For normal impingement of a clrcular jet of an invisctd flutd on a flat surface, the flow quickly spreads out uniformly in all directions. With an inviscid fluid the flow only slows in the region of the stagnation point. At a distance away from the stagnation point approximately equal to the jet 

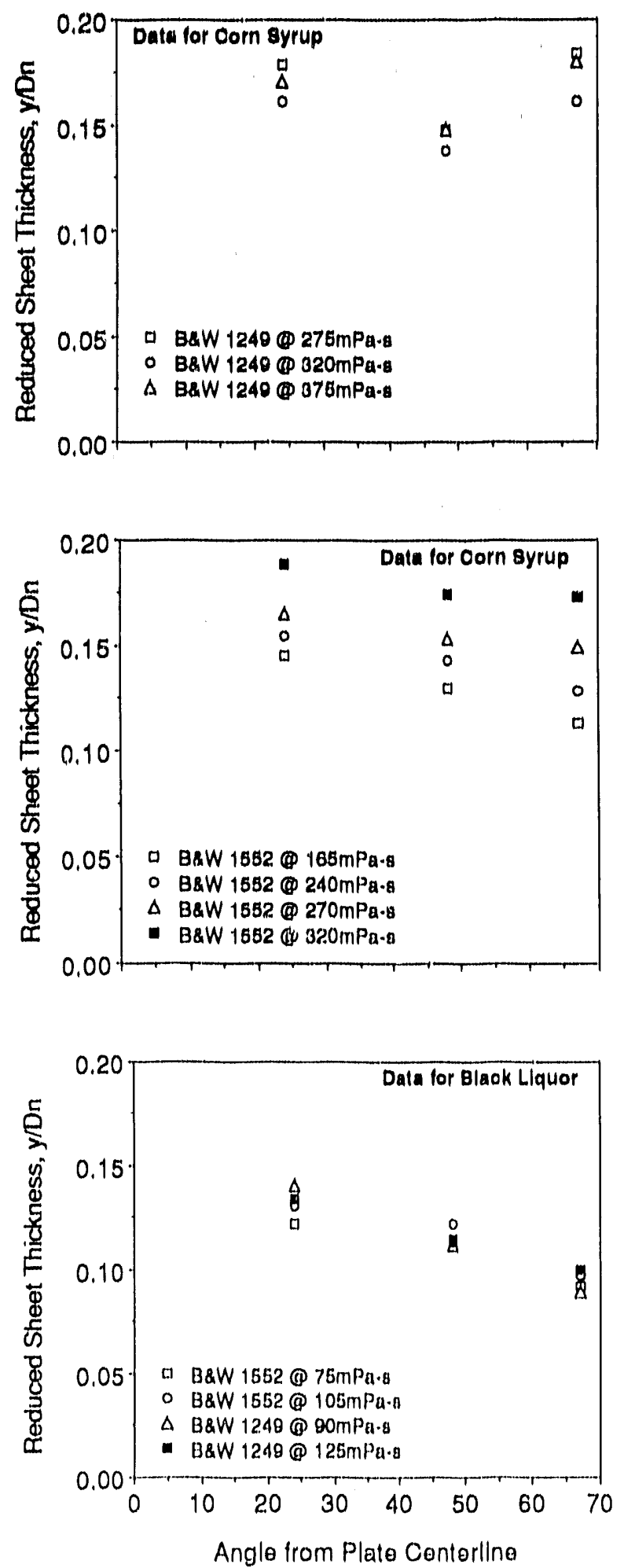

Flgure 4.6. Reduced sheet thickness as a function of angular postition for all test sertes. 

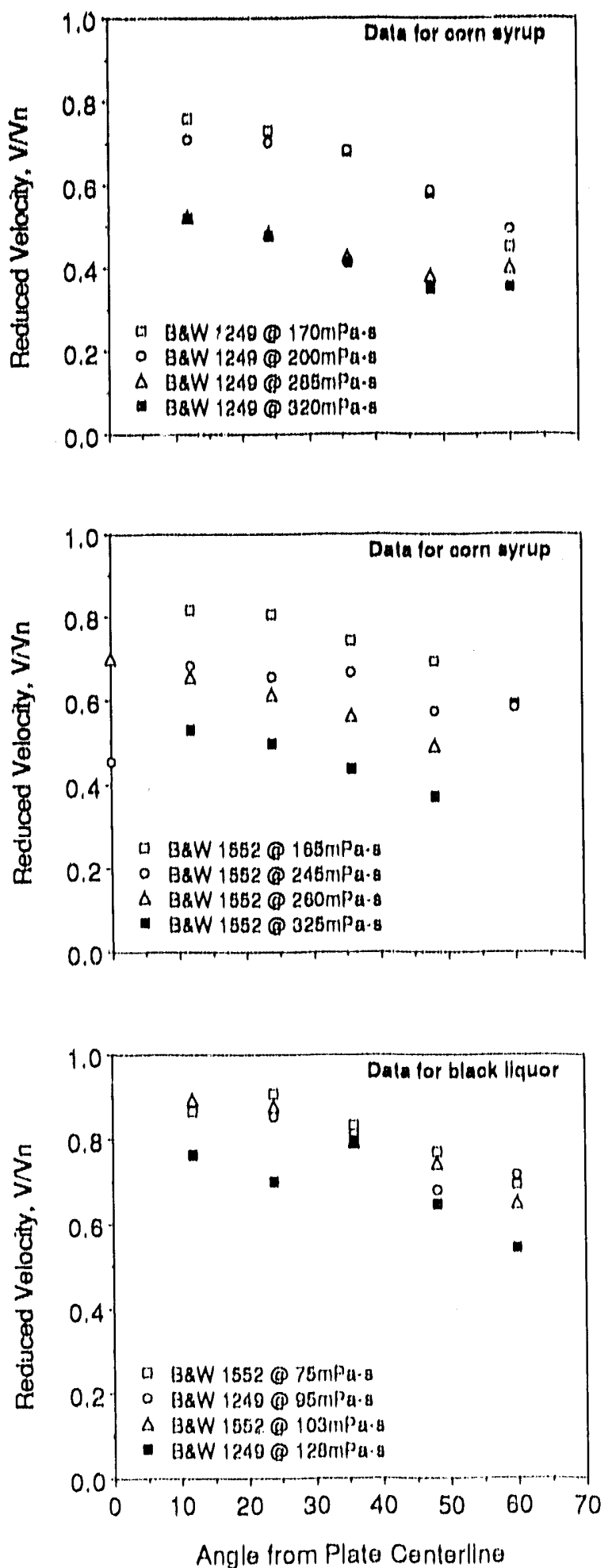

Ftgure 4.7. Reduced sheet top surface velocity as a function of angular position for all test sertes. 
dlameter the flow velocity is substantially parallel to the plate surface and equal to the initial jet velocity. The thickness of the sheet is dictated by continulty. The thickness times the clrcumference of the sheet must equal the inttial jet area.

With viscous flulds this pattern changes. Continulty stlll dictates that the thickness times the circumference tlimes the average sheat velocity must be a constant equal to the initial jet volumetric flow. However, viscous drag at the plate surface slows the flow and produces a veloctty profile. Because the flow is slower, the thickness at each radial location is greater than for the inviscid case. For the case where the measurement radius is well away from the stagnation point, certain assumptions will a'low a simple analysis of both continutty and momentum to be made from a knowledge of sheet thickness and top surface velocity. These assumptions are that: 1) the velocity profile is linear so that the average sheet velocity is equal to one-half the top surface velocity, and so that the shear rate is just the ratto of top surface velocity to the sheet thickness, and 2 ) all the viscous losses occur after the potnt where the sheet velocity is substantially parallel to the plate surface.

Based upon the two above assumptions the continulty equation can be expressed as:

$$
2 \pi R Y=\frac{\pi}{4} D^{2} V_{n}
$$

where:

$R=$ radius along the plate from the stagnation point, $\mathrm{mm}$

Equation (4) can be rewritten in the form:

$$
V_{r}=\left(\frac{1}{Y_{r}}\right)\left(\frac{1}{8} \frac{D}{R}\right)
$$

According to Equation (4-5) the reduced velocity should plot as a stratght line as a function of the reciprocal of the reduced thickness. The distance to the measurement point is fixed by the thickness measuring apparatus, so "R" in Equation $(4-5)$ is the same for both nozzles. Equation $(4-5)$ then indicates that the slope of the plat of $V_{r}$ versus $1 / Y_{p}$ should be lower for the 12-49 nozzle than for the 15-52 nozzle. 
The reduced veloctty for each tost, averaged over the measurement angles, is plotted in Figuras 4.8 and 4.9 as a function of reciprocal reduced thlckness, also averaged over angle. All the data for both nozzles plot as reasonably stralght itnes. Considering that the data are averaged over an angular range, and that not all data are avallable at all angles, the continulty equation is reasonably satisfled. As well, comparison of the two flgures shows the slope of the $12-49$ plot is indeed less than that for the 15-52. plot by approximately the ratlo of the dilameters of the two nozzles.

The momentum equation in this analysis is more complex than the cont inutty equation. Using a linear velocity proflle at each radial location, the shear stress at the plate surface for a clrcular differential element is:

$$
\tau_{W} \mathrm{dA}=2 \pi R \mu \frac{\mathrm{V}}{\mathrm{Y}} \mathrm{dR}
$$

where:

$$
\begin{aligned}
& \tau_{W}=\text { shear stress at the wall, } \mathrm{Pa} \\
& \mathrm{dA}=\text { differential area, } \mathrm{mm}^{2} \\
& \mathrm{dR}=\text { differential radius, } \mathrm{mm}
\end{aligned}
$$

The momentum flow through any cross-section is:

$$
M=2 \pi R Y \rho V^{2}\left(\frac{1}{3}\right)
$$

The final term on the RHS of Equation (4-7) results from the integration of the linear velocity profile across the face of the flow cross-section.

The momentum equation becomes:

$$
0=\frac{2}{3} \pi \rho \frac{\partial\left(\mathrm{R} Y \mathrm{~V}^{2}\right)}{\partial \mathrm{R}}+2 \pi \mathrm{R} \mu \frac{\mathrm{V}}{\mathrm{Y}}
$$

Using the continulty equation, this can be rewritten:

$$
0=\frac{\partial V}{\partial R}+\frac{192 \mu}{\rho D^{4} V_{n}^{2}} R^{2} V^{2}
$$




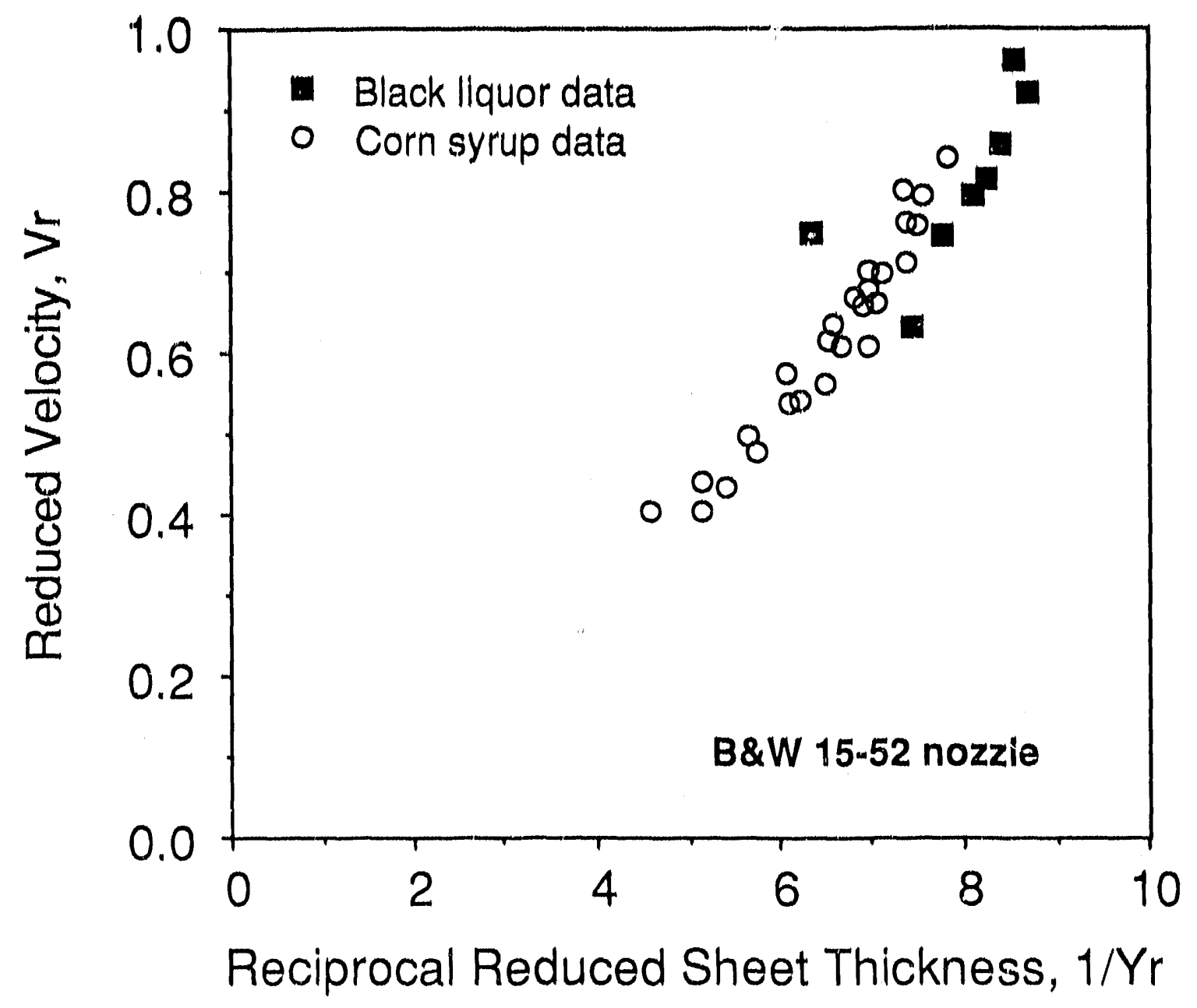

Flgure 4.8. Correlation between raduced sheet veloctty and reduced sheet thickness based on the continutty equation for the B\&W 15-52 nozzle. 


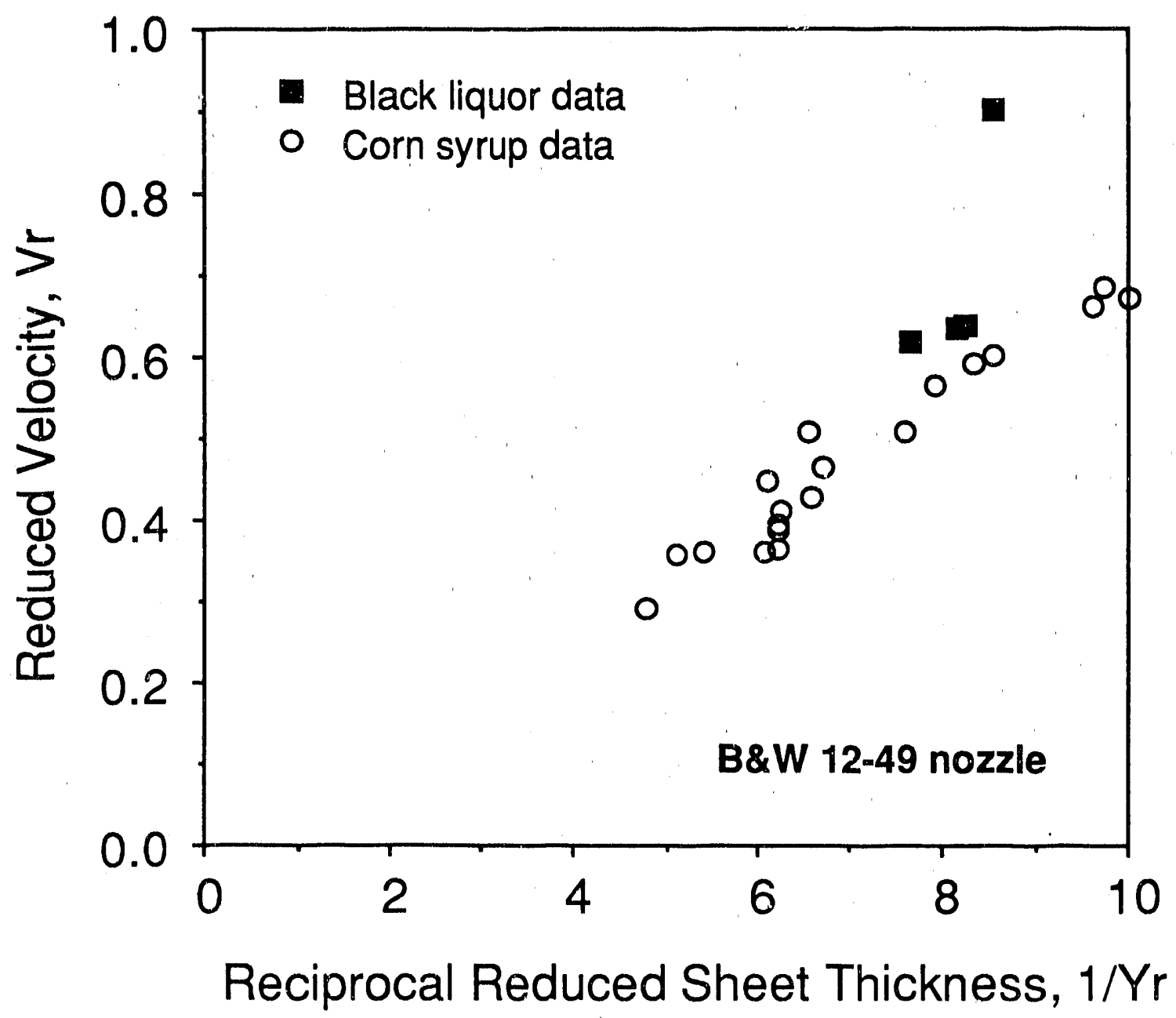

Figure 4.9. Correlation between reduced sheet velocity and reduced sheet thickness based on the continuity equation for the B\&W 12-49 nozzle. 
Using a boundary condition that the top surface velocity equals the nozzle velocity at the location where viscous losses start:

$$
V=V_{n} \text { at } R=R_{0}
$$

The momentum equation integrates to:

$$
\frac{1}{\mathrm{~V}_{\mathrm{r}}}-1=192 \mu_{\mathrm{r}}\left[\left(\frac{\mathrm{R}}{\mathrm{D}}\right)^{3}-\left(\frac{\mathrm{R}_{0}}{\mathrm{D}}\right)^{3}\right]
$$

The last bracketed term on the RHS of Equation (4-11) is a constant for each nozzle. The reciprocal reduced velocity should be a linear function of the reduced viscosity. The LHS of Equation (4-11) is plotted as a function of the reduced viscosity in Figures 4.10 and 4.11 for the two nozzles. Considering the averaging of the data over angle, the plots are reasonably good straight lines.

For convenience, Equation (4-11) can be rewritten in three alternative forms:

$$
\begin{aligned}
\frac{1}{V_{r}} & =r C_{1}+C_{2} \\
Y_{r} & =r C_{3}+C_{4} \\
Y_{r}\left(1-V_{r}\right) & =r C_{5}+C_{6}
\end{aligned}
$$

where:

$$
C_{1} \ldots C_{6}=\text { are constants for each nozzle }
$$

The vaiues of the constants in Equations (4-12)-(4-14) determined by leastmean-square (LMS) fits of the data are given in Table 4.2 .

TABLE 4.2

Values for the LMS fit constants for Equations (4-12)-(4-14)

Nozzle

$c_{1}$

$\mathrm{C}_{2}$

$\mathrm{C}_{3}$

$\mathrm{C}_{4}$

$C_{5}$

$\mathrm{C}_{6}$

B\&W 12-49

632.4

0.8738

31.85

0.08308

37.85

0.001057

B\&W 15-52

375.5

0.9344

23.85

0.1080

30.16

0.001447 


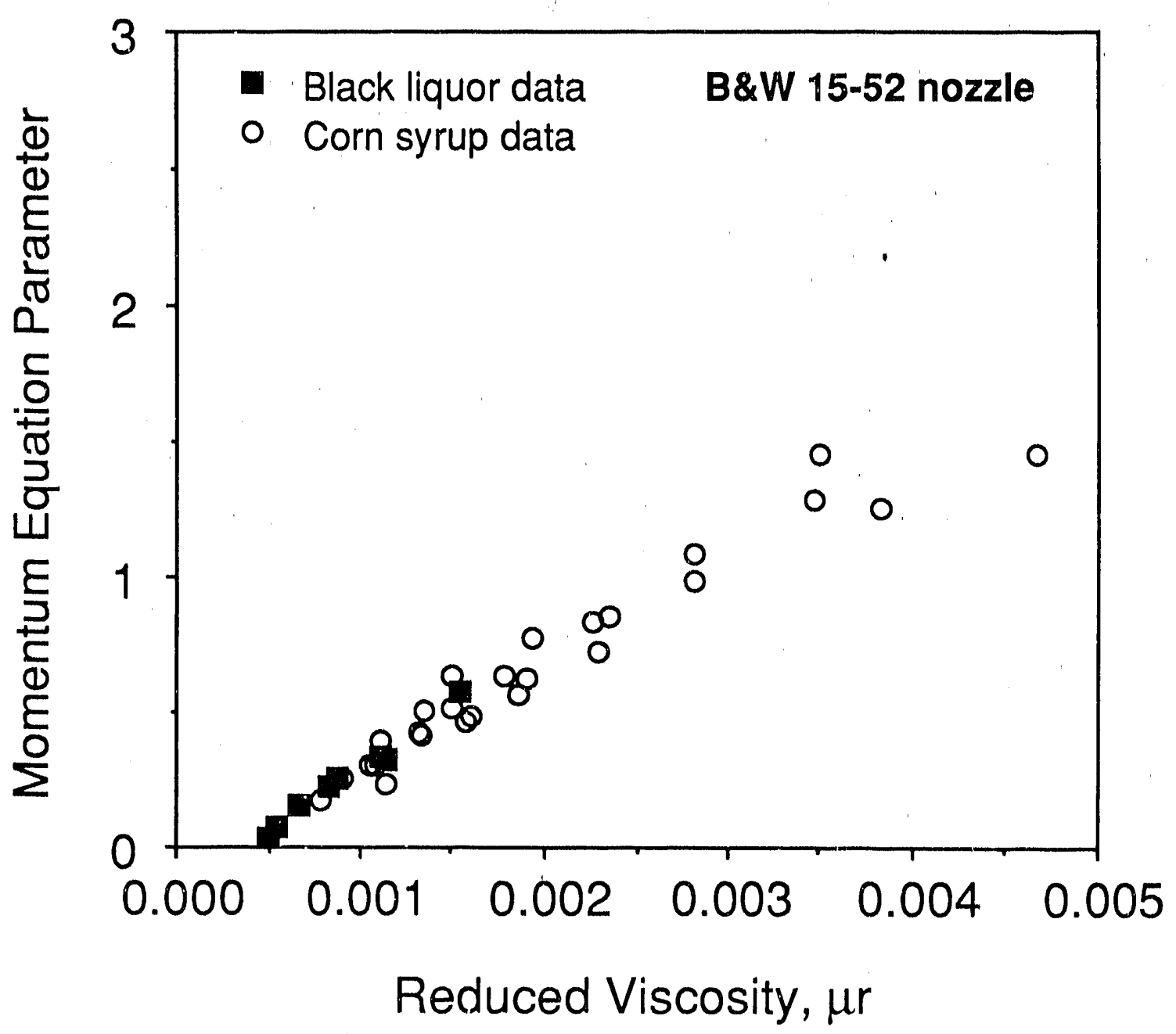

Figure 4.10. Momentuin equation parameter, $1 / V r-1$, as a function of the reduced viscosity for the B\&W 15-52 nozzle. 


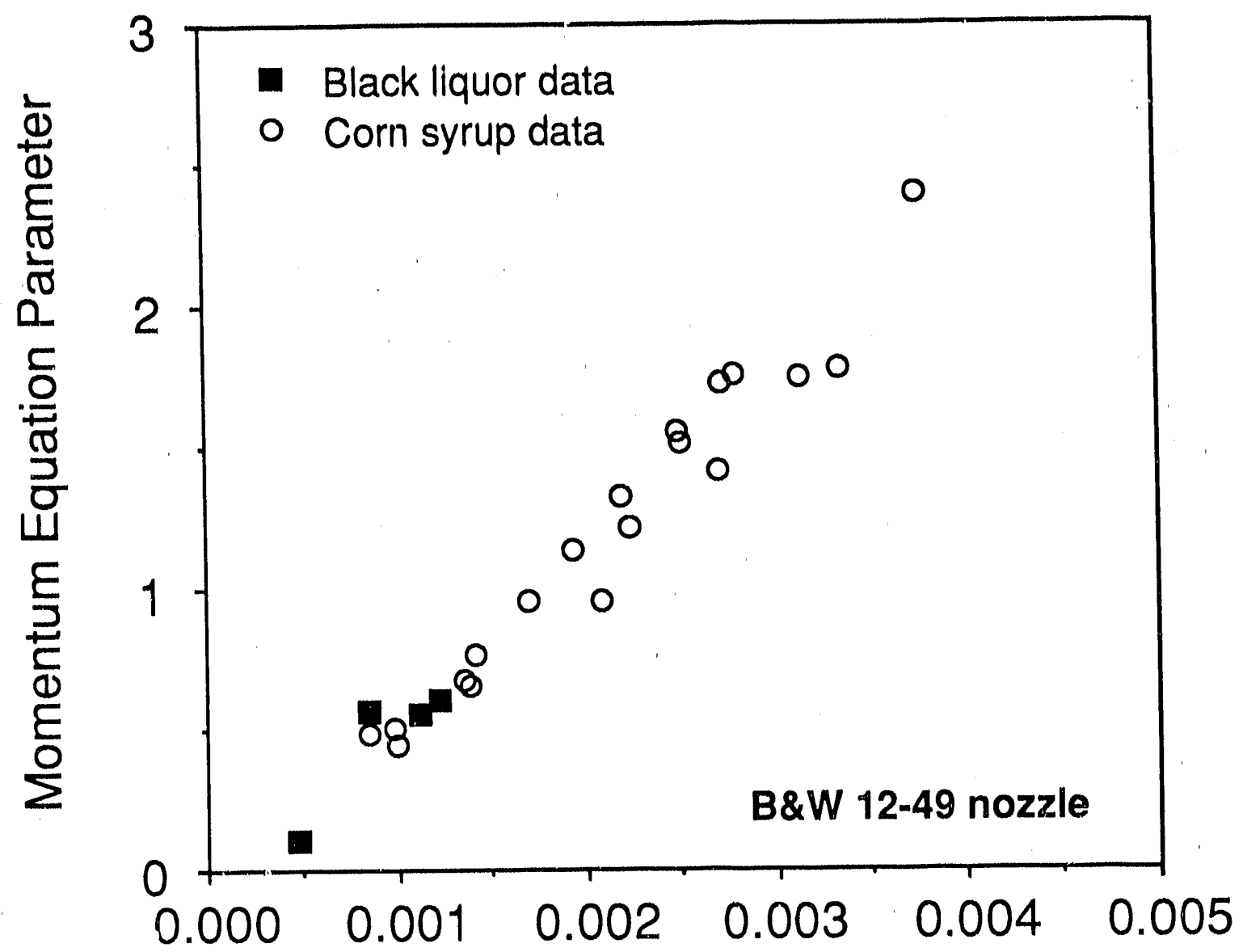

Reduced Viscosity, $\mu \mathrm{r}$

Figure 4.11. Monentum equation parameter, $1 / \mathrm{Vr}-1$, as a function of the reduced viscosity for the B\&W 12-49 nozzle. 


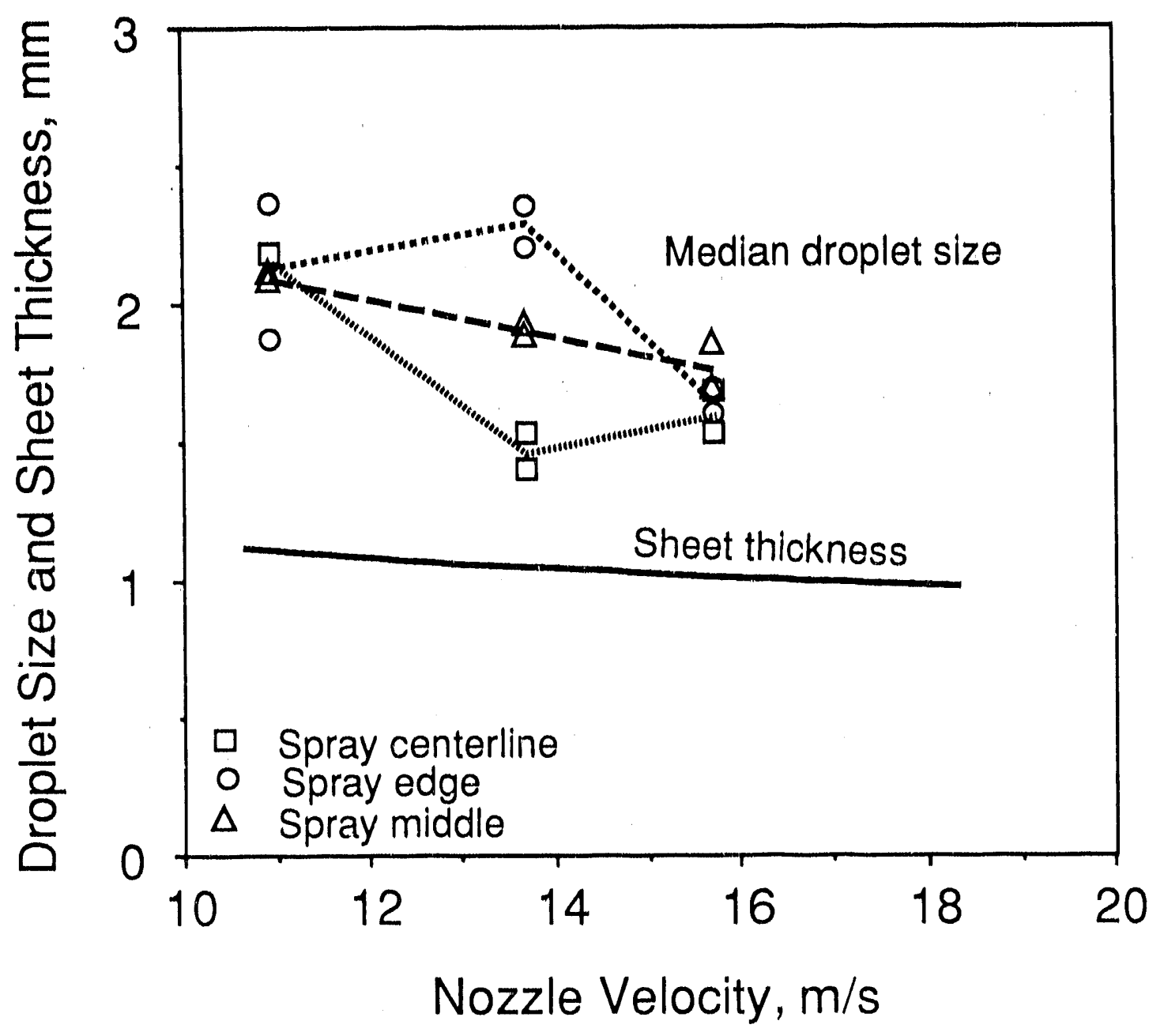

Figure 4.12. Comparison of droplet median size data and calculated sheet thickness as a function of nozzle velocity for a B\&W 12-49 nozzle firing liquor at a viscosity of $150 \mathrm{mPa}$. 


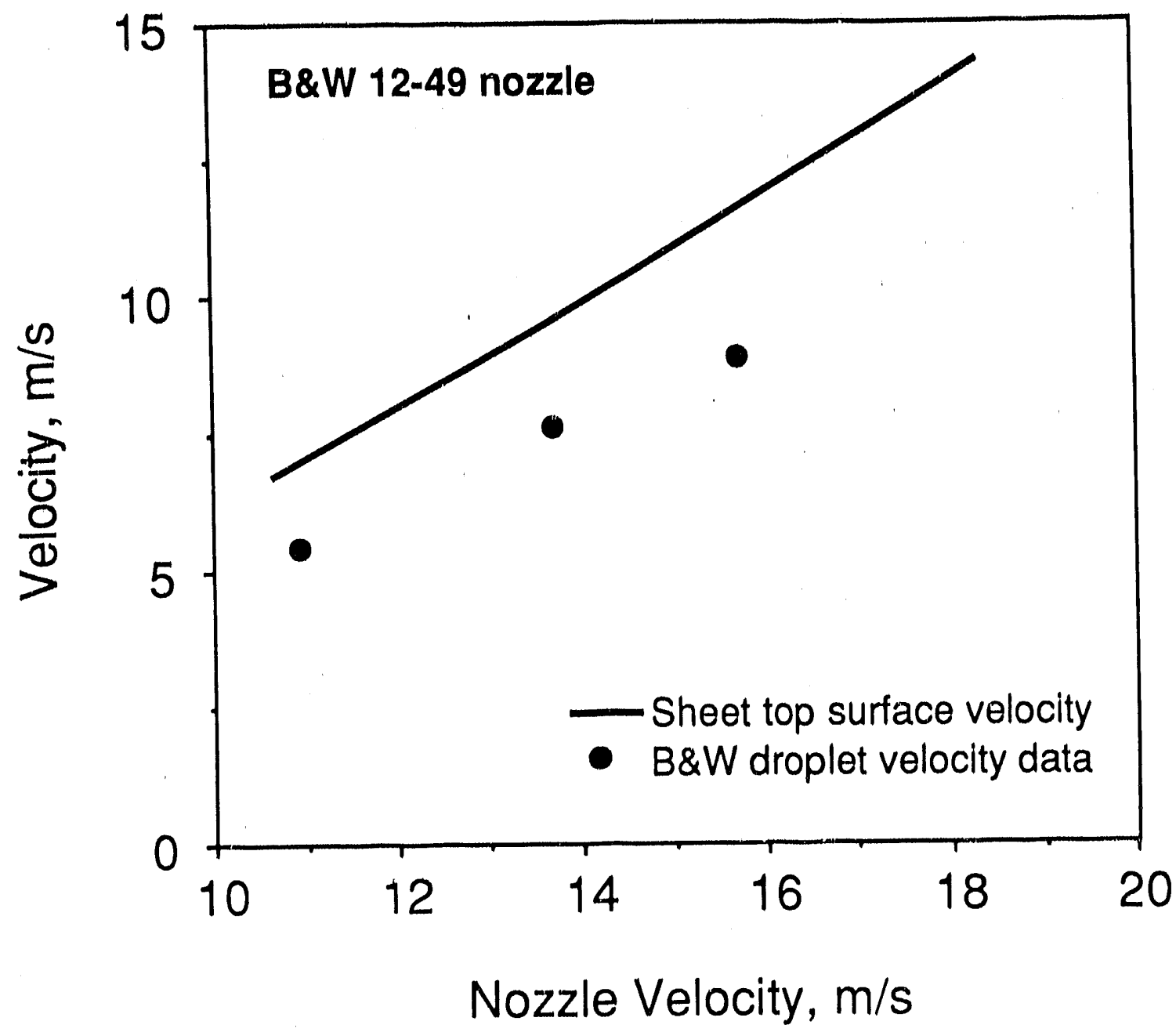

Figure 4.13. Comparison of droplet velocity data and calculated sheet top surface as a function of nozzle velocity for a B\&W 12-49 nozzle firing liquor at a viscosity of $150 \mathrm{mPa}-\mathrm{s}$. 
Because of the limited data and the simplifying assumptions, these equations and derived constants must be viewed simply as conventent correlating equations for the data. They will be used below to compare the present data to previous data on the spray characteristlcs of one of these nozzles, and to estimate the sensitivity of spray drop size to viscosity.

\subsection{DISCUSSION}

Prevlous data on flutd sheet thickness and velocity are not avallable for comparison, but data are avallable for one of the nozzles used in these tests on droplet size and droplet velocity $(4,18)$. Previous analytical work $(8,9,10,14)$ has shown a direct relationship between fluid sheet thickness and ultimate droplet size so that trends in one should be reflected in the other.

Reported data $(4,18)$ for the impact of nozzle velocity on both droplet size and velocity are avallable for the B\&W 12-49 nozzle. The data were taken with black liquor as a working flutd. The black liquor was fired at approximately $53 \%$ solids and $25^{\circ} \mathrm{C}\left(77^{\circ} \mathrm{F}\right)$ resulting in a viscosity of 150 $\mathrm{mPa}-\mathrm{s}(150 \mathrm{cP})$. Data were collected on droplet size distribution and velocity with a Malvern Drop Size Analyzer at a location approximately $1.22 \mathrm{~m}$ $(4 \mathrm{ft})$ from the nozzle. Data were collected at three locations: along the centerline of the spray, at the edge of the spray, and at a location half way between these two. The mass median droplet diameter is shown as a function of the nozzle velocity in Figure 14 for all three locations along with a curve for sheet thickness based on Equation (16). The generally decreasing trend in the data with increased velocity is matched nicely by the sheet thickness correlation. As well, the sheet thickness is approximately $60 \%$ of the ultimate mass median drop diameter, consistent with analytical development $(1,8,9,10,14)$.

Data from the same study by Babcock \& Wilcox $(4,18)$ also deals with the velocity of the droplets at a distance of approximately four feet from the nozzle. The liquid sheet leaves the nozzle with an average velocity approximately half the top surface velocity. The resulting free fluid sheet, ligainents, and ultimately droplets are acted on by aerodynamic drag. The speed of the droplets at a distance of four feet would be expected to be somewhat less than the average sheet velocity. Plotted in Figure 15 are the B\&W data for droplet velocity as a function of nozzle velocity along with the velocity based on Equation (15). Again, the comparison of trend is quite good.

Though neither of these comparisons is definitive concerning the operation of even this one nozzle, the levels and trends are consistent. The insight derived from the data and correlations can be used to examine one other aspect of nozzle performance which is of inmediate practical importance. Black liquor in pulp and paper mill operation ts being fired at higher dry solids levels than in the past for reasons of energy efficiency, higher recovery botler capacity, and greater safety. This trend seems likely to continue with industry average as-fired liquor solids increasing from the current level of between 65 and $70 \%$ to a level between 75 and $80 \%$. 
Higher firing temperatures can be used to offset the dramatic increase in viscosity that results with higher liquor solids. However, the maximum temperature is 11 mitad by flashing ahead of the nozzle, so higher as-fired liquor viscosity can be anticipated at the higher solids levels. Equation (16) gives some insight into the impact of black liquor viscosity on the fluid sheet thickness and therefore into ultimate droplet size. Plotted in Figure 16 is the fluid sheet thickness as a function of viscosity for one nozzle (the $B \& W 12-49$ ) and for one flow rate $(1.11 / \mathrm{s}$ or $17 \mathrm{gpm}$ ) corresponding to a nozzle velocity of $15 \mathrm{~m} / \mathrm{s}(49 \mathrm{ft} / \mathrm{s})$. The viscosity range covered is from 25 to $1000 \mathrm{mPa}-\mathrm{s}$ (25 to $1000 \mathrm{cP}$ ) which spans the range of current and anticipated as-fired black liquor viscosity. Not surprisingly, the sheet thickness increases with viscosity. The increase in droplet size would be expected to be similar. However, the sheet thickness increases by less thar a factor of two and a half for a ten-fold increase in viscosity. This relatively low sensitivity of sheet thickness is consistent with theory $-(8-10)$ and means that at least this one type of nozzle should allow relatively easy transition to higher black liquor dry solids in normal pulp and paper mill operation.

\subsection{CONCLUSIONS ON FLUID SHEET CHARACTERISTICS FOR A BLACK LIQUOR NOZZLE}

The fluid sheet thickness and top surface velocity have been measured for one type of black liquor spray nozzle using two working flutds - black liquor, and corn syrup. Several conclusions can be drawn from both the experimental data and the correlations developed from simple theory.

1. Due to their large physical size, black liquor nozzles provide a unique opportunity to investigate the fluid sheet formation process.

2. Due to back flow from the stagnation point on the splashplate surface, the fluid flow pattern for B\&W splashplate nozzles is complicated along the centerline of flow and at the edge of the spray.

3. Data on flutd sheet thickness and top surface velocity taken at angular positions between these two extremes result in fairly regular and consistent flow data.

4. Plots of fluid sheet thickness and top surface velocity show a generally decreasing trend with increasing angle away from the centerline of the spray. They also show an increase in sheet thickness and a decrease in top surface velocity with increasing fluid viscosity.

5. Application of the continuity and momentum equation to a simpler flow geometry under two very specific assumptions leads to equations for sheet thickness and top surface velocity which correlate the data very wel1.

6. Comparison of the correlations of the data presented here with previous data on droplet size and velocity for a B\&W 12-49 nozzle show good correspondence.

7. Application of one of the correlations to the practical mill problem of increasing as-fired liquor solids results in a plot of sheet thickness as a function of viscosity. Consistent with theory, the sheet thickness (and therefore likely the droplet size) is not very sensitive to fluid viscosity, changing by a factor of less than two and a half for a ten-fold increase in viscosity. This relatively low sensitivity means that at least one nozzle, the splashplate, should allow relatively easy transition to higher black liquor dry solids in normal mill operation. 


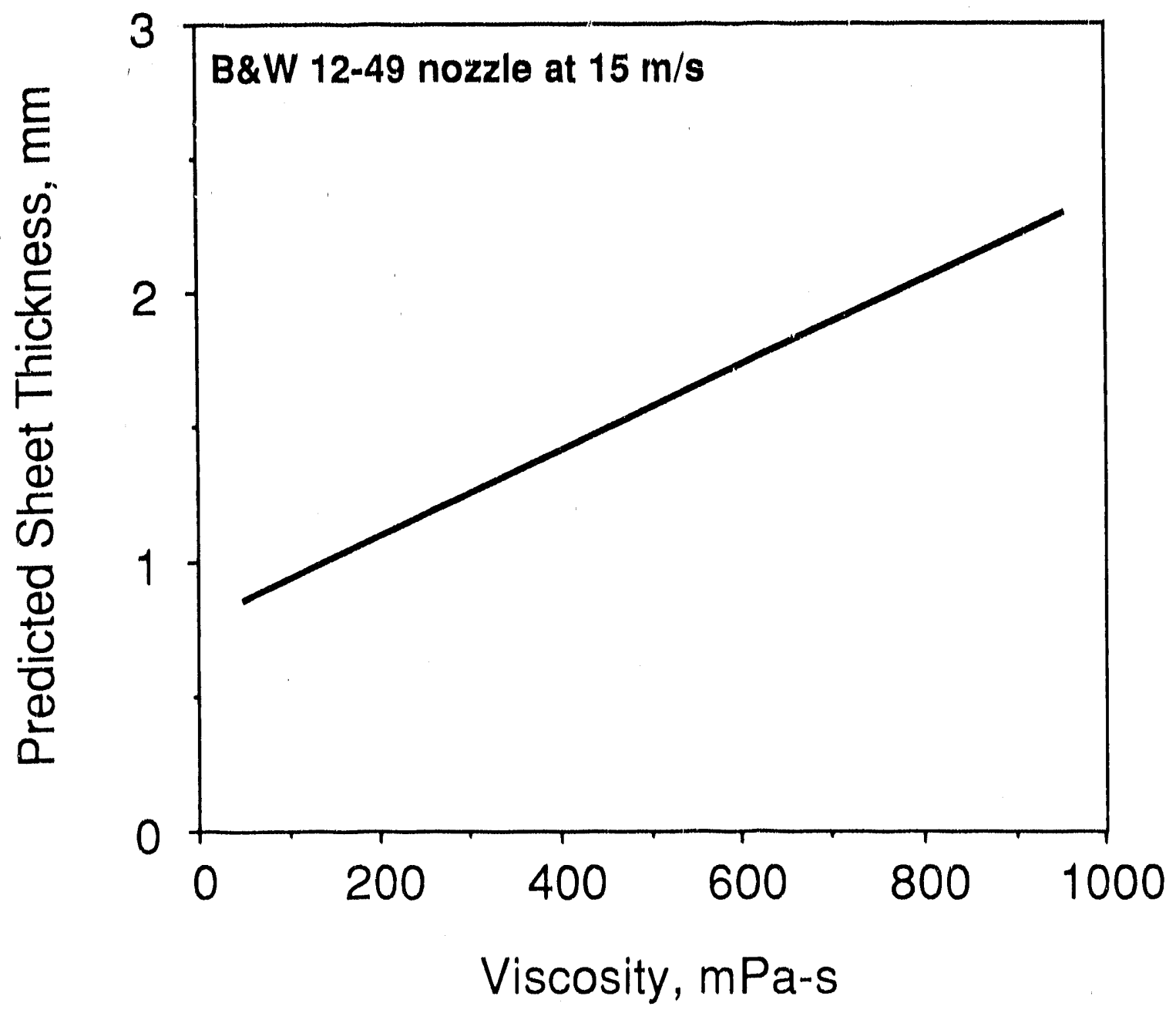

Figure 4.14. Calculated sheet thickness as a function of fluid viscosity for a B\&W 12-49 nozzle operating at $15 \mathrm{~m} / \mathrm{s}$ (17 gpm). 


\subsection{OROPLET SIZE UISTRIBUTION OF BLACK LIQUOR SPRAYS}

\subsection{INTRODUCTION}

Desplte the importance of droplet size and size distribution to optimum recovery bofler performance and safety, only one prevlous study has dealt with the charactertzation of black liquor sprays from conventional nozzles [6]. One further study (20) has investlgated black llquor droplat forination from jets using vibratory assist to produce narrow size distributions.

This section presents data from recent studles of black "iquor droplet formation from conventional splashplate and swirl cone recovery boller nozzles. These studles were carried out at two different laboratory fact. littes, the Allyance Research Center of the Babcock \& W/lcox Co. and IPST. Both studtes used kraft black liquor as the test fluld and used nozzles which are commerctally avallable from the two North Amerlcan recovery botler vendors, though they were the smallest nozzles avallable for this purpose.

\subsection{FACILITY DESCRIPTIONS AND TEST CONDITIONS}

B\&W All tance Research Center

The tests were conducted in the Atomization Facllity. This facllity has two $1.2 \mathrm{~m} \times 2.5 \mathrm{~m}(4 \mathrm{ft} \times 8 \mathrm{ft})$ glass windows along the opposite sides of a spray booth. These windows provide optical access for the laser-based droplet sizing instrumentation. A splashplate nozzle is installed near the upstream end of the windows, about $15 \mathrm{~cm}$ ( 6 tnches) above the bottom edye of the windows. The plane of the nozzle splashplate is nearly vertical, with the flow axts of the spray dilected horlzontally. The resulting flat vertical liquid sheet and spray occupy most of the vlew through the windows.

Droplet size is measured at a distance of approximately $1.2 \mathrm{~m}$ (4 ft) downstreain of the splashplate and at three vertical locations. The inttial 1 tquid sheet breaks into droplets before reaching this distance of $1.2 \mathrm{~m}$. The three vertical locattons correspond to the spray centerltine, the edye of the spray, and a position intermedlate between these two.

The black liquor droplet size distributions were measured with a Malvern ST2600 Droplet and Particle Stze Analyzer. Thls analyzer is particularly good at measuring the lower end of the size spectrum. This is shown in the data from a calibration test using drllled holes in brass shim stock. Table 5.1 shows the compartson of actual to measured values.

Heavy black liquor was obtatned from a kraft mill at $63 \%$ solfds. This liquor was diluted to $53 \%$ solfds so that ths room temperature viscostty was approxtimately $0.15 \mathrm{~Pa}-\mathrm{s}(150 \mathrm{cP})$ simulating the viscostty of hot, as -fitred black liquor at typtcal operating condittons. The viscostty of the lifuor was measured under several condtitons both before and after the spray tests. For these tests the liquor was matntatned between $24^{\circ} \mathrm{C}$ and $27^{\circ} \mathrm{C}$ $\left(76^{\circ} \mathrm{F}\right.$ and $\left.31^{\circ} \mathrm{F}\right)$. 
Table 5.1. Malvern St2600 Analyzer Callbratton.

\begin{tabular}{ccc}
\hline Hole Size, & Measured Size, & Difference \\
ImIm & 6.43 & -19 \\
7.94 & 2.69 & +4.3 \\
2.58 & 1.57 & +4.0 \\
1.51 & 0.858 & -3.6 \\
0.89 & & \\
\hline
\end{tabular}

Two nozzles were used during the B\&W Alllance Research Center study. Both were splashplate nozzles of standard B\&W destgn. They had the same nozzle orffice size of $0.95 \mathrm{~cm}(3 / 8-1 \mathrm{nch})$, but had different splashplate angles. One was $49^{\circ}$ and the other $35^{\circ}$. These nozzles were operated at three flow rates between $0.75 \mathrm{~L} / \mathrm{s}$ to $1.14 \mathrm{~L} / \mathrm{s}$ (12 to $18 \mathrm{GPM})$. A total of thirty five runs were carrled out. Black llquor droplet size distrlbution data for three of the runs are shown in Flgure 5.1. Complete speciffcation of the test conditions and the size distribution results are presented in table 5.2 .

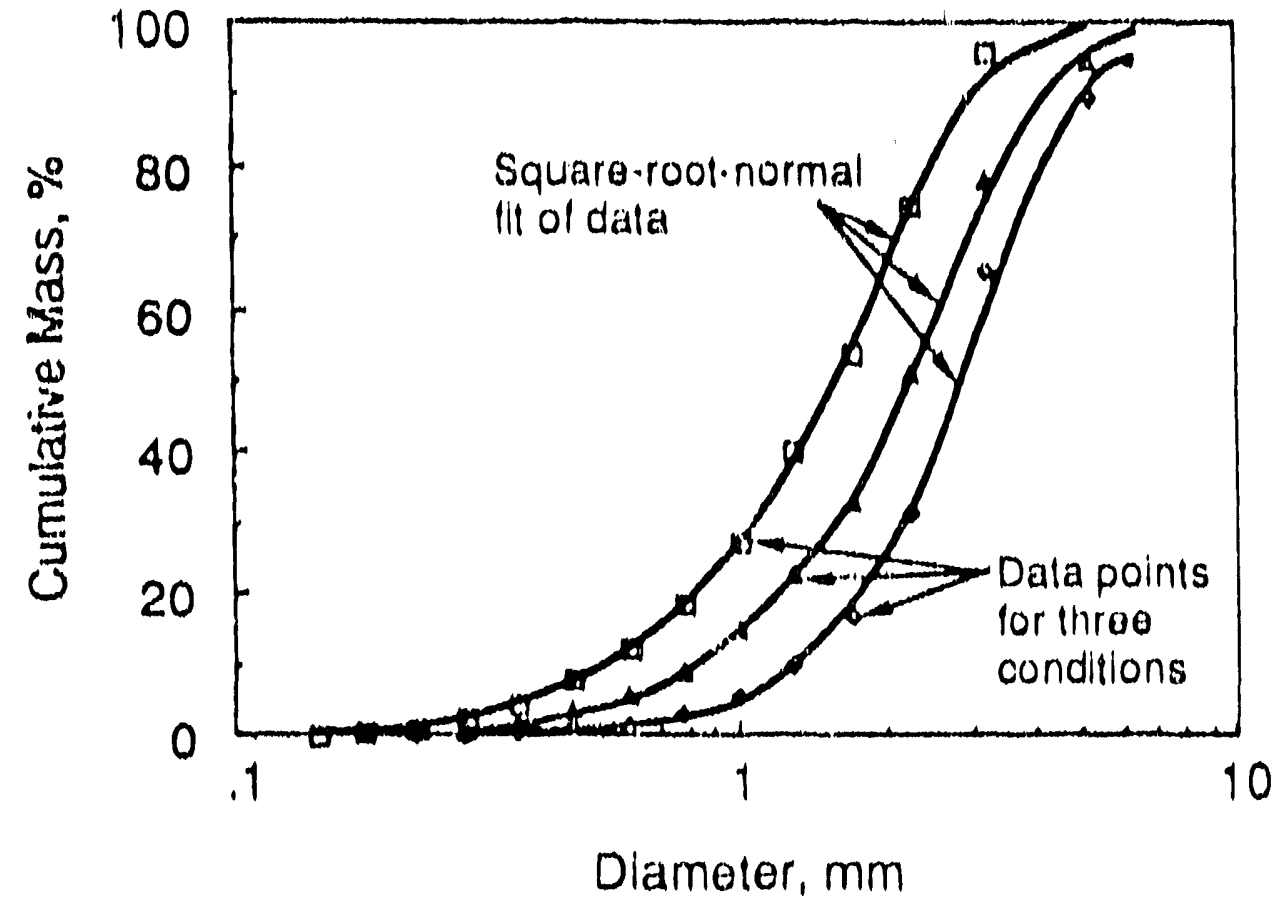

Figure 5.1. Compartson of black lfquor droplet slze distribution data for three test condtitons with square-root-riorilal fit of the data for B\&w splashplate nozzles 


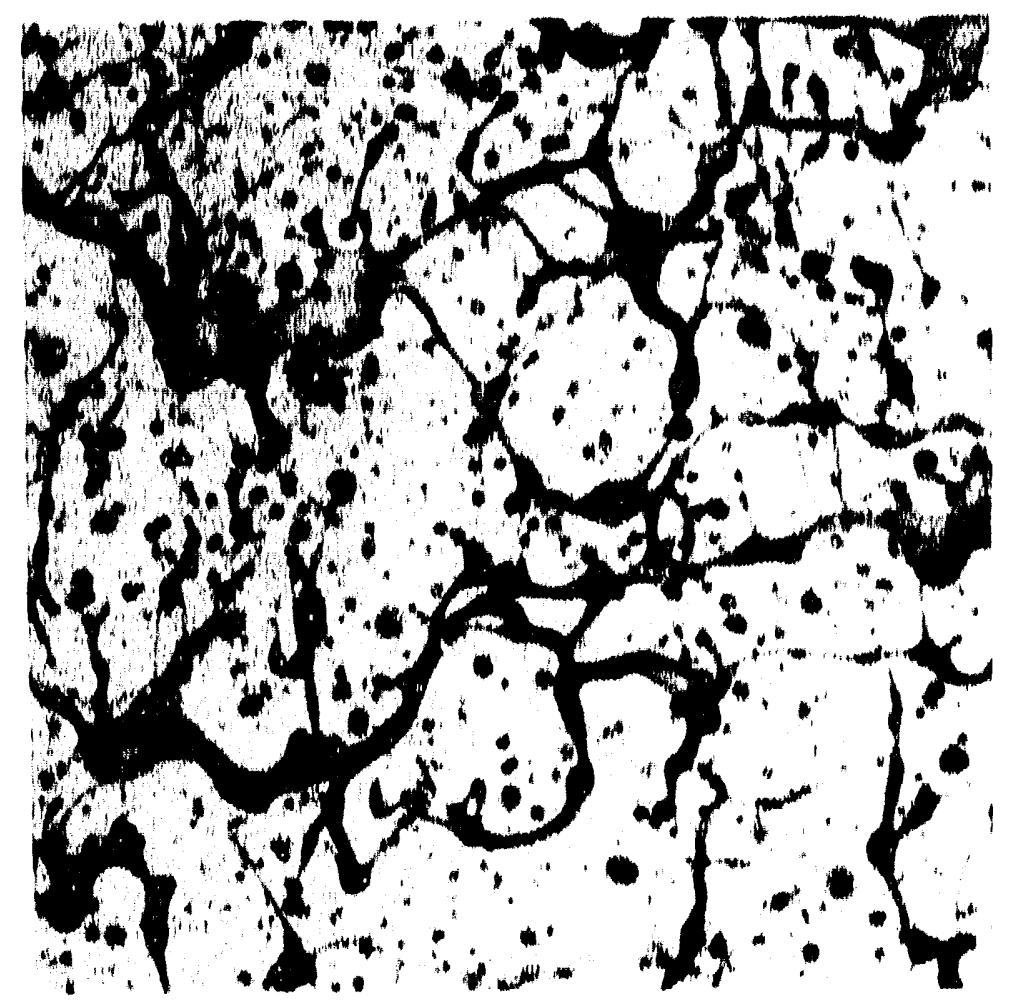

Fig. 5.2. Shadowgraph Image for a black liquor spray using the IPST flash X-ray Imaging System.

Heavy black 1lquor was obtained from a kraft mill. The chemical makeup of the llquor was obtalned and the viscosity determilned for a varlety of conditlons which spanned the normal operating range for the $m i 11$. The oxidation state of the sulfur was monitored during the test program in order to observe changes in the nature of the llquor when it was sprayed and

recycled back to the storage tank. No clear trend could be observed from these data. The range of condltions selected for these spray tests covered the usual range of soldds and temperature for many kraft mil1s, 66-72\% dry sollds and $104^{\circ} \mathrm{C}$ to $127^{\circ} \mathrm{C}\left(220^{\circ} \mathrm{F}\right.$ to $\left.260^{\circ} \mathrm{F}\right)$. Thls corresponded to a viscostty range of $29 \mathrm{cP}$ to $66 \mathrm{CP}$. Three nozzles were used in these tests. One nozzle was identical to the $0.95 \mathrm{~cm}\left(3 / 8\right.$ inch) $49^{\circ}$ B\&W splashplate nozzle used in the tests at the B\&W All lance Resarch Center. A second B\&W splashplate nozzle was used whlch had a nozzle orlfice $1.27 \mathrm{~cm}(0.5$ inch) in diameter and a splashplate angle of $49^{\circ}$. The thilrd nozzle was a CE swirl cone nozzle. This nozzle had an exit orlfice of $1.27 \mathrm{col}(0.5$ inch) but contalned a standard internal swirl block consisting of two spiral grooves which limpart the swirl to the black llquor flow just ahead of the exlt orlfice. The total open flow area of these two grooves is equivalent to the area of a $0.95 \mathrm{cIII}(3 / 8$ inch) diameter hole. This is the inl nimum flow area for the nozzle and therefore the location of the maximum fluld velocity. This equlvalent diameter will be used as the characterlstic dimenston for the nozzlo.

For the B\&W nozzles data were taken along the centerline of the spray. For the CE nozzle a mechantcal catcher was used to divert a portilon of the spray cone out of the fleld of vlew of the $x \rightarrow r a y$ systell. As a result the $x-$ ray only passed through the spray sheat once, as with the flat: $B$ WW splashplate sprays. 
Table 5.2. Data from B\&W All lance Research Center

\begin{tabular}{|c|c|c|c|c|c|c|c|c|c|c|c|}
\hline $\begin{array}{c}\text { Hotal } \\
\text { Type }\end{array}$ & $\begin{array}{l}11001 \\
10011\end{array}$ & gheofielate & $\begin{array}{l}\text { betay } \\
\text { looglion }\end{array}$ & $10 ! 1 d 0$, & $T: 0 p, 1$ & Viougl & $\begin{array}{l}M \text { I UN, } \\
\text { OPH }\end{array}$ & $\begin{array}{c}\text { Man, Vol. } \\
\text { lile }\end{array}$ & Hain HedI H & $\begin{array}{l}\text { He indard } \\
\text { lieviallon }\end{array}$ & $\begin{array}{l}\text { Hocmallu, } \\
\text { Itd. Dev. }\end{array}$ \\
\hline 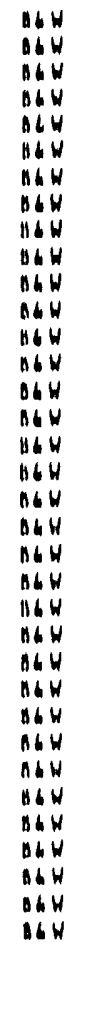 & 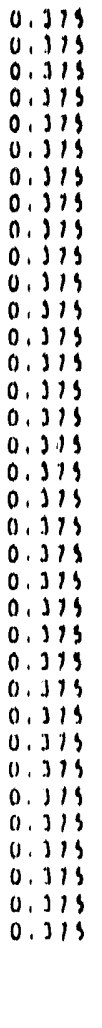 & $\begin{array}{l}49 \\
49 \\
19 \\
49 \\
49 \\
44 \\
49 \\
44 \\
49 \\
44 \\
49 \\
49 \\
49 \\
49 \\
49 \\
44 \\
49 \\
13 \\
39 \\
39 \\
39 \\
39 \\
19 \\
39 \\
39 \\
39 \\
39 \\
13 \\
39 \\
34 \\
19 \\
39 \\
39 \\
19 \\
39\end{array}$ & 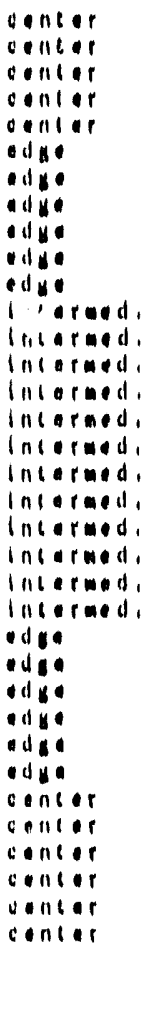 & 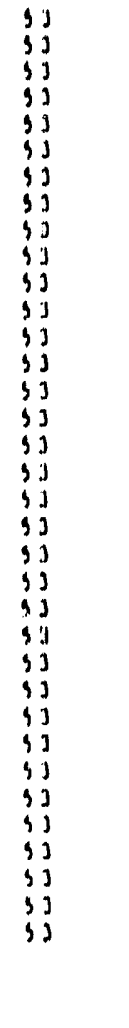 & 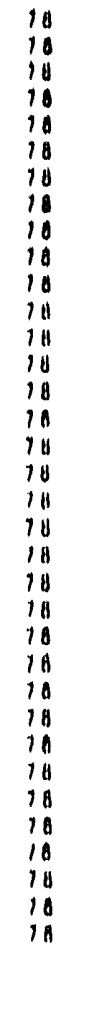 & $\begin{array}{l}190 \\
190 \\
190 \\
190 \\
190 \\
190 \\
190 \\
190 \\
190 \\
190 \\
190 \\
190 \\
190 \\
190 \\
190 \\
190 \\
190 \\
190 \\
190 \\
190 \\
190 \\
190 \\
190 \\
190 \\
190 \\
190 \\
190 \\
190 \\
190 \\
190 \\
190 \\
190 \\
190 \\
190 \\
190\end{array}$ & 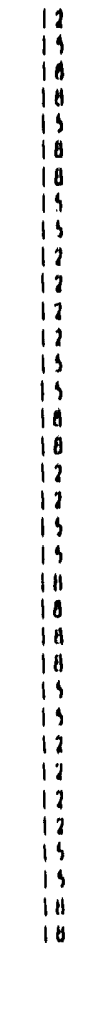 & 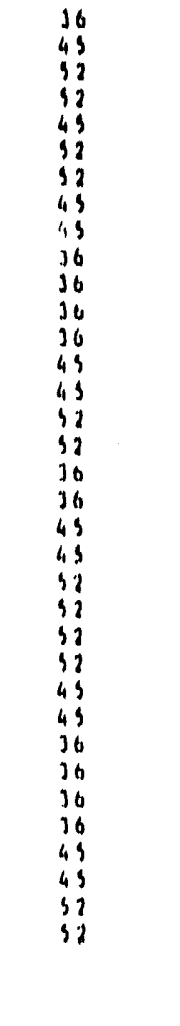 & 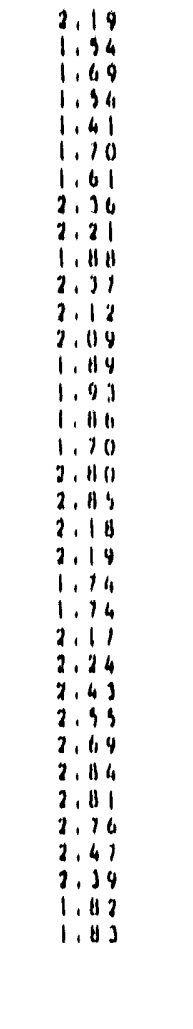 & 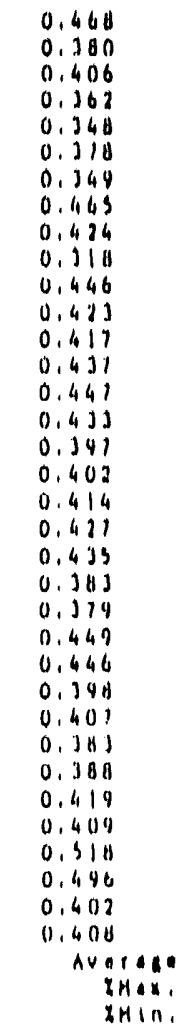 & 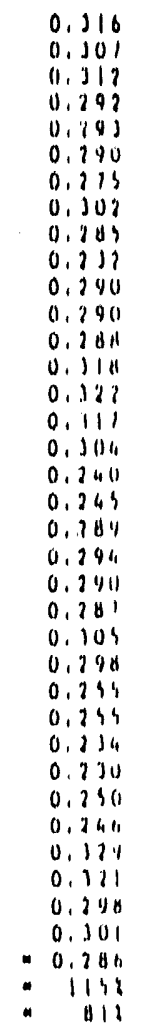 \\
\hline
\end{tabular}

Instlucte of Paper Sclence and Technology

The IPST tests were conducted in the flash $x$-ray Spray factlity. In this facllity black llauor is sprayed clownward into a catch tank. A HewlettPackard $43731 \mathrm{~A} 150 \mathrm{kV}$ flash $x$-ray source is almed horlzontally through the spray toward a shent of Korlak DEF $x$-ray fllm. The black llquor droplets absorb more of the $x$-rays than the surrounding alr and therefore leave a shadow on the exposed fllm. The use of flash $x$-ray to limage a varlety of flows has been discussed by farrington [6.]. A typlcal $x$-ray shadowgraph for the spray from a Bew splashplate nozkle is shown in Figure? The flash $x$-ray systam Is lociated approximately $0.9 \mathrm{~m}(3 \mathrm{ft}$ ) below the nozzle for BuW nozkles and approximately 0.6 in (? ft) for col noz\%les. It is apparent from ligure 5.? that the llqutd sheet and 11 caments of black lyaur have not completely broken toto droplets at this location. 
The tmages of the sprays on the shadowgraphs were analyzed with a Traptx 56/512 tmage analyzer. Between 2000 and 4000 drops were examt ned for each condition. Droplets smaller than 0.5 min were not included tri the automatic analysis of these shadowgraphs, so there is an artifletal lower limtt at 0.5 mill which ts apparent in the three size distribution data sats presented In Figure 5.3. The potential effect of this lower limit will he discussed below. A complete set of operating spectfications and results for the elght test condittons is presented in Table 5.3 .

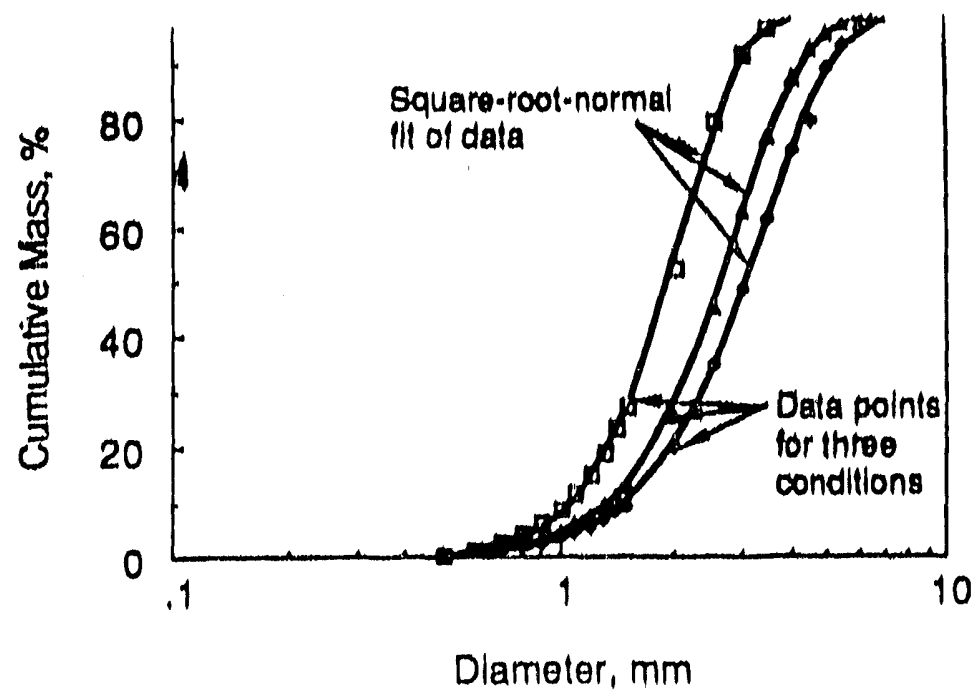

Flgure 5.3. Compartson of black liquor droplet size distribution data for three test condttions with square-root-norimal fit of the data for CE swirl cone nozzles.

TABLE 5.3 Data from the Institute of Paper Sctence \& Technology

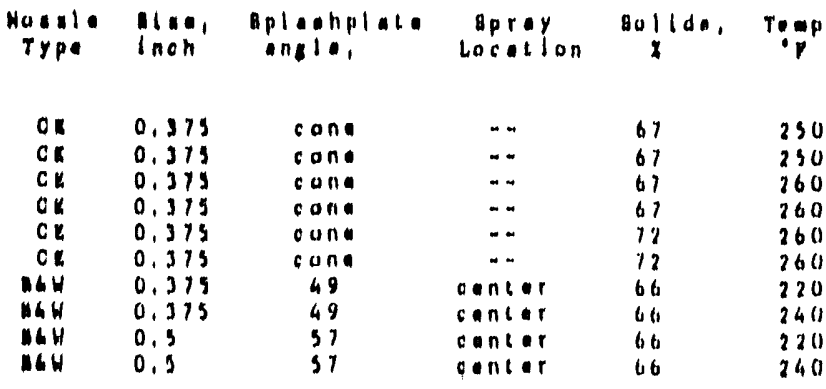




\subsection{CORRELATION OF SIZE DISTRIBUTION DATA}

Characterizing the data curves in terms of only a few parameters can be very useful in determining the effects of nozzle geometry and operating conditions on droplet size distribution. Several distribution curves have been suggested including log-normal, square root-normal, and Rosin-Rammler. For pressure atomizers and two-fluid atomizers the square root-normal distribution has been the most successful (17). This distribution has the form:

$$
f(D)=-\frac{1}{\sqrt{2 \pi}} \exp \left[-\frac{(D 1 / 2-(M M D) 1 / 2)^{2}}{2}\right]
$$

where:

$$
\begin{aligned}
f(D) & =\text { distribution function } \\
D & =\text { droplet diameter } \\
M M D & =\text { mass median diameter } \\
S & =\text { standard deviation }
\end{aligned}
$$

The square root-normal distribution fits the data for the black liquor nozzles used in both sets of tests as is demonstrated in Figures 5.1 and 5.3. The applicability of the square root-normal distribution to the data allows each of the size distribution curves to be represented by just two parameters, the mass median diameter. MMD, and the standard deviation, $s$. These values are included for each test run in Tables 5.2 and 5.3 , along with another parameter formed from them, the normalized standard deviation. For the square root normal distribution, the normalized standard deviation is defined as:

$$
S^{\prime}=\frac{S}{M M D}
$$

This latter parameter is a better measure of the breadth of the size distribution because it removes the effect of the median size.

For the spray data from the B\&W Alliance Research Center the black liquor properties such as percent solids, temperature, and viscosity were not varied, so it is easy to determine the effects of the other variables: splashplate angle, spray location, and flow velocity. The effects of these variables on the mass median diameter and the normalized standard deviation are shown in Figures 5.4 and 5.5 . 


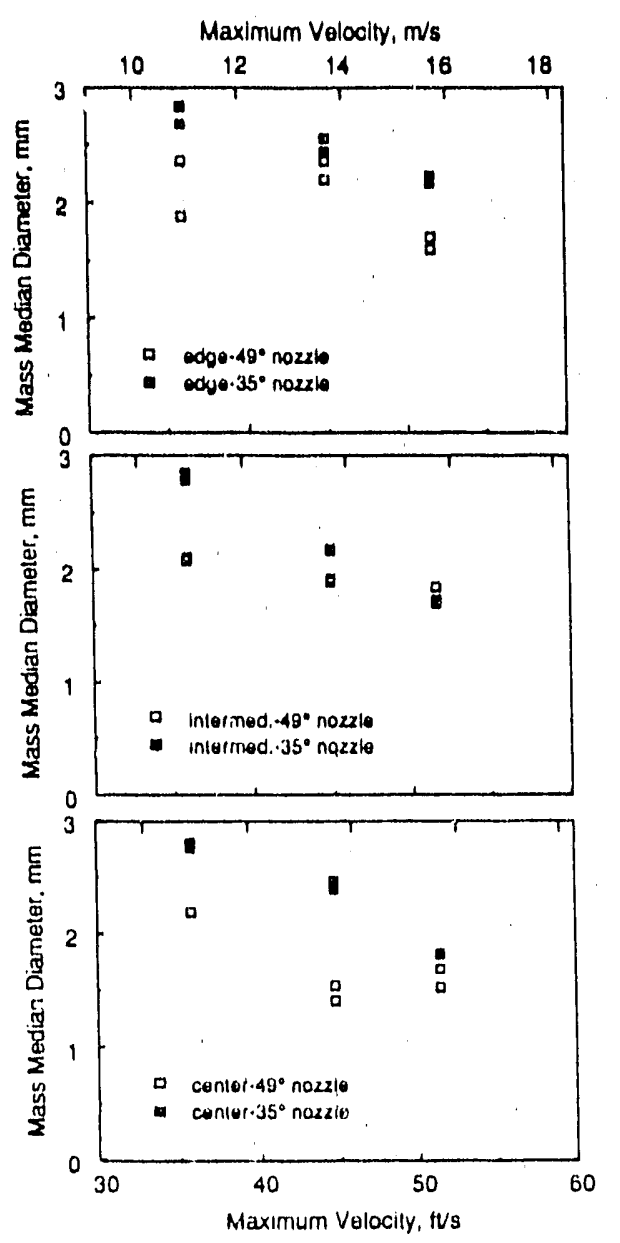

Figure 5.1. Mass median droplet diameter of black liquor sprays from B\&W nozzles as a function of maximum nozzle velocity for three spray locations and two splashplate angles.
Maximum Velocity, $\mathrm{m} / \mathrm{s}$

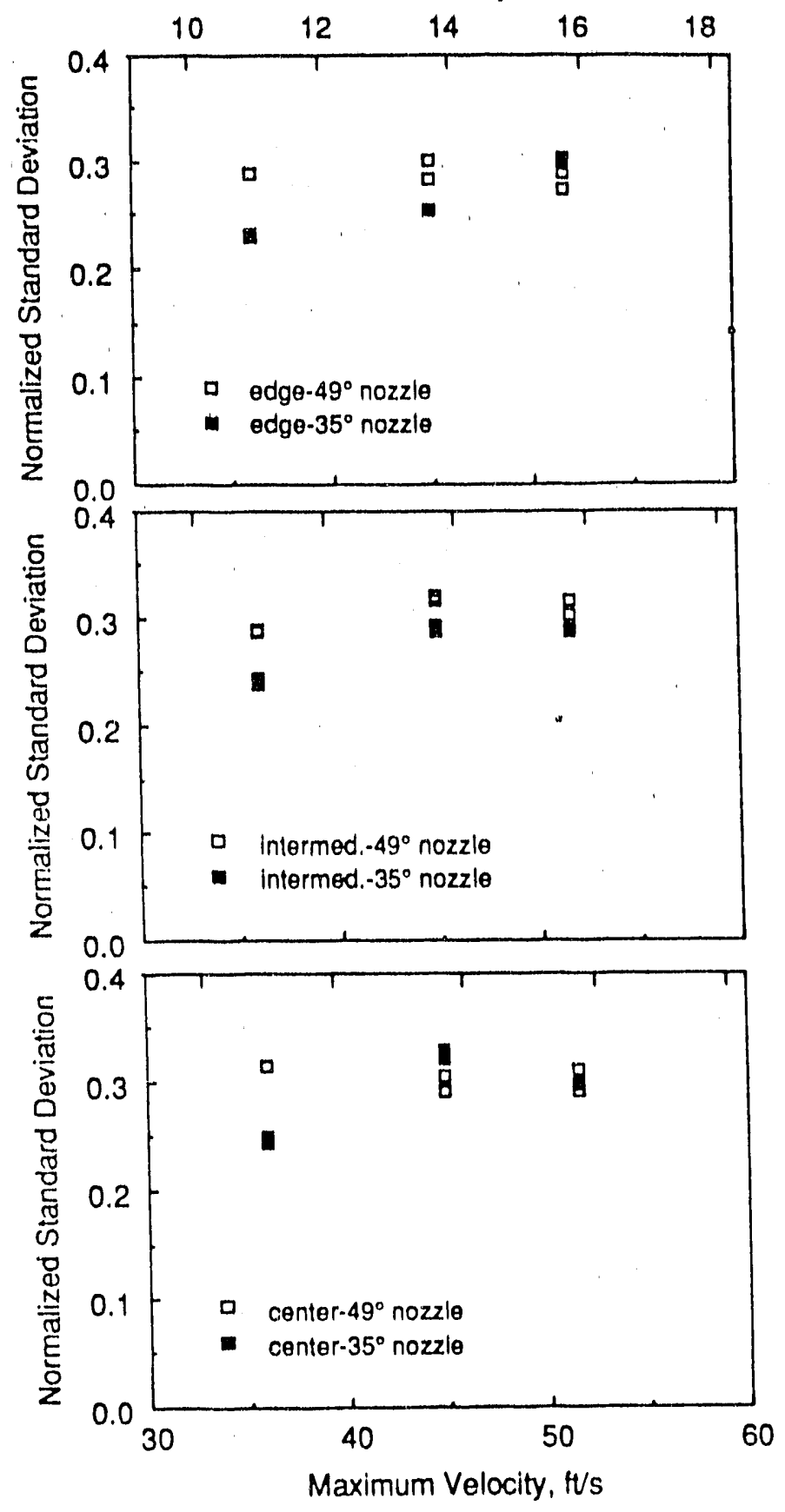

Figure 5.5. Normalized standard deviation of black liquor sprays from $B \& W$ nozzles as a function of maximum nozzle velocity for three spray locations and two splashplate angles. 
As can be seen in Figure 17, there is relatively little scatter between duplicate runs, the $35^{\circ}$ splashplate produces a larger mass median spray size for given conditions compared to the $49^{\circ}$ splashplate, and the spray becomes finer as flow is increased. Though some of the curves in Figure 4 appear to be nearly linear, there is enough curvature in the others to make any specific conclusion difficult.

Quite a different picture emerges from Figure 18. Only relatively small deviation from an overall average value is seen for the normalized standard deviation and no clear trend is apparent. From this it can be inferred that the size distribution about the median does not change appreciably under conditions which do change the MMD by nearly a factor of two. This point will be discussed further below.

\subsection{DISCUSSION}

The extensively developed literature on droplet formation and spray nozzles indicates there are many variables which affect the ultimate size distribution. These variables include nozzle geometry, nozzle size, liquid flow rate, fluid properties, and measurement location. The data from the present two studies and from a previous study of black liquor sprays [6] are too limited to clearly establish the impact of any one of these parameters on black liquor sprays in recovery furnaces. However, the present results are consistent with several aspects of previous observations of spray performance. The most important result from the present work is that practical advantage can be taken of the dependence of spray size on flow velocity. The results presented in Figure 18 show that the normalized size distribution for the spray is not strongly affected $b_{i j}$ flow velocity. This means that the fraction of droplets below a given size can be reduced by increasing the mass median size. This is demonstrated in the three curves of Figure 5.1. The mass of droplets smaller than $1 \mathrm{~mm}$ decreases substantially for the conditions which produce larger values of mass median. diameter. Though there is still considerable uncertainty about the size of droplets which produce carryover and boiler pluggage [1], it is clear that reduced entrainment can reduce carryover. Avoiding the production of undersized droplets by avoiding small values of MMD is one approach to doing this.

Bennington [5] summarized the results of many previous spray characterizations which show the mass median droplet diameter decreases approximately with the square root of the flow velocity. Bennington's work with small swirl cone nozzles and black liquor also showed a decrease with flow velocity raised to the 0.54 power. The data of the current study are too limited for a good correlation. However, the data of Figure 17 show the trend that higher flow velocity produces smaller values of MMD. Using larger nozzles for a given black liquor flow rate would reduce the flow velocity and increase the MMD. Considering the limited extent of these data and the need to avoid char bed blackout, caution would have to be used in testing oversized liquor nozzles on an operating recoveiy boiler. Spray size distribution data are usually badly scattered and specific conclusions about correlations may be statistically correct but may not accurately describe a specific nozzle or condition. 
The basic feature of sprays which allows control of undersized droplets is the insensitivity of the normalized size distribution to system and operating parameters. The data of Figure 5.5 show the variation for various test conditions. From Table 5.2 the average value for all the conditions is 0.286 . The maximum value is $15 \%$ greater than this and the minimum value is $19 \%$ less.

The values in Table 5.2 are for one nozzle type (B\&W splashplate), one black liquor, and une measurement technique. Bennington used water, glycerol, and black liquor with very small swirl cone nozzles and obtained droplet size distributions with average normalized standard deviation of about 0.30 . The maximum was $20 \%$ greater and the minimum $19 \%$ smaller.

Simmons [17] reported very extensive data on small pressure atomized nozzles using a range of fuel $011 \mathrm{~s}$. These data covered more than two thousand tests of one hundred nozzles using fuels which spanned the range of viscosit les from 0.001 to $0.02 \mathrm{~Pa}-\mathrm{s}$ ( 1 to $20 \mathrm{cp}$ ). Two data acquisition techniques were employed, frozen wax-droplet and optical recording with subsequent image analysis. The average value for the normalized standard deviation of all the tests was 0.24 with a maximum 17\% greater and minimum $20 \%$ smaller.

Finally, the eight tests with hot black 1iquor at IPST 1isted in Table 5.3 show a normalized standard deviation for all three nozzles and all test conditions of 0.234 with a maximum $22 \%$ greater and minimum $20 \%$ smaller. This value of normalized standard deviation is smaller than that calculated for the Alliance data (0.286) and that of Bennington (0.3). This may be caused by the artificial minimum droplet size of $0.5 \mathrm{~mm}$. Omitting the smaller droplets tends to increase the MMD while reducing the standard deviation, thereby decreasing the value of the normalized standard deviation.

In each of the four studies there is no obvious correlation of the normalized standard deviation with any of the operating parameters. The data of Figure 5.5 appear to be typical. The numerical value of normalized standard deviation is slightly different for each of the studies, but the statistical scatter in its value is very similar. At this point it is not possible to conclude whether system and analys is technique or actual nozzle and fluid parameters affect its value. Regardless of the cause of the differences, the data support the use of oversized nozzles for carryover control in recovery boilers.

What is most surprising from the data of Table 5.3 is the similarity of the droplet size distribution from the splashplate and swirl cone nozzles. This is supported by the comparison of the Alliance Research Center and the Bennington data as well as by the direct comparisons within the IPST data. Note that this similarity holds despite significant differences in liquor operating conditions for some of the data. The similarity of the MMD between similarly sized nozzles at similar flow velocities is also surprising, but this may be an artifact of the IPST data. The IPST data were taken at a spray location closer to the nozzle than for the other studies. Incomplete droplet formation is evident in Figure 5.2. This, along with the artificial lower limit of $0.5 \mathrm{~mm}$ in the analysis of these data, would tend to move the droplet size distribution toward larger drop sizes. This 
is evident in comparing data on the $49^{\circ} B \& W$ splashplate nozzle taken at the Alliance Research Center and IPST. Considerably more data will be required before conclusions can be drawn about the performance of these two nozzles.

An important additional observation from these tests which is not reflected in the data concerns spray stability. The reported data are for conditions which produced good droplet formation. In both test programs very poor droplet formation occurred at conditions not too far removed from those reported. The potentially hazardous condition of black liquor roping reported by mill operators will depend on fuel and operating parameters. Maps of nozzle operating stability would be extremely useful results accompanying further tests of black liquor spray size distribution.

\subsection{CONCLUSIONS FROM SIZE DISTRIBUTION DATA}

Two recent test programs have added considerably to the data base of black liquor. Conclusions which can be drawn from this work are:

1. A square root-normal size distribution function provides very good correlations of black liquor spray size distributions. This is consistent with previous spray studies of black liquor and other fluids and allows characterization of size distribution with only two parameters, the mass median drop diameter and the normalized standard deviation.

2. Available spray data indicate that the normalized size distribution doesn't change, or changes very little, as a function of nozzle geometry, flow conditions, and fluid properties.

3. Both the available black liquor data on droplet size distribution and the insensitivity of normalized standard deviation lead to a practical approach to control of undersized droplets. Oversized nozzles give lower flow velocities for a given black liquor flow. This results in a larger mass median droplet diameter and a lower fraction of undersized droplets. Cautious use of this approach is needed to avoid unstable nozzle operating conditions which cause poor droplet formation conditions.

4. There is still insufficient data on black liquor spray nozzles to draw conclusions about the impact of nozzle geometry and fluid properties.

5. More data are needed on conditions which produce stable nozzle operation and good droplet formation before droplet correlations can be used confidently in mill operations. 


\subsection{DROPLET SIZE DISTRIBUTION FUNCTIONS}

\subsection{INTRODUCTION}

The purpose of spraying is to break a coherent stream of fluid into many individual fluid elements. This increases the surface area of the fluid available for enhanced heat and mass transfer between the fluid and the surrounding gaseous media. Spray drying of foods and fuel atomization for combustion are two examples. The individual fluid elements are, of course, droplets, with an accompanying implication of spherical geometry. This is often, but not always, correct. For single phase liquids the ultimate fluid element shape is approximately spherical. For materials or mixtures which change phase while equilibrating with the surroundings, other shapes may be formed. For almost all commerclal spraj's the fluid passes through a transition stage where the shape is approximately cylindrical. This is the stage of ligament formation and breakup. The ligaments and the subsequent droplets usually have a wide range of sizes.

Accurate portrayal of the spray process requires description of both the shape and the size distribution of the fluid elements of the spray. This description changes as the spray passes through various breakup stages, and may not have an ultimate or final stage. For example, the combustion of black liquor involves the breakup of a liquor stream first into ligaments, then into "droplets", and finally into gaseous combustion products. For the large droplet sizes characteristic of black liquor sprays the overlap of the droplet formation and droplet combustion stages is considerably less than for other fuel atomization situations. Comparison of different black liquor spraying conditions can probably be accurately portrayed on the basis of the size distribution of the approximately spherical droplets of liquor just prior to combustion.

\subsection{NORMAL DISTRIBUTION}

The range of droplet sizes in most commerctal sprays is very broad, more than two orders of magnitude between the diameter of the smallest and that of the largest. Indeed, like many processes found in nature, there is no "smallest" or "largest" drop size of the spray. This is inherent in the normal or Gaussian distribution used to describe many naturally occurring phenomena.

Droplet sizes away from the mid-range simply occur less frequently. Practical measurement techniques span only a finite range of sizes, so they inherently lose some information about the spray size distribution in the wings of the distribution.

Mathematical description of droplet sizes in a spray are most often presented in the form of distribution functions. Many of these distribution functions have the basic form of the normal or Gaussian distribution:

$$
f(x)=\frac{1}{s \sqrt{2 \pi}} \quad \exp \left[\frac{(x-\bar{X})^{2}}{2 s^{2}}\right]
$$


where:

$$
\begin{aligned}
f(X) & =\text { fraction which lie between } X \text { and } X+d X \\
X & =\text { distributed variable } \\
S & =\text { standard deviation of the distribution } \\
X & =\text { medtan value of the distribution }
\end{aligned}
$$

This is the familiar bell-shaped normal distribution when the fraction in a small increment, $d X$, is plotted as a function of the distributed variable, $x$. For spray characterization there is a more useful form which is the "cumulative fraction less than". This can be expressed:

$$
c(x)=\int_{-\infty}^{x} \frac{1}{s \sqrt{2 \pi}} \exp -\left[\frac{(x-\bar{x})^{2}}{2 s^{2}}\right] d x
$$

where:

$$
\begin{aligned}
C(X)= & \text { Cumulative fraction of material with a distributed variable } \\
& \text { smaller than } X \text {. }
\end{aligned}
$$

A more useful form of this expression can be obtained by changing the variable from $X$ to a variable which is the "number of standard deviations,

$$
n:
$$

The expression for $c$ then becomes:

$$
c(n)=\int_{-\infty}^{n} \frac{1}{\sqrt{2 \pi}} \exp \left[-\frac{n^{2}}{2}\right] d n
$$

This is the familiar normal curve expressed in standard deviations away from the median. It is shown in Figure 6.1. Note that there is $68.2 \%$ within \pm 1 standard deviation of the median and $98.8 \%$ between \pm 2.5 standard deviations.

\subsection{SIZE DISTRIBUTION OF BLACK LIQUOR SPRAYS}

The above expressions were presented using a distributed variable, $x$, instead of droplet diameter, $D$, because for most sprays the droplet diameter is not distributed in the manner of a normal curve. This is illustrated in Figures 6.2 and 6.3 for some black liquor spray size distributions. The data in Figure 6.2 are spray distributions for a B\&W splashplate nozzle taken by the B\&W Alliance Research Labs., while those in Figure 6.3 are for both CE swirl cone nozzles and B\&W splashplate nozzles taken by IPST. Both sets of data are plotted as the Cumulative Per Cent Less Than a Given Diameter versus Droplet Diameter. All the data show an "S-shaped" curve, but the top portion of the curve is much longer than the 
bottom portion. If the droplet diameter were normally distributed, then the curves in Figures 6.2 \& 6.3 should look like that in Figure 6.1 ; $1 . e$. the tall should be as long as the head.

From a comparison of Figures $6.1,6.2$, and 6.3 it can be concluded that droplet diameter for black liquor sprays is not normally distributed about the median droplet size. This is a common result for most spray situations and for many other physical processes such as pulverization. Other size distributions are developed to describe the Cumulative - Percent - Less Than as a function of Droplet or Particle Diameter. These distributions often rely on the form of the normal distribution but use a function of the diameter as the distributed variable. One widely used distribution is the log-Normal distribution. For this distribution it is assumed that the logarithm of the diameter is normally distributed. This is often very good for fuel and mineral pulverization, for example. For spray situations a Square Root-Norinal distribution has been more successful.

\subsection{DISTRIBUTION FUNCTION FOR BLACK LIQUOR SPRAYS}

Distributions other than the norinal distribution are, for the most part, simply handy empirical expressions to describe complex distribution data. Judgment of the utility of a given distribution function to describe spray or particle size distribution is based on comparison of certain plots of the data. The most common application of this is a log-normal plot. The data are plotted on a grid with one axis being a logarithm scale while the other is a normal scale. The normal scale is linear in the number-ofstandard-deviations away from the median, $n$. It is usually shown as Cumulative - Percent - Less - Than with the scale based on the normal curve of Figure 6.1. On such a grid a true log-normal distribution would plot as a straight line.

Spray droplet size distribution data have been found to fit a Square Root-Normal curve better than Log-Normal. To provide a visual comparison for judging the plotting method, a set of curves has been presented in Figure 6.4. These four curves show how an assumed Square Root-Normal distribution would look when plotted on grids which are: square rootnormal, linear-normal, quarter root-normal, and log-normal. Of course the assumed Square Root-Normal distribution plots as a straight line on a Square Root-Normal grid. On the other grids it is decidedly curved.

One complicating factor with these plots is that the actual distribution may not follow the assumed distribution over the entire range of diameters. This is often due to an upper or lower cutoff either in the droplet size distribution or in the measuring technique. For example, in a real spray situation aerodynamic forces may break up the largest droplets, thus limiting the maximum droplet size. Another example would be the lower limit of detectibility of the measuring instrument which could limit the smallest droplet size measured. Upper and lower cutoffs modify the plots of the data in particular ways. The effect of a lower cutoff on the square root-normal distribution is shown in Figure 23. As the lower cutoff 1 imit is approached, the straight line curves downward. An upper cutoff would cause the straight line to curve upward as the upper cutoff limit was approached. 
Plots for one of the B\&W black liquor sprays are shown in Figure 6.6 using the same grids as in Figure 6.4: Square Root-Normal, Linear-Normal, Quarter Root-Normal, and Log-Normal. A straight litne is shown in the square rootnormal plot. The B\&W data are most linear in this plot, but it does curve downward at the low end Just as for the curve in Figure 6.5 for a lower cutoff $1 \mathrm{imit}$. The other three curves in Figure 6.6 are all curved at both upper and lower ends. At the lower end they curve downward in the manner of a lower cutoff limit. The curvature at the upper end of each curve is similar to that in the equivalent grid of Figure 6.4. Taken together these curves indicate that the droplet distribution for the B\&W data is best represented by a square root-normal distribution with a lower cut off.

Shown in Figure 6.7 are data for four of the B\&W sprays plotted on Square Root-Normal grids. Similar plots for the IPST spray data are shown in Figures 6.8 - 6.10 for both B\&W "plashplate nozzles and CE nozzles. Scatter in these data is evident, but all of them show nearly linear profiles at the upper end and downward curvature at the lower end. This indicates that a square root-normal distribution with a lower cut off limit will provide the best representation of black liquor spray size distributions.

\subsection{ESTIMATING THE MEDIAN DIAMETER}

Each spray measurement system will have limitations on the range of droplet sizes which can be accurately measured. Figure 6.5 showed the effect of a lower cutoff limit on the square root-normal plot of the data. Though the data from both B\&W and IPST show only a lower cutoff, there is potential for an upper cutoff. It is important to be able to estimate the impact of these measurement errors on the estimation of the true median diameter.

Figure 6.11 shows the impact of a lower cutoff limit on both the shape and the observed median diameter for four ratios of lower cutoff limit-tomedian diameter, LCO/MD - 0, 0.3, 0.6, 0.9. When LCO/MD is smal1, less than about 0.3 , most of the plot is still a straight line and the observed median diameter is very close to the true value. For larger values of LCO/MD the curve becomes progressively more curved and larger errors are incurred in the observed median diameter. Figure 6.12 shows the error in the measurement of median diameter as a function of the ratio of the lower cutoff limit to the observed median diameter. Serious errors are avoided as long as the lower cutoff is less than about one-third of the observed median diameter.

An upper cutoff limit would have a similar effect on both the curvature and the error in the observed median diameter. Figure 6.13 shows the error in the measurement of the nedian diameter as a function of the ratto of the upper cutoff 11 mit to the observed median diameter. Serious error is avoided in the measurement of median diameter as long as the upper cutoff limit is more than twice the observed median diameter.

These results indicate that plots of spray size distribution data on square root-normal grids can be used to judge the quality of the measured data. The plots should be linear through the iniddle region, the apparent lower cut off limit should be no more than one-third of the observed median, and the apparent upper cutoff $1 \mathrm{imit}$ should be at least twice the observed median. 


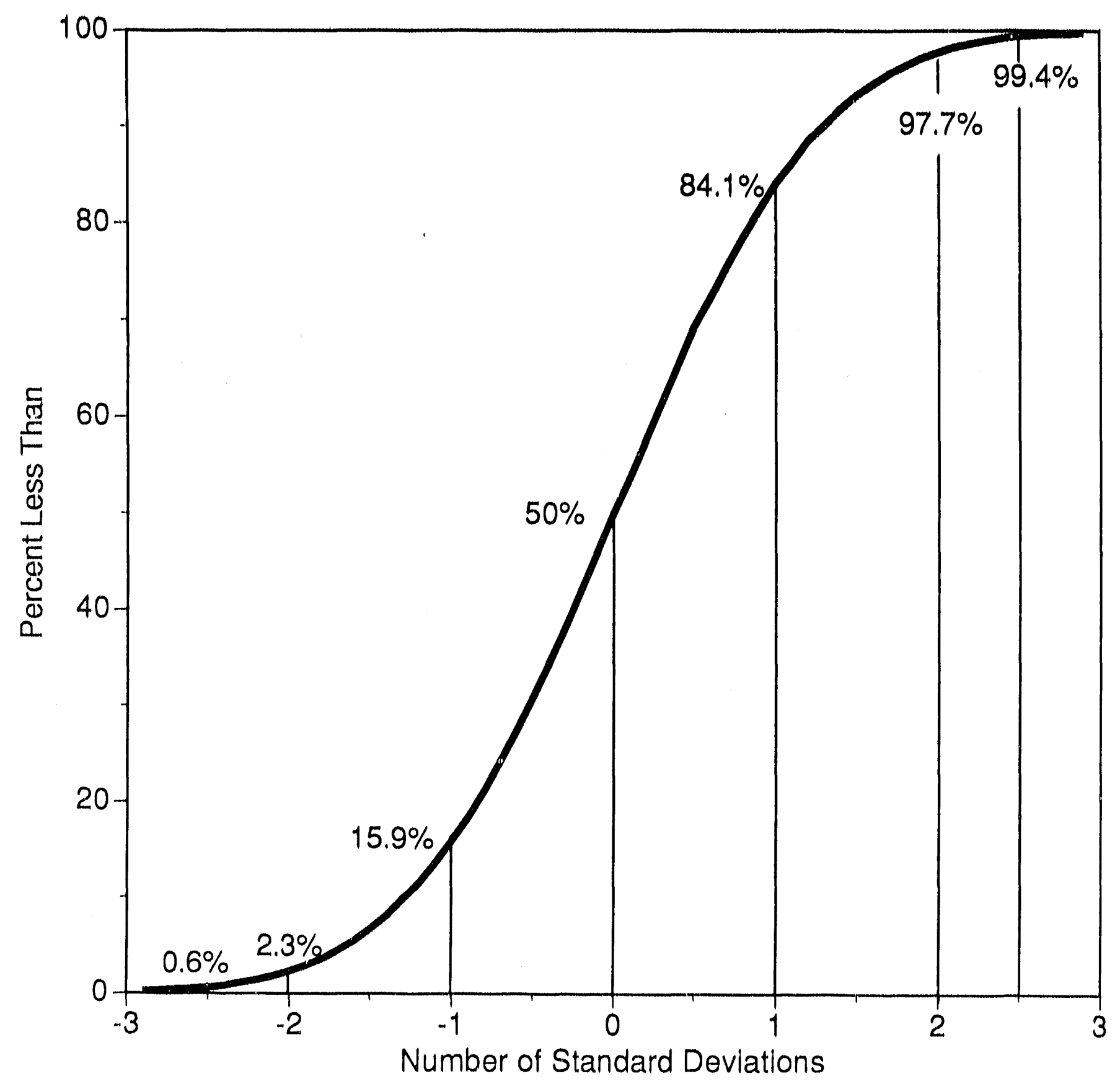

Figure 6.1. Vormal curve plotted as a function of the number of standard devtations away from the median. Note that there is $68.2 \%$ between +1 standard deviation, and $98.8 \%$ between +2.5 standard deviations. 


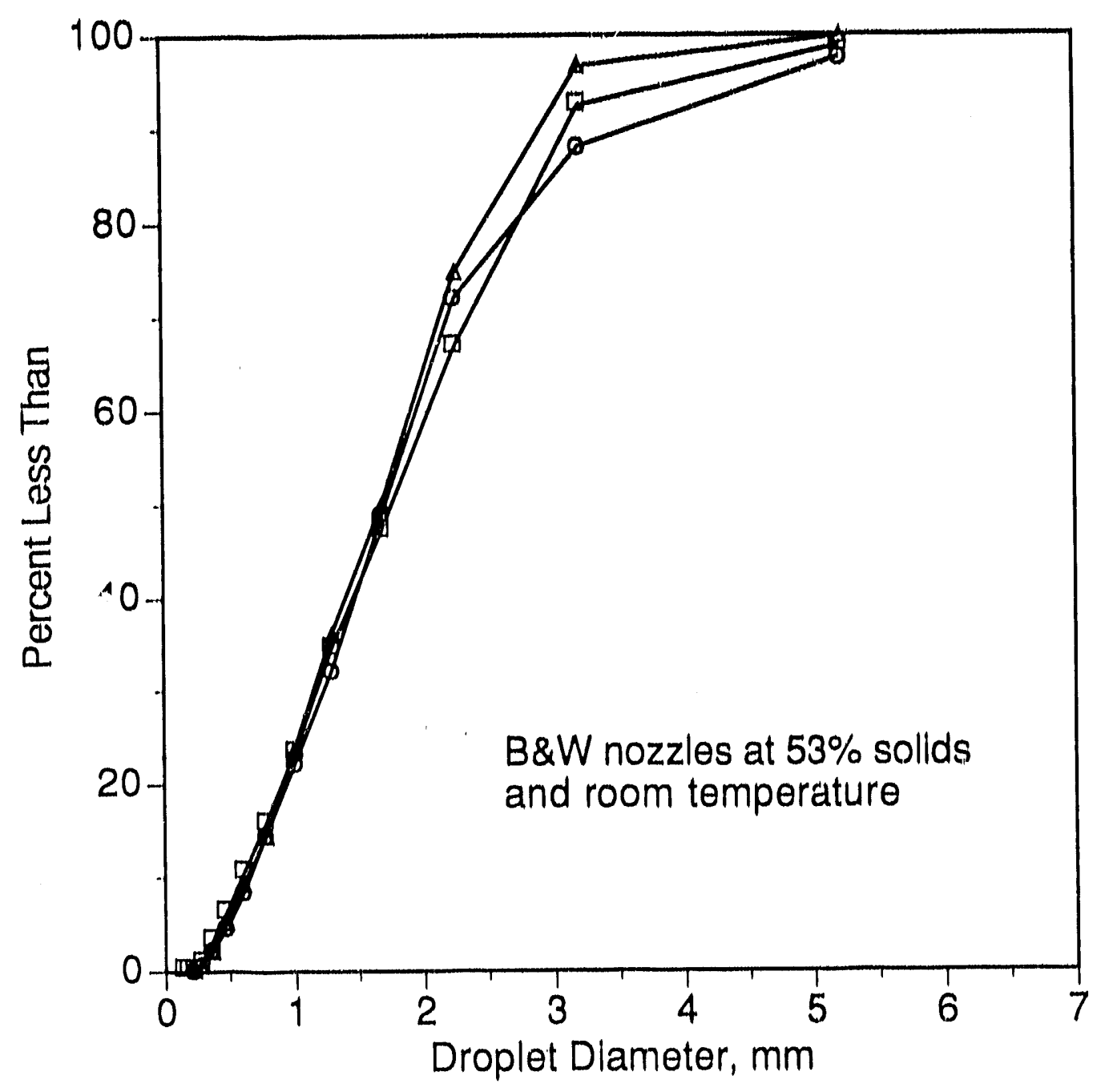

Figure 6.2. Sample plats of black llquor spray slze distrtbutton for two B\&W S.Plashplate nozzles taken by B\&W Alltance Research Center using a Malvern Analyzer. 

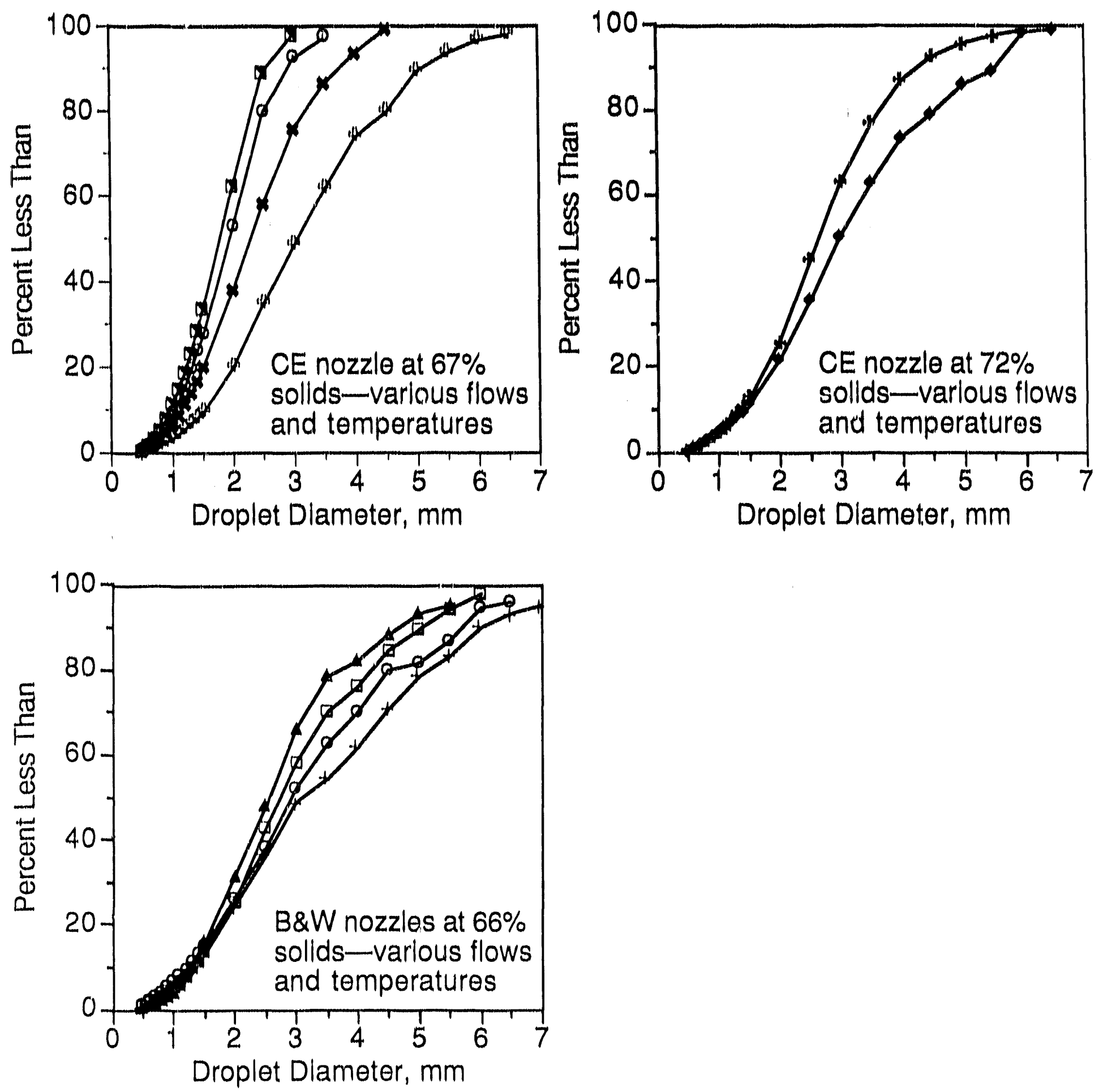

Flgure 6.3. IPST black liquor spray size distribution date for two nozzle types and vartous operating condtitions. 

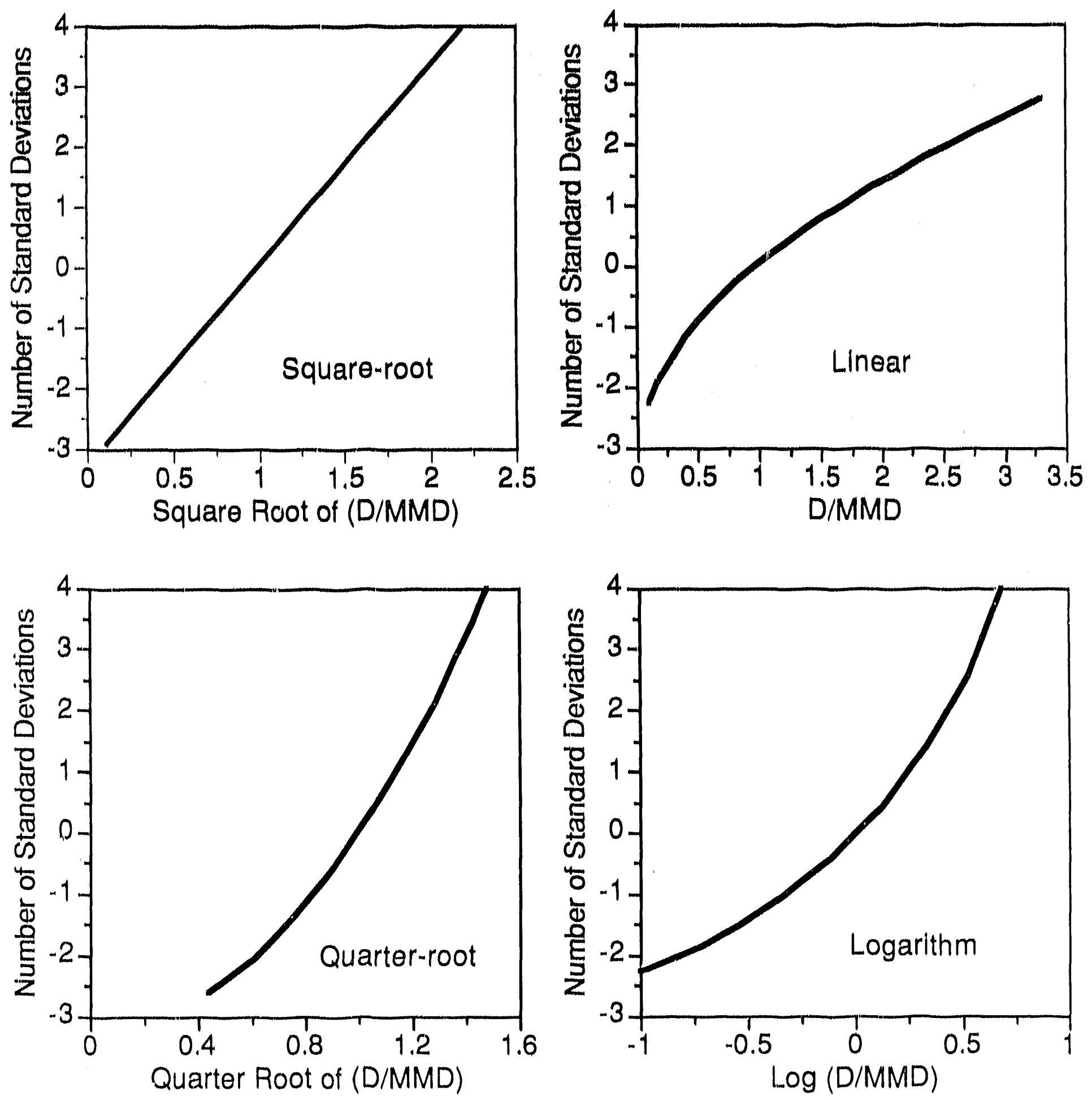

Figure 6.4. Plot of a square-root normal size distribution using four assumed scales -. square-root, 11 near, quarter-root, and logarithm. 

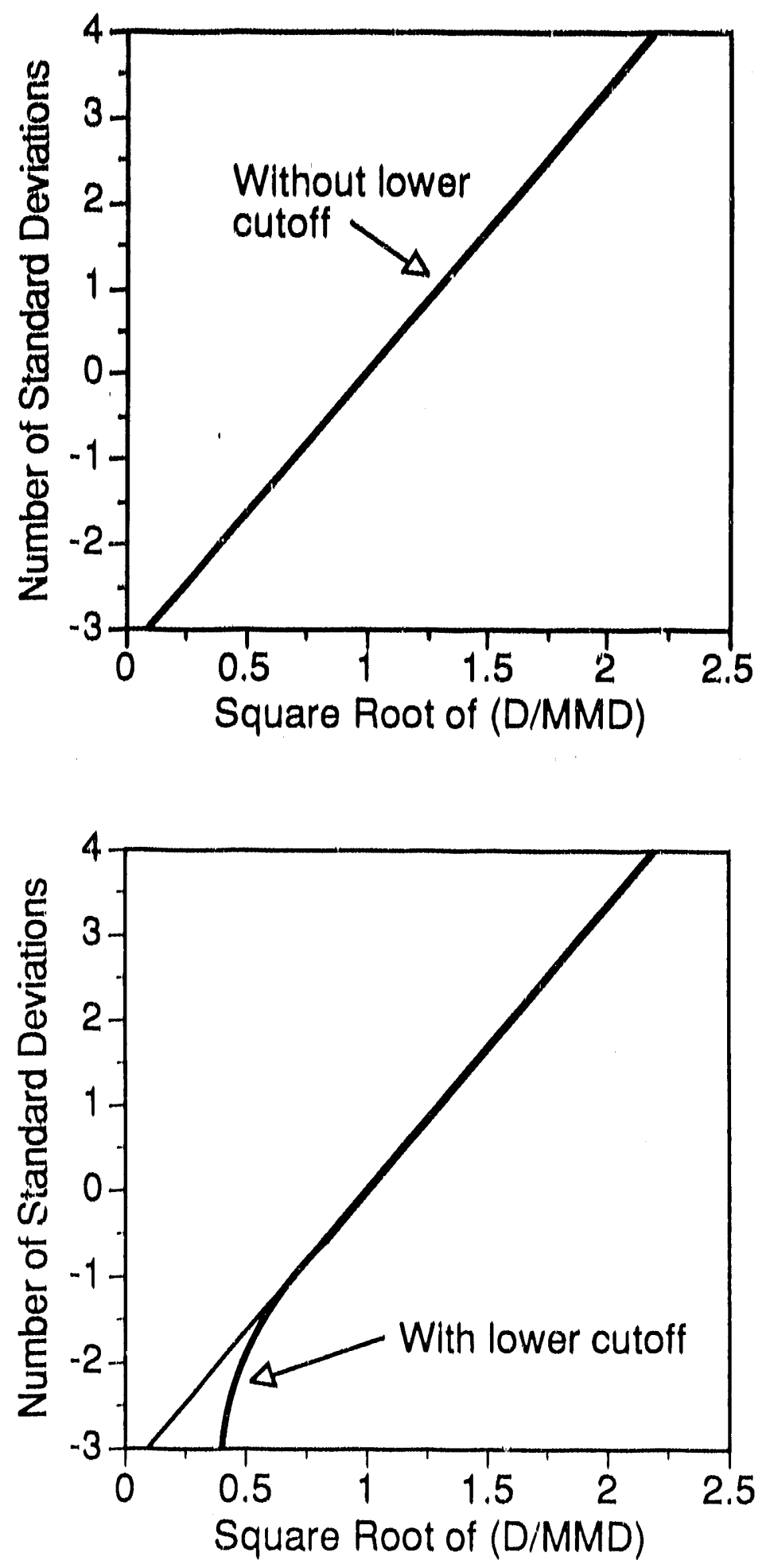

Figure 6.5. Plot of a square-root normal distribution with and without a lower cutoff limtt. 

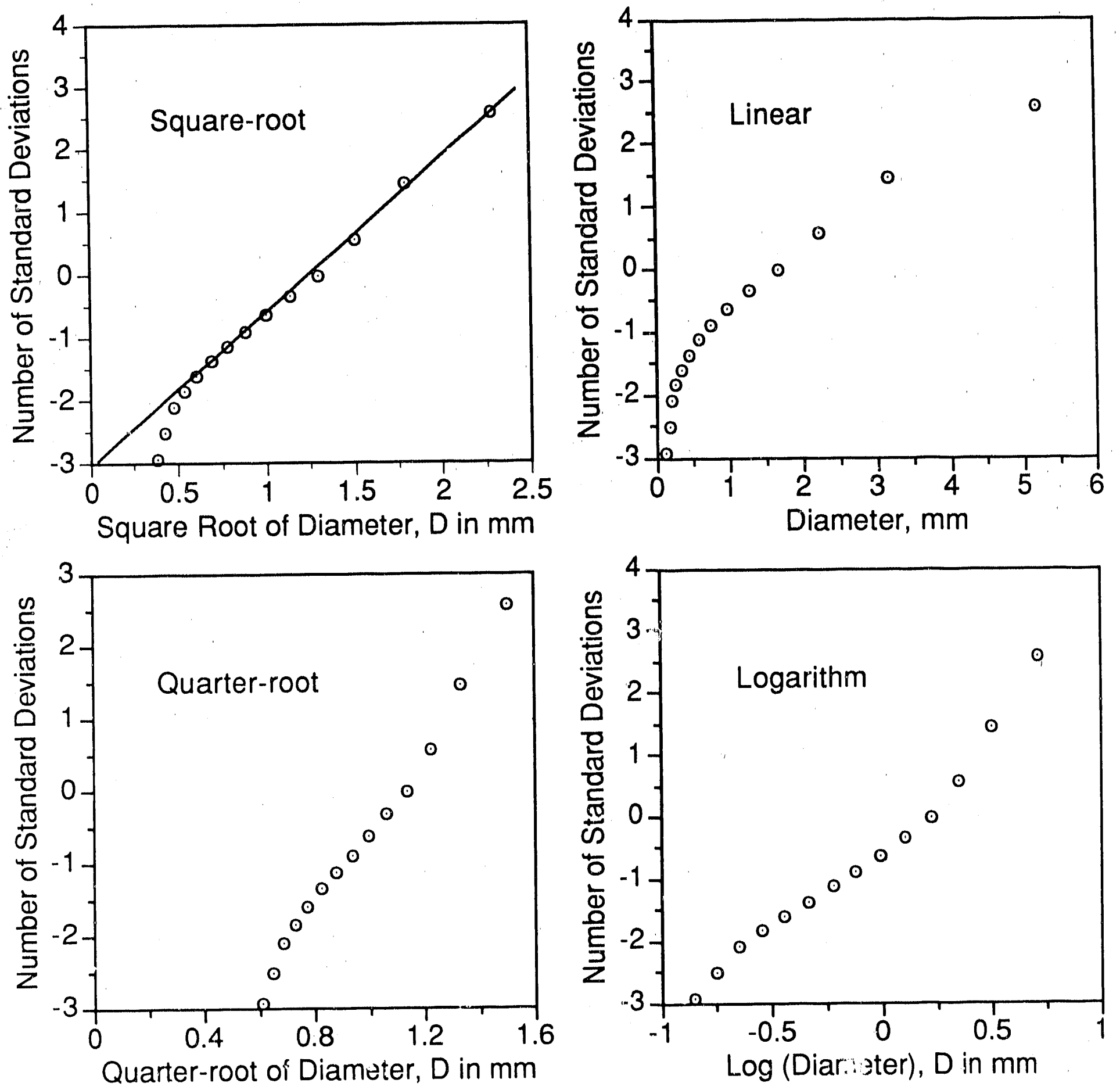

Figure 6.6. Data for one B\&w hlack spray size distribution plotted using four assumed scales -- square-root, linear, quarter-roct, logarithm. 

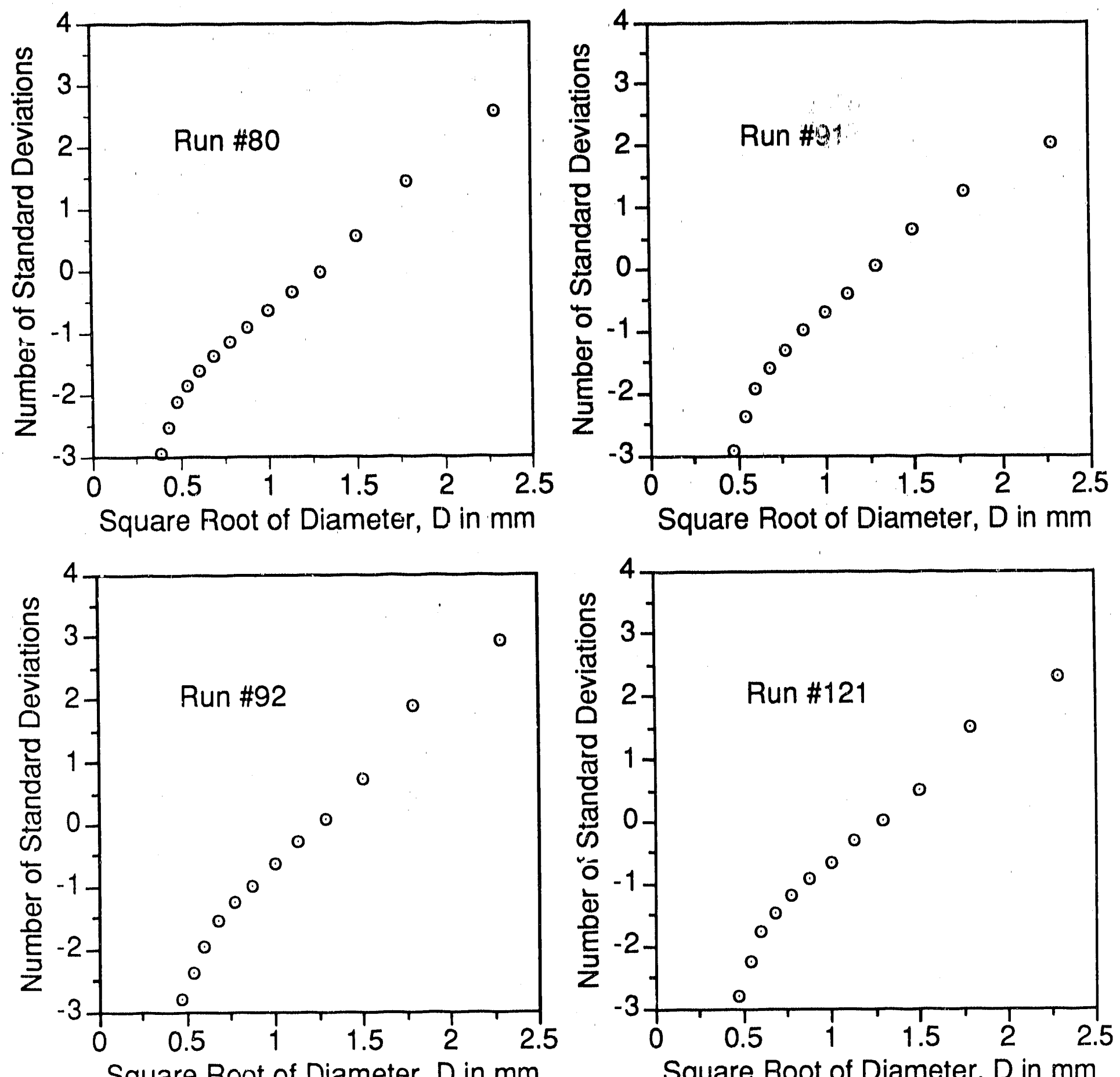

Figure 6.7. Square-root normal plots of four B\&W black liquor spray size distributions. 

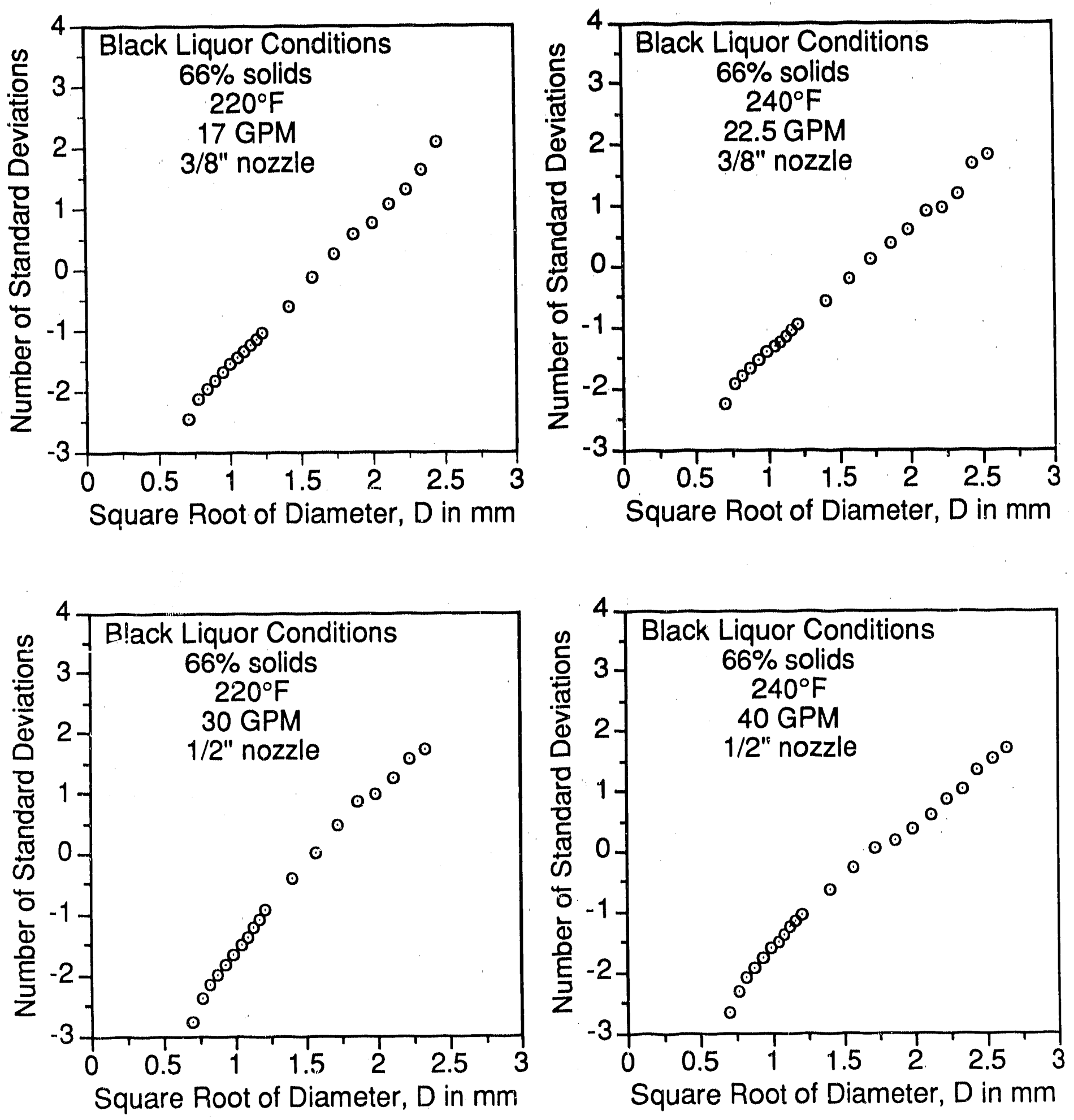

Figure 6.8. Square-root normal plots of four IPST black liquor spray size distributions for two B\&W splashplate nozzles operating at $66 \%$ solids. 

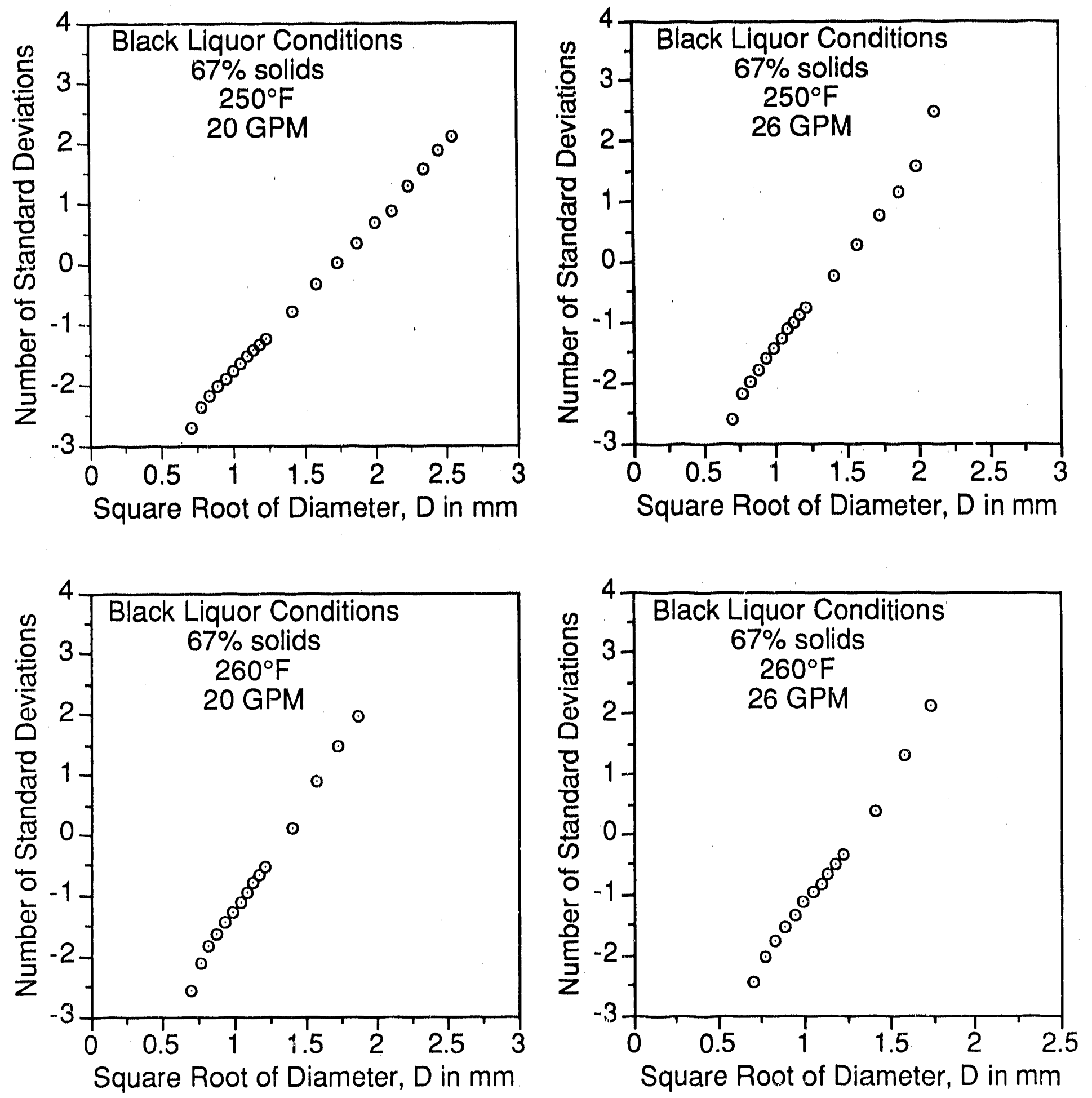

Figure 6.9. Square-root normal plots of four IPST black liquor spray size distributions for a $1 / 2$ inch CE swirl cone nozzle. 

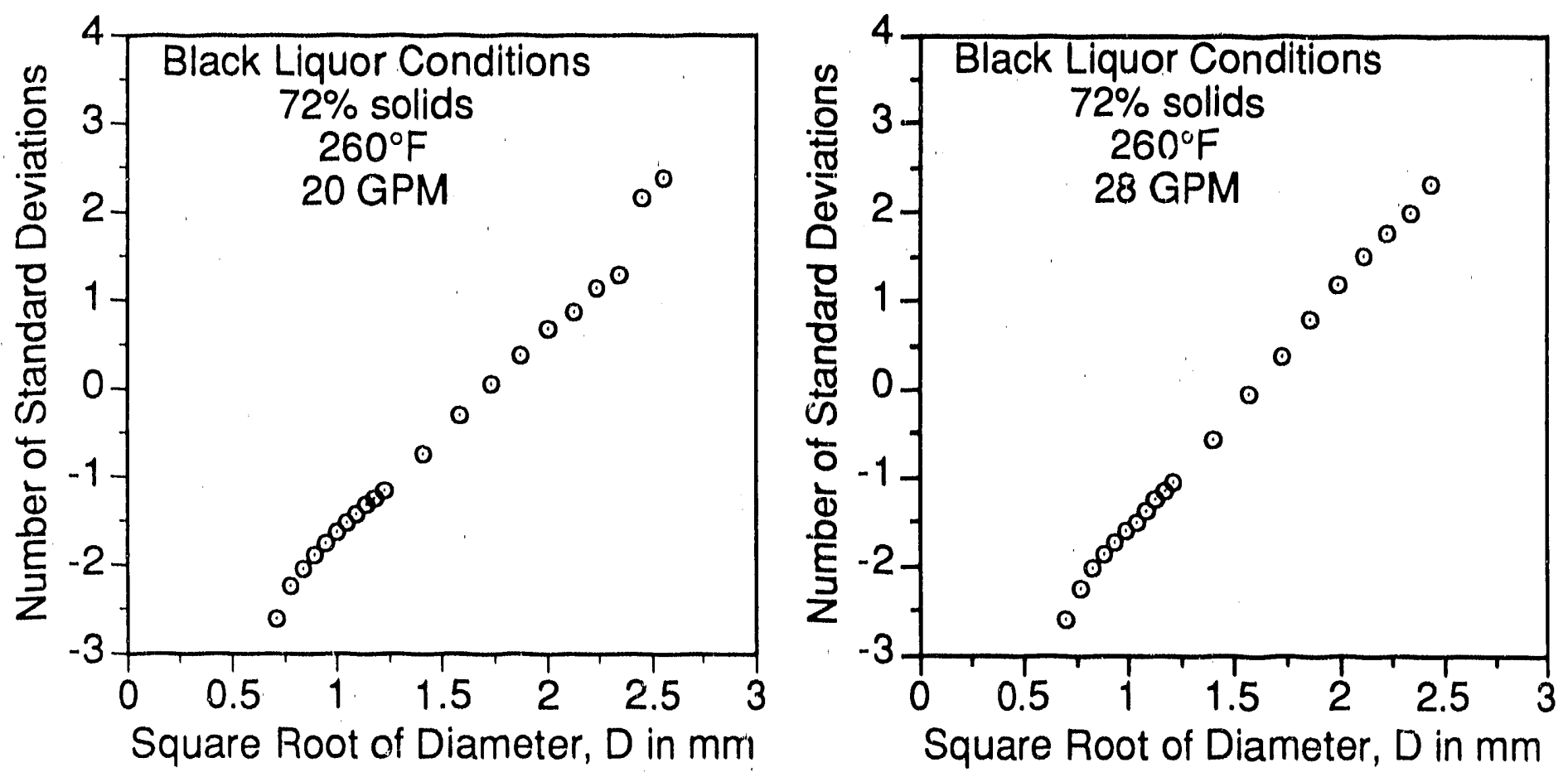

Figure 6.10. Square-root normal plots of four IPST black liquor spray size distributions for a $1 / 2$ inch CE swirl cone nozzle operating with $72 \%$ black liquor solids. 


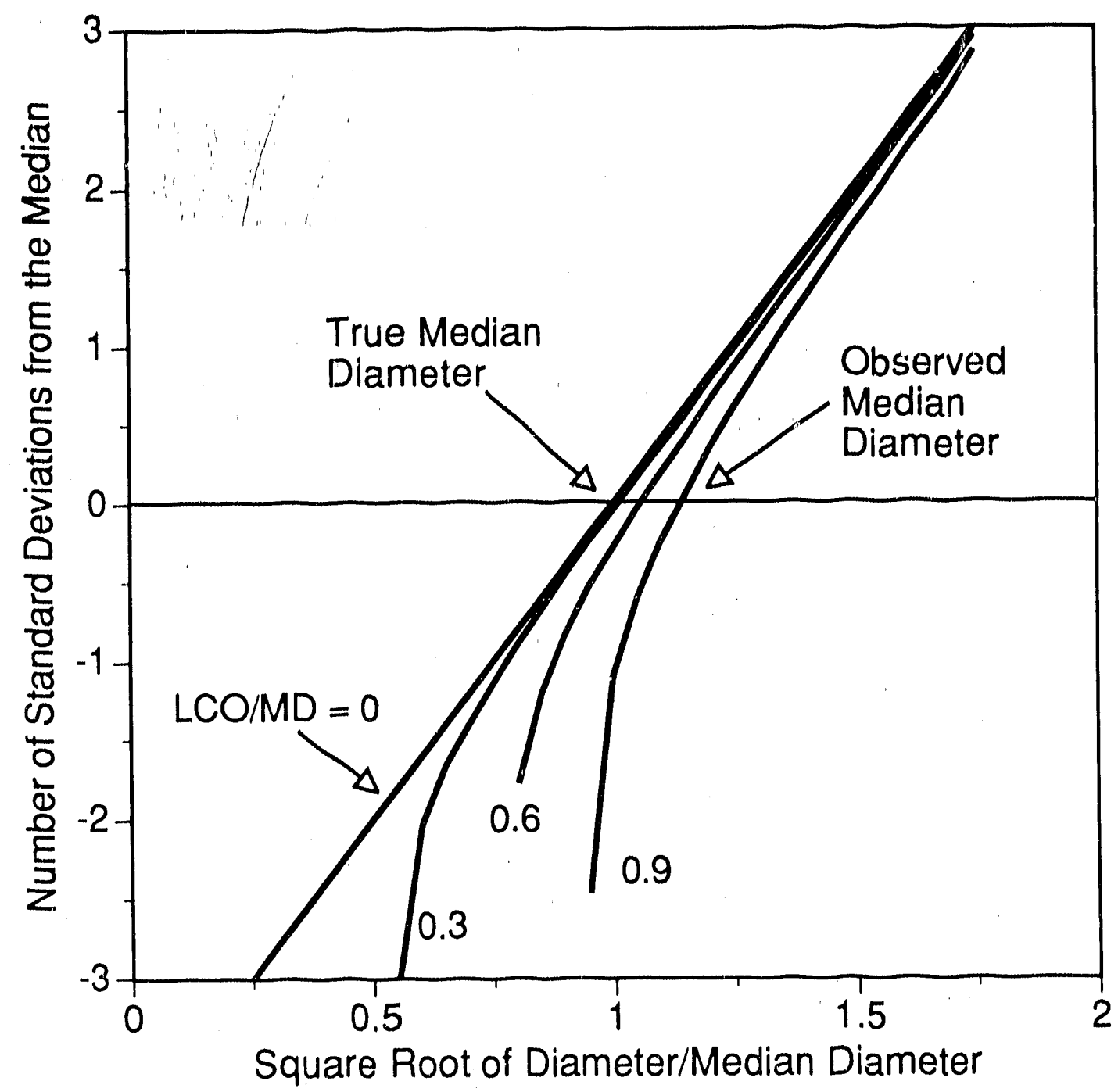

Figure 6.11. Effect of a lower cutoff limit on the square root-normal plot shape and observed median diameter for four ratios of lower cutoff limit to merlian diameter, LCO/MS $-0,0.3,0.6,0.9$. 


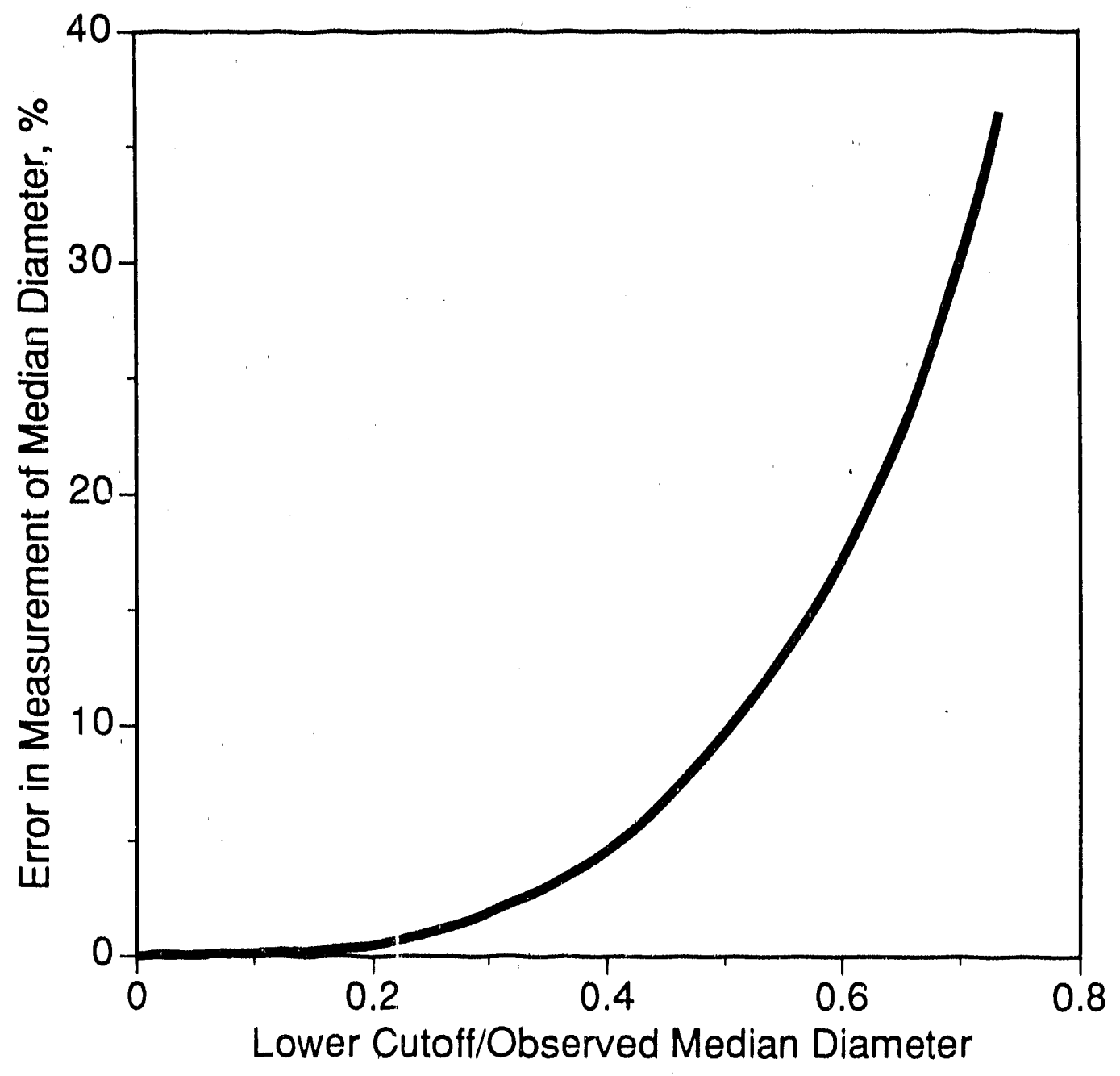

Figure 6.12. Error in measurement of the median diameter due to a lower cutoff limit. 


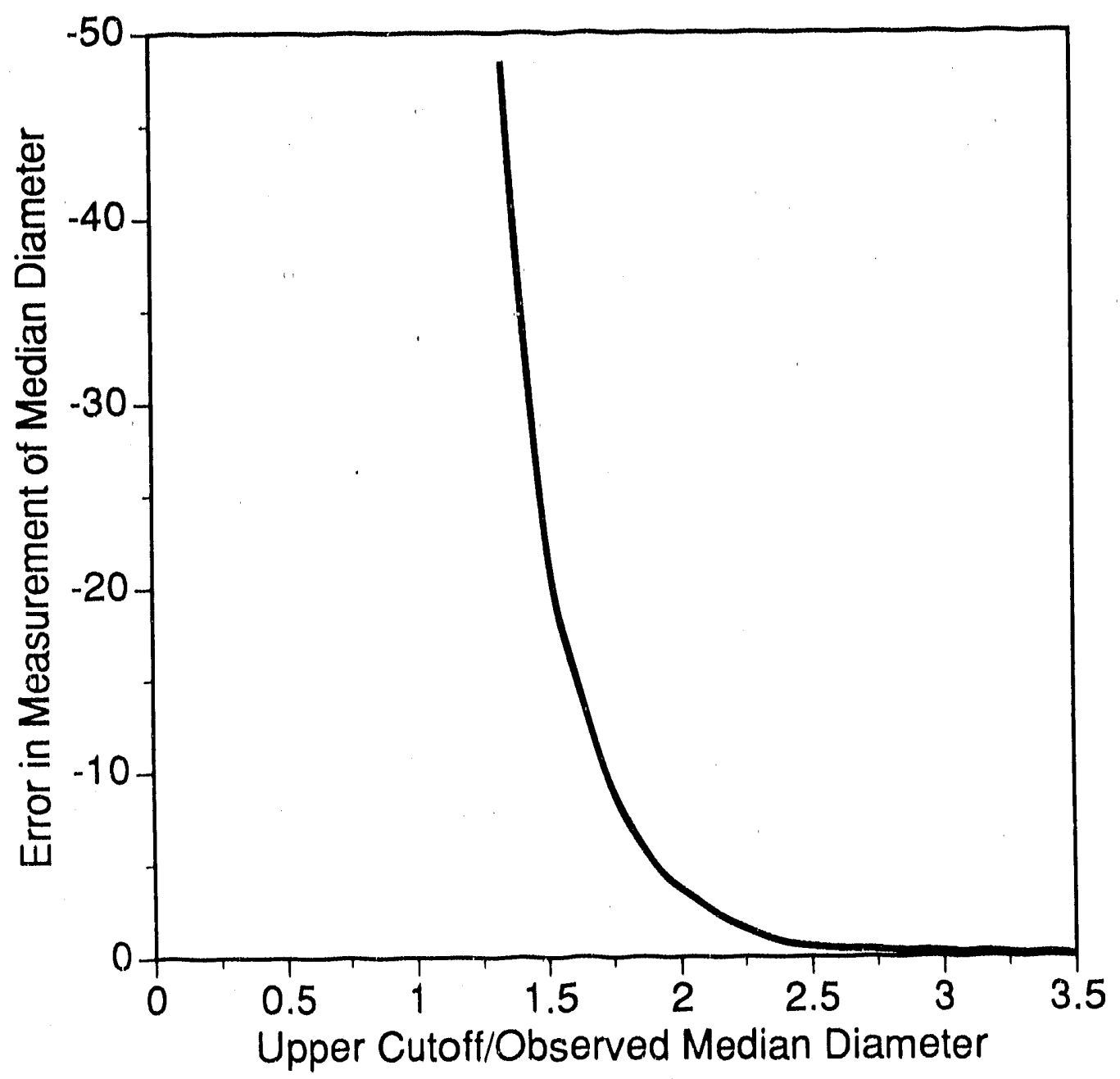

Figure 6.13. Error in measurement of the median diameter due to a upper cutoff limit. 


\subsection{FLASH X-RAY TECHNIQUE FOR BLACK LIQUOR SPRAYS}

\subsection{INTRODUCTION}

An fmaging technique based on the use of short bursts of $x$-rays has been developed at the Institute to visualize flutd flows. The technique was originally developed to capture information about ballistic or explosive events. Short bursts of $x$-rays on the order of 100 nanoseconds or less were used to obtain stop-action images. This technique allowed images to be taken within optically opaque test specimens.

The applicability of the flash $x$-ray technique (FXR) to situations relevant to the pulp and paper Industry was recognized by Ted Farringl 1. Farrington and co-workers modifted and developed this techni, er for coating and forming flows as well as sprays $(11,12)$.

Several advantages have been recognized for FXR in flow visualization -imaging flows within opaque coating flows, stop-actions of impulse drying events, stop-action of droplet formation. Under proper circumstances, excellent resolution on the order of $1.00 \mathrm{~mm}$ is possible. However, the constraints on system arrangement for good resolution and fimage contrast are relatively rigid. The ifmitations of the FXR technique for inaging industrial scale black liquor sprays is presented below.

7.2 Image Blur or Penumbra

The Flash $X$-ray technique is similar to ordinary medical $x$-ray both in terms of general arrangement and dose. The signiffcant difference comes in the very short duration of the $x$-ray burst with FXR. X-rays are generated at a source, travel in straight lines away from the source, are partially absorbed by various media, and expose fllm sheets specifically manufactured for sensitivity to $x$-rays. The image on the film is a shadow of the objects located between the source and the film. The image density and image contrast depend on the absorptivity of objects for x-ray radiation.

The image sharpness or resolution of a film exposed by FXR depends on the specific geometry of the source, object, and film as well as on the $x$-ray source size. Because FXR is a shadow technique, the geometry is very straightforward. Shown in Figure 7.1 is the general geometric layout of the source, object, and film. The example situation depicted in this figure is for a black liquor drop being linaged with the Hewlett-Packard $150 \mathrm{KV}$ Flash $X$-ray Source. Not shown are the film holder and screens which are used to protect the film and enhance the image.

All $x$-ray sources liave a fintte size. The HaP 150kV source is approximately $3 \mathrm{~mm}$ in diameter. Just as with ordinary visible shadows, the specific geometry of source, object, and film can affect the magnification of the shadow. On top of this is the blur or penumbra due to the finite source size. The three $x$-ray lines show that a partial shadow will surround the 
Image that would be formed with an infinitesimally sinall source (that assoclated with the middle of three $x$-ray ines). The magnitude of the blur depends on the size of source, the source-to-film distance, and the objectto-film distance. The simple equation for blur is:

$$
\text { Blur }=\quad \frac{\text { OTFD }}{\text { STFD-OTFD }} \times S
$$

where:

$$
\begin{aligned}
S & =\text { source size, } \mathrm{mm} \\
\text { OTFD } & =\text { object-to-film distance, } \mathrm{cm} \\
\text { STFD } & =\text { source-to-f } 11 \mathrm{~m} \text { distance, cm }
\end{aligned}
$$

For example, with a $3 \mathrm{~mm}$ scurce, an OTFD of $15 \mathrm{~cm}$ ( 6 inches), and a STFD of $150 \mathrm{~cm}$ ( 60 inches) the blur is $0.33 \mathrm{~mm}$. This would significantly complicate timage analysis of droplets smaller than $0.5 \mathrm{~mm}$.

Minimizing blur for a particular application primarlly involves correct posttioning of the source and $f 11 \mathrm{~m}$ with respect to the object being studied. The next sections deal with constraints on OTFD and STFD for industrial scale black liquor sprays.

\subsection{BLACK LIQUOR SPRAY THICKNESS}

Investigation of black 1iquor sprays and spray nozzles $[16,18]$ has confirmed that the basic mechanism of droplet formation is identical to that for other pressure-atomized nozzles. The mechanism of spray formation is deptcted in Figure 7.2. Typically, the spray nozzle transforms the fluid approach flow into a flat or conical sheet. The fluid sheet leaves the top of the nozzle and soon begins to oscillate. The expanding fluid sheet thins out as it moves away from the nozzle. The oscillation breaks the thinning sheet into fluid ligainents which subsequently break down into droplets.

The important feature of sheet break up for the present discussion of $x$-ray image quality is the sheet oscillation. These oscillations give the droplets a range of trajectories. All the droplets generally move away from the nozzle, but their flight paths lie in a range of angles on either side of the illitial sheet flight path. This causes the spray volume to thicken with distance away from the nozzle.

The spray facllity at IPST incorporated a spray booth with an integral collection tank. The width of the collection tank was $1.2 \mathrm{~m}$ (4 feet). A spray nozzle was attached to a mounting apparatus located approximateiy 2.1 $\mathrm{m}$ ( 7 feet) above the collection tank. Sprays were directed downward to the collection tank with the wide spray fan oriented parallel to the long dimenston of the spray tank, which was approximately $3.1 \mathrm{~m}$ (10 feet). With this arrangement the width of the spray in the direction perpendicular to the sheet fan could be determined by observing the width of the splash pattern on the surface of the liquor pond in the collection tank. 
Many spray nozzles have been collected and tried in the spray booth. However, a majorlty of the spray testing has been carrled out on two B\&W splashplate nozzles - a 12-49 and a 15-52. These nozzles are at the very smallest end of the spectrum of black liquor nozzles used in commerclal service. With elther of these nozzles the spray/shaet thickness near the nozzle is quite small, generally less tharl $1 \mathrm{~cm}(0.4$ inches). However, when the spray hits the collectloll tunk pond, the splash pattern is nearly the full width of the tank, about $1.2 \mathrm{~m}$ (4 feet). Between these two locations the thickness vartes in the approxtmate shape of a wedge.

The important point of these observations is that the width of the spray, and therefore the object-to-film distance, is relatively large. Over most of the region of 1 igament break up and droplet formation the spray is more than $0.3 \mathrm{~m}$ ( 1 foot) thick. To protect the $x$-ray film and film holder apparatus, the object-to-fllin distance would have to be slightly greater than this.

The $x$-ray limage quality is strongly affected by the object-to-fillm distancc (OTFD). For small-scale sprays or for larger sprays near the nozzle OTFD can be quite modest, less than a few centlmeters. However, to observe the droplet formation process of ultimate droplet size distribution of industrial-scale spray, the OTFD will be greater than $15 \mathrm{~cm}$ ( 6 inches).

\subsection{I.IMITATIONS OF THE SOURCE-TO-FILM DISTANCE}

The physical properties of industrial sprays set bounds on the OTFD. The other important dimension is the source-to-filim distance, STFD.

The blur equation presented above depends on both the OTFD and the STFD. For any given $x$-ray source stze the blur can be reduced by decreasing the OTFD or increasing the STFD. Limftation on the minimum x-ray dose to expose the fflm and the absoiptivity of air sets an upper 1imit on the STFD.

Each $x$-ray source produces an inttial dose of radiation. This initial dose is usually specified at a location $20 \mathrm{~cm}$ in front of the source. The unit of measure is typically milli-Roentgen (mR). For the H-P 150kV source the dose at $20 \mathrm{~cm}$ is $40 \mathrm{mR}$. The dose requitred to produce an image on $x$-ray fflm varies with specific film type and other considerations such as whether or not enhancing screens are emplayed. Direct Exposure Fl1m (DEF) has been used for the black liquor spray work. It has been found to be the most effective in this application [21]. The required dosage to expose DEF film is approximately $1 \mathrm{mR}$.

$x$-ray dosage decreases with the square of the distance from the $x$-ray source. This rapidly drops the dosage away from the source. As well, atr absorbs $x$-rays, further reducing the dosage avatlable to expose the film.

$x$-rays interact with the electrons which surround individual atoms; so all materials absorb or scatter $x$-rays. The attenuation of $x$-rays passing through a material is expressed as:

$$
\frac{D}{D o}=e^{-\mu a e} 1
$$


whare:

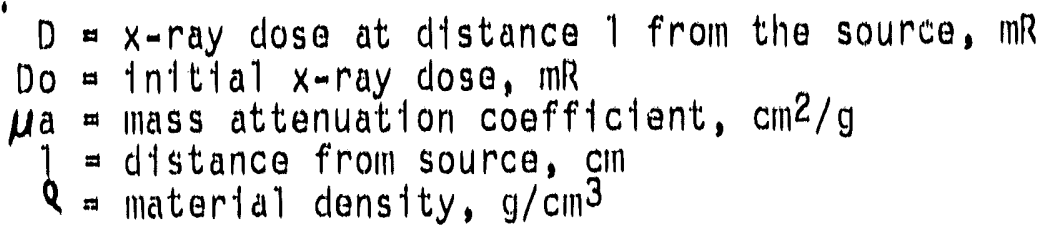

The mass attenuation coefflctent, $\mu a$, is only a constant for monoenergetlc $x$-rays. All $x$-ray sources put out a spectrum of $x$-rays. This is shown in Flyure 7.3. This spectrum is specifilcally for an H-P $300 \mathrm{kV}$ source simtlar to the unit used at IPST for black liquor spray timaging. X-rays with photon energies less than $10 \mathrm{keV}$ are referred to as soft $x$ mays. Those above $100 \mathrm{keV}$ are hard $x$-rays. Most $x$-ray lmaging of soft matertal is done with the softer $x$-rays.

The vartation of the mass attenuation coefficient with $x$-ray energy for varlous materlals is shown in Flgure 7.4. Larger, heavler atoms absorb $x$-rays more effictently. Aluminum, copper, and tungsten are all better absorbers than carbon. Oxygen and nitrogen will be better than carbon, whlle hydrogen will be worse than beryllium. Sodtum and sulfur will be similar to aluminum.

Materials can both absorb and scatter x-ray radiation. Usually, only absorption is important in forming an tmage on a film. This 1imits the maxtmum inoton energy which can be effectively used in FXR. For carbon, $x$-rays hirder than $15 \mathrm{keV}$ will not contribute to image formation. For air, water, aild black liquor only $x$-rays softer than 20 koV will be important in FXR optinization of tmage qualtty.

oxygen and nitrogen in atr both absorb x-rays more strongly than carbon. $x$-ray close will fall off with distance away from the source due both to the $r$-squared loss and to absorption by the alr. Shown in Figure 7.5 is a plot of the dosage as a function of distance from the source (expressed as STFD) for travel through a vacuum or through aitr. The absorption by ait was calculated from data on mass attenuation coeffictent est tmated from Figure 7.4 using the $x$-ray energy spectruin of Figure 7.5 . In both the vacuum and the atr cases the dosage falls off very rapldiy with STFD. Dosage falls below that requited to expose the fllim, about 1 in $R$ in a distance less than $100 \mathrm{~cm}$ ( 3 feet).

Based on the available data, the maxtmum STFD is approxlmately $100 \mathrm{~cm}$ (3feet). From the discusston above, the mintmum OTFD for industrial-scale sprays is approximately $15 \mathrm{~cm}$ ( 6 tnches), while the $x$-ray source size is about $3 \mathrm{~mm}$. Using Equation $(7-1)$, the expected level of blur is then approximately $0.5 \mathrm{~mm}$.

\subsection{X-RAY IMAGE CONTRAST}

The relatively large blur imposed by constraints on both OTFD and STFD complicates the task of linaging black liquor droplets which are typically $0.1 \mathrm{~mm}$ to $5 \mathrm{~mm}$ in size. Adding to the difficulty of triage analysis is the limtted contrast that can be achieved with such small droplets. 
Contrast is the difference in gray-scale intiensity between the firage of a droplet shadow and the background. The droplet absorbs some of the $x$-rays strlking $1 t$, thus lowerlng the dosage at the film. However, smaller droplets absorb a lower fraction of the $x$-ray dose, thus narrowing the difference between the shadow and the background.

A.r and black liquor have simllar mass attenuation coefflctents. Based on Equation $(7-2)$ this means that differences in absorption by these two matertals depends on differences in denstty and path length. Alr and black liquor densittes are such that $x$-ray absorption by one meter of alr a typtcal STFD) is stintlar to that for one millimeter of black liquor a typlcal droplet size). This is shown graphically in Figure 7.6 where the absorptivity of $1 \mathrm{~m}$ ( 3 feet) of air is compared to that for $1 \mathrm{ill}$ (3 feet) of atr plus $1 \mathrm{~min}(0.04$ inches) of black liquor. Image contrast is due to the difference in these two curves.

The geometry of Figure 7.1 can be used along with the absorptivity data to predict the gray level varlation of the shadows of black liquor droplets. The vartation in gray level for a droplet is shown schematically in Figure 7.1 for a STFD of $1.5 \mathrm{~m}$ (60 inches) and an OTFD of $0.15 \mathrm{~m}$ ( 6 inches). These are very conservative values for each. The gray level of the background without droplet absorption is taken as 1.0 while complete absorption is 0.0 . The absolute value of the gray scale of the background vartes due to geometric arrangement, attenuation due to distance from the $x$-ray source, and absorption by atr. Flgure 7.7 shows the vartation in relative gray level with distance away from the droplet shadow centerline for several black 1 iquor droplet sizes. The contrast, or difference in gray level, for the 1.0, 2.0, and $5.0 \mathrm{~mm}$ droplets is quit te good. Images on the $x$-ray film of these droplet stzes would be relatively easy to analyze.

The contrast for the $0.5 \mathrm{~mm}$ droplet is borderline for good timage qualtity. As well, the effect of blur can be seen clearly for this stze droplet. The width of the timage of the $0.5 \mathrm{~mm}$ droplet is more than $1.0 \mathrm{~min}$ wide. Contrast for 0.2 min droplets is very poor and blur would make size analysts very difficult.

The predictions of limage qualtty in Figure 7.7 are based on data for matertal absorption and $x$-ray source energy spectrum. They are only approxlinate, but Ftgure 7.8 shows an actual FXR shadowgraph of a black ifquor spray. The general features of droplet formation are shown quite clearly in this shadowgraph. The fluid sheet has broken into ligaments which are breaking into droplets. Closer examination, however, shows that shadows smaller than 2.0 minl have poor contrast with the background. Very few shadows smaller than 1.0 miln can be seen in this or any other shadowgraph of an industrial scale black liquor spray. This severely ifints the utility of the FXR technique for deterinining droplet size distribution.

This 1fmitation on the FXR tecintque is not necessartly true of other geometries. Shorter OTFD can dramatically lmprove the resolution of the $x-$ ray tmage. Using the same prediction techntque as before but with an OTFD 
of $0.025 \mathrm{~m}$ ( $1 \mathrm{inch}$ ), the relactve gray level of a $0.1 \mathrm{~mm}$ clay sphere can be predlcted. This is shown in Flgure 7.9. Reasonable contrast and a quite narrow limage are obtalned with this simall OTFD. As before, this predicted result is conflrined by a FXR timage of a simall spray in Figure 7.10. Signiftcantly better resolution is apparent in Figure 7.10 than was the case in Figure 7.8 .

\subsection{CONCLUSIONS}

The limltatlons of the Flash $X$-ray Shadowgraph technlque have been examtned as they upply to industrtal scale black liquor spray analysts. Several conclustons can be drawn:

1. FXR is a shadow techntque which forms an lmage on an xuray film due to absorption by the object being investigated.

2. Resolution of the resulting limage is important for timage analysts. Resolution is reduced by biur which depends on simple geometric relathonshtp of the $x$-ray source, the object, and the film.

3. Industrlal scale black liquor sprays are more than $15 \mathrm{~cm}$ (6 inches) thick. This sets the lower linit for the object-to-ftlm distance, OTFD, for the application of FXR.

4. Attenuation of the $x$-ray dose with distance from the source is due both to absorption of $x$-rays by atr and the usual inverse square-law for optical power. This, along with the inintimum dosage needed to expose the $x$-ray film, limlts the imaxtinum source-to-fflin distance, STFD, to approximately $\lim (3.3$ feet $)$.

5. Combining the mintmum OTFD and the maxtmum STFD results in a blur of approximately $0.5 \mathrm{~mm}$ (0.02 inches). This significantly 1 intts the resolution of droplet sizes below $1 \mathrm{~mm}$ ( 0.04 inches).

6. The absorption of $x$-rays by black liquor is simllar to that for atr at the same optical depth. This makes the absorption of $x$-rays by $1 \mathrm{~m}$ $(3.3$ feet) of atr nearly the same as for $1 \mathrm{~mm}(0.04$ tnches) of black itquor.

7. Image contrast on the $x$-ray filin is due to $x$-ray absorption by the object. Black Ilquor ts a relatively weak absorber so that the contrast for droplets smaller than $0.5 \mathrm{~mm}(0.0$ ? inches) is poor. 


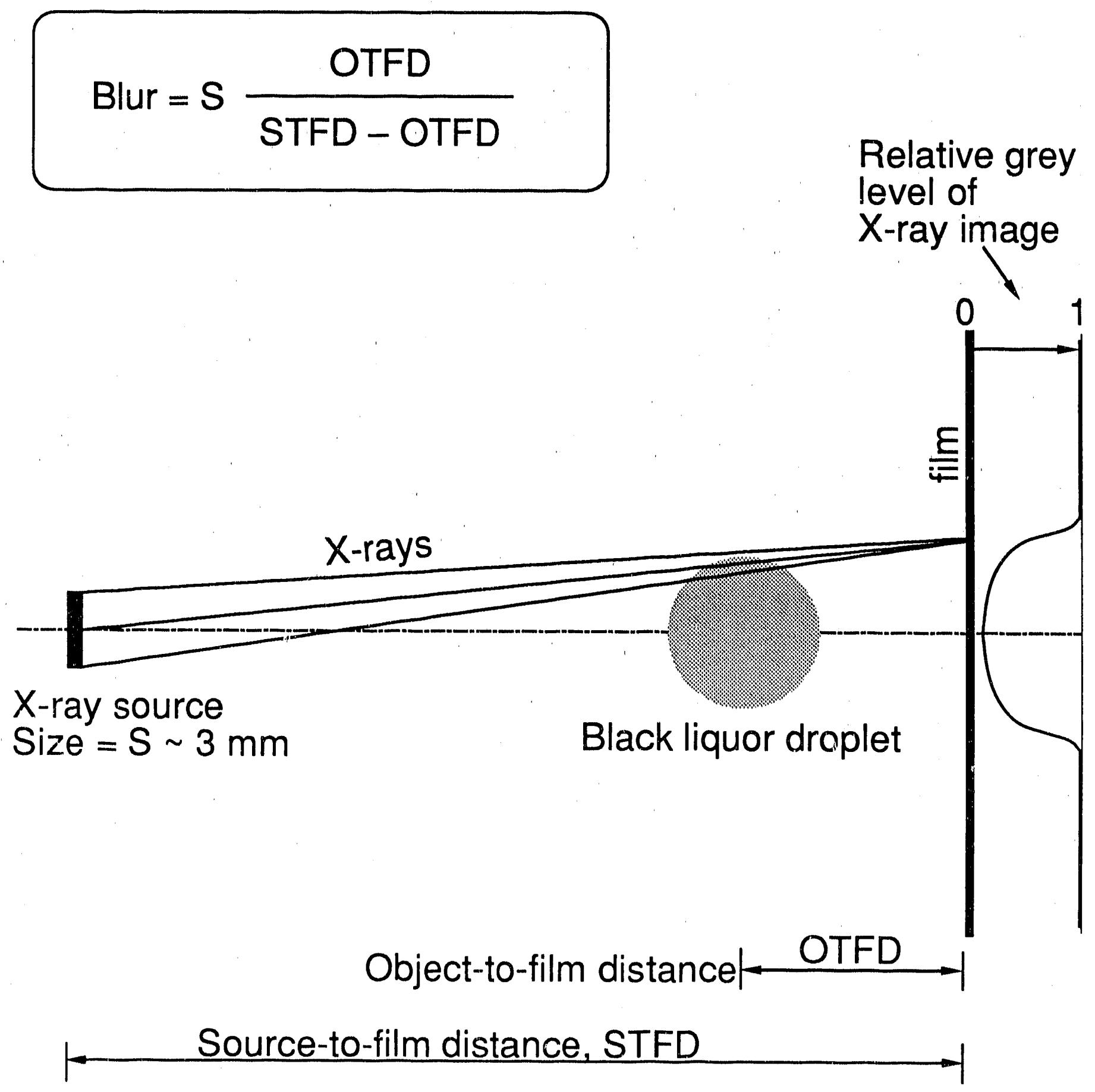

Figure 7.1. Geometry for x-ray absorption and image grey level on the film. 


\section{Liquid sheet}

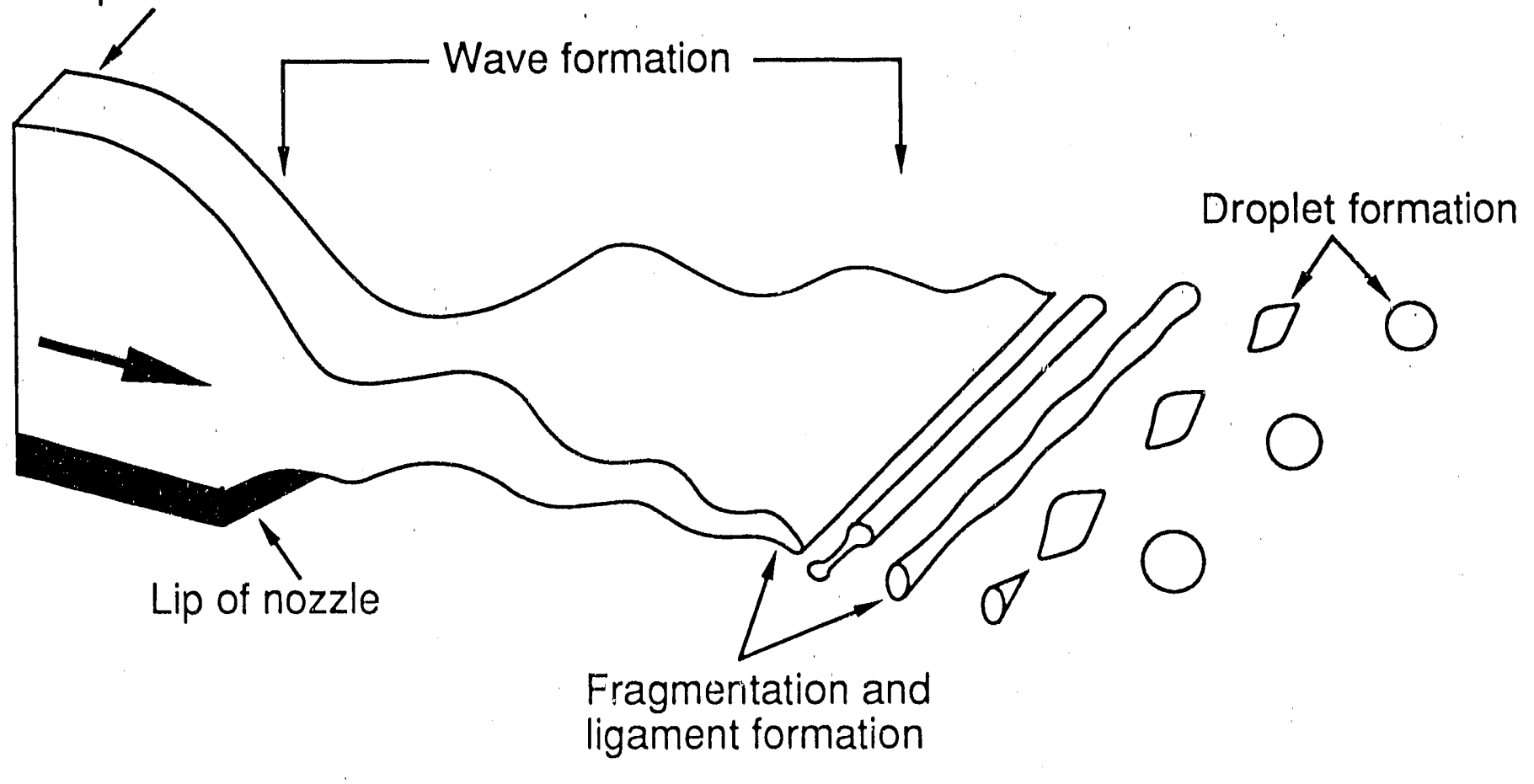

Figure 7.2. Droplet formation by liquid sheet disintegration. 


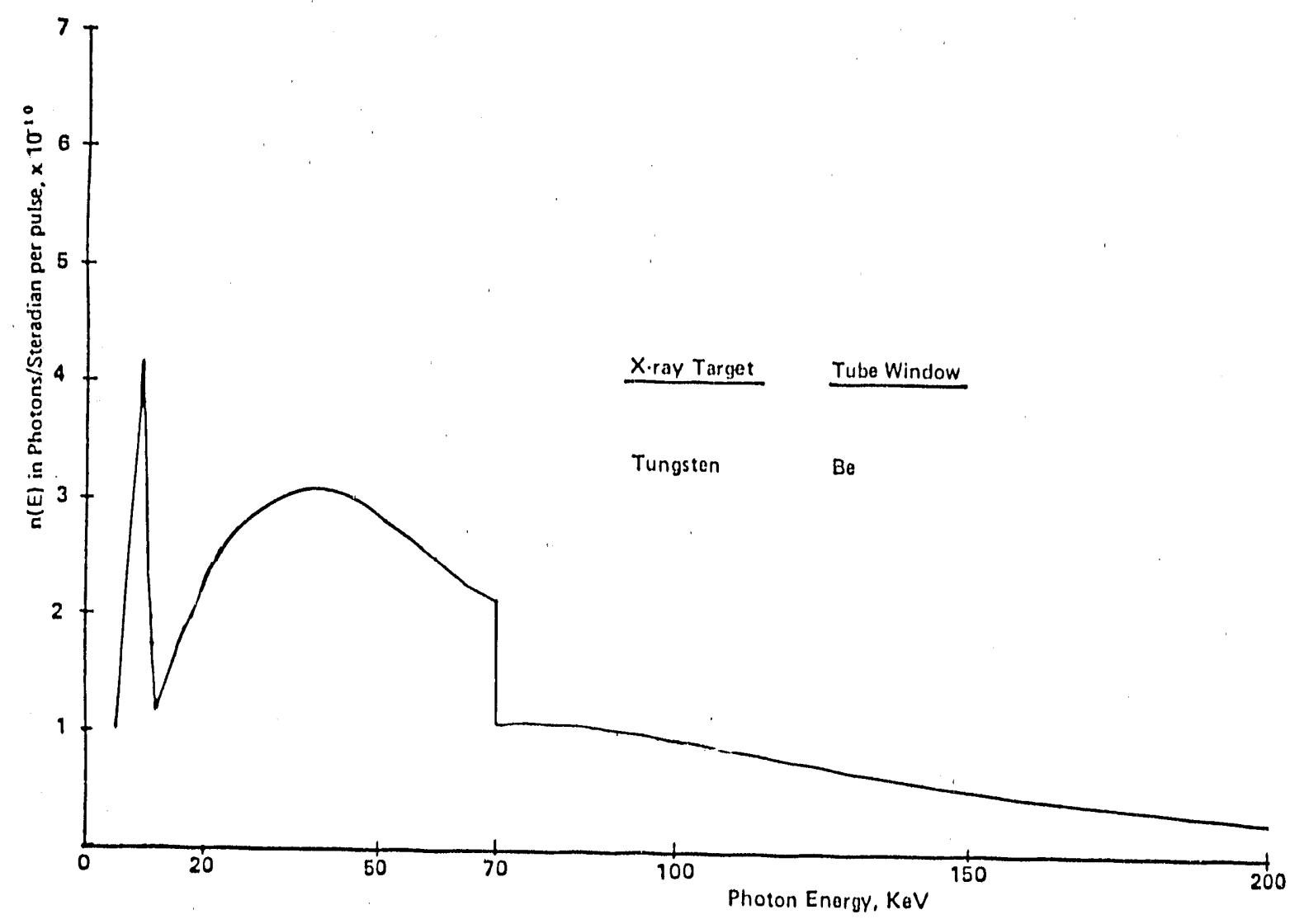

Figure 7.3. Photon energy spectrum for a flash $x$-ray source [10.] 


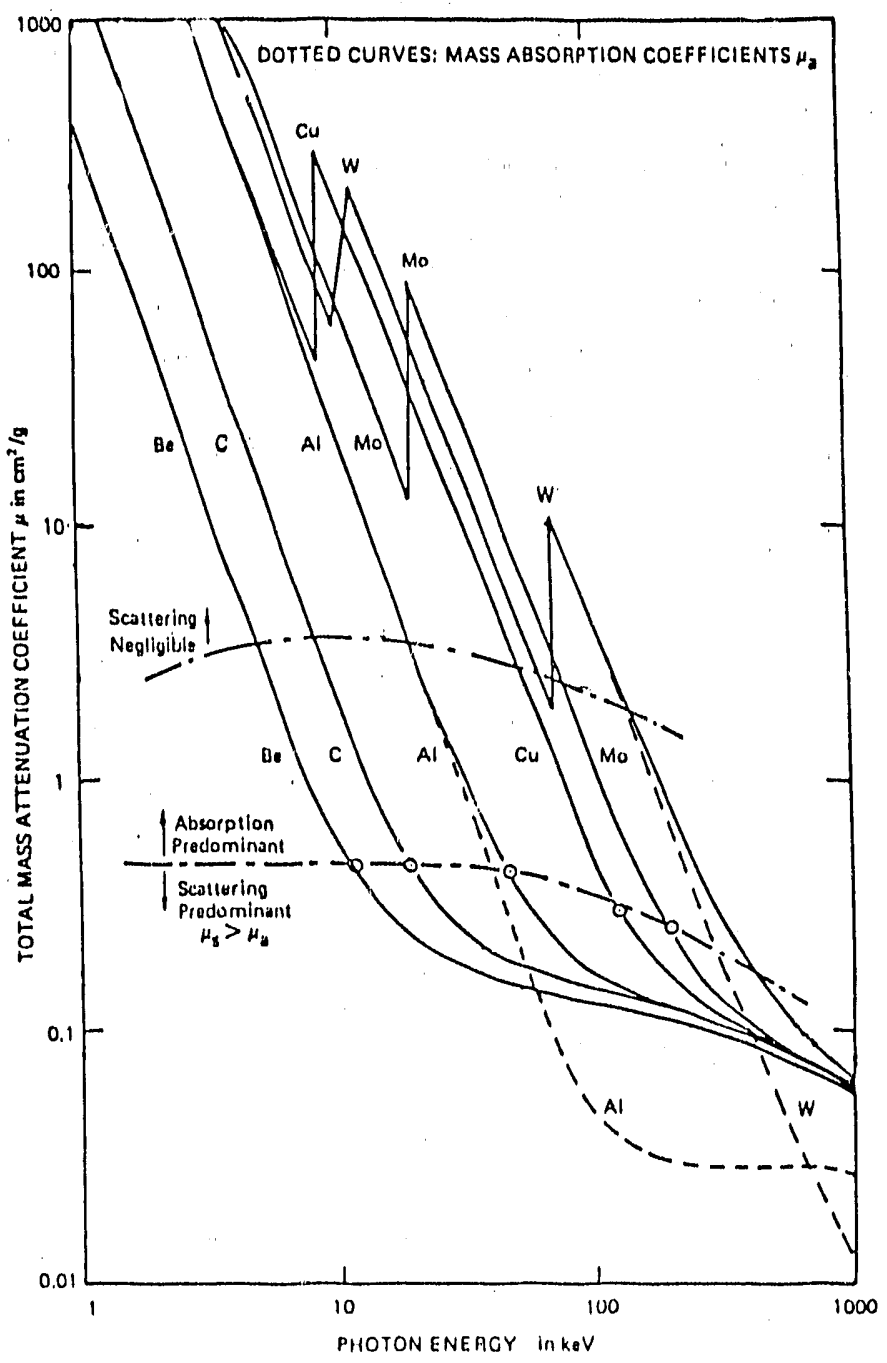

Figure 7.4. Mass attenuation coefficients for monoenergetic $x$-rays for various materials [10]. 


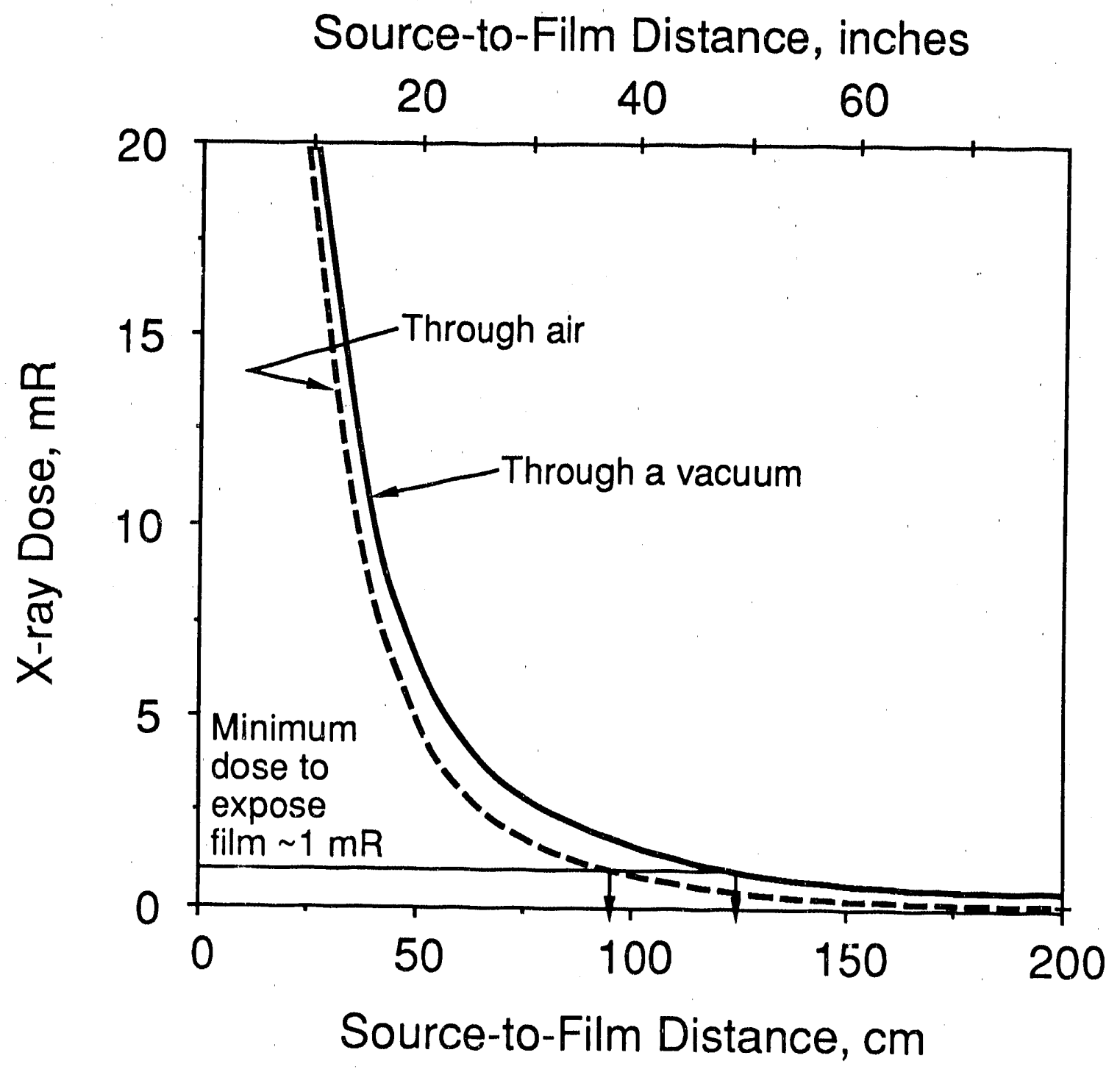

Figure 7.5. Attenuation of the $x$-ray dose with distance from the source through a vacuum and through air. Dose at $20 \mathrm{~cm}$ for the Hewlett-Packard $150 \mathrm{kV}$ source is $40 \mathrm{mR}$. 


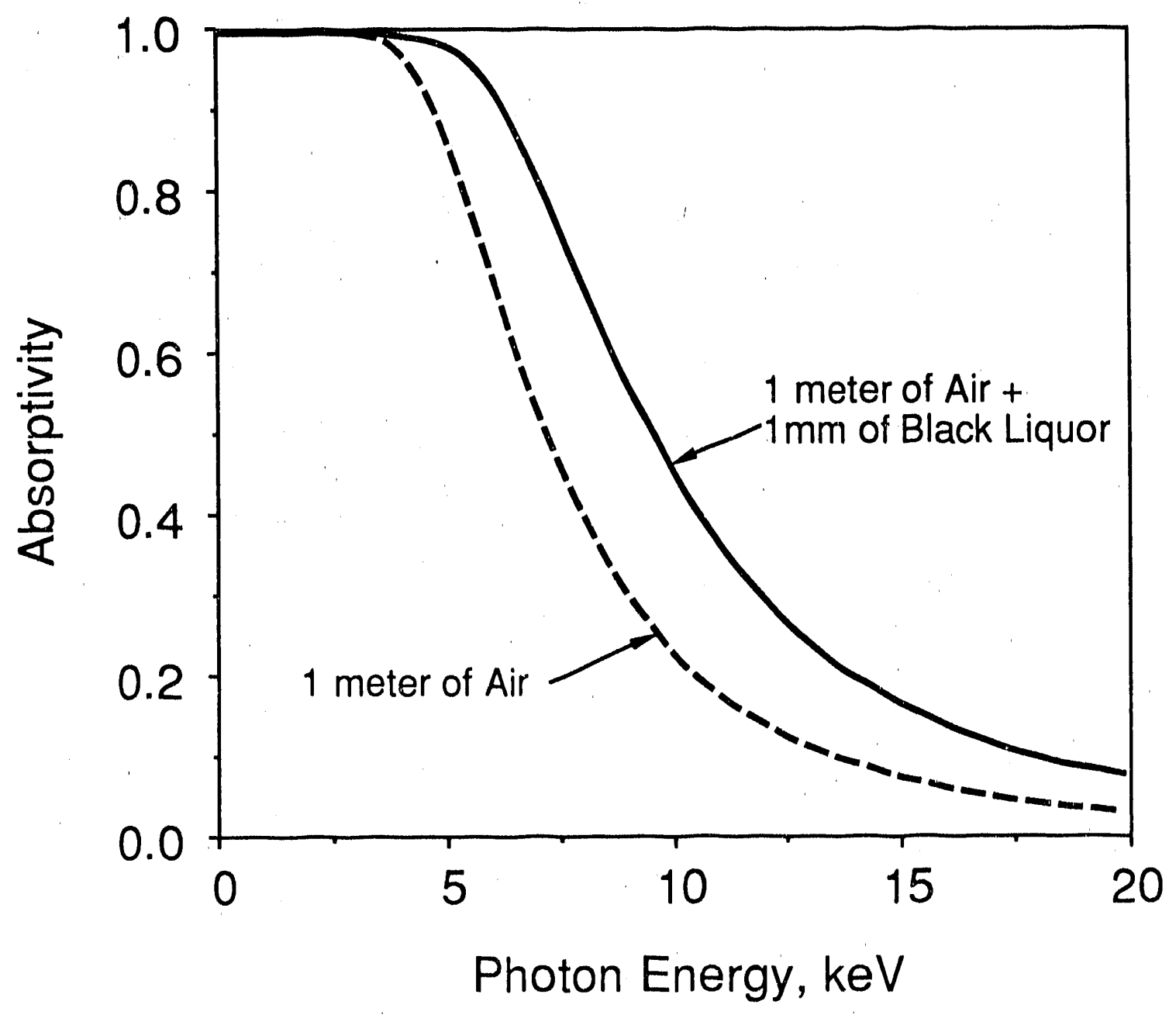

Figure 7.6. Absorptivity of $x$-rays by air alone and by air plus black liquor as a function of photon energy. 


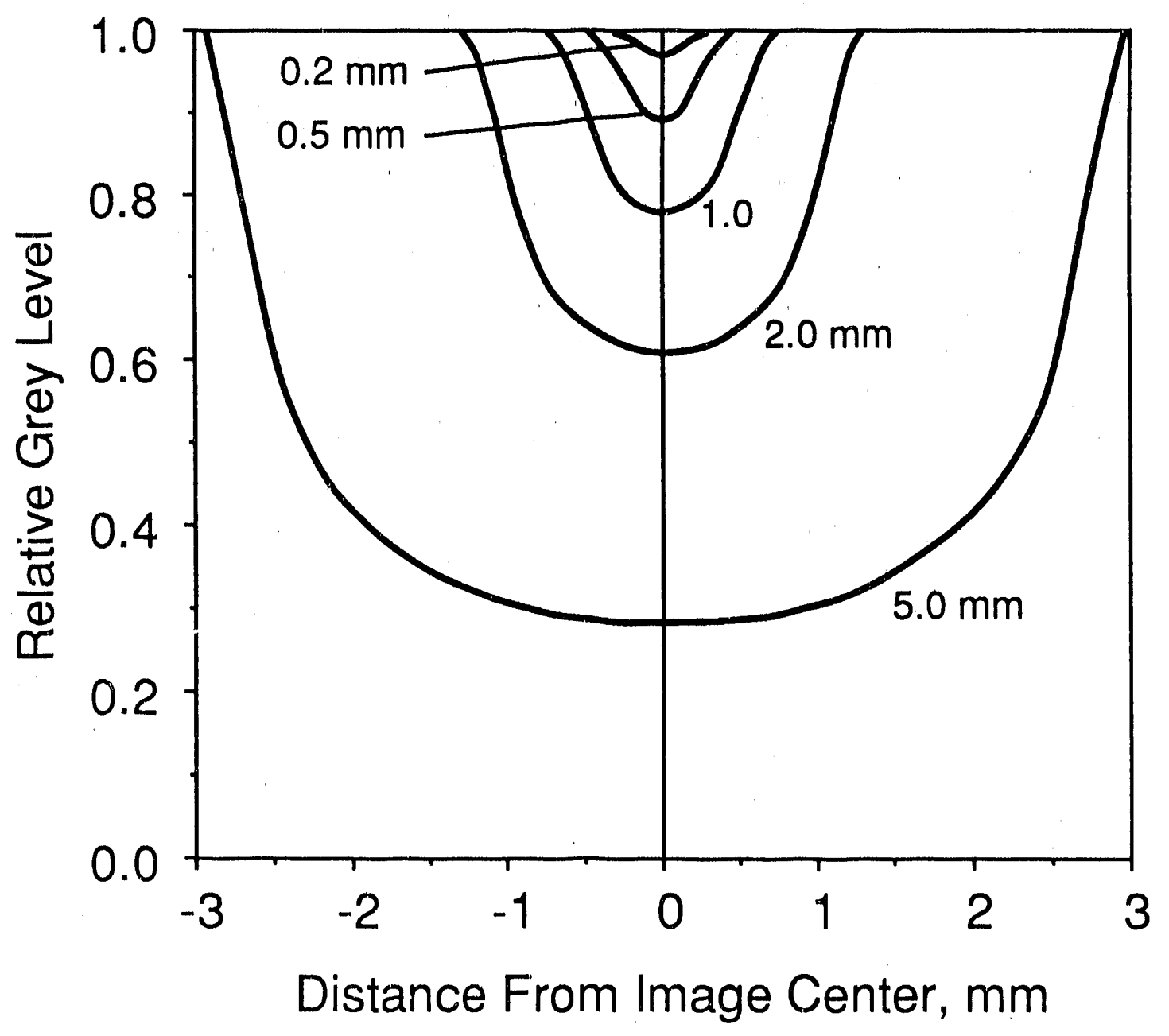

Figure 7.7. Relative grey level of a flash x-ray image of black liquor droplets of various sizes. STFD $=1.5 \mathrm{~m}$ (60 inches), OTFD $=0.15 \mathrm{~m}$ ( 6 inches $)$. 


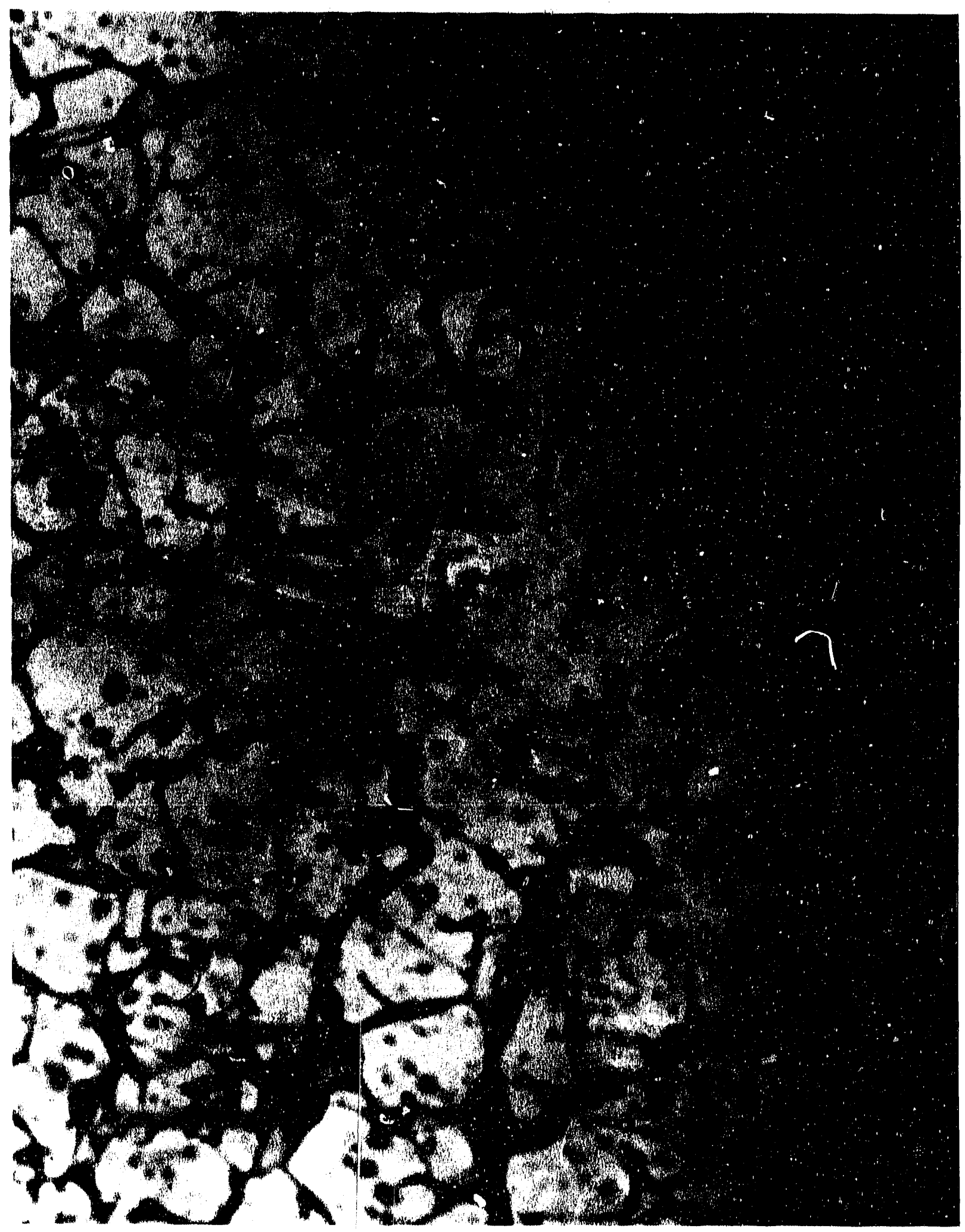

Fiqure 7.8. Flash x-ray shadowgraph for a black liquor spray. Resolution below $0.5 \mathrm{~mm}$ is poor. 


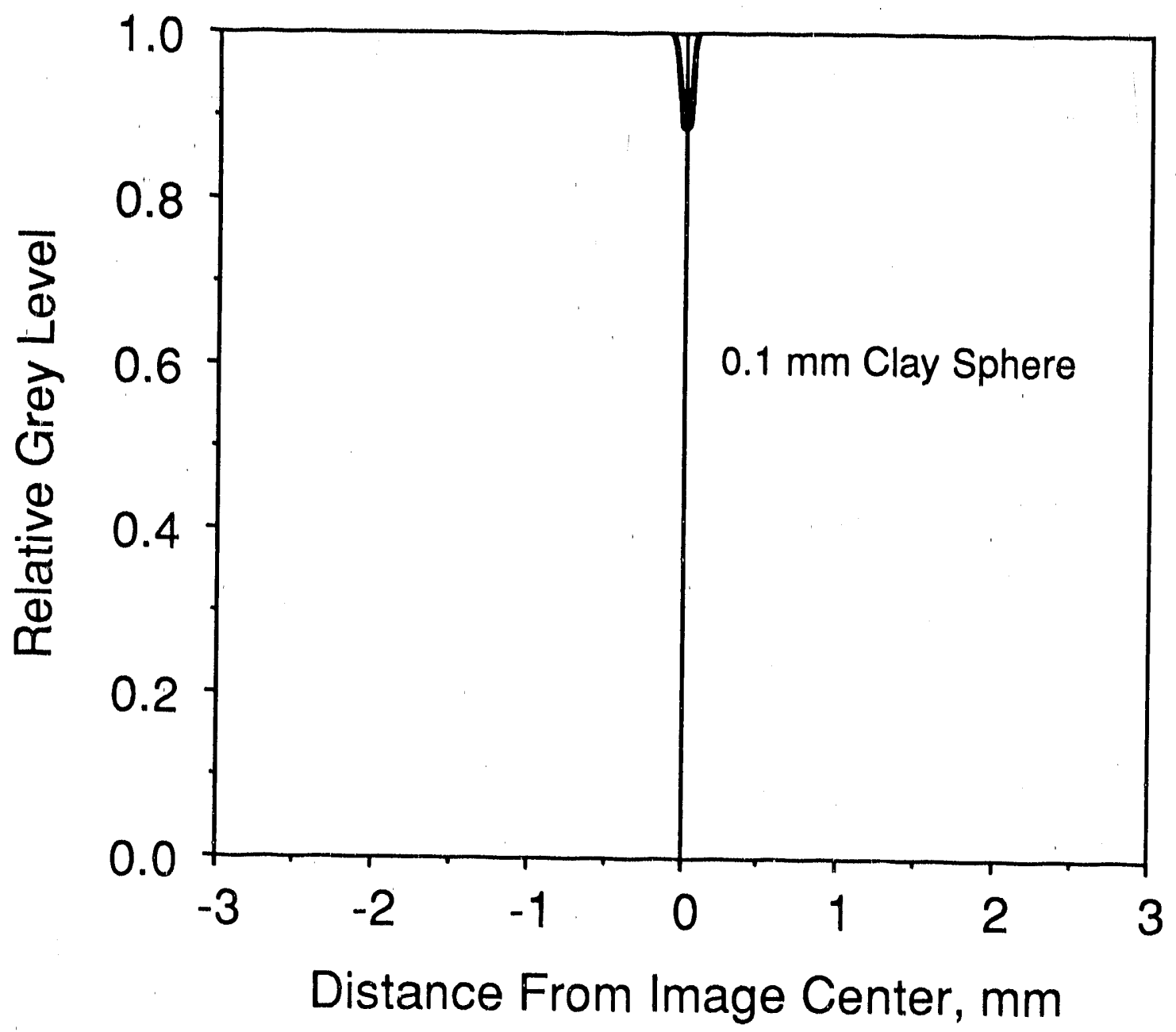

Figure 7.9. Relative grey level of a flash X-ray inage of a $0.1 \mathrm{~mm}$ clay sphere. STFD $=1.5 \mathrm{~m}$ (60 inches), OTFD $=0.025 \mathrm{~m}$ (1 inch) . 


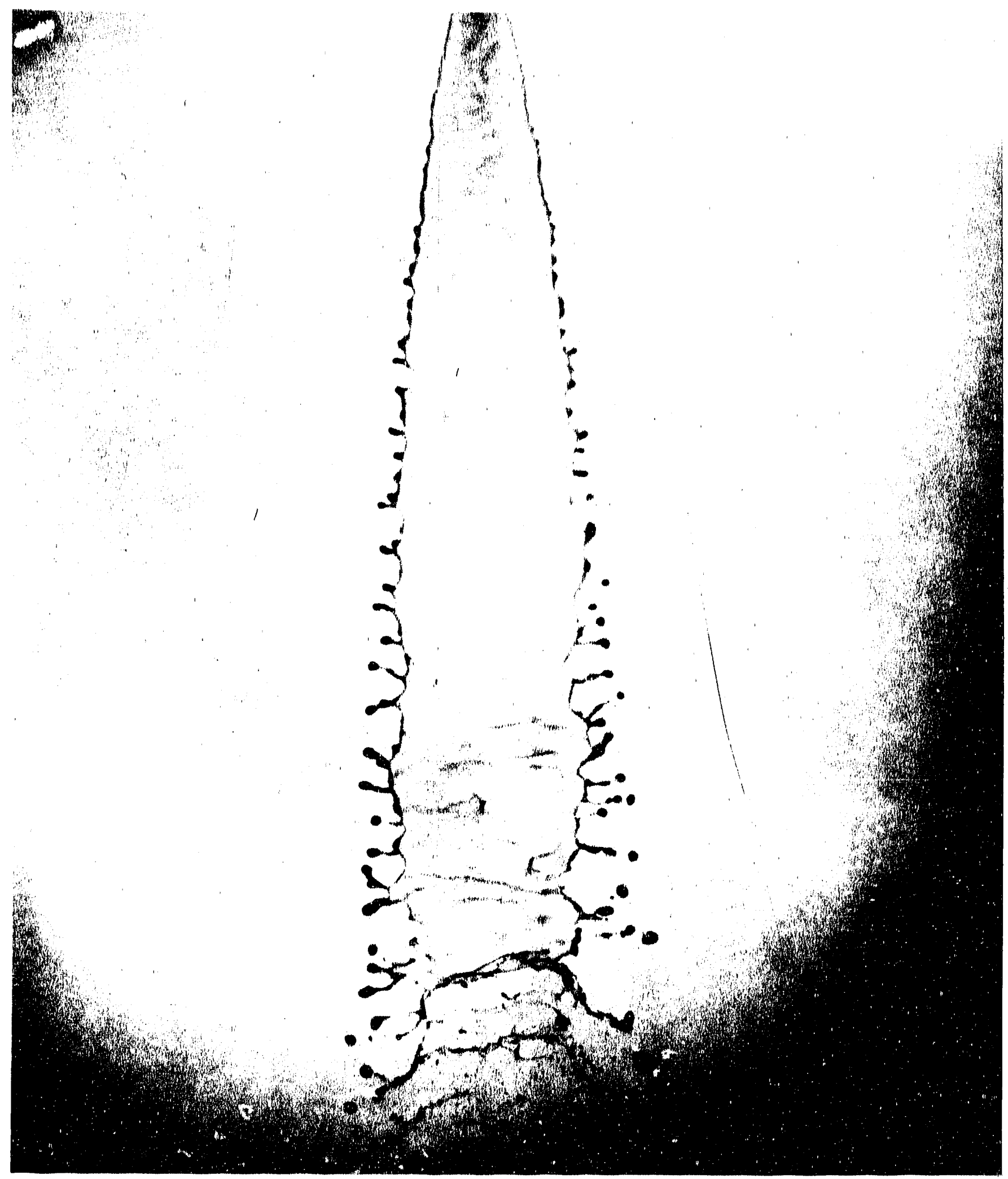

Figure 7.10. Flash $x$-ray shadowgraph of a smali spray showing good resolution. 


\subsection{High Speed Video}

An ISG-250 high speed video camera manufactured by xybion corporation is capable of collecting 60 images per second with an exposure time which can be set anywhere from 25 nanoseconds to 20 microseconds per image. The images are recorded with a super VHS video tape recorder to maintain the resolution delivered by the camera $(768 \times 493$ pixels $)$. Simultaneously, the signal from the camera can also be sent to a video monitor and the images viewed in real time. The operation of the high speed video system is as simple as operating a conventional video system with the additional flexibllity of controlling exposure time.

The motion blur in the short exposure time high speed video images is negitgible. The field of view of the camera is simply a function of the lens used and the object-to-film distance. Thus, the full sheet area can easily be captured on a single inage. Alternatively, with the proper selection of lens and geometry, droplets as small as $0.1 \mathrm{~mm}$ in diameter can be resolved.

It is important to note that there is a trade off between field of view and resolution. For example, if $0.1 \mathrm{~mm}$ diameter drops are to be imaged and these drops are to be recorded as a single pixel in the tmage, then the field of view will be only 30 square centimeters. In fact, in most image analysis applications an object should occupy at least 9 pixels if statistically significant measurements of their geometry are to be made. Thus, the maximum field of view in this case would be only 3.3 square centimeters. If a full sheet is to be imagnd (a 0.2 meter square area) then objects smaller than 4.8 square millimeters will not occupy the required 9 pixels.

There is also a trade off between exposure time and avallable light. As the exposure time decreases, the light incident on the camera must be increased to obtain the same contrast. Black lighting (placing the light sources behind the spray and projecting them through the spray toward the camera) has proven to be the most successful geometry thus far.

\subsection{Veloctty Measurements}

As with the flash $x$-ray technique, velocity measurements must be made from multiple exposures of the spray. This process is much simpler with the xybion camera, however. In its nurmal operating mode, an electronic signal is sent internal to the camera causing it to shutter and collect an image once every sixtieth of a second. To obtain multiple exposures, the signal can be routed to a device external to the camera, which would then signal the camera to shutter two or more times every sixtieth of a second. Since the image is only cleared every sixtieth of a second, a multiple exposure is obtained.

\subsection{High Specd Video Imaging}

The sprays produced by a B\&W splash plate nozzle and a CE swirl cone nozzle were imaged through a gun port of an operating recovery boiler. Because of the limited optical access, the spray could be imaged no further than about 16 inches from the nozzles. 
The spray just off the tip of a splash plate nozzle results in a solid sheet that extends some distance off the tip. Further downstream perforations in the sheet appear, indicating the onset of break-up.

Examination of a close-up view of this perforated region reveals smail holes, believed to be initiated either by the impaction of droplets or solid particles onto the sheet, or by the presence of gas bubbles or solid particles in the she at itself. These small holes grow and intersect other growing holes to cause the break-up of the sheet into a mass of interconnected strands.

At about 16 inches from the nozzle, the spray exhibits both interconnected and free strands. These strands are expected to ultimately break up into individual droplets further down stream as was seen in the flash $x$-ray images.

The spray just off the tip of a swirl cone nozzle shows perforations and tears in the sheet a short distance from the nozzle, indicating that break-up of the sheet is initiated closer to the nozzle than it is in spiash plate sprays. For the spray 8 inches from the nozzle, large clumps, strands, and some droplets are visible. Further break-up of the strands into drops is evident when the spray is 12 inches from the nozzle outlet.

\subsection{Discussion}

From the previous discussion it is obvious that both flash $x$-ray and high speed video imaging can be used to study black liquor sprays from conventional nozzles. In both techniques images of the spray can be recorded and analyzed to determine droplet size distribution. However, high speed video imaging offers some distance advantages.

The rate of imaging sprays with the flash $x$-ray system is limited by the time intensive process of developing the exposed sheets of film. In the study done at IPST a maximum of forty images per day were collected. Even with automated developing systems, rates of no greater than 100-150 images per day can be expected. In contrast, the high speed video system collects sixty images per second in its normal operating mode. In addition, the images obtaineci with the high speed video are displayed in real time on a video monitor as they are collected. Thus, adjustments to the geometry and lighting can be made to optimize the image quality as the experiments are run. With the long developing times required for flash $x$-ray imaging, improper geometry or other problems resulting in poor image quality can not be detected until hours after the experiments are completed.

Another advantage of high speed video imaging is the comparative ease in obtaining velocity data. The xybion camera is equipped to collect the multiple exposures needed to determine the velocity of the droplets. A second unit is needed to obtain multiple images using the flash $x$-ray technique. In addition, the contrast between droplets and background is already limited in single exposure flash $x$-rays of sprays. The quality of multiple exposures may not be adequate for the analysis of the images and the measurement of droplet size and velocity distributions. 
A final problem associated with the use of the flash $x$-ray technique is the complications resulting from the use of high energy $x$-rays. Because of the health risk involved, all imaging is done in a specially constructed, lead-lined room. Thus field studies are impossible and all spray geometries must conform to the confines of the lead room. With the high speed video system, images can be collected anywhere conventional video is possible. As discussed, images were collected through the qun port of an operating recovery boiler. This would be impossible with the fiasi $x$-ray, not only because of the health risk, but also because of the inability to position in the boiler beyond the piece of film spray.

\subsection{Conclusion}

Significant benefits in terms of increased boiler capacity and energy conservation may be realized by controlling the droplet size and velocity distributions of black liquor sprays. High speed videv imaging can be used to measure these distributions and to study the fundamental mechanisms which affect these distributions.

High speed video imaging offers clear advantages over flash x-ray radiography in terms of ease of operation, speed of image co?lection, and flexibility of experimental design. High speed video imaging can also be used to study the spray processes in actual recovery boilers, thus providing a means to validate the results obtained in a laboratory environment. 
9.0 NOZZLE STABILITY AND THE IMPACT OF HIGH SOLIDS

\subsection{BLACK LIQUOR FL.ASHING INSIDE A NOZZLE}

The term "nozzle stability" refers to the ability of a nozzle to produce a steady spray pattern over a range of operating conditions. Every recovery boiler operator has had to deal with black liquor roping when the liquor was either too cold or being fired at too low a pressure. Likewise, liquor that is too hot will flash ahead of the nozzle and produce intermittent spurts of flow. Neither of these conditions is safe nor efficient. Experience with these two instabilities leads to operation in a fairly narrow range of liquor temperature and operating pressure.

Observations of nozzle operation in this work under liquor conditions very similar to normal mill operation have identified nozzle stability as a key element of practical nozzle design. Little data is available for any nozzle on stability, but the physical situation of flashing is relatively easy to quantify.

Flashing of the liquor will occur whenever the black liquor is operated at a temperature above its elevated boiling point (EBP). What is important is the degree of flashing and its location. With mild superheat, the nozzle operating pressure suppresses flashing until the liquor exits from the minimum flow area. For the B\&W splashplate and CE U- or V-type nozzle, this is at the nozzle exit. For the CE swirl cone, the minimum flow area is inside the nozzle cap, so flashing will always occur within the nozzle. When liquor operating temperature is higher than the boiling temperature at the operating pressure, then flashing will occur inside all black liquor nozzles and unstable flow will occur.

To avoid flashing ahead of the nozzle entirely, it is only necessary to use operating temperatures below the elevated boiling point of the liquor. with lower as -fired dry solids levels this was possible because temperatures below the elevated boiling point yielded acceptable liquor viscosities. With dry solids above $75 \%$ this will be more difficult because viscosity increases more quickly than boiling point when dry solids are increased. This is shown in Figure 9.1 for a typical black liquor. 


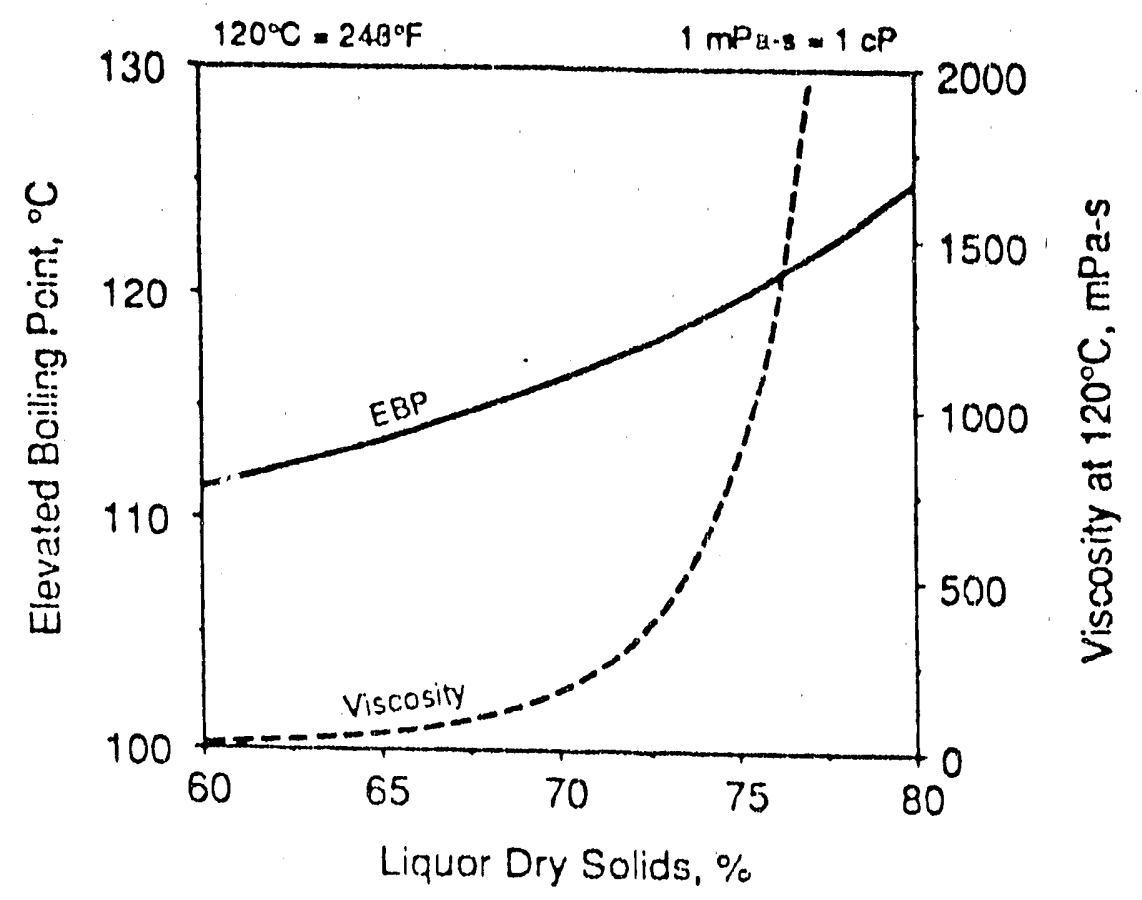

Figure 9.1. Viscosity \& elevated boiling point (EBP) as a function of liquor dry solids content for one liquor which has a viscosity of $100 \mathrm{mPa}-\mathrm{s}$ at $66 \% 110^{\circ} \mathrm{C}$. 
The range of viscosities known to produce acceptable black liquor sprays is from about 30 to $300 \mathrm{cP}$ ( 30 to $300 \mathrm{mPa}-\mathrm{s}$ ). This range may be extended as a greater understanding of black liquor sprays is developed $(15,19)$. However, the problem of high solids firing with current limits on viscosity is clear. Black liquor with properties similar to those shown in Figure 9.1 could not be fired at temperatures below the EBP for dry solids greater than $72 \%$. At $80 \%$ solids, more than $36^{\circ} \mathrm{F}\left(20^{\circ} \mathrm{C}\right)$ of superheat would be required to keep the liquor viscosity below $300 \mathrm{cP}(300 \mathrm{mPa}-\mathrm{s})$. This specific conclusion is only true for one black liquor, the one used in the example. Other liquors will show the same general trend, but with curves shifted along the solids axis.

\subsection{PERFORMANCE AT TYPICAL CONDITIONS}

A convenient way of characterizing liquor properties is to use a viscosity and elevated boiling point specified at some "standard" condition. The "standard" condition arbitrarily chosen here is $66 \%$ solids and $230^{\circ} \mathrm{F}$ $\left(110^{\circ} \mathrm{C}\right)$. These conditions are fairly near actual firing conditions in many mills, but are low enough so it is still relatively easy to measure the two important properties. The liquor used above has an EBP at $66 \%$ solids of $237^{\circ} \mathrm{F}\left(114^{\circ} \mathrm{C}\right)$, and a viscosity at the "standard" conditions, $66 \%$ solids and $230^{\circ} \mathrm{F}$, of $100 \mathrm{cP}(100 \mathrm{mPa}-\mathrm{s})$. This is a fairly normal liquor. A thin liquor would have a viscosity of $50 \mathrm{cP}(50 \mathrm{mPa}-\mathrm{s})$ at these conditions, while a thick liquor would have a viscosity of $250 \mathrm{cP}(250 \mathrm{mPa}-\mathrm{s})$.

The range of EBP at $66 \%$ dry solids is fairly narrow for kraft black liquor, from about $232^{\circ} \mathrm{F}$ to $243^{\circ} \mathrm{F}\left(111\right.$ to $\left.117^{\circ} \mathrm{C}\right)$ [1]. However, viscosity at $66 \%$ solids and $230^{\circ} \mathrm{F}$ can vary more widely from liquor-to-liquor, millto-mill, and hour-to-hour. The range is at least from 10 to $250 \mathrm{cP}$ (10 to $250 \mathrm{mPa}-\mathrm{s})$.

Shown in Figure 9.2 is the dry solids content which yields a viscosity of $300 \mathrm{cP}$ at the EBP plotted as a function of the viscosity as measured at "standard" conditions. For the thickest liquors (viscosity of $250 \mathrm{CP}$ at $66 \%$ and $230^{\circ} \mathrm{F}$ ), the viscosity at the EBP is greater than $300 \mathrm{cP}$ even at current firing solids between $67 \%$ and $72 \%$. Even for the fairly light liquors (viscosity of $50 \mathrm{cP}$ at $66 \%$ and $230^{\circ} \mathrm{F}$ ) operation above the EBP will be required at $80 \%$ solids to keep the viscosity below $300 \mathrm{cP}$.

Flashing ahead of the nozzle can be suppressed by adjusting the operating pressure of black liquor nozzles. Close attention to this fact, and a knowledge of the flow/ $\Delta P$ characteristics of black liquor nozzles, will allow practical selection of nozzles for a particular boiler and liquor at all solids levels. It is the lower pressures which must be avoided in order to avoid flashing ahead of the nozzles. Shown in Figure 9.3 is a plot of the minimum nozzle pressure to suppress flashing ahead of the nozzle as a function of as-fired liquor dry solids for three liquors. Fiashing is clearly not a problem for the light liquor (viscosity $=50 \mathrm{cP}$ at $66 \%$ solids and $230^{\circ} \mathrm{F}$ ). For the typical liquor with $100 \mathrm{cP}$ at the same "standard" conditions, flashing is also not a problem below $72 \%$, but minimum pressures of at least $25 \mathrm{psi}(172 \mathrm{kPa}$ ) would be required to suppress flashing at $80 \%$ solids. This would require drastic changes in the usual operating pressures of CE swirl cone, V-type and U-type nozzles, but could be accommodated fairly easily with a B\&W splashplate nozzle. 


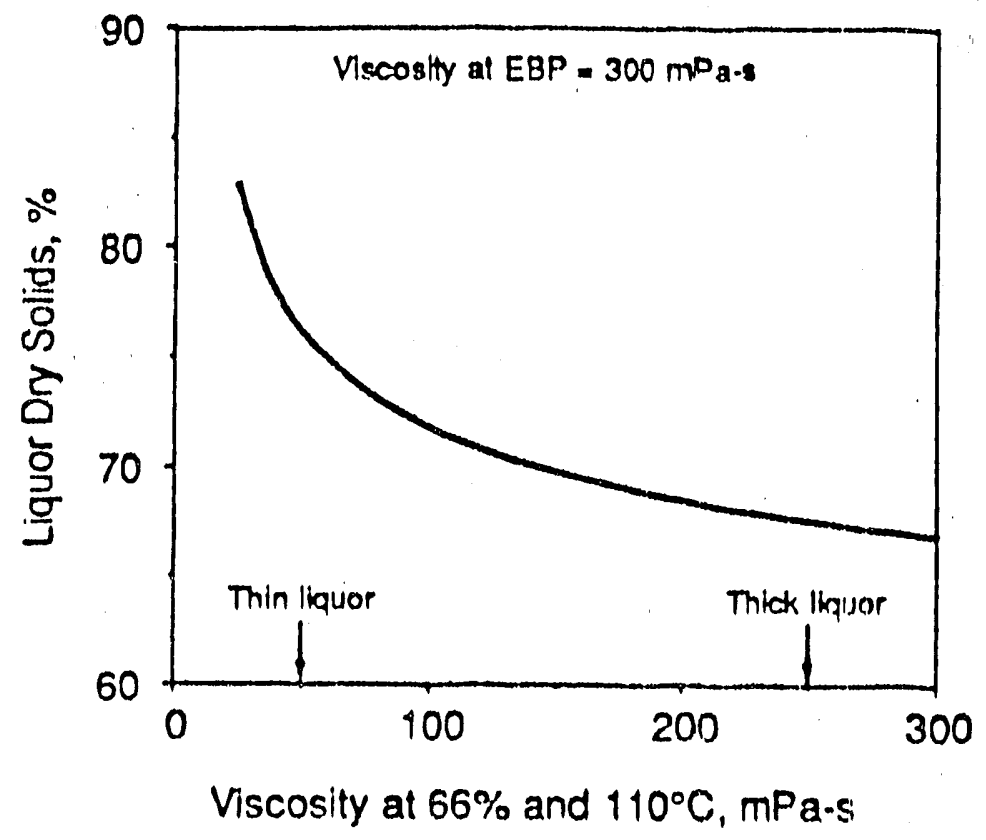

Figure9. 2. Maximum liquor dry solids content which has a viscosity less than $300 \mathrm{mPa} \cdot \mathrm{s}$ at the elevated boiling point (EBP) as a function of the viscosity at $66 \%$ solids and $110^{\circ} \mathrm{C}$. 


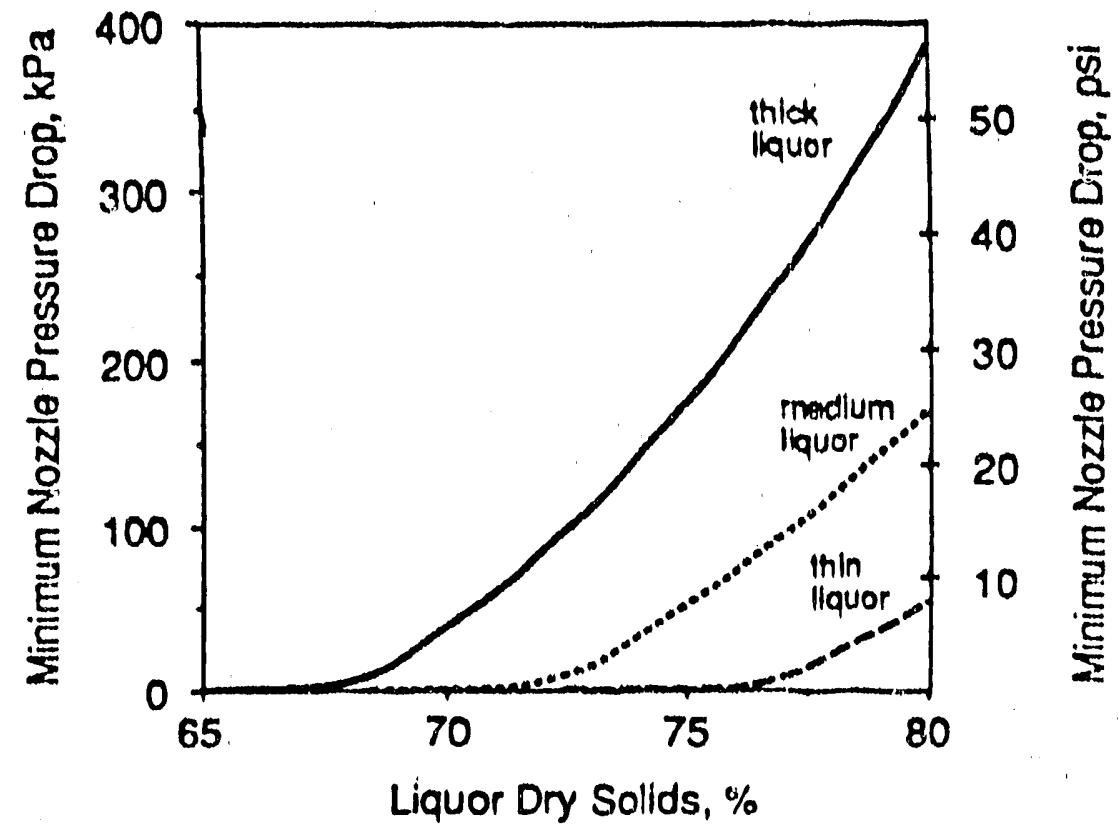

Figure 9. 3. Minimum nozzle pressure drop required to suppress flashing ahead of the nozzle for three liquors. Viscosities at $66 \%$ solids and $110^{\circ} \mathrm{C}$ are: thick liquor = $250 \mathrm{mPa}$-s, medium $=100 \mathrm{mPa}$-s, thin liquor $=50 \mathrm{mPa}-\mathrm{s}$. 


\subsection{PERFORMANCE AT HIGH SOLIDS}

With the thickest liquor, flashing is always a problem. Pressures well beyond the normal range for black liquor service would be required to suppress flashing ahead of the nozzle.

Complications with flashing at high solids will manifest themselves in different ways. First, the nozzle stability will be reduced at the low pressure end of their operating range. This will complicate trials of high solids firing and subsequent optimization of recovery boiler operation. Second, increasing operating pressure leads to higher velocities, which means smaller droplet size, all other factors being equal. Current understanding of recovery boiler operation would ind cate that this will increase carryover. Third, higher velocities, particularly much higher velocities for heavy liquors, mean significant changes in liquor droplet trajectory. This element by itself could easily confound the apparent benefit of high solids firing. Very careful nozzle selection will be required for valid mill trials of high solids firing or other liquor system modification. 


\section{REFERENCES}

1. Adams, T. N., and Frederick, W. J., Kraft Recovery Boiler Physical and Chemical Processes, American Paper Institute, New York, NY, 1988.

2. Adamis, T. N., T. M. Grace, \& E. W. Malcolm, "Kraft Black Liquor Delivery Systems", U.S. DOE Contract No. FC02-88CE40839, IPST.

3. Adams, T. N., "Black Liquor Spray Nozzles for Kraft Recovery Boilers". Kraft Recovery Operations Seminar, Orlando, FL (Jan. 1990).

4. Bailey, R. T., "Size and velocity of drops formed by black liquor splash plate nozzles," Babcock \& Wilcox Co. rept. RDD:88:2118-04-01:01, Alliance, $\mathrm{OH}, \mathrm{Jan} .1988$.

5. Bennington, C.P.J., "The Effect of Temperature on Drop Size of Black Liquor Sprays," MASc Thesis, Univ. of British Columbia, Vancouver, BC, 1983.

6. Bennington, C.P.J. and Kerekes, R.J., Proc. 1985 Int'1. Chemica1 Recovery Conf., TAPPI, Atlanta, p. 345-354, 1985.

7. Clay, D.T., et al., "Fundamental Studies of Black Liquor Combustion." Report No. 1 U.S. DOE Contract No. AC02-83CE40637, IPST (1985).

8. Crapper, G.D.; Dombrowski, N.; and Jepson, W.P., Proc. Royal Soc. London, A. 342:225-236(1975).

9. Dombrowski, N., and Wolfsohn, D.L., J. Inst. Fuel, 45:327-331(1972).

10. Dombrowski, N., and Tahir, M.A., J. Inst. Fue1, 50:59-67(1977).

11. Farrington, T.E.,Jr., "A more fundamental approach to the problem of high consistency forming", IPC tech. paper series, No. 175, May, 1986.

12. Farrington, T.E.,Jr., "Flash $x$-ray imaging of kraft black liquor sprays", IPC tech. paper series, No. 229, March, 1987.

13. Franzen, M.F., Tappi J., 70(7):63-67(1987).

14. Fraser, R.P.; Eisenklam, P.; Dombrowski, N.; and Hasson, D., AIChE J., $8(5): 672-680(1962)$.

15. Fricke, A. L., Physical Properties of Kraft Black Liquors, US DOE Contract No. ACO2-82CE40606, University of Florida.

16. Obuskovic, N. and T. N. Adams, "Fluid Sheet Thickness and Velocity at the Tip of a Black Liquor Splashplate Nozzle," AIChE Ann. Mtg., San Francisco, CA, Nov. 1989.

17. Simmons, H.C., "The Correlation of Drop-Size Distributions in Fuel Nozzle Sprays," Trans. ASME, J. of Engr. Power, p. 309-319, July, 1977. 
18. Spielbauer, T.N.; Adams, T.N.; Monacelli, J.E.; and Bailey, R.T., "Droplet size distribution of black liquor sprays, "TAPPI/CPPA IntT. Chemical Recovery Conf., Ottawa, Canada, April 1989.

19. Stocke1, I. H., "Black Liquor Droplet Formation Project", U.S. DOE Contract No. AC 02, 83CE40626, U. of Maine.

20. Stockei, I.H., Research on Droplet Formation for Application to Kraft Black Liquors, Technical Report No. 4 DOE/CE/40626-T2 (Oct., 1988).

21. Triantafillopoulos, N., "Study of Coating Flows with Flash X-ray Radiography", IPC A490 Progress Report, May 1987. 


\section{BLACK LIQUOR SPRAY NOZZLES FOR KRAFT RECOVERY BOILERS}

Terry N. Adams

Instutute of Paper Science and Technology

57514 th St. NW

Atianta, GA 30318

\section{ABSTRACT}

The performance of spray nozzles for kraft black liquor has been the subject of several recent investigations. Though research is incomplete, some information is avallable about the performance of the three basic types of black liquor spray nozzles: the splashplate, the swirl cone, and the U- or V-type. Data are presented on the how and pressure drop characteristios of two of these nozzle types which allows judgement of the sensitivity of the flow to normal mill variations in liquor properties. Data are also presented on several aspects of spray formation and droplet size distribution. Nozzle stability is discussed with respect to flashing ahead of the nozzle. It is found that the minimum nozzle operating pressure will have to be signiflcantly increased to suppress flashing ahead of the nozzle when firing high solids, viscous liquors.

\section{INTRODUCTION}

Black liquor is introduced into recovery boller fumaces through a set of nozzles. The purpose of these nozzles is to break the black liquor stream into a spray of properly sized droplets, typically between the sizes of $0.5 \mathrm{~mm}$ and $5 \mathrm{~mm}$. The specific geometric design of black licjuor nozzles varies from one manufacturer to the next, as does the larget mean droplet size. Current nozzle designs have been adequale for their purpose in the past, but present demands on recovery boller capacity require nozzle optimization. Both improving control of droplet size 10 avoid carryover and pluggage, and accommodating of the trend toward higher llquor dry solids content is needed. For these reasons, the U.S. Department of Energy (DOE) has funded several studies of black liquor physical properties [1], droplet formation [2,3], and droplet and bed combustion [.4].

Black liquor viscosity, surface tension, and density are known to affect droplet size from spray nozzles [5-7], and have also been found to affect droplet combustion directly [8]. Viscosity has been the most difficult to characterize, but is now reasonably understood as a result of the DOE project led by Fricke [1], and subsequent DOE-funded work on viscometer development 19,10$]$. Thorough work on Scandinavian liquors by Soderhjelm [11-13] and Wennberg $[14,15]$ have added to our understanding of black liquor viscosity. Current data support the use of the simple lowshear Newtonian viscosity in characterizing black liquor for spray and droplet formation $[7,10,16\}$. This viscosity can be readily measured with ordinary viscometers, though data extrapolation techniques [10] or very careful data acquisition [1] is required for evaluating black llquor viscosity at normal firing conditions.

Nozzles are designed to form sprays of droplets from fluid streams. The mechanisms for stream break-up lall into two basic regimes: ordered and chaotic. The DOE has funded work at the University of Maine [2] on advanced nozzlo concepts which fall in the former category and offer the por thal for very significant improvement in droplet size and ize distribution control. However, most common commercial spray nozzles arid atomizers fall in the latter category, as do all current black liquor nozzles used in recovery boilers in pulp and paper mills. The U.S. DOE has also funded work at the Institute of Paper Chemistry (now the Institute of Paper Science and Technology, Atlanta, GA) primarlly focused on these nozzles [3]. This paper deals with the characteristics of currently used black liquor nozzles: splashplates, swirl conos, U-type and V-type nozzles.

There is a basic pattern to the breakup of fluld streams into sprays of droplets. The fluid stream (usually circular) is flattened into a sheet which expands after leaving the nozzle into a flat, conical, or elliptical sheet. Aerodynumic drag causes the fluld sheet to oscillate and perforate, forming fluid ligaments. These ligaments subsequently break and coalesce into droplets. This pattern can be seen with the use of elther a strobe light or a high speed video cameru in ali types of black liquor nozzles, and most other nozzles used in commercial spray applications.

The purpose of this paper is to describe several aspects of black liquor nozzle performance as they are known today. The paper is broken into sections which: 1) present descriptions of the nozzles currently used fo, black liquor spraying in recovery boilers, 2) present data on the flow and pressure drop characteristles of black liquor nozzles, 3) describe the impact of fluld properties and operating parameters on the fluld sheet thickness and velocity, 4) present data on droplet size distribution for one of the nozzles, and finally, 5) examine the impact of high solids black liquor on nozzle performance.

\section{DESCRIPTION OF BLACK LIQUOR NOZZLES}

Two basic types of black liquor nozzles have been used in North America for many years: the Babcock \& Wilcox Co. (B\&W.) splashplate nozzle and the Combustion Engineering Inc. (CE) swirl cone nozzle. In the last few years $C E$ has introduced the $U$ type and V-type nozzles for black liquor service. Many variations of these basic types are now available from the three Scandinavian recovery boller vendors - Ahlstrom, Gotaverken, and Tampella.

Shown in Figure 1 is a photograph of a B\&W splashplate nozzle. Figure 2 is a schematc diagram of this nozzle. Black liquor enters the nozzle at a relatively low velocity. It accelerates in the tapered section and finally exits from the short straight section. The stream of black liquor impinges on the flat splashplate fixed at an angle to the fluid jet. The jet spreads out on the plate into a broad flat sheet which continues to expand in a flat fan shape after leaving the splashplate rim. The events of sheet oscillation, breakdown into ligaments, and subsequent breakdown into droplets are shown schematically in Figure 3. 


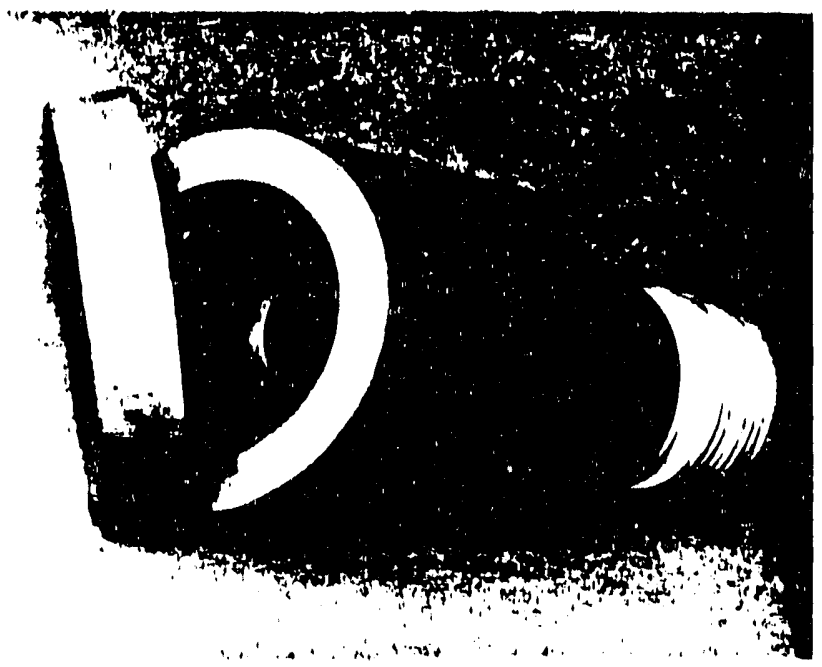

Flgure 1. Photograph of a B\&W splashplate black llquor nozzle.

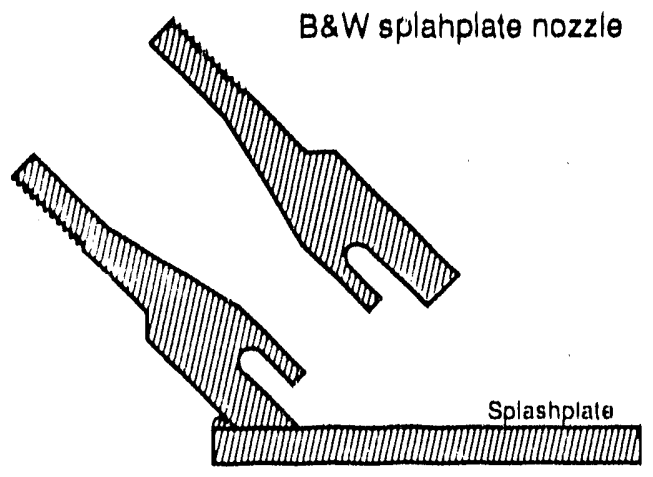

Figure 2. Schematic diagram of a $B \& W$ splashplate black liquor nozzle.

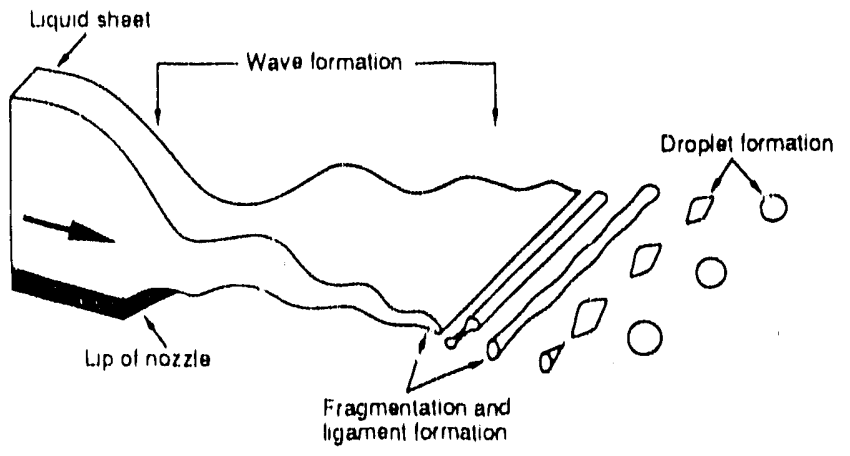

Figure 3. Droplet formation by liquid sheet disintegration [17].
A photograph of a CE swirl cone nozzle is shown in Figure 4 and a schematic diagram is shown in Figure 5. Black liquor again enters the nozzle at relatively low velocity and is accelerated in the tapered spiral grooves in the swirl plate. Black liquor exits the swirl plate with a spiraling motion and is flattened into a sheet on the surface of the cone leading to the exit orifice. The liquor leaves the nozzle in a swirling expanding cone which, as it thins, breaks up in a manner similar to that depicted in Figure 3.

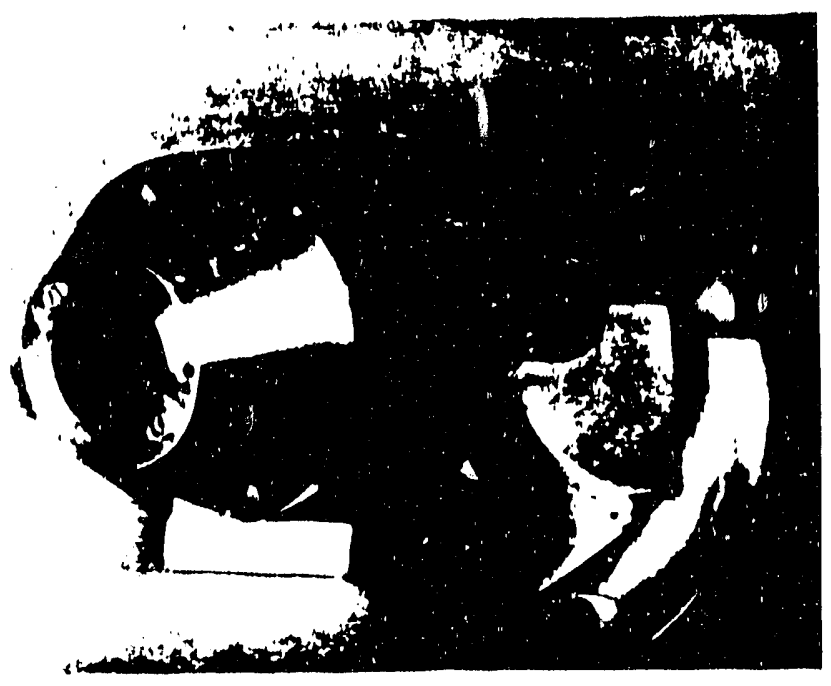

Figure 4. Photograph of a CE swirl cone black liquor nozzla.

\section{CE swirl cone nozzle}

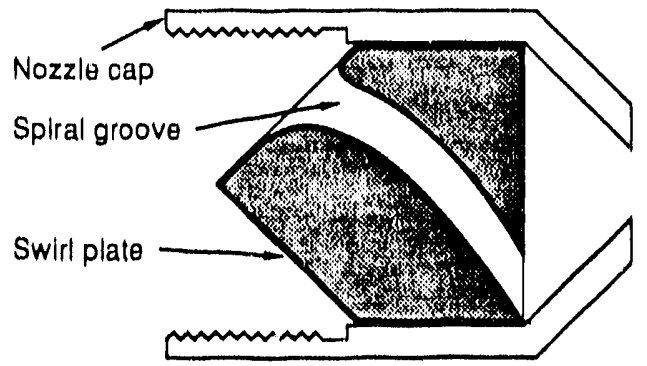

Flgure 5. Schematic dlagram of a CE swirl cone black liquor, 10zzle.

A photograph of the front view of a CE U-type and V-type black likuor nozzle is shown in Figure 6. A schematic for each is shown in Figure 7. Each consists of a cylindrical channel topped with a hemisphere which has been cut across the tip with a U-shaped or $V$-shaped channel. Black liquor flows at relatively low velocity to a point Just ahead of the nozzle exit opening and then is acceleruled and discharged in an elliptical flow pattern. 


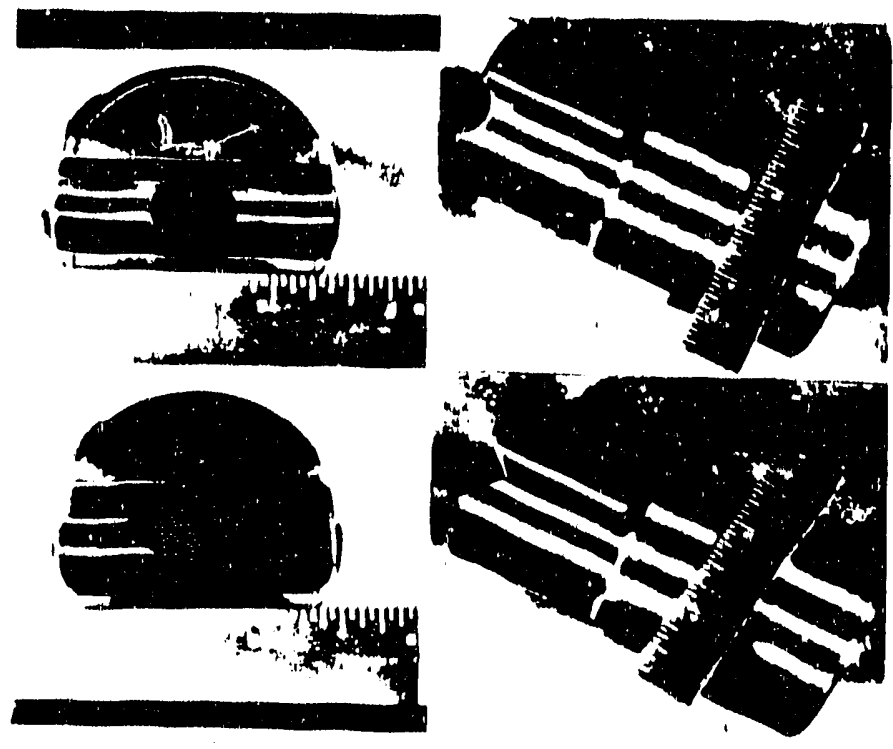

Flgure 6. Photograph of a CE U.typa and V-type black liquor nozzle.
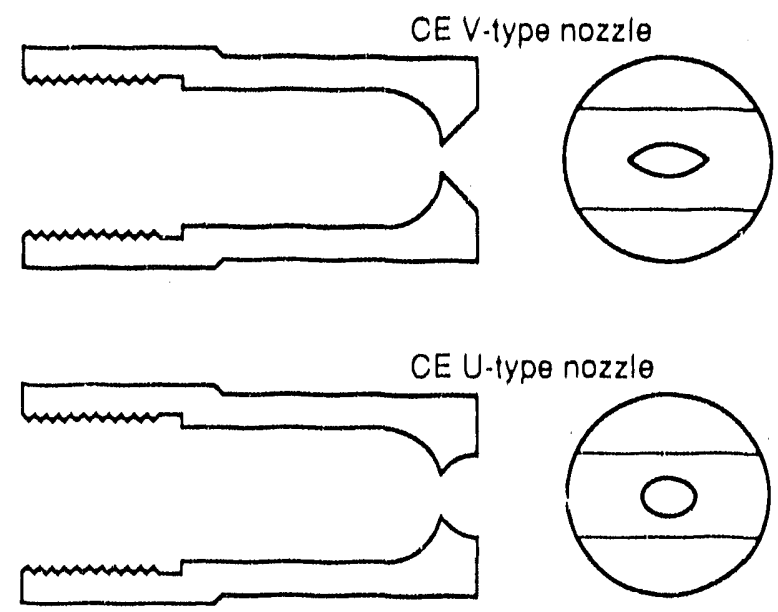

Figure 7. Schematic diagram of a CE U-type and a CE $\checkmark \cdot$ type black liquor nozzle.

The minimum flow area for each of these black liquor nozzles can be calculated from simple geometry. The B\&W splashplate exit orifice is circular and designated by the nozzle number measured in thirly-seconds of an inch. A B\&W 24.49 nozzle has an exit orifice diameter of $24 / 32$ inches $(0.75$ inches or $1.9 \mathrm{~cm}$ ). The second number indicates the angle of the splashplate relative to the nozzle exil flow.

For CE swirl cone nozzles, the combined groove flow area is al wilys smaller than the exit orifice area. The minimum flow area for the CE swirl cone is equal to lwice the area of one of the Iwo spiral grooves. Each is semi-circular in flow cross-section, so the flow area is equal to the area of a circle with the groove diameter. For the largest CE swirl cone nozzle used in black liquor service, a \#6 CE nozzle, the groove diameter is $3 / 4$ inch $(1.9 \mathrm{~cm})$. The nozzle exit orifice for this nozzle is 1 inch $(2.5 \mathrm{~cm})$.

The exil orlfice area for the CE U-type and V-type nozzles is the minimum flow area for each. The plan area of the U-type is nearly elliptical, while the V-type is somewhat less 50 . The area of each can be calculated with the equations:

$$
\begin{aligned}
& A_{u}=\frac{\pi}{4} b c \\
& D_{u}=\sqrt{b c} \\
& A_{V}=0.9 \frac{\pi}{4} b c \\
& D_{V}=0.95 \sqrt{b c}
\end{aligned}
$$

where:

$A_{u}=$ nozzle area for $U$-type nozzle

$D_{u}=$ equivalent circular diameter for the U-type nozzle

$A_{V}=$ nozzle area for the $V$-type nozzle

$D_{V}=$ equivalent nozzle diameter for the $V$-type nozzle

$b, c=$ major and minor axis dimensions for the U- and V-type nozzles

\section{FLOW CHARACTERISTICS OF BLACK LIQUOR NOZZLES}

Recovery bollers usually operate with muliple black liquor nozzles. A few small bollers operate with only one nozzle, but most use from two to twelve nozzles depending on nozzle type and boller size. Black liquor is delivered to the individual nozzles through flexible hoses from a ring header which surrounds the boiler. Operating pressure is usually measured in the ring header at one location. Calculating the flow and pressure drop characteristics of the delivery piping system is relatively straightorward using standard engineering techniques, but the flow/ $\Delta$ P characteristics of the nozzles are not as straightforvard. Knowledge of the flow/ $\triangle P$ characteristics of the nozzles is required for proper selection of the size and number of nozzles for nomial operation, and for estimating the impact of changes such as firing liquor at high dry solids.

Work at the Institute of Paper Chemistry on black liquor nozzles [3] has resulied in flow coefficient correlations for two lypes of black liquor nozzles: the B\&W splashplate and the CE U. and V. type, and to an estimate for the CE swirl cone |16]. These are based on data taken with both hot and cold black liquor, and com syrup. Corn syrup has been used in tests of black liquor nozzles because Its viscosity and density are similar to those for black liquor, and it is considerably easter to handle. Two studies have shown that corn syrup preforms in a manner similar to black liquor in many flow siluations $[7,16]$. Table I shows the range of conditions covered by the flow coeflicient rests. 
TABLE 1. Fluid properties and operating conditions for the IPC tests.

\section{Black Liquor}

Com Syrup

\begin{tabular}{lcc} 
Speciffic gravity & $1.35-1.39$ & 1.38 \\
Dry solids & $66-69 \%$ & $73 \%$ \\
Temperature & $\begin{array}{c}92-117^{\circ} \mathrm{C} \\
\left(198-243^{\circ} \mathrm{F}\right)\end{array}$ & $\begin{array}{c}25-94^{\circ} \mathrm{C} \\
\left(77-201^{\circ} \mathrm{F}\right)\end{array}$ \\
Prossure & $21-502 \mathrm{kPa}$ & $41-646 \mathrm{kPa}$ \\
& $(3-73 \mathrm{psi})$ & $(6-94 \mathrm{psi})$ \\
Flow & $0.5-2.5 \mathrm{~V} / \mathrm{s}$ & $0.3-2.3 \mathrm{Vs}$ \\
& $(1.5-40 \mathrm{gpm})$ & $(5-36 \mathrm{gpm})$ \\
Viscosity & $34-140 \mathrm{mPa} / \mathrm{s}$ & $160-1238 \mathrm{mPa}-\mathrm{s}$ \\
& $(34-140 \mathrm{cP})$ & $(160-1238 \mathrm{cP})$ \\
Data points & 37 & 88 \\
\hline
\end{tabular}

$P$ essure drop across any flow element can be expressed in the form:

$$
\Delta P=C_{f} \frac{1}{2} \rho V_{n}^{2}
$$

where:

$$
\begin{aligned}
& \Delta P=\text { pressure drop across the nozzle } \\
& C_{f}=\text { flow coefficient } \\
& \rho=\text { fluld density } \\
& V_{n}=\text { nozzle characteristic velocity }
\end{aligned}
$$

Blacik liquor nozzles vary in flow cross sectional area. There is no single flo." velocity throughout the nozzle as there would be in a pipe, for examiple. It is necessary to use a characteristic velocity, which is the velocity at the minirnum flow area.

The flow coefficient is often taken as a constant for many flow elements such as elbows, expansions, and contractions. However, the flow reglme covered by black liquor nozzles stretches from laminar flow through transition flow, to fully turbulent flow. The Reynolds number, $\rho V D / \mu$, is the parameter used to gauge the flow regime, with Reynolds numbers lower than 2000 indicating laminar flow. Table 2 shows the typical range of operation for each black liquor nozzle.

Data taken of the flow coefficient for two types of black liquor nozzles are shown in Figure 8 along with correlation curves for each. Comparing these curves to the practical mill flow conditions listed in Table 2 reveals that, except at the extreme lower end of operation, both the $\mathrm{B} \& \mathrm{~W}$ splashplate and the $\mathrm{CE} U$ - and V-type nozzles operate in the region of constant flow coefficients.
TABLE 2. Typical dimensions and nows for black llquor nozzles

\begin{tabular}{lcc} 
& $\begin{array}{c}\text { B\&W } \\
\text { splashplate }\end{array}$ & $\begin{array}{c}\text { CE swirl cone, } \\
\text { U- and V-type }\end{array}$ \\
\hline Nozzle diameter & $\begin{array}{c}1.9-3.2 \mathrm{~cm} \\
(0.75-1.25 \mathrm{ln} .)\end{array}$ & $\begin{array}{c}1-1.9 \mathrm{~cm} \\
(0.4-0.75 \mathrm{in} .)\end{array}$ \\
Operating pressure & $124-330 \mathrm{kPn}$ & $82-125 \mathrm{kPa}$ \\
& $(18-48 \mathrm{psi})$ & $(12-18 \mathrm{psi})$ \\
Nozzlo velocity & $13.7-24 \mathrm{~m} / \mathrm{s}$ & $9-11 \mathrm{~m} / \mathrm{s}$ \\
& $(45-80 \mathrm{ft} / \mathrm{s})$ & $(30-37 \mathrm{ft} / \mathrm{s})$ \\
Viscosity & $50-250 \mathrm{mPa}-\mathrm{s}$ & $30-150 \mathrm{mPa}-\mathrm{s}$ \\
& $(50-250 \mathrm{cP})$ & $(30-150 \mathrm{cP})$ \\
Reynolds number & $1400-21,000$ & $810-9405$ \\
\hline
\end{tabular}

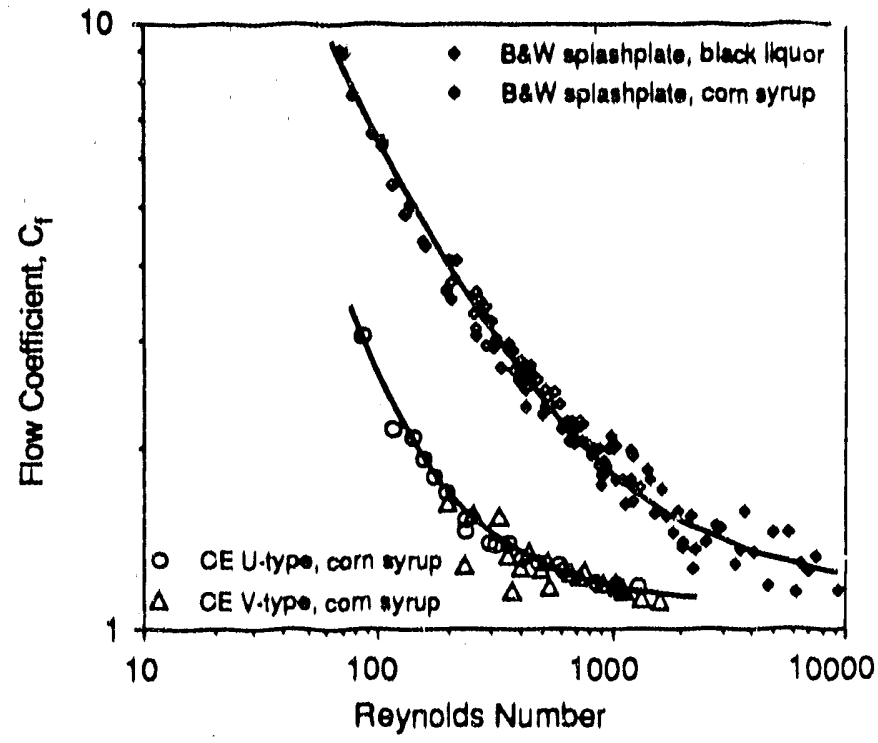

Figure 8. Flow coetficient data and correlation for two black llquor nozzles using two fluids-black liquor and corn syrup.

The equations for the flow coefficients are:

$$
\begin{array}{ll}
\text { B\&W splashplate: } & \mathrm{C}_{f}=1.17+\frac{373}{\mathrm{Re}^{0.92}} \\
\text { CE U. and V-type: } & \mathrm{C}_{f}=1.16+\frac{2780}{\mathrm{Re}^{1.65}}
\end{array}
$$

$$
\begin{aligned}
& \text { where: } \\
& \qquad \begin{aligned}
C_{l} & =\text { flow coefficient } \\
\operatorname{Re} & =\text { Reynolds number, } \rho V D / \mu
\end{aligned}
\end{aligned}
$$


The B\&W splashplate and CE U- and V-type nozzles will have a nearly constant flow coefficient in the normal range of operation and therefore will be insensitive to normal fluctuations in black liquor viscosity, temperature, and percent dry solids. The CE swirl cone nozzle, despite its obvious geometrical differences, probably has a flow coefficient correlation similar to the B\&W splashplate [16]. Table 2 shows that the CE swirl cone operates in a somewhat different regime than the $\mathrm{B} \& \mathrm{~W}$ splashplate. The $\mathrm{CE}$ swirl cone nozzle will have a flow soefficient which varies conside ably over its normal range of operation, and it will therefore be more sensitive to normal mill fluctuations. This will make the swirl cone nozzle harder to use and harder to adapt to new operating conditions such as high solids firing.

\section{FLUID SHEET THICKNESS}

The formaton of droplets from a black liquor stream requires the prior formation of a fluld sheet fur all types of liquor nozzles. The ultimate droplet size can bo directly related to the initial sheet thickness and velocity [17]. For most commercial spray nozzles it has been impossible to directly measure sheet thickness and velocity, Due to their large physical size, black liquor nozzles provide a unique opportunity to measure these parameters. Determining the sheot thickness and velocity of black liquor nozzles has also been a purt of the IPC project [3] and has been reported in detail [7]. Shown in Figure 9 are sheet thickness and surface velocity data for one B\&W splashplate nozzle. Data on sheet thickness and velocity were taken with both black liquor and corn syrup over a range of conditions which spans the normal range of mill operating viscosity, temperature and percent dry solids.

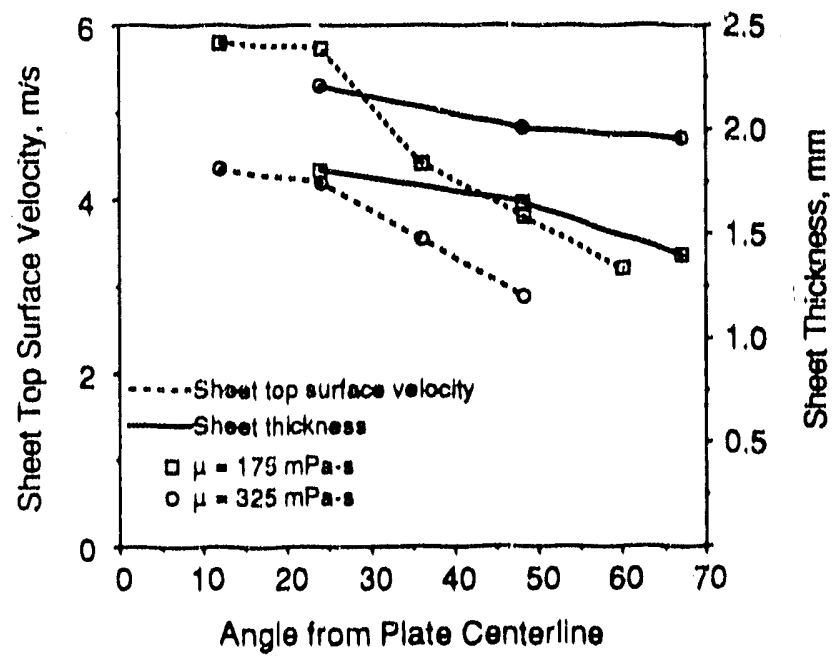

Figure 9. Sheet top sliface velocity and shoet thickness data for a B\&W 15.52 nozzlo using corn syrup as a working fluid at a nozzle flow of $0.79 \mathrm{l} / \mathrm{s}(12.5 \mathrm{gpm})$. The nozzle diameter is $11.9 \mathrm{~mm}$ and the nozzle velocity is 7.1 $\mathrm{m} / \mathrm{s}$.
By themselves, the data are very limited in their application. Howover, by using a simplified geometry, the equations of continuity and momentum can be solved to yleld useful correlating equations for this data. The correlating equations have the form:

$$
\begin{aligned}
& V_{p}=C_{1} \frac{\mu}{\rho D V_{a}}+C_{2} \\
& \frac{Y}{D}=C_{3} \frac{\mu}{\rho D V_{a}}+C_{4}
\end{aligned}
$$

whero:

$$
\begin{aligned}
& D=\text { nuzzle exil diameter } \\
& V=\text { sheet top surface velocity } \\
& V_{n}=\text { nozzle velocity } \\
& Y=\text { sheet thilokness } \\
& \rho=\text { density of the fluid } \\
& C_{1} \ldots C_{4}=\text { constants for each nozzle }
\end{aligned}
$$

Theso equations allow comparison of the sheet thickness data to data which show the impact of flow velocity on black liquor drop sizes [6]. Shown in Figure 10 is a comparison of droplet size data and fluid sheet thickness based on the correlation of Equation (9) for a B\&W 12-49 nozzle. The trend of the correlation is quite good and it is offset downward from the drop size data, consistent with the theory of droplet formation [17].

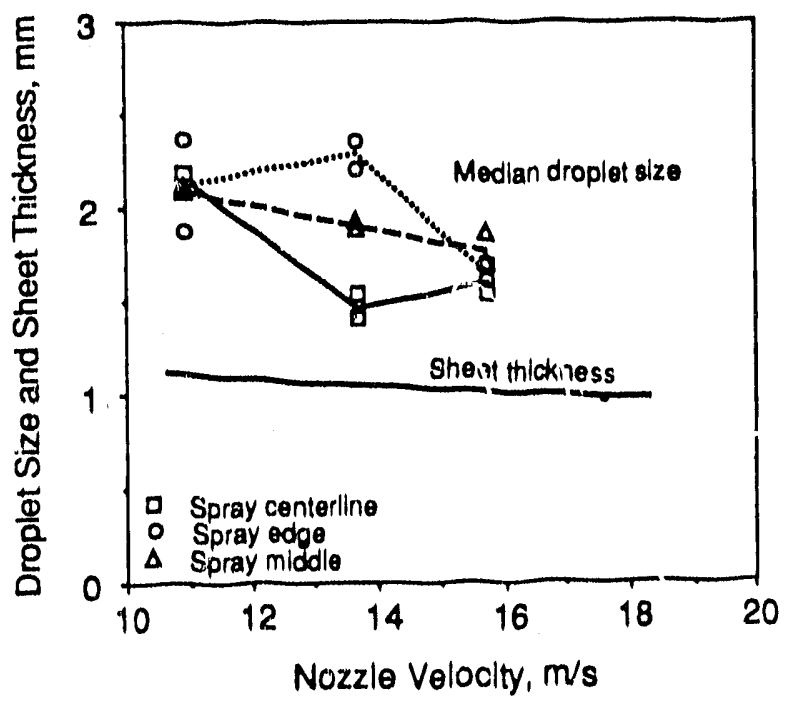

Flgure 10. Comparison of droplet median size datal (F) and calculated sheot thicknoss as a function of nozzlo velocity for a B\&W 12.49 nozzlo fining liquor at a viscosity of $150 \mathrm{mPQ}-\mathrm{s}$.

Of more interest is the anticipated effects of high solids firing on droplet size from black liquor sprays. One impact of higher solids is increased viscosity. Typically, black liquor viscosity at firing 
conditions is in the range of about 30 to $300 \mathrm{cP}$ (30 to $300 \mathrm{mPa}$ s). Liquor temperature can be used to control viscosity under most circumstances, but for firing solids near $80 \%$ the viscosity is likely to be between 250 to $300 \mathrm{cP}(250$ is $300 \mathrm{mPa}-\mathrm{s})$ [18, 19]. Shown in Figure 11 is a plot of fluid sheet thickness as a function of viscosity based on Equation (9). Fluid sheet thickness, and thercfore ultimate liquor droplet size, does increase with viscosity. However, this increase is less than a factor of two and a half for an increase in viscosity of a factor of ten. This change in nozzle performarice at high solids for the B\&W splashplate nozzle would be mild enough to allow routine mill optimization of existing nozzles without resorting to entirely new liquor nozzles when shanging to high solids firing.

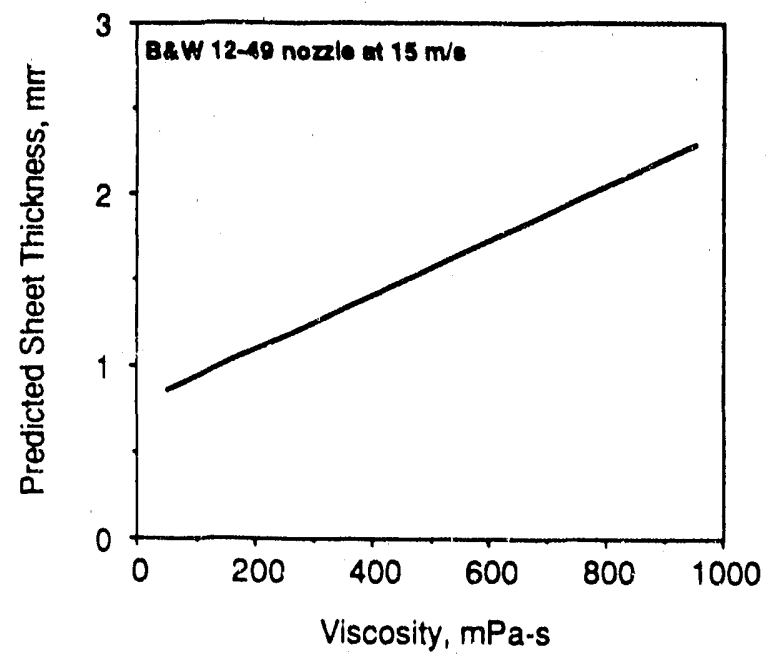

Figure 11. Calculated sheet thiciness as a function of fluid viscosity for a B\&W 12.49 nozzle cperating at $15 \mathrm{~m} / \mathrm{s}$ (17 gpm).

\section{BLACK LIQUOR DROPLET SIZE DISTRIBUTION}

The purpose of black liquor nozzles is to break a stream of liquor into a spray of droplets. The size of these droplets is important for the efficient, stable, and safe operation of recovery boilers. Some data are available on the droplet size and size distribution from black liquor nozzles $[5,6]$, but considerably more data is needed to provide practical guidance in control and optimization of nozzles in normal pulp and paper mill operation [3].

Black liquor nozzles, like all nozzles which depend on chaotic breakup, produce not a single size but a range of droplet sizes. Data on the droplet size distribution from a $B \& W$ splashplate nozzle and a CE swirl cone nozzle are presented in Figures 12 and 13 [6]. The data for the CE nozzle is slightly truncated because the measurement technique used had a lower cutoff limit of $0.5 \mathrm{~mm}$. The CE data was taken for hot black liquor at normal mill firing conditions. The B\&W splashplate data was taken with slightly diluted black liquor (approximately $53 \%$ solids) at roorn temperature.

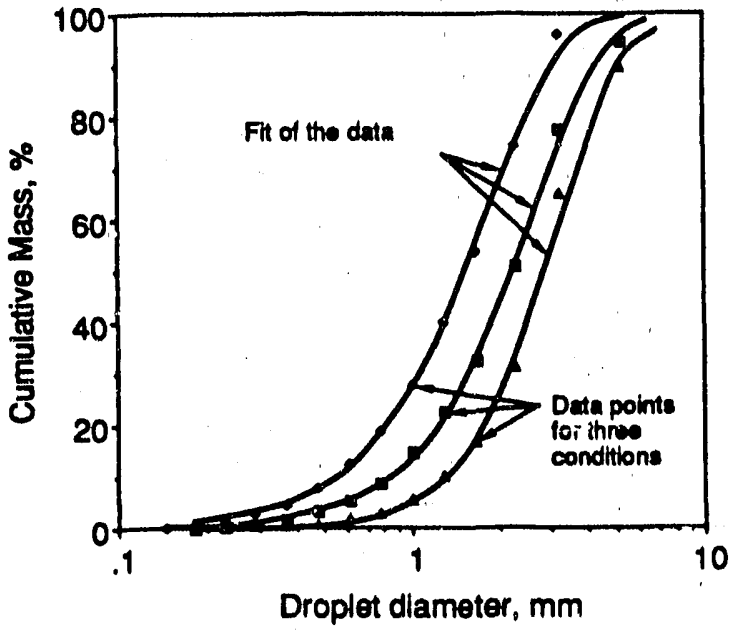

Figure 12. Comparison of droplet size distribution data for three conditions for a B\&W 12.49 splashplate nozzlo [6].

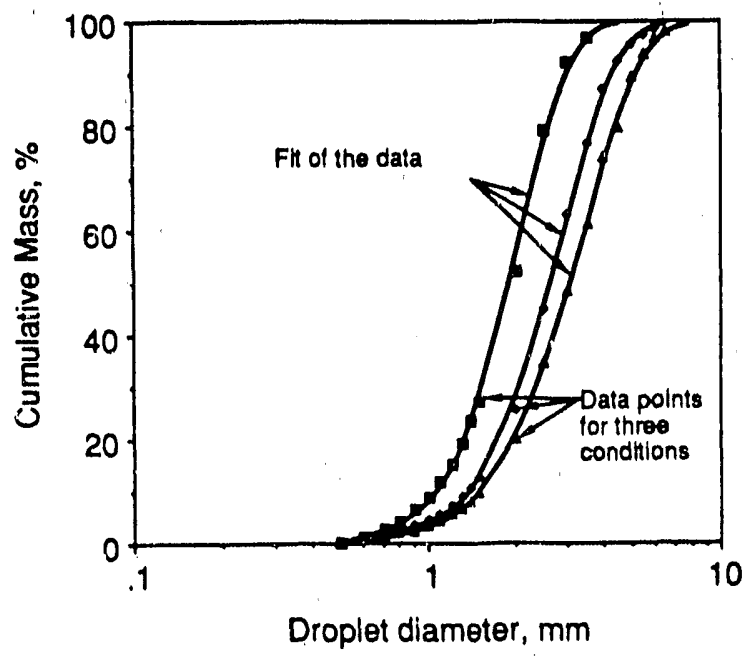

Figure 13. Comparison of droplet size distribution data for three conditions for a CE swirl cone nozzle [6].

A total of forty-five data points on three nozzles are currently available. This is definitely not enough to predict the performance of black liquor nozzles in mill operation, or reliably establish the impact of black liquor variables on mean droplet size. However, a few general conclusions can be drawn from the available data. First, the mean droplet size does vary with operating conditions. The data in Figure 10 show the effect of nozzle velocity on mass median droplet size. Droplet size is only a fairly weak function of liquor velocity or flow rate. Based on available data it also appears that droplet size is a fairly weak function of all fluid and operating parameters. This is consistent with droplet formation theory [17]. This is initially inconsistent with field observations where small 
changes in liquor temperature, for example, have a pronounced effect on recovery boiler performance. However, this apparent inconsistency probably only indicates that there are features of nozzle performance other than droplet size which impact boiler performance, such as droplet trajectory and subsequent droplet combustion.

The second important conclusion from the available black liquor spray data is that the size distribution is almost the same for all nozzles. Just as indicated in Figure 12, conditions which produce larger mean droplets also produce broader size distributions. This is most neatly demonstrated with data from the work of Bennington [5] on black liquor sprays. Shown in Figure 14 is a plot of droplet size distribution for one very small swirl cone nozzle for three fluids: water, glycerol, and black liquor. The three distributions are clearly different with black liquor being, by far, the largest and broadest. However, when these data are normalized by dividing the actual droplet size by the mass median droplet size, the three curves collapse into one as shown in Figure 15.

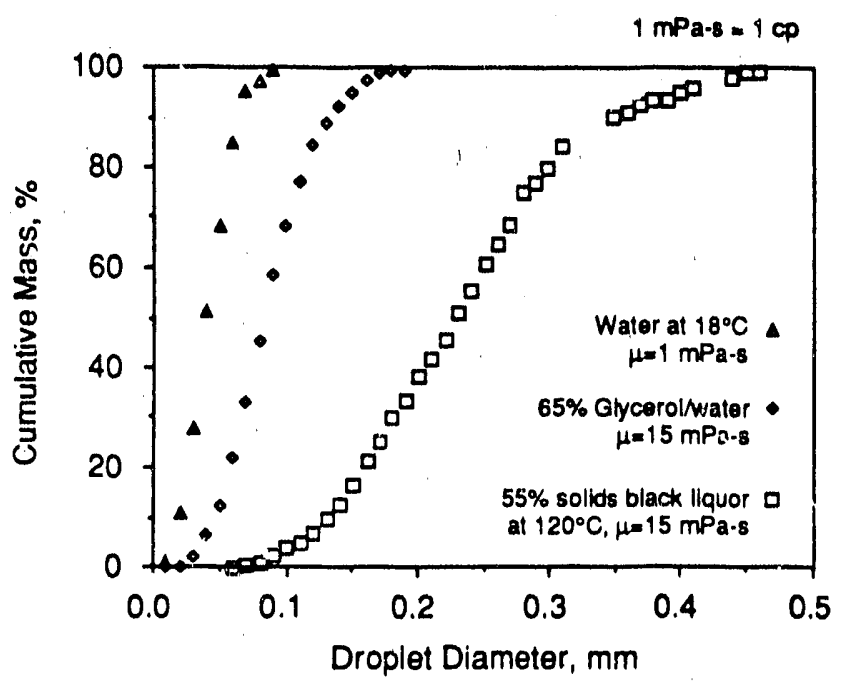

Figure 14. Droplet size distribution data for a small grooved-core nozzle [5].

The curve shown in Figure 15 proves to be nearly universal for pressure atomized spray nozzles including black liquor nozzles. There appears to be very little impact of nozzle geometry, fluid properties, or operating conditions. This is still under intense investigation because of the dramatic impact of the tail of this curve on carryover [3].

Practical interpretation of this information suggests that any two nozzles and operating conditions which produce the same mean size also produce the same size distribution. Major emphasis should first be on understanding the impact of nozzle geometry, fluid properties, and operating concitions on the mean size of

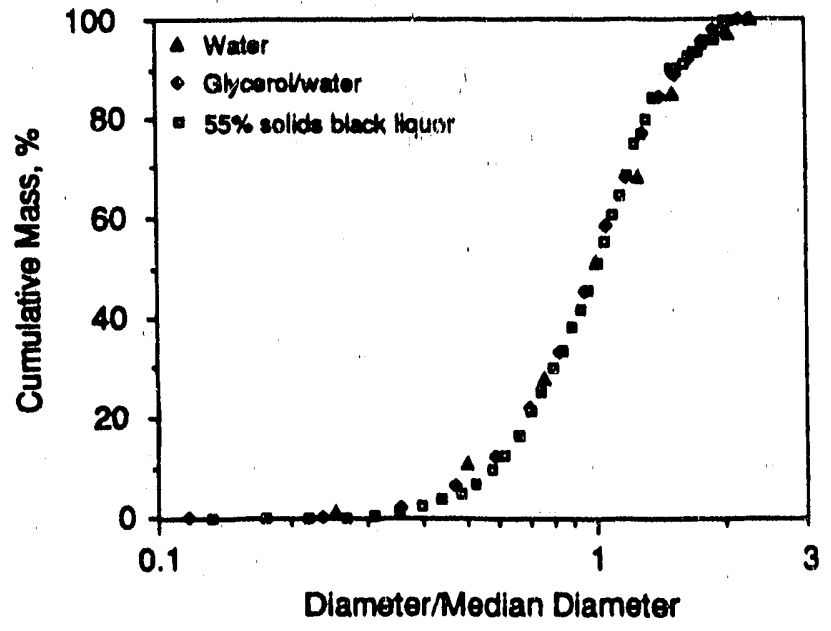

Figure 15. Droplet size distribution data normalized by dividing the actual diameter by the median diameter [17].

droplets formed in a spray. After this information is available in a practical form, then control of droplet size distribution by advanced techniques such as vibratory assist [2] should be pursued.

\section{NOZZLE STABILITY AND THE IMPACT OF HIGK SOLIDS}

The term "nozzle stability" refers to the ability of a nozzle to produce a steady spray pattern over a range of operating conditions. Every recovery boiler operator has had to deal with black liquor roping when the liquor was either too cold or being fired at too low a pressure. Likewise, liquor that is too hot will flash ahead of the nozzle and produce intermittent spurts of flow. Neither of these cciditions is safe nor efficient. Experience with these two instabilities leads to operation in a fairly narrow range of liquor temperature and operating pressure.

Observations of nozzle operation at the Institute of Paper Chemistry [3] under liquor conditions very similar to normal mill operation have identified nozzle stability as a key element of practical nozzle design. Little data is available for any nozzle on stability, but the physical situation of flashing is relatively easy to quantify.

Flashing of the liquor will occur whenever the black liquor is operated at a temperature above its elevated boiling point (EBP). What is important is the degree of flashing and its location. With mild superheat, the nozzle operating pressure suppresses flashing until the liquor exits from the minimum flow area. For the B\&W splashplate and CE U- or V-type nozzle, this is at the nozzle exit. For the $\mathrm{CE}$ swirl cone, the minimum flow area is inside the nozzle cap, so flashing will always occur within the nozcle. When liquor operating temperature is higher than the boiling temperature at the operating pressure, then flashing will occur inside all black liquor nozzles and unstable flow will occur. 
To avoid flashing ahead of the nozzle entirely it is only necessary to use operating temperatures below the elevated boiling point of the liquor. With lower as-fired dry solids levels this was possible because temperatures below the elevated boiling poin: yielded acceptable liquor viscosities. With dry solids above 75\% this will be more difficult because viscosity increases more quickly than boiling point when dry solids are increased. This is shown in Figure 16 for a typical black liquor. The viscosity curve is dramatically more sensitive to dry solids content than the elevated boiling point.

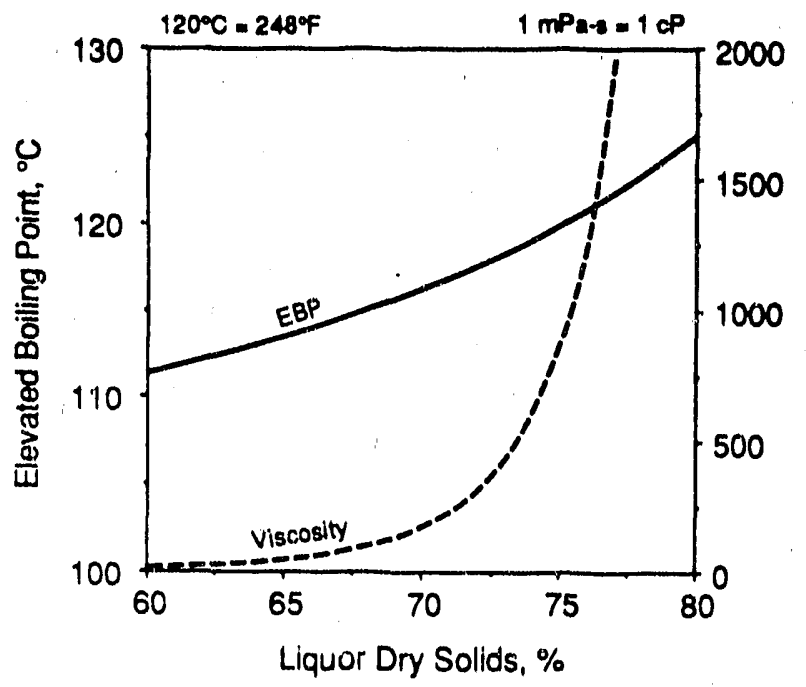

Figure 16. Viscosity and elevated boiling point (EBP is a function of liquor dry solids content for one liquor $u$ ch has a viscosity of $100 \mathrm{mPa}-\mathrm{s}$ at $66 \%$ and $110^{\circ} \mathrm{C}$.

This same data can be cast in a slightly different form which clarifies the impact of high solids firing on flashing. In Figure 17 the liquor viscosity at the elevated boiling point and at temperatures above and below the elevated boiling point by fixed amounts is plotted as a function of solids. Remember that the EBP is not a constant, but also increases with solids. The curve of viscosity at the EBP corresponds to a viscosity at both an increasing solids and increasing temperature.

The range of viscosities known to produce acceptable black liquor sprays is from about 30 to $300 \mathrm{cP}$ (30 to $300 \mathrm{mPa}-\mathrm{s}$ ). This range may be extended as a greater understanding of black liquor sprays is developed [2,3]. However, the problem of high solids firing with current limits on viscosity is clear. Black liquor with properties similar to those shown in Figure 16 could not be fired at temperatures below the EBP for dry solids greater than $72 \%$. At $80 \%$ solids, more than $36^{\circ} \mathrm{F}\left(20^{\circ} \mathrm{C}\right)$ of superheat would be required to keep the liquor viscosity below $300 \mathrm{cP}(300 \mathrm{mPa}-\mathrm{s})$. This specific conclusion is only true for one black liquor, the one used in the example. Other liquors will show the same general trend, but with curves shifted along the solids axis.

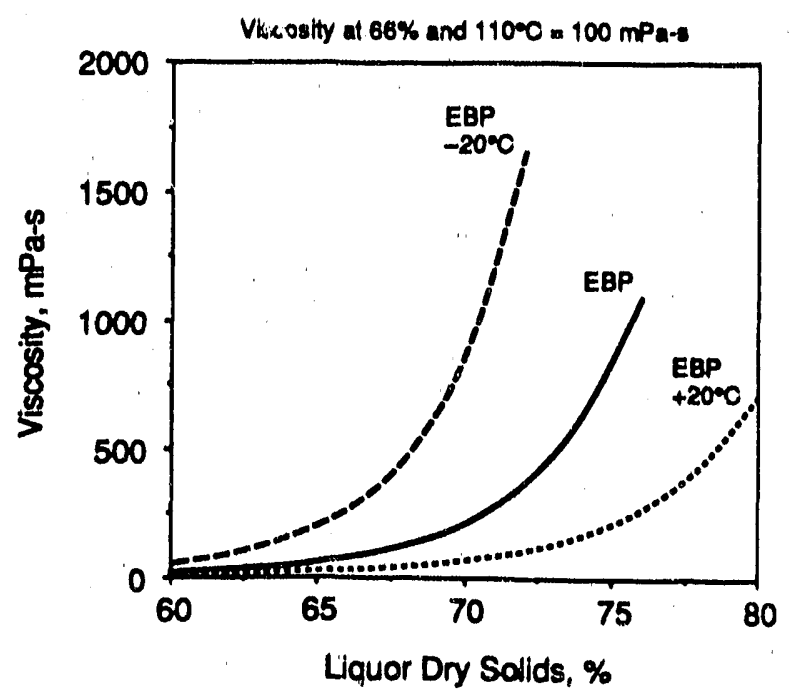

Figure 17. Viscosity at the elevated boiling point and at temperatures above and below the EBP by $20^{\circ} \mathrm{C}$ as a function of liquor dry solids for one liquor which has a viscosity of $100 \mathrm{mPa}-\mathrm{s}$ at $66 \%$ and $110^{\circ} \mathrm{C}$.

A convenient way of characterizing liquor properties is to use a viscosity and elevated boiling point specified at some "standard" condition. The "standard" condition arbitrarily chosen here is $66 \%$ solids and $230^{\circ} \mathrm{F}\left(110^{\circ} \mathrm{C}\right)$. These conditions are fairly near actual firing conditions in many mills, but are low enough so it is still relatively easy to measure the two important properties. The liquor used above has an EBP at $66 \%$ solids of $237^{\circ} \mathrm{F}\left(114^{\circ} \mathrm{C}\right)$, and a viscosity at the "standard" conditions, $66 \%$ solids and $230^{\circ} \mathrm{F}$, of $100 \mathrm{cP}(100 \mathrm{mPa}-\mathrm{s})$. This is a fairly normal liquor. $\mathrm{A}$ thin liquor ;would have a viscosity of $50 \mathrm{cP}(50 \mathrm{mPa}-\mathrm{s})$ at these conditions, while a thick liquor would have a viscosity of $250 \mathrm{cP}(250 \mathrm{mPa}$ s).

The range of EBP at $66 \%$ dry solids is fairly narrow for kraft black liquor, from about $232^{\circ} \mathrm{F}$ to $243^{\circ} \mathrm{F}\left(111\right.$ to $\left.117^{\circ} \mathrm{C}\right)$ [17]. However, viscosity at $66 \%$ solids and $230^{\circ} \mathrm{F}$ can vary more widely from liquor-to-liquor, mill-to-mill, and hour-to-hour. The range is at least from 10 to $250 \mathrm{cP}$ (10 to $250 \mathrm{mPa}-\mathrm{s}$ ).

Shown in Figure 18 is the dry solids conient which yields a viscosity of $300 \mathrm{cP}$ at the EBP plotted as a function of the viscosity as measured at "standard" conditions. For the thickest liquors (viscosity of $250 \mathrm{cP}$ at $66 \%$ and $230^{\circ} \mathrm{F}$ ), the viscosity at the EBP is greater than $300 \mathrm{cP}$ even at current firing solids between $67 \%$ and $72 \%$. Even for the fairly light liquors (viscosity of $50 \mathrm{cP}$ at $66 \%$ and $230^{\circ} \mathrm{F}$ ) operation above the EBP will be required at $80 \%$ solids to keep the viscosity below $300 \mathrm{cP}$.

Flashing ahead of the nozzle can be suppressed by adjusting the operating pressure of black liquor nozzles. Close attention to this fact, and a knowledge of the flow/ $\mathrm{P}$ characteristics of black liquor nozzles, will allow practical selection of nozzles for a particular boiler and liquor at all solids levels. It is the lower 


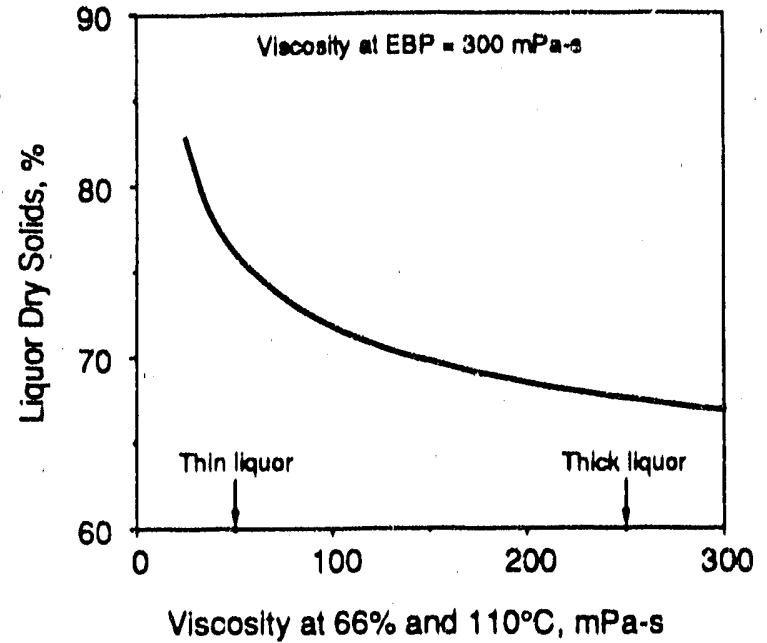

Figure 18. Maximum liquor dry solids content which has a viscosity less than $300 \mathrm{mPa}$-s at the elevated boiling point (EBP) as a tunction of the viscosity at $66 \%$ sollds and $110^{\circ} \mathrm{C}$.

pressures which must be avoided in order to avoid flashing ahead of the nozzles. Shown in Figure 19 is a plot of the minimum nozzle pressure to suppress flashing ahead of the nozzle as a function of as-fired liquor dry solids for three liquors. Flashing is clearly not a problem for the light liquor (viscosity $=50 \mathrm{cP}$ at $66 \%$ solids and $230^{\circ} \mathrm{F}$ ). For the typical liquor with $100 \mathrm{cP}$ at the same "standard" conditions, flashing is also not a problem below $72 \%$, but minimum pressures of at least $25 \mathrm{psi}(172 \mathrm{kPa})$ would be required to suppress flashing at $80 \%$ solids. This would require trastic changes in the usual operating pressures of $C E$ swirl cone, $V$-type and U-type nozzles, but could be accommodated fairly easily with a $B \& W$ splashplate nozzle.

With the thickest liquor, flashing is always a problem. Pressures well beyond the normal range for black liquor service would be required to suppress flashing ahead of the nozzle.

Complications with flashing at high solids will manifest themselves in different ways. First, the nozzle stability will be reduced at the low pressure end of their operating range. This will complicate trials of high solids firing and subsequent optimization of recovery boiler operation. Second, increasing operating pressure leads to higher velocities. From Figure 10 above this means smaller droplet size, all other factors being equal. Current understanding of recovery boiler operation would indicate that this will increase carryover. Third, higher velocities, particularly much higher velocities for heavy liquors, mean significant changes in liquor droplet trajectory. This element by itself could easily confound the apparent benefit of high solids firing. Very careful nozzle selection will be required for valid mill trials of high solids firing or other liquor system modification.

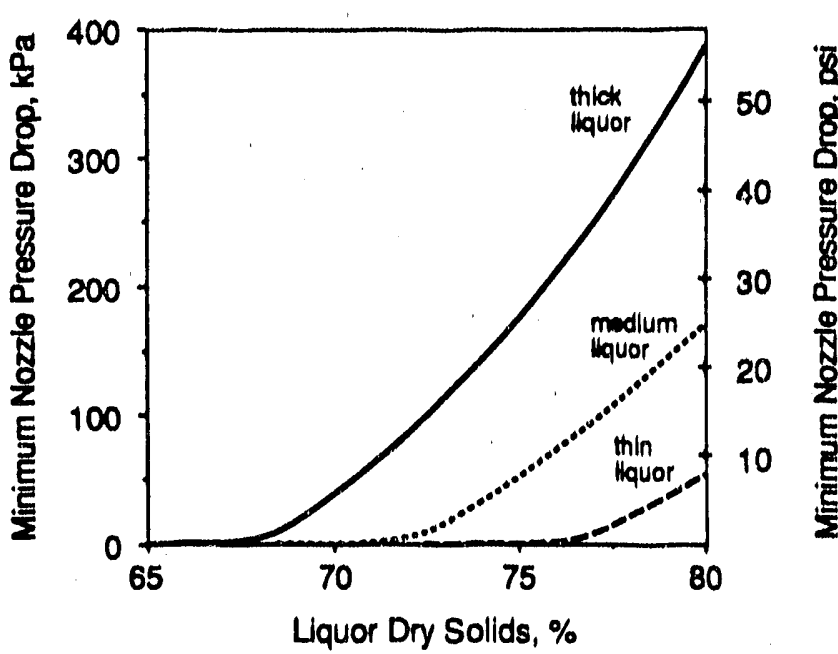

Flgure 19. Minimum nozzle pressure drop required to suppress flashing ahead of the nozzle for three liquors. Viscosities at $66 \%$ solids and $110^{\circ} \mathrm{C}$ are: thick liquor . $250 \mathrm{mPa}-\mathrm{s}$, medium $=100 \mathrm{mPa}-\mathrm{s}$, thin liquor $=50 \mathrm{mPa}$-s.

\section{CONCLUSIONS}

The performance of black liquor spray nozzles has been the subject of several investigations. Projects are on-going, and a fuller understanding will emerge with time, but several key features of black liquor nozzles have been revealed.

1. The geometry of current black liquor nozzles, such as the B\&W splashplate and CE swirl cone, U- and V-type nozzles, are relatively simple.

2. The flow and pressure drop characteristics for two of these nozzles-the splashplate and the U-and V-type-have been measured. The flow coefincient correlations for these nozzles are consistent with the specific geometry of each. This allows reasonable speculation about the flow characteristics of the other nozzle, the swirl cone.

3. Within their typical range of operation, neither the splashplate nor the U- or V-type nozzles are very sensitive to normal fluctuations in liquor property variations. This is apparently not the case for the swirl cone nozzle, and additional investigation of this type nozzle is needed.

4. Fluid sheet thickness is a key element in determining the ultimate droplet size of a spray. Sheet thickness has been measured for one black liquor nozzle, the splashplate. Correlations of sheet thickness are consistent with other data for this nozzle and allow assessment of the sensitivity of droplet size to changes in fluid properties and operating conditions. Increased liquor viscosity will be one impact of firing at higher liquor dry solids. Available data indicate that sheet thickness (and likely droplet size) will increase by less than a factor of two and a half for a ten-fold increase in viscosity. 
5. A modest amount of data is avallable on droplet size distribution from black liquor nozzles. The mean droplet size is affected by fluid properties, operating conditions, and nozzle geometry. However, the normalized size distribution is nearly constant for all conditions and nozzles.

6. Nozzle stability is an important aspect of nozzle performance. Both roping and flashing are instablitites common to black liquor nozzles. The impact of high liquor dry solids on one of these, flashing, has been estimated. Higher solids require higher operating pressure to suppress flashing ahead of the nozzle. This will be a significant problem for heavy liquors at higher dry solids firing conditions.

\section{ACKNOWLEDGEMENT}

The research on black liquor spray nozxles at the Institute of Paper Science and Technology is supported by a grant from the U.S. Department of Energy.

\section{NOMENCLATURE}

$A_{u}=$ nozizle area for $U$-type nozzle

$A_{V}=$ nozzle area for the $V$-type nozzle

$b, c=$ major and minor axis dimensions for the $U$ - and V-type nozzles

$\mathrm{C}_{1} \ldots \mathrm{C}_{4}=$ constants for each nozzle

$\mathrm{C}_{\mathrm{f}}=$ flow coefficient

$D=$ nozzle exit diameter

$D_{\mathrm{u}}=$ equivalent circular diameter for the U-type nozzle

$D_{V}=$ equivalent nozzle diameter for the V-type nozzle

$\Delta \mathrm{P}=$ pressure drop across the nozzle

$\mathrm{Re}=$ Reynolds number, $\rho \mathrm{DV} / \mu$

$V=$ sheet top surface velocity

$V_{n}=$ nozzle characteristic velocity

$Y=$ sheet thickness

$\rho=$ fluid density

\section{REFERENCES}

1. Physical properties of kraft black liquors, US DOE Contract No. ACO2-82CE40606, Fricke, A. L., Univ. of Florida.

2. Black Liquer Droples Eormation Projecs, US DOE Contract No. AC02-83CE40626, Stockel, I. H., Univ. of Maine.

3. Kraft Black Liquar Delivery Systems, US DOE Contract No. FC02-88CE40839, Adams, T. N., Grace, T. M., and Malcolm, E. W., Institute of Paper Chemistry, Appleton, WI.

4. Eundamental Studies of Black Liquer Combustion, US DOE Contract No. ACO2-83CE40637, cooperative program between the Institute of Paper Chemistry, Appleton, WI, and the National Bureau of Standards, Gaithersburg, MD.

5. Bennington, C.P.J., and R.J. Kerekes, Proc, 1985 Int'l. Chemical Recovery Conf., TAPPI, Atlanta, pp. 345-354, 1985.

6. Spielbauer, T.M., Adams, T.N., Monacelli, J.E., and Bailey, R.T., "Droplet size distribution of black liquor sprays," TAPPLCPPA Intl. Chemical Recovery Conf., Ottawa, Canada, April 1989.

7. Obuskovic, N., and Adams, T.N.,"Fluid sheet thickness and velocity at the tip of a black liquor splashplate nozzle," AIChE Annual mig., San Francisco, CA, Nov, 1989.
8. Clay, D.T., Lien, S.J., Grace, T.M., Macek, A., Amin, N., Semerfian, H.G., and Charagundla, S.R., "Fundamental study of black liquor combustion. Report No. 2-Phase 1," US DOE DE-ACO2-83CE40637, Jan, 1988.

9. Development of an on-line black liquer viscositv meter and controller for knaft recovery boillers. US DOE Contract No. DE-ACO3-88ER80661, J. H, Jansen Co., Inc., Woodinville, WA, Jan. 1989.

10. Adams, T.N.,"Technical aspects in the selection of an on-line viscometer for black liquor," AIChE Annual mtg., San Francisco, CA, Nov, 1989.

11. Soderhjelm, L., and U. Koivuniemi, "Recent developments in black liquor analysis," Black Liquor Recovery Boiler Symposium, Helsinkd, B2:1-12, Aug., 1982.

12. Soderhjelm, L., "Properties of black liquor," DOE Black Liquor Research Review conf., DOE report no. CONF. 8707139 (DE88004597), Gaithersburg, MD, July 1987.

13. Soderhjelm, L., "Viscosity of strong black liquor from sulphate mills," TAPPICPPA Intl. Chemical Recovery Conf., Ottawa, Canada, April 1989.

14. Wennberg, O., "Boiling point elevation and viscosity of black liquor at high solids and high temperature," 1985 TAPPI Int'l. Chem. Recovery Conf., New Orleans, April, 1986.

15. Wennberg, O., "Rheological properties of black liquor," TAPPI/CPPA Intl. Chemical Recovery Conf., Ottawa, Canada, April 1989.

16. Spielbauer, T. M., and Adams, T. N., "Flow and pressure drop characteristics of black liquor nozzles," AIChE Annual Mtng., San Francisco, CA, Nov. 1989.

17. Adams, T. N. and Frederick, W. J., Kraft.Recovery Boiler Bhysical and Chemical Processes, American Paper Institute, New York, NY, 1988.

18. Nordstrom, E.T., and Karki, R.T.J., "Evaporation to ultrahigh solids," 1988 TAPPI KROS, Orlando, FL, Jan, 1988.

19. Hyoty, P.A., "Combustion of black liquor at $80+\%$ dry solids content," Univ, of Toronto, Intl. Colloquium on Black Liquor Combustion, Parry Sound, Ontario, Canada, Nov. 1987. 


\section{Appendix 2 IMAGING EQUIPMENT SPECIFICATIONS}

FAST VIDEO DATA ACQUISITION CAMERA

All of the LSI's, discrete components, and other circuitry for Xybion ISG cameras are contained on printed circult boards housed in the body of the camera. One separate High Voltage Power Supply (HVPS) potted circuit board is housed on top of the camera.

The following list outlines the features which make the ISG unique products.

* Small size

* Light weight

* Rugged construction - extruded aluminum housing

* Single power source: 11-15 VDC at approximately 10 watts, or 117 AC $50 / 60 \mathrm{~Hz}$ with power supply module

* Frame scan or field scan (factory select)

* Standard RS-170 output format

* Available with Crystal, Sync Lock or H \& V Lock Control

* Automatic intensifier gating

* Direct control of intensifier gating

* Intensifier gain readout

* Automatic is is control

* Automatic/Manual intensifier gain limit

* Extremely good anti-blooming performance

* Pattern noise cancellation

* Clock noise filtering

* Image inhibit feature For Very Low Light Level and "Snapshot" Applications (ISG-240 only).

* True Horizontal Aperture Correction (Enhanced Image Sharpness).

* Automatic Black Level Circuit

* Adjustable Mechanical Back Focus

* Randoin Event, External Triggerable Gated Image Capture 
* User adjustable Image capture gate range from $20 \mathrm{~ms}$ to less than $25 \mathrm{~ns}$

* User adjustable delay from trigger to start of image capture, from $1 \mathrm{~s}$ to $90 \mathrm{~s}$.

* 1/4×20 Mounting Holes on Top and Bottom 


\title{
XYBION
}

XYBION ELECTRONIC SYSTEMS

USER'S MANUAL

\author{
TFOR \\ ELECTRONICALLY GATED \\ INTENSIFIED CCD CAMERA
}

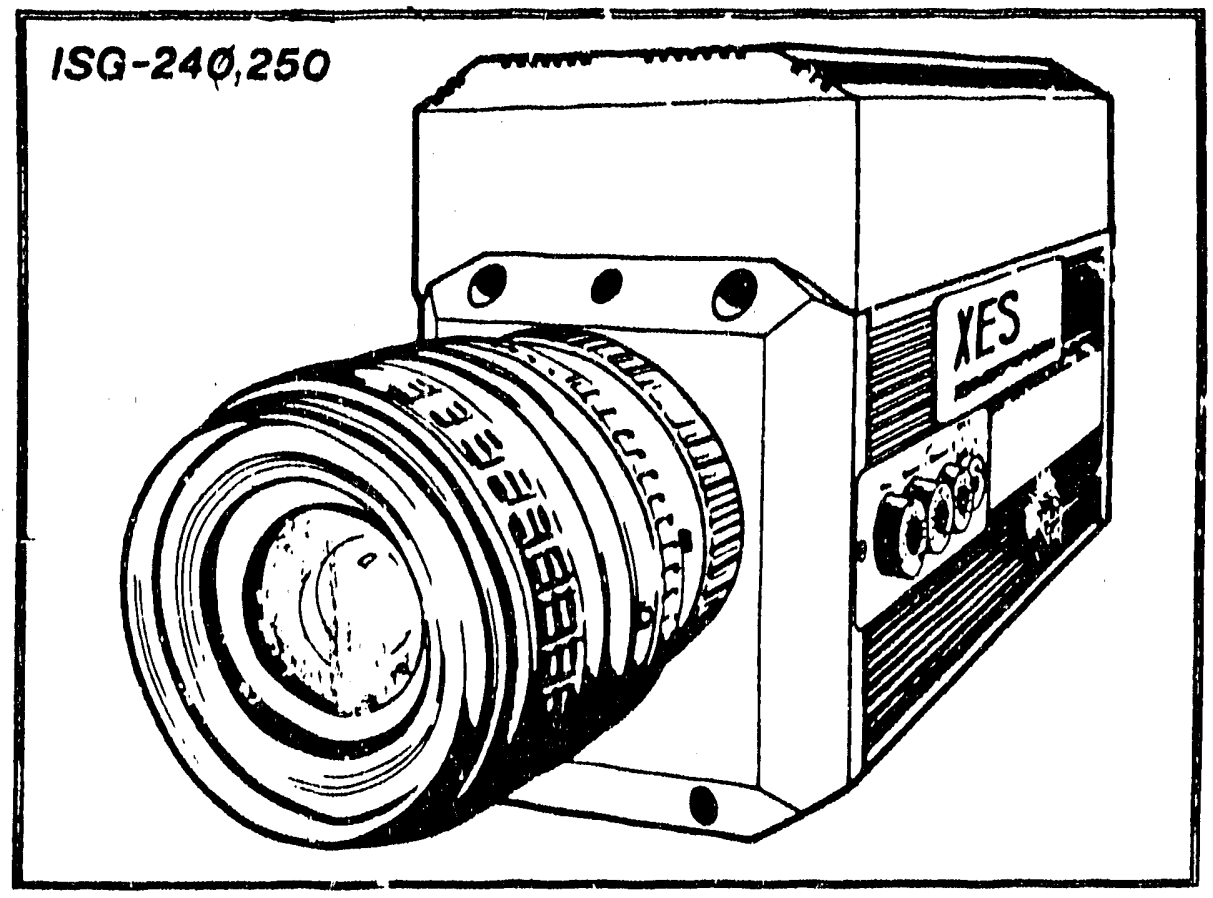

XYBION ELECTRONIC SYSTEMS CORPORATION 8380 MIRALANI DRIVE

SAN DIEGO CA 921.26-4347

$619 / 566-7850$

FAX: 619/566-2032 


\section{Section 1 - System Description}

This section contains briel descriptions of the physical components and soltware used in the TN-8500 system.

\section{System Conflgurations}

The TN-8500 may be purchased in any of three configurations:

a) EDS configuration (includes Hems C, D, and F shown at right).

b) Imaging configuration (inctudes items $B, C, D, E$, and $F$ shown at night).

c) Combined EDS and Imaging configuration (inchides items B, C, D, E, and F shown at right).

\section{Comporients}

A - Printer (optional)

B - Control monitor

C - Image monitor

D - Mouse

E - Operator's Console

F - Mainirame

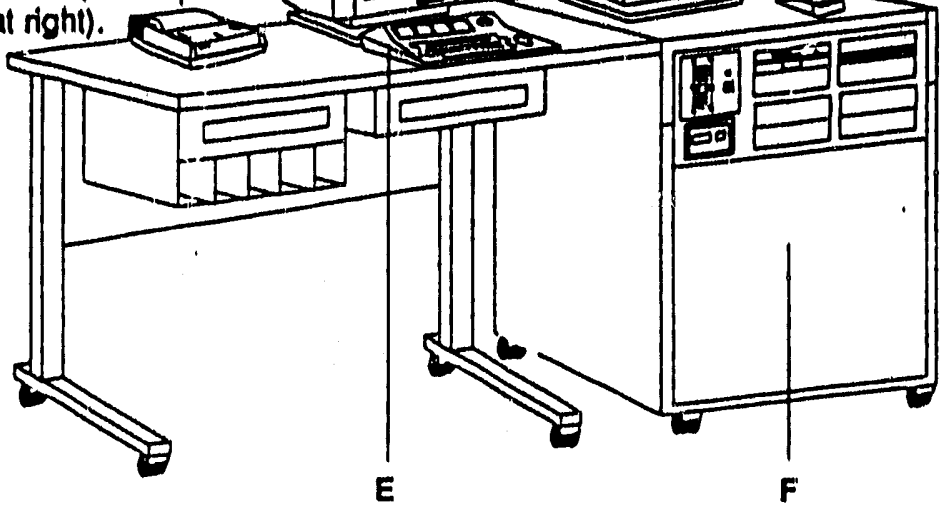

(System shown with largo tajle. A smaller table is also available.)

\section{Mainframe}

The maintrame cabinet contains all of the system elecironics and the mass storage devices (disk drives).
A. Main power switch.
B - Resel switch.
C - Super Scan Generator controls; optional with elec- tron microscope intertace only.
D. Disk drives.
E - Streaming tape backup system.

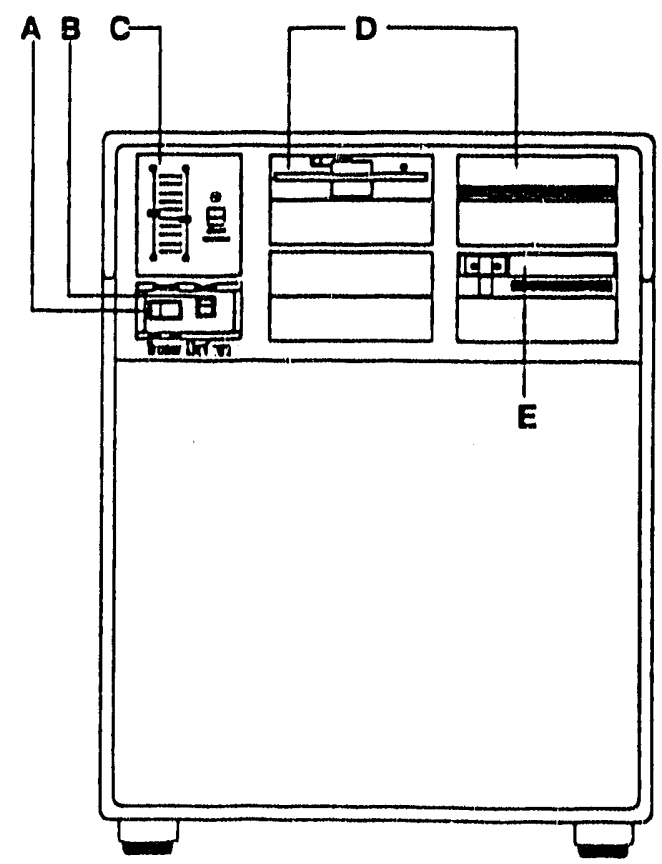


Flgure 8.3. Proposed expertmental apparatus.

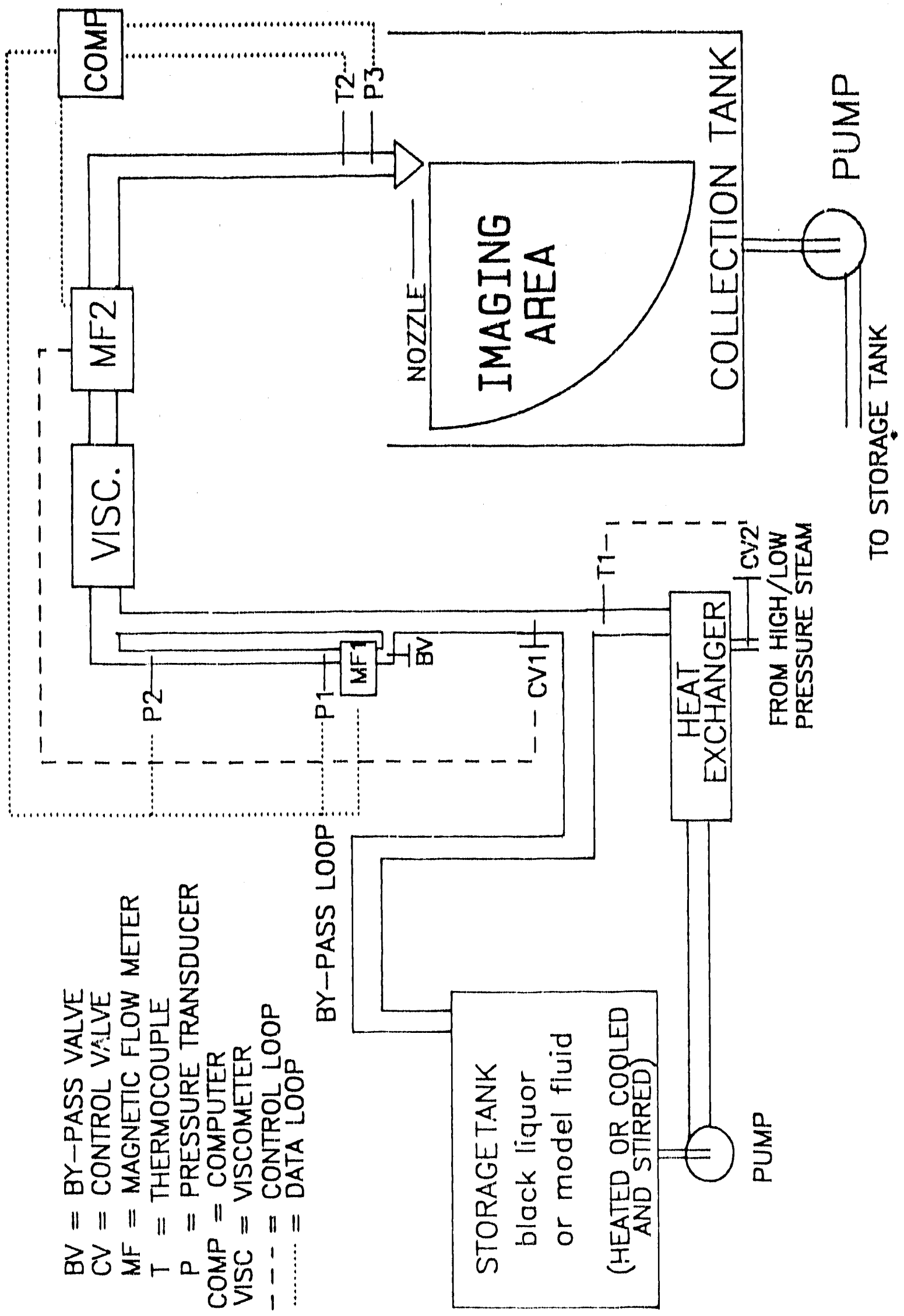



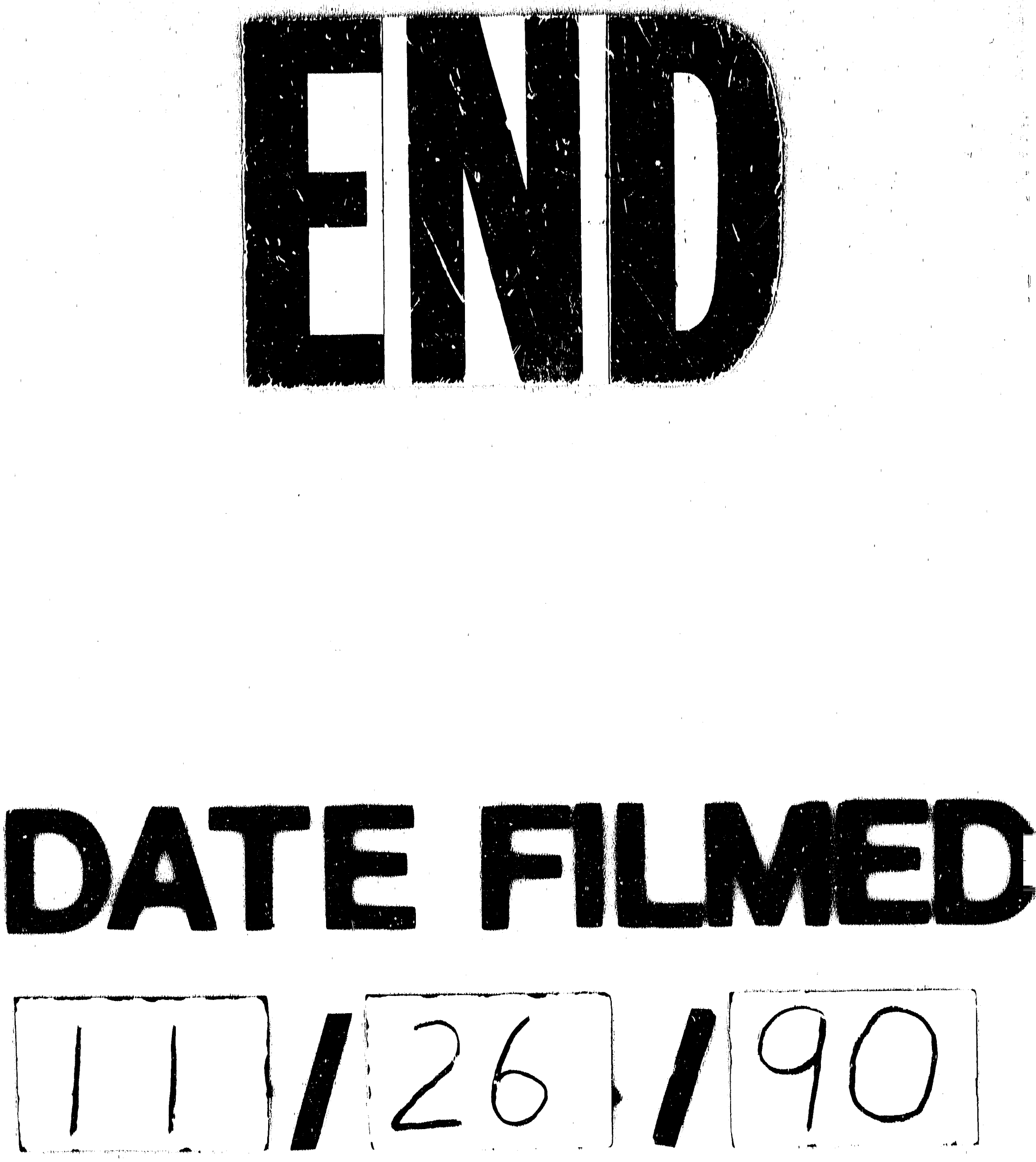
